\title{
Essays on international financial integration
}

Citation for published version (APA):

Vermeulen, R. (2010). Essays on international financial integration. [Doctoral Thesis, Maastricht

University]. Universiteit Maastricht. https://doi.org/10.26481/dis.20100630rv

Document status and date:

Published: 01/01/2010

DOI:

10.26481/dis.20100630rv

Document Version:

Publisher's PDF, also known as Version of record

\section{Please check the document version of this publication:}

- A submitted manuscript is the version of the article upon submission and before peer-review. There can be important differences between the submitted version and the official published version of record.

People interested in the research are advised to contact the author for the final version of the publication, or visit the DOI to the publisher's website.

- The final author version and the galley proof are versions of the publication after peer review.

- The final published version features the final layout of the paper including the volume, issue and page numbers.

Link to publication

\footnotetext{
General rights rights.

- You may freely distribute the URL identifying the publication in the public portal. please follow below link for the End User Agreement:

www.umlib.nl/taverne-license

Take down policy

If you believe that this document breaches copyright please contact us at:

repository@maastrichtuniversity.nl

providing details and we will investigate your claim.
}

Copyright and moral rights for the publications made accessible in the public portal are retained by the authors and/or other copyright owners and it is a condition of accessing publications that users recognise and abide by the legal requirements associated with these

- Users may download and print one copy of any publication from the public portal for the purpose of private study or research.

- You may not further distribute the material or use it for any profit-making activity or commercial gain

If the publication is distributed under the terms of Article $25 \mathrm{fa}$ of the Dutch Copyright Act, indicated by the "Taverne" license above, 
ESSAYS ON

InTERnAtional FinANCIAL INTEGRATiOn

Robert Vermeulen 
(C) Robert Vermeulen, 2010

All rights reserved. No part of this publication may be reproduced, stored in a retrieval system, or transmitted in any form, or by any means, electronic, mechanical, photocopying, recording or otherwise, without the prior permission in writing from the author.

This book was typeset by the author using $\mathrm{H}_{\mathrm{E}} \mathrm{X}$.

ISBN: 978-90-9025491-3

Printed in the Netherlands by Datawyse Maastricht 


\title{
ESSAYS ON \\ INTERNATIONAL FINANCIAL INTEGRATION

\author{
DISSERTATION
}

\author{
PhD-FDEF-1-2010 \\ in candidature for the degree of \\ Docteur de l'Université du Luxembourg en Sciences Économiques, \\ at the Faculty of Law, Economics and Finance, \\ and \\ Doctor at Maastricht University, \\ on the authority of the Rector Magnificus Prof. dr. G.P.M.F. Mols \\ in accordance with the decision of the Board of Deans, \\ to be defended in public in Maastricht, the Netherlands \\ on Wednesday 30 June 2010 at 12:00 hours \\ by \\ Robert John Gerard Vermeulen \\ Born on 25 September 1983 in Heerlen, the Netherlands
}

\section{Dissertation defense committee:}

Prof. dr. M. Beine, dissertation supervisor (University of Luxembourg)

Dr. A. Cosma (University of Luxembourg)

Prof. dr. P. De Grauwe (Catholic University of Leuven)

Prof. dr. J. Muysken, Chairman (Maastricht University)

Prof. dr. J.-P. Urbain (Maastricht University)

Prof. dr. C.C.P. Wolff, Vice Chairman (University of Luxembourg) 


\section{Supervisors:}

Prof. dr. M. Beine (University of Luxembourg)

Prof. dr. B. Candelon (Maastricht University)

\section{Assessment Committee:}

Prof. dr. J. Muysken (Maastricht University, chairman)

Prof. dr. P. De Grauwe (Catholic University of Leuven)

Prof. dr. J.-P. Urbain (Maastricht University)

Prof. dr. C.C.P. Wolff (University of Luxembourg)

This research was financed by the Fonds National de Recherche Luxembourg under grant FNR/06/30/10. 
"If I have seen a little further it is by standing on the shoulders of Giants."

Isaac Newton, letter to Robert Hooke, 1676 



\section{ACKNOWLEDGEMENTS}

During the second year of my research master Bertrand Candelon asked me if I would be interested in pursuing a $\mathrm{PhD}$. He proposed to engage in a joint $\mathrm{PhD}$ together with the University of Luxembourg, where both Michel Beine and Bertrand would share the supervision. We agreed quickly on the practical matters, where I would work three days a week in Luxembourg and the other two days in Maastricht. We agreed on the topic international financial integration and the Fonds National de Recherche Luxembourg provided funding for three years. From the start I enjoyed conducting research and I like it even more after finishing this dissertation. Even though writing a dissertation is lot of individual effort, I could not have finished it without the support of many others. Therefore, I want to express my gratitude to all of you.

Before this book could be printed many formalities with quite a few hurdles had to be solved, which took much longer than initially expected. Eventually, it took around two years before a contract between both universities was signed. Therefore, I want to thank Bertrand and Michel for the time they invested in working out the official bureaucracies to make this joint $\mathrm{PhD}$ possible. I know that this was frustrating for you as well. As my PhD progressed I had the pleasure to enjoy both Bertrand's and Michel's enthusiasm, creativity, determination and professionalism. I have learned a lot from both of you.

I would like to thank the members of my assessment committee: Paul de Grauwe, Joan Muysken, Jean-Pierre Urbain and Christian Wolff for their careful reading and constructive comments. A special word of thank to Jean-Pierre for his econometrics classes, where I learned the essential tools to conduct applied economic research, and his constructive comments on 
my work. I also owe much to Joan for giving me the opportunity to be his research assistant and become acquainted to economic research. I benefited much from this experience during my $\mathrm{PhD}$.

Research is much more than reading articles, waiting for a splendid idea and conducting regression analysis. I learned most from the discussions with my colleagues and coauthors. Discussions about research, everyday life and the common frustrations $\mathrm{PhD}$ students have. Thank you Antonio, Bertrand, Elisabetta, Joan, Michel and Nils for the enjoyable and fruitful cooperation. I would also like to thank my friends and colleagues for their friendship and professional input. A special word of thank to my (former) officemates in Luxembourg and Maastricht: Elisabetta, Francois, Jeroen, Nils and Skerdi. Thank you for making my working day enjoyable.

Being a PhD student in two universities implies that the administrative hassle increases exponentially. Fortunately, with the secretarial support and helpfulness of Elisa Ferreira, Fleur Keune and Silvana de Sanctis I was able to fill out any form.

After more than one year of preparations the Spring Meeting of Young Economists was held in Luxembourg from 15-17 April 2010. I would like to thank my co-organizers Paola Dumet and Eva Sierminska for their good cooperation. In addition, Elisa's support before, during and after the conference was instrumental to its success.

This dissertation would not have been completed without the continuous support of my closest family members. My parents Ed and Christel and my brother Raymond made me the person that I am today. I am very grateful for your encouragement and continuous support. Thanks also to my girlfriend's parents Willem and Ingrid Straaten for your support. Finally, I am most grateful to my girlfriend Inge. For you it was not always easy when I packed my bag to leave for Luxembourg every Sunday evening and listening to my crazy econspeak. Thank you for your unconditional love and support.

Robert Vermeulen

Maastricht, May 2010 


\section{Contents}

Acknowledgements

vii

Contents

ix

List of Tables

xiii

List of Figures

XV

1 Introduction 1

1.1 What is international financial integration? . . . . . . . 1

1.2 History on financial integration in a nutshell . . . . . . . . 2

1.3 Why matters financial integration today? . . . . . . . . 4

1.4 Structure of the dissertation . . . . . . . . . . . . 6

2 The Dark Side of Global Integration: Increasing Tail Dependence $\quad 11$

2.1 Introduction . . . . . . . . . . . . . . . . . . 11

2.2 Literature review . . . . . . . . . . . . . . . . . . . 13

2.3 Measuring and explaining comovement . . . . . . . 16

2.3.1 Measuring comovement . . . . . . . . . . 16

2.3.2 The model and empirical methodology . . . . . . . 18

2.4 Data . . . . . . . . . . . . . . . . . 20

2.4.1 Stock market returns . . . . . . . . . . . . . . 20

2.4.2 Financial liberalization . . . . . . . . . . . . . 21

2.4 .3 Trade integration . . . . . . . . . . . . . . . 22

2.4 .4 Industrial structure . . . . . . . . . . . . . . 23 
2.4.5 Exchange rate volatility . . . . . . . . . . . . . . 24

2.5 Results . . . . . . . . . . . . . . . 24

2.5.1 Baseline results . . . . . . . . . . . . . . 24

2.5.2 Comparing coexceedances with correlations . . . . . 27

2.5.3 Robustness . . . . . . . . . . . . . . 28

2.6 Conclusion $\ldots \ldots \ldots \ldots \ldots \ldots$

2.7 Appendix A: Data sources . . . . . . . . . . . . . . . 32

2.8 Appendix B: Excluded non-trading days . . . . . . . . . 34

3 Dynamic International Portfolio Adjustment: Rational Investors and the Home Bias 35

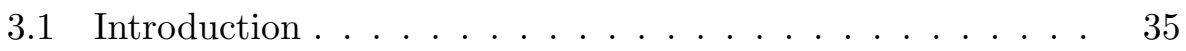

3.2 Empirical methodology . . . . . . . . . . . . . . . . 39

3.2.1 Capturing stock market comovement . . . . . . . . 39

3.2 .2 Estimation method . . . . . . . . . . . . . 42

3.3 Data . . . . . . . . . . . . . . . . . 44

3.4 Results . . . . . . . . . . . . . . . . . . . 47

3.4 .1 Baseline results . . . . . . . . . . . . . . . 47

3.4 .2 Statistical poolability . . . . . . . . . . . . 51

3.4.3 Economic poolability . . . . . . . . . . . . 52

3.5 Robustness . . . . . . . . . . . . . . . 55

3.5.1 Additional control variables . . . . . . . . . . . . 55

3.5.2 Asset allocations in levels . . . . . . . . . . 58

3.5.3 Does the degree of home biasedness matter? . . . . . 60

3.6 Conclusion . . . . . . . . . . . . . . . . . 62

3.7 Appendix A: Data sources . . . . . . . . . . . . . . 63

3.8 Appendix B: Country sample . . . . . . . . . . . . . . 64

4 The International Wealth Effect: A Global Error-Correcting Analysis $\quad 65$

4.1 Introduction . . . . . . . . . . . . . . 65

4.2 Constructing the GVAR model . . . . . . . . . . . 71

4.2.1 Variable selection and data considerations . . . . . . 71

4.2.2 The GVAR methodology . . . . . . . . . . 73

4.2.3 Properties and specification of the data series . . . . 78

4.3 Generalized Impulse Response Analysis . . . . . . . . . . . 82

4.3.1 Domestic and international wealth effects in the US 84

4.3.2 Domestic and international wealth effects in the UK 86 
4.3.3 Domestic and international wealth effects in France. 89

4.3.4 Domestic and international wealth effects in Japan and Germany . . . . . . . . . . . . . . . . . 91

4.4 Forecast error variance decomposition . . . . . . . . . . 93

4.5 Stability and specification of the global VAR . . . . . . 96

4.6 Conclusion . . . . . . . . . . . . . . . . 100

4.7 Appendix: Data sources . . . . . . . . . . . . . . . 101

5 Remittances and Financial Openness 103

5.1 Introduction . . . . . . . . . . . . . . . . . 103

5.2 Motivation, existing related literature and stylized facts . . 105

5.2.1 Related literature on the effects of remittances . . . 106

5.2 .2 Government policies . . . . . . . . . . . . . 107

5.2 .3 Stylized facts . . . . . . . . . . . . . . . . 109

5.2.4 Financial openness as an option . . . . . . . . . . 111

5.3 The Model . . . . . . . . . . . . . . . . . . . . . . . . . . 113

5.3 .1 The household . . . . . . . . . . . . . . . . 113

5.3 .2 The migrant . . . . . . . . . . . . . . . . . 114

5.3 .3 The government . . . . . . . . . . . . 116

5.4 Empirical Analysis . . . . . . . . . . . . . . . . . . . . . . . . . . . . . . . . . 118

5.4 .1 Data . . . . . . . . . . . . . . . . 118

5.4 .2 Gologit model . . . . . . . . . . . . . . . . 123

5.4 .3 Benchmark results . . . . . . . . . . . . . 126

5.4 .4 Instrumentation . . . . . . . . . . . . . . . 129

5.4.5 Marginal effects . . . . . . . . . . . . . . . 135

5.5 Counterfactual analysis . . . . . . . . . . . . 137

5.6 Conclusion . . . . . . . . . . . . . . . . . . . . . . . . . 142

5.7 Appendix A: Robustness balanced panel pooled OLS estimation . . . . . . . . . . . . . . . . . . . 142

5.8 Appendix B: Robustness using System GMM and 2SLS . . 144

5.9 Appendix C: Counterfactual analysis . . . . . . . . . 145

$\begin{array}{ll}\text { Bibliography } & 149\end{array}$

Nederlandse Samenvatting (Summary in Dutch) 165

$\begin{array}{ll}\text { Short Curriculum Vitae } & 171\end{array}$ 



\section{LIST OF TABLES}

2.1 Descriptive statistics of equity returns: 1/1/1974-31/12/2006 21

2.2 Explaining codependence (baseline specification). . . . . . 25

2.3 Explaining codependence with realized correlation. . . . . . 27

2.4 Explaining codependence local returns (Fisher-Z transformation). . . . . . . . . . . . . . . . 29

2.5 Explaining codependence using the IMF capital controls dummy. . . . . . . . . . . . . . . . 30

2.6 Explaining codependence with no t-1 shift for Canada and the United States. . . . . . . . . . . . . . . . . . 31

2.7 Non-trading days (excluded from analysis) . . . . . . . . 34

3.1 Dynamic Adjustment International Equity Investment: System GMM, full sample . . . . . . . . . . . .

3.2 Dynamic Adjustment International Equity Investment: Restricted Sample, statistical reduction . . . . . . . . . . 52

3.3 Dynamic Adjustment International Equity Investment: OECD Sample . . . . . . . . . . . . . . . 54

3.4 Dynamic Adjustment International Equity Investment: Ro-

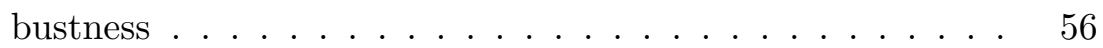

3.5 Dynamic Level International Equity Investment: System

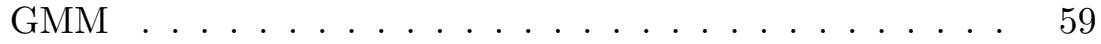

3.6 Dynamic Adjustment International Equity Investment: System GMM and Home Bias . . . . . . . . . . . . . . 61

3.7 Source and host country sample . . . . . . . . . . . 64

4.1 Countries and regions in the model . . . . . . . . . . . 69 
4.2 Trade weight matrix . . . . . . . . . . . . 74

4.3 VARX order and number of cointegrating relationships . . . 76

4.4 Weighted symmetric unit root test results . . . . . . . . 79

4.5 Weighted symmetric unit root test results cont'd . . . . . 80

4.6 Weak exogeneity test . . . . . . . . . . . . . 83

4.7 Proportion of the N-step ahead Forecast Error Variance Explained by Conditioning on Contemporaneous and Future Innovations of the Country Equations _ . . . . . . . . 95

4.8 Tests of parameter constancy . . . . . . . . . . . 97

4.9 Correlation coefficients of country-specific foreign variables using constant and time-varying trade weights . . . . . . . 99

5.1 Cost of remitting $\$ 500 \ldots \ldots \ldots \ldots \ldots$

5.2 Benchmark results . . . . . . . . . . . . . . 127

5.3 First stage . . . . . . . . . . . . . . . . . . 132

5.4 Instrumentation Second Stage Gologit . . . . . . . . . . . 134

5.5 Marginal effects . . . . . . . . . . . . . . 136

5.6 Benchmark results (balanced panel) . . . . . . . . . . 143

5.7 Robustness using System GMM and 2SLS . . . . . . . . . 144

5.8 Counterfactual scenarios . . . . . . . . . . . . . . . . . 145

5.8 Counterfactual scenarios . . . . . . . . . . . . . . . . 146

5.8 Counterfactual scenarios . . . . . . . . . . . . . . . . . 147 


\section{List OF Figures}

4.1 United States: Domestic response to a real effective exchange rate (first column), real stock price (second column) and real housing price shock (third column) . . . . . . . . . 85

4.2 United Kingdom: Domestic response to a real effective exchange rate (first column), real stock price (second column) and real housing price shock (third column) . . . . . . 88

4.3 France: Domestic response to a real effective exchange rate (first column), real stock price (second column) and real housing price shock (third column) . . . . . . . . . . 90

4.4 Japan: Domestic response to a real effective exchange rate (first column) and real stock price shock (second column) .

4.5 Germany: Domestic response to a real effective exchange rate (first column) and real stock price shock (second column) 94

5.1 Quantile graph of KAOPEN 1980-2005 . . . . . . . . . 121

5.2 Scenario 1 (zero remittances) . . . . . . . . . . . . . 139

5.3 Scenario 2 (double remittances) . . . . . . . . . . . . 141 



\section{1}

\section{INTRODUCTION}

\subsection{What is international financial integration?}

Before discussing the determinants, implications, pros and cons of international financial integration we need to clarify what international financial integration is. Providing a single complete definition is not easy. Hence, this section aims to introduce a broad and general definition of what international financial integration entails. Fortunately, there are some clear definitions which jointly provide a good overview of what is meant by international financial integration. The first definition is from Alan Deardorff's Glossary of International Economics: "Freedom of participants in the financial markets of two countries to transact on markets in both countries, thereby causing returns on comparable assets in the two countries to be equalized through arbitrage". ${ }^{1}$

This definition is quite abstract, but becomes obvious when using a simple example. Suppose an investor from the Netherlands wants to buy 100 shares of Royal Dutch Shell, the Anglo-Dutch oil giant. He can decide to buy these shares either on the Amsterdam Stock Exchange, the London Stock Exchange or even on a different stock exchange. Since each share is identical no matter where it is traded, i.e. receives the same dividends, its stock price should be the same through arbitrage wherever the investor may decide to buy it. With full international financial integration both British and Dutch investors can buy stocks of Royal Dutch Shell, either in London or Amsterdam, for the same price. ${ }^{2}$

One step further is to recognize that financial integration is not a black and white story, where two countries are either financially integrated or not. In contrast, it is important to recognize that financial integration is

\footnotetext{
${ }^{1}$ http://www-personal.umich.edu/ alandear/glossary/f.html

${ }^{2}$ Actual prices may differ slightly do to UK Pound/euro exchange rate movements.
} 
a process that changes over time. A second broader definition highlights this aspect: "It is the process through which financial markets of several countries remove restrictions on cross-border financial flows and on foreign entry into the domestic financial system so that all potential participants, local and foreign, in a market are subject to the same rules and have equal access" (Tahari et al., 2007).

Equal access is not trivial because there can be many restrictions, for example a cap on the foreign ownership of certain stocks. This implies that foreign investors cannot own more than $25 \%$ say, of the outstanding shares of a firm. This type of restriction is still common for weapons manufacturers in many countries in the twentyfirst century. However, it was not uncommon that countries were completely closed for foreign investors at some point in history. For example, most emerging markets were virtually completely closed to international investors after colonization ended and the 1970s.

In short, international financial integration can be summarized by all international financial transactions, where integration characterizes the easiness, comparability and similarity to conduct these financial transactions across countries. The most common and well known financial instruments are bank accounts, government bonds, company stocks and mortgages. Within each category there are many different sub-products, e.g. a company can sell nominal bonds, inflation indexed bonds and convertible bonds, to name a few. All this products can be traded internationally, however the extent of integration differs.

This dissertation focuses on the implications of financial liberalization for the macro economy and how the macro economy affects financial integration. Financial integration will be viewed in its broad context. A short (and naturally incomplete) overview of the history of financial integration illustrates some of the many changes that took place during the past 400 years.

\subsection{History on financial integration in a nutshell}

This section does not aim to provide an exhaustive discussion on the history of financial integration. It merely aims to place the current state of the world in a historical perspective. Section 1.3 discusses the relevance and implications of financial integration in today's world. To keep this section 
as broad as possible, some general history on the financial integration of cross border investments will be discussed. These investments can consist of a large variety of assets (e.g. stocks or government bonds) and foreign direct investments.

The first company to issue stock was the Dutch East India Company (VOC) on 20 March 1602. Its initial public offering raised 6.4 million guilders to finance the ships, voyages, offices and plantations necessary to compete mainly with the English and Portuguese for spices trade. Naturally, international trade in VOC shares was quite different from stock exchanges today. With the risk of war looming, British and Portuguese investors would not invest in this Dutch company.

During the seventeenth and eighteenth century the Amsterdam stock exchange started to flourish and international investments became more popular. There were even investment funds similar to the mutual funds we know nowadays. "For example, the 1774 "Negotiatie onder de Zinspreuk EENDRAGT MAAKT MAGT" organized by Abraham van Ketwich, obliged the manager to hold as close as possible an equal-weight portfolio of bonds from the Bank of Vienna, Russian government bonds, government loans from Mecklenburg and Saxony, Spanish canal loans, English colonial securities, South American plantation loans and securities from various Danish American ventures, all of which were traded in the Amsterdam market at the time" (Goetzmann et al, 2005). This example shows that risk diversification was not some sophisticated magic potion invented in the late twentieth century. In addition, the international scope was quite large with investments across Europe and in the colonies. ${ }^{3}$

With the expansion of colonialism, stock ownership and transnational investments became even more international during the nineteenth and early twentieth century. For example, Great Britain was a large provider of investment funds to construct the American railroad system during the nineteenth century. ${ }^{4}$ In addition, the European colonial powers invested heavily in their colonies, thereby creating a truly globalized economy. To put things in perspective, the ratio of stock market capitalization / gross domestic product, a widely used indicator of financial development, was at

\footnotetext{
${ }^{3}$ In 2008 governments across the globe banned naked short selling. However, this is also not a recent phenomenon. In 1609 the Dutch government banned naked short selling when the activist shareholder Isaac le Maire was conducting this practice on VOC shares.

${ }^{4} \mathrm{~A}$ large part of these assets were sold to finance the British war effort during World War 1.
} 
the same level in 1913 as it was in 1990 (Rajan and Zingales, 2003).

However, two important events in the twentieth century halted further global economic and financial integration. First, the two World Wars and second, the Wall Street stock market crash of 1929. This second event resulted in an enormous reduction in global trade due to government policies closing their domestic economies to imports. In the aftermath of World War 2, Europe lost its leading position in the global economy and most colonies gained their independence. In addition, after World War 2 the Bretton Woods fixed exchange rate mechanism was introduced. Since cross border capital flows had to be strongly regulated to keep the exchange rate mechanism working, the possibilities of cross border financial transactions were severely limited. ${ }^{5}$ However, in 1973 the Bretton Woods exchange rate mechanism was abandoned and combined with a privatization wave in the 1980s, a new era of financial deregulation emerged.

During the seventies and eighties most developed countries started liberalizing financial transactions, resulting in a large increase in financial integration. Moreover, during the late eighties and early nineties many developing countries became more open and by 1990 the world economy became comparably globalized to the start of the century. Inspired by the Washington Consensus, which had strong market oriented policy advices for governments the financial liberalization process continued during the 1990s and 2000s. Many new financial products were invented and stock market investment became popular with the public during the boom of the 1990s. During the 2000s, financial integration and the amounts traded daily internationally increased exponentially and the financial economy is now far larger than the real economy. The crash of the IT bubble in 2000 and the subsequent stock market slump did not halt this process. In 2007, the outbreak of the subprime mortgage crises, followed by the financial and economic crisis, shows clearly the huge impact of financial markets on the real economy.

\subsection{Why matters financial integration today?}

The enormous volume of outstanding equity, corporate and government bonds, mortgage loans and consumptive loans is much larger than the

\footnotetext{
${ }^{5}$ The impossible trinity states that governments can only control two out the following three policies: 1) Fixed exchange rates, 2) Free capital flows and 3) Domestic interest rates.
} 
total size of the world economy. Introducing actual numbers illustrates this point immediately. First, according to IMF data world gross domestic product is around US $\$ 57$ trillion in 2009. Second, the market value of outstanding equity reaches approximately US\$ 30 trillion mid-2009 (Datastream). Third, BIS data shows that the market value of outstanding debt (corporate and government) is about US\$ 89 trillion. Perhaps the most staggering amount is the value of outstanding derivatives at US\$ 530 trillion. This number shows that the total value of derivatives is about ten times as large as world gross domestic product.

Therefore, changes in these derivatives' underlying values have large effects on investor's wealth, which will be transmitted to the real economy. In turn, economic developments will trigger changes in the values of assets, creating a two-way relationship. The ongoing globalization and financial integration implies that e.g. United States mortgages are held by a large variety of international investors (directly or through funds). This implies that when a Norwegian pension fund invests in these mortgages and these decrease in value, (future) payments to Norwegian (future) retirees will be affected. In addition, real economies are also linked more and more through trade, e.g. when the United States imports fewer manufactures real activity in China decreases. International trade has grown faster than world gdp for decades.

Naturally, financial and economic integration provide opportunities and risks. The complex combination of a cheap Chinese currency, American demand for manufactures and the Chinese's buying of U.S. government bonds has lifted hundreds of millions of Chinese residents out of poverty. On the other hand, risk taking and excessive lending cause a reversal and the next decade will teach us how globalized financial markets will survive.

This dissertation aims to provide insights in the complex economic relationships between financial markets and the real economy, by studying the effects of financial integration from different angles in an international context. Globalization issues are discussed from a macroeconomic perspective, where the aggregate behavior of individuals in a country and the world is studied. However, it is important to realize that financial integration has a direct effect on every single participant in the global economy. This implies that everyone can personally relate to the main research question of each chapter. In order to grasp the main message it is therefore useful to ask oneself what his or her role is in the economic relationship analyzed.

There are many opportunities created by international financial inte- 
gration, which some of us may have used extensively already. Perhaps even without realizing it. For example, one of the questions posed in a later chapter is: How do households change their consumption pattern when the value of their house increases? The strong house price increases during the 1990s and early 2000s creates home equity, i.e. the difference between the value of the house and the mortgage debt increases. Financial innovations allow households to take out loans based on this home equity, which can be consumed to buy e.g. a new car or boat. Part of this consumption is imported from abroad and this dissertation asks what the effects on countries' trade balances are and whether there are commonalities and/or differences across countries.

With increasing opportunities because of financial integration we also need to pay attention to the risks induced by this process. One important issue this dissertation sheds light on is tail risk. More specifically, tail risk in equities is the risk that two or more stocks jointly crash. Investing in two equities that jointly crash is something most investors want to avoid. The financial crisis, which had its largest impact after the collapse of Lehman Brothers, shows the importance of a deeper understanding of those tail risks. During the financial crisis virtually all stocks experienced decreases and effective diversification appeared to be difficult. In addition, the aftermath of the financial crisis has a huge impact on global economic prospects. Knowledge on the role and determinants of tail events helps us to better navigate through economic crises.

\subsection{Structure of the dissertation}

All following chapters of this dissertation correspond to one essay/paper per chapter, where each chapter is self-contained and can be read individually. Therefore, each chapter is ended by an individual conclusion and no overall conclusion is presented. However, this section will give some insights in how the joint results of chapters can be interpreted. The notation used to characterize variables in equations is not always consistent throughout this dissertation as the chapters are based on individual essays. Naturally, within each chapter the notation is always consistent.

Chapter 2, "The Dark Side of Global Integration: Increasing Tail Dependence", studies the effects of global macroeconomic integration on stock market comovement. Specifically, the effects of financial integration 
on tail dependence are highlighted. Stock market coexceedances are measured using the methodology of Cappiello et al. (2005). This method enables us to measure comovement at each point of the return distribution. First, annual coexceedance probabilities are calculated for both lower and upper tail return quantiles using daily data from 1974-2006. These probabilities will be explained in a panel gravity model framework. Results show that macroeconomic variables have an asymmetric impact on stock market comovement across the return distribution. Financial liberalization significantly increases left tail comovement, whereas trade integration significantly increases comovement across all quantiles. Decreasing exchange rate volatility results in increasing lower tail comovement. The introduction of the euro increases comovement across the entire return distribution, thereby significantly reducing the benefits of portfolio diversification within the euro area.

Chapter 3, "Dynamic International Portfolio Adjustment: Rational Investors and the Home Bias", investigates the dynamic adjustment process of international investors' asset allocations. Standard portfolio theory suggests that home biased investors should invest in foreign assets which have low comovement with their domestic stock market. The year-to-year portfolio adjustment process is studied in a dynamic panel System-GMM framework, taking explicit care of the potential endogeneity of comovement. CPIS data on bilateral cross-border equity holdings is used, capturing 40 source countries and 44 host countries from 2001-2007. Results show that investors adapt their international portfolio allocations, by investing less in foreign stock markets which correlate strongly with their domestic one. Failing to account for endogeneity results in biased estimates leading to potentially misleading conclusions. However, when calculating upper and lower tail dependence investors do not significantly diversify away from foreign stock markets which jointly crash with their domestic stock market. This shows that extreme negative risks are not optimally diversified. In contrast, investors do diversify away strongly from foreign equity markets that jointly boom with the domestic one.

Chapter 4, "The International Wealth Effect: A Global Error-Correcting Analysis", analyzes the empirical link between asset prices, consumption and the trade balance using a global macroeconometric model developed by Pesaran, Schuermann, and Weiner (2004). The model is estimated for 29 countries with quarterly data from 1981Q1 to 2006Q4. Motivated by increasing international financial and real integration, and pronounced 
cycles in stock and housing prices, we employ generalized impulse response functions for a group of five of the world's most industrialized countries. Results show that shocks to asset prices transmit into consumption decisions and subsequently into the trade balance. This transmission channel is referred to as the international wealth effect and find it to be present in the US, UK and, to a lesser extent, in France, but absent in Japan and Germany.

Finally, Chapter 5, "Remittances and Financial Openness", deals with the effects of remittance receipts on country's financial openness policy. Remittances have greatly increased during recent years, becoming an important and reliable source of funds for many developing countries. Therefore, there is a strong incentive for receiving countries to attract more remittances, especially through formal channels. One way of doing so is to increase their financial openness, but this is not without costs. More specifically for developing countries, governments need to weight the positive effects of remittances with the additional risks in terms of macroeconomic volatility associated to financial openness. In this Chapter the link between remittance receipts and financial openness is investigated. A small model is developed and statistically tested for the existence of such a relationship with a sample of 66 mostly developing countries from 1980 to 2005. Empirically, a dynamic generalized ordered logit model is used to deal with the categorical nature of the financial openness policy. We account for the persistence of financial openness, initial conditions, trade openness, institutional quality and domestic financial development. In addition, we apply a two-step method akin to two stage least squares to deal with the potential endogeneity of remittances. We find a strong positive effect of remittances on financial openness, i.e. the more remittances a country receives, the more likely it will be financially open. This positive effect is both statistically significant and economically large. Finally, a counterfactual study shows that large remittance receiving countries (measured in percentage of gross domestic product) would be much less financially open when they do not receive any remittances anymore.

Combining the results of individual chapters provides new insights and enables us to answer questions that overlap the several chapter's topics. Chapter 3 shows that international investors do not effectively diversify away from foreign equities that jointly turn bad with domestic equities. One explanation is the apparent difficulty of diversifying away from jointly crashing equities. However, the results of Chapter 2 provide guidance 
to improve the investment performance by showing the importance of macroeconomic and financial factors in the determination of tail risk. These asymmetric effects have so far been neglected by investors.

One of the findings in Chapter 2 is the important positive effect of financial liberalization on stock market comovement. On the other hand, the results of Chapter 5 show that remitting migrants strongly increase the probability of financial liberalization in their home country. Combining these two results indicate that it is important for investors to realize that large remittance receiving countries are not decoupled from developed economies and investments there will be affected by global shocks, especially when markets turn bad. Chapter 5 also addresses the trade off between increased financial openness and the higher risk of being hit by external shocks.

The results in Chapter 4 show that especially U.S. and U.K. citizens adapt their consumption plans in response to changes in stock prices and housing wealth. This consumption behavior shapes trade patterns and results in increased trade when household wealth increases. Results in Chapters 2 and 3 show that increased bilateral trade does not necessary lead to increased stock market comovement or a sharp increase in foreign asset holdings, conditional on existing trade patterns.

Summing up the individual contributions creates an overall picture of the opportunities facilitated and risks induced by the global integration of financial markets. This dissertation provides guidance for individuals, portfolio investors and governments on the effects of international financial integration. 



\section{2}

\section{The Dark Side of Global INTEGRATION: INCREASING TAIL DEPENDENCE}

\section{$2.1 \quad$ Introduction}

Over the last thirty years, emerging and developed countries have been undergoing a large globalization process. ${ }^{1}$ Most countries have become increasingly integrated, both in terms of real and financial transactions. The academic literature tends to emphasize the crucial role of trade and financial openness for the economic development of countries. Trade integration has been identified as a major source of growth by the growth literature (Wacziarg and Welch, 2008). Likewise, the process of financial liberalization has been found to foster the economic development of a large set of countries including the less developed ones (see for instance Bekaert et al., 2005).

Globalization reflected by trade and financial integration is likely to have a bright and a dark side for investors. The bright side of globalization is the opportunity to diversify their assets worldwide, i.e. investors can easily buy and sell financial assets in a large number of financial markets. In turn, this enables them to grab interesting opportunities and hence boost their long run investment returns. Nevertheless, in terms of risk management, the impact of integration is not so obvious. Indeed, the impact in terms of diversification will be beneficial to the extent that globalization does not lead to an increase in the degree of comovement between international stock markets. This is especially true if liberalization tends to increase stock market comovement during periods of financial

\footnotetext{
${ }^{1}$ This chapter is based on the paper Beine et al. (2010) and contains additional results.
} 
downturn, exactly when the positive effects of diversification are most needed.

The main objective of this chapter is to test whether globalization exhibits a dark side for international investors in quest for portfolio diversification. To this aim, we look at whether trade and financial integration tend to increase the degree of comovement on the left hand side of the return distribution. So far, while there has been an extensive empirical literature devoted to the impact of integration in terms of stock market correlations, no study has been able to identify the impact on the different regions of the support of the distribution of stock returns. ${ }^{2}$

We rely on a recently developed coexceedance methodology by Cappiello et al. (2005) in order to determine how two assets comove in a certain part of the return distribution. We combine this quantile regression approach along with a subsequent dynamic panel data analysis to address a couple of specific questions that have not been considered in the literature. In particular, we address two specific questions that turn out to be crucial for the international investor. First, do various forms of macroeconomic integration affect stock market comovement in all parts of the return distribution? In other words, we investigate whether integration exerts asymmetric effects on the degree of stock market comovement. Second, we try to determine which forms of integration do affect the probability of having simultaneous extreme negative returns across international stock markets.

Using stock market index data of seventeen mostly developed countries we study 136 bilateral relationships during 1974-2006. For each pair we estimate an annual probability that two markets jointly experience tail comovement. These annual bilateral probabilities are analyzed in a dynamic panel framework in line with Beine and Candelon (2009). Within this framework, we relate tail comovement to several explanatory variables that capture global integration: trade, financial liberalization, industrial dissimilarity and exchange rate volatility. These macroeconomic indicators are calculated for each country pair to investigate which macroeconomic factors impact the comovement of two stock market indexes. ${ }^{3}$ In addition,

\footnotetext{
${ }^{2}$ See next section for a literature review. Existing studies include among many others Bekaert and Harvey (2000); Forbes and Rigobon (2002); Chinn and Forbes (2004); Beine and Candelon (2009).

${ }^{3}$ One may also be interested in the comovement of a group of countries. However, in this case it is only possible to investigate how such a group of countries reacts to
} 
by considering bilateral coexceedances we show directly the advantages of coexceedance probabilities compared to correlation measures.

The key results show that trade integration increases comovement across the entire return distribution. In contrast, financial liberalization increases comovement strongest on the left tail, whereas its effect is limited for the right tail. Hence, open financial markets increase the likeliness of a joint crash in all markets. Additional results also emphasize the asymmetric impact on comovement of other variables such as monetary integration and exchange rate volatility.

The chapter is organized as follows. Section 2.2 provides a literature review on methodologies to measure comovement and on which macroeconomic variables seem to impact comovement. Section 2.3 explains the methodology to measure comovement and introduces the gravity model. In Section 2.4 we introduce the explanatory variables. Results are discussed in Section 2.5 together with robustness checks. Section 2.6 concludes.

\subsection{Literature review}

This chapter builds on a vast literature aiming to measure and explain stock market comovements. ${ }^{4}$ A common feature of this literature is that it measures the average effect of factors in terms of comovement, neglecting the diverse impact that these factors can have on different regions of the joint return distribution. This chapter addresses the last issue.

There are various approaches to measure international stock market comovements. One approach uses first and second moments of the return series, whereas another strand of the literature is based on extreme value theory. Our modeling strategy might be seen as a mix of those approaches. Therefore we review here the existing literature related only to these strands and we do not cover alternative approaches such as the one using factor models (see for instance Chinn and Forbes, 2004).

Not surprisingly, within the first approach, correlation is by far the most widely considered moment to assess the joint behavior of two stock

\footnotetext{
"common" factors, e.g. regional interest rates (see Bae et al., 2003). In such a framework it is not possible to capture the effect of intensified trade between markets A and B, for instance. The bilateral framework is able to capture these factors specific to countries A and $\mathrm{B}$.

${ }^{4}$ For extensive reviews consult the survey articles of Karolyi and Stulz (2003) and Dungey et al. (2005).
} 
market return series. One first evidence stemming from this research stream shows that correlations between international stock markets vary over time, indicating that benefits from international diversification are timevarying (Longin and Solnik, 1995). These authors show that correlation has been increasing since the 1960s leading to smaller diversification benefits. Because international investment opportunities have been increasing during these same decades, leading to more diversification possibilities, it is unclear what the net effect of globalization on risk diversification is. Goetzmann et al. (2005) study even a longer period. Using 150 years of data they find a U-shaped pattern in stock market correlations.

Focusing on the determinants of correlations in general and on the impact of integration in particular, Bekaert and Harvey (2000) show for a sample of emerging countries that financial liberalization decreases the cost of capital and increases correlations with other markets. This finding suggests that correlations increase due to globalization. However, Forbes and Rigobon (2002) show theoretically that correlation is biased upwards in periods of high volatility and can give a misleading picture of actual market dependencies.

The strong impact of trade and financial integration on stock market comovement also applies to European countries, see Wälti (2008). In addition, he stresses the role of exchange rate volatility and the introduction of the euro to explain the large increases in correlation among European stock markets. Beine and Candelon (2009) use the same gravity model approach to study only developing countries. They too document a large positive impact of bilateral trade and trade/financial liberalization on stock market comovement.

Another approach considers extreme dependence measures to assess the probability of a joint crash in two or more markets. Starting from extreme value theory Hartmann et al. (2004) develop an extreme dependence measure, which aims to capture the probability that two markets co-crash. The authors find that joint stock market crashes are much more likely to occur than what a multivariate normal distribution would suggest. In the context of contagion Bae et al. (2003) conclude that information on the joint occurrence of extreme returns is more useful than the one obtained by assuming a normal, student-t or GARCH model for the multivariate distribution. They find that interest rates, exchange rates and stock market volatility provide predictable power on the likeliness of contagion. However, in this framework exceedances are determined unconditionally, i.e. simply 
the lowest and highest 5\% returns are considered as extreme, without accounting for e.g. volatility effects.

A recent paper by Christiansen and Ranaldo (2009) applies the method of Bae et al. (2003) to compare the financial integration of the old and new EU countries' stock markets. The authors find strong persistence of coexceedances for both regions. They also find that lower tail coexceedances are more related to international stock market developments, in contrast to upper tail coexceedances, which seem to be more related to developments in other asset classes. In order to assess risk at any point in the return distribution Engle and Manganelli (2004) introduce the CAViaR method. ${ }^{5}$ This CAViaR method directly models the return quantile generating process.

In line with the literature, we mainly focus on the impact of trade and financial integration on comovements. Nevertheless, we include as additional determinants of comovement other control variables that have received attention in earlier works. An example is exchange rate volatility. Using a multivariate GARCH framework, Fratzscher (2002) shows that exchange rate volatility negatively impacts stock market comovements. The elimination of exchange rate volatility due to the introduction of the euro in 1999 led to an increased comovement for EMU countries. In addition, a couple of authors (e.g. Roll, 1992), document the role of industry structure on stock market comovement. Stock markets with a similar industry structure tend to comove more than stock markets with a very different industry composition. Hence, to the extent that industry structures become dissimilar over the investigated period, it is important to account for such a development in the specification of a model to be estimated. Given our panel data approach and the inclusion of cross-section fixed effects, we are able to account for the influence of time-constant factors such as geographical distance between markets or language similarity (Flavin et al., 2002). Likewise, the time series dimension allows us to include period fixed effects that capture the role of common factors on the comovement. This can be seen as an alternative to the inclusion of global observable variables such as US interest rates (Chinn and Forbes, 2004).

\footnotetext{
${ }^{5}$ CAViaR: Conditional Autoregressive Value at Risk by Regression Quantiles.
} 


\subsection{Measuring and explaining comovement}

\subsubsection{Measuring comovement}

Bilateral stock market comovements are measured using the methodology of Cappiello et al. (2005), which in turn is based on the CAViaR method developed in Engle and Manganelli (2004). Given a time series $\left\{y_{d}\right\}_{d=1, \ldots, D}$ of returns of a stock market index, the CAViaR method aims to model only one specific quantile $q_{\theta d}$ of the conditional return distribution, that is the value for which $\operatorname{Pr}\left[y_{d}<q_{\theta d} \mid \Omega_{d}\right]=\theta$ holds, where $y_{d}$ is the actual return, $\Omega_{d}$ the information set up to time $d$ and $\theta$ is the probability level (e.g. 10\%) corresponding to the quantile whose process is to be modeled. ${ }^{6}$ In words, $q_{\theta d}$ is the value such that there is a probability $\theta$ that $y_{d}$ is lower than it and a $(1-\theta)$ probability that $y_{d}$ is higher.

An explicit data generating process describing the behavior of the quantiles is necessary to calculate the regression quantiles $q_{\theta d}$. Following Cappiello et al. (2005) the CAViaR specification is: ${ }^{7}$

$q\left(\beta_{\theta}\right)_{d}=\beta_{1}+\beta_{2} * y_{d-1}+\beta_{3} * q\left(\beta_{\theta}\right)_{d-1}+\beta_{4} * y_{d-2}+\beta_{5} *\left|y_{d-1}\right|+\delta_{1} d_{1}+\ldots+\delta_{T} d_{T}$.

The parameter vector $\beta_{\theta}$ is estimated by minimizing the objective function first introduced by Koenker and Bassett Jr. (1978):

$$
\min _{\beta_{\theta}} \mathrm{D}^{-1} \sum_{d=1}^{D} \rho_{\theta}\left(y_{d}-q\left(\beta_{\theta}\right)_{d}\right),
$$

where $\rho_{\theta}(\lambda)=[\theta-I(\lambda \leq 0)], \lambda$ is the quantile loss function, $I($.$) the$ indicator function, and $\theta$ the probability level. The set of yearly dummies $\delta=\left\{d_{t}\right\}_{t=1, \ldots, T}$ is included in (2.1) to ensure that also in a finite sample there are exactly $\theta * D_{t}$ exceedances in each year, where $D_{t}$ is the number of trading days in year t. Due to the long time series available, in practical implementations it is often numerically infeasible to minimize (2.2) relative to the set of parameters $\left\{\beta_{\theta}, \delta\right\}{ }^{8}$ We then perform a two step estimation

\footnotetext{
${ }^{6}$ The subscript $d$ indicates that we consider a daily time series, whereas a subscript $t$ implies an annual time series. Hence, $\mathrm{T}$ is the total number of years in the latter time series and $\mathrm{D}$ the total number of days in the former.

${ }^{7}$ In Cappiello et al. (2005) $\beta_{4}$ is constrained as $-\beta_{2} * \beta_{3}$, here $\beta_{4}$ is unconstrained.

${ }^{8}$ In our implementation it implies estimating 37 parameters jointly.
} 
procedure. In the first step we solve the minimization problem $(2.2)$ with respect to $\beta_{\theta}$ using the specification (2.1) without the yearly dummies, then we plug these first estimates $\left\{\hat{\beta}_{\theta}\right\}$ into the complete specification (2.1), and minimize (2.2) only with respect to $\delta=\left\{d_{t}\right\}_{t=1, \ldots, T}$. The set of estimates we obtain from the above procedure delivers a fitted process $\hat{q}_{\theta d}$ such that the yearly rate of exceedances matches the nominal value $\theta$.

For each series $\left\{y_{d}\right\}$ it is possible to build the indicator vector $I_{d}^{Y}\left(\hat{\beta}_{\theta}\right) \equiv$ $I\left(y_{d}<\hat{q}_{\theta d}\right)$ that takes the value one for each date in which an exceedance takes place, i.e. $y_{d}<\hat{q}_{\theta d}$, and value zero otherwise. Since our analysis focuses on comovements between series, coexceedence probabilities

$$
p_{x y, d}(\theta) \equiv p\left(x_{d}<q_{\theta d}^{X} \mid y_{d}<q_{\theta d}^{Y}\right)=p\left(x_{d}<q_{\theta d}^{X}, y_{d}<q_{\theta d}^{Y}\right) / \theta,
$$

between pairs of series $\left\{x_{d}\right\}$ and $\left\{y_{d}\right\}$ are needed. These are readily obtained by regressing the coexceedance frequencies $I_{d}^{X Y}\left(\hat{\beta}_{\theta}^{X}, \hat{\beta}_{\theta}^{Y}\right) / \theta \equiv I_{d}^{X}\left(x_{d}<\right.$ $\left.q_{\theta d}^{X}\right) I_{d}^{Y}\left(y_{d}<q_{\theta d}^{Y}\right) / \theta$ on yearly dummy variables. The coefficients of the dummy variables are estimates of the time varying annual conditional coexceedance probabilities $\hat{p}_{x y, t}(\theta)$. For more details and proof of the consistency of the estimators, see Cappiello et al. (2005). ${ }^{9}$

When compared with other methods to analyze stock return comovements, the methodology of Cappiello et al. (2005) offers certain advantages. First, quantile regression is effective as a tool for exploring and modeling the nature of dependence of the return distribution on the conditioning variables, when the latter have different effects on different parts of the conditional distribution of the returns. This is particularly important when there are asymmetries in the impact of integration on the comovement of financial indexes.

Alternatives based on modeling first and/or second moments of return series, such as correlation (e.g. Forbes and Rigobon, 2002) do not allow for this possibility. They focus on one single point of the conditional distribution function, while in the framework of quantile regression, any value of $\theta$ (e.g. $1 \%$ or $90 \%$ ) can be chosen, allowing to measure codependence on any subset of the support of the joint distribution. ${ }^{10}$ Moreover, due to its flexibility, the CAViaR method is not constrained in

\footnotetext{
${ }^{9}$ The analysis is conducted in Matlab and based on the codes of Simone Manganelli.

${ }^{10}$ In a finite sample only few observations are available for the extreme quantiles resulting in inaccurate estimates.
} 
the choice of the quantile to model, whereas in measures based on extreme value theory the choice is constrained by the threshold level beyond which asymptotic theory applies (Danielsson and De Vries, 2000).

The specification of (2.1) has been chosen using the DQ test as model specification test (for details on the DQ test, see Engle and Manganelli, 2004).

\subsubsection{The model and empirical methodology}

This chapter uses the panel gravity model of Beine and Candelon (2009) to analyze the annual bilateral coexceedance probabilities calculated in Section 2.3.1 above. Define the general panel model as

$$
p_{i j, t}(\theta)=\beta_{1} p_{i j, t-1}(\theta)+\ldots+\beta_{m} p_{i j, t-m}(\theta)+X_{i j, t}^{\prime} \gamma+\eta_{i j}+\sum_{t=2}^{T} \delta_{t} d_{t}+\varepsilon_{i j, t},
$$

where $p_{i j, t}(\theta)$ is the coexceedance probability between countries $i$ and $j$ at time $t, X_{i j, t}$ the matrix of exogenous variables, a cross section dummy $\eta_{i j}$, a time dummy $d_{t}$ and $\varepsilon_{i j, t}$ is the error term of the bilateral pair $i, j$ at time t. To simplify notation, from now on we assume that the value of $\theta$ has been fixed, and we drop the explicit dependence of $p_{i j, t}$ on $\theta$. With seventeen countries, the cross sectional dimension of the panel consists of $\mathrm{N}=136$ bilateral relationships and the time dimension of $\mathrm{T}=32$ years, resulting in potentially 4352 observations.

The matrix of exogenous variables $X_{i j, t}$ aims to capture the channels through which shocks may be transmitted from one country to the other. The empirical counterparts of all variables in $X_{i j, t}$ are introduced in Section 2.4. This chapter focuses on two particular channels of transmission related to integration.

Our first interest lies in the impact of financial integration. Through the finance channel investors are able to diversify and rebalance asset portfolios globally. The possibility of investing abroad allows investors to take benefit from investment opportunities. When investors act globally, it might be expected that all markets will suffer more from global shocks. In this case, financial integration is likely to increase $p_{i j, t}$.

The second channel relates to trade integration. Trade patterns will affect business cycle fluctuations and hence stock market prices. If two 
countries trade extensively, it might be expected that their business cycles and their stock markets will be more correlated. The openness of one particular country to foreign trade can also act as a signaling device to international investors and lead them to buy domestic assets more extensively. Beine and Candelon (2009) find empirical evidence for this argument. This could strengthen the positive impact on $p_{i j, t}$.

In order to minimize the likelihood of misspecification, we also control for differences in industrial structures and for variations in exchange rates. The industrial composition of a country's stock market determines the extent to which countries face similar industry shocks. The more similar two countries' industrial structures are, the more their stock markets are likely to comove.

Other important controls are related to exchange rate movements. An investor prices currency risk and this price is determined by (expected) exchange rate movements. Exchange rate changes alter the return a foreign investor receives in his domestic currency. However, if currency risk is eliminated, e.g. through the introduction of the euro, the costs of rebalancing portfolios is lower. Moreover, exchange rate movements are not able to mitigate stock market movements anymore.

Following Beine and Candelon (2009) the model deals explicitly with unobserved heterogeneity by including cross section and time effects. In addition, by including dynamics in the model it is possible to take care of serial dependence directly, thus addressing the persistence of correlations in the residuals. Although a dynamic panel data model with cross section effects induces the well known Nickell (1981) bias, this bias is likely to be small due to the relatively large time dimension with respect to the cross section dimension.

The model is estimated using a FGLS approach taking care of potential heteroskedasticity. Due to the bilateral nature of the data cross section dependence is likely to be present. We use Panel Corrected Standard Errors, which are robust to cross-sectional dependence. In addition, Phillips and Sul (2003) argue that time effects reduce the bias induced by cross section dependence. ${ }^{11}$

\footnotetext{
${ }^{11}$ Alternative estimation methods aim to correct explicitly for cross-section dependence by e.g. median unbiased estimation (Phillips and Sul, 2003) or imposing a factor structure (Pesaran, 2006). The correction by Phillips and Sul (2003) allows for dynamics, but is only valid assuming $\mathrm{T} \rightarrow \infty$ and the impact of including exogenous regressors is unclear. Exogenous regressors are included in the correction by Pesaran (2006), however
} 


\subsection{Data}

\subsubsection{Stock market returns}

In order to build the quantiles $q_{\theta d}$ and the measures of coexceedance $p_{i j, t}$, we first need to define the stock market returns. The sample consists of daily local currency denominated country stock market index returns from Thomson Datastream for 1974-2006. ${ }^{12}$

There are 17 countries in the sample: Australia, Austria, Belgium, Canada, Denmark, France, Germany, Hong Kong, Ireland, Italy, Japan, Netherlands, South Africa, Singapore, Switzerland, United Kingdom and United States. Non trading days are excluded from the sample. ${ }^{13}$ To avoid problems of nonsynchronous trading we assume that the trading day starts in the US (d) and match this return with the one of the following day in Asia, Africa and Europe $(\mathrm{d}+1)$. The underlying assumption is that all (or most) news is generated in the US (North America) and spreads one calendar day later to Asia, Africa and Europe.

Table 2.1 presents descriptive statistics of the stock market index series used. There is some variation in the average daily return, with the lowest return in Japan $(0.023 \%)$ and the highest in South Africa $(0.061 \%)$. This implies that returns in South Africa are about three times as high as in Japan. However, part of this difference can be explained by different inflation rates in both countries, since returns are denominated in local currencies.

One might expect that these countries also have the lowest and highest

dynamics cannot be included explicitly resulting in biases due to autocorrelation. GMM based estimation does not suffer from the Nickell (1981) bias and is robust to potential endogeneity. However, a main disadvantage of GMM is the appropriate selection of an instrument set. Since potentially many different instrument sets are possible (i.e. not rejected by the Sargan test), estimations results turn out to be very unstable across valid instrument sets.

${ }^{12}$ Stock market returns can either be denominated in local currencies or in a common currency (e.g. US\$). Several authors advocate the use of local currency returns (e.g. Longin and Solnik, 1995; Fratzscher, 2002; Hartmann et al., 2004), whereas others (e.g. Chinn and Forbes, 2004) prefer common currency denominated returns. This chapter opts for local currency returns because the use of common currency returns "may also introduce a bias in that a high degree of integration may simply be due to a similarity in exchange rate changes rather than direct financial integration" (Fratzscher, 2002, p. 191). Moreover, taking all returns in US\$ implicitly assumes investors are not able to hedge currency risk.

${ }^{13} \mathrm{~A}$ full list of all excluded non-trading days is provided in the Appendix. 
Table 2.1: Descriptive statistics of equity returns: 1/1/1974-31/12/2006

\begin{tabular}{lccccc}
\hline \hline country & $\begin{array}{c}\text { avg return } \\
\text { (\% per day) }\end{array}$ & $\begin{array}{c}\text { st. deviation } \\
\text { (\% per day) }\end{array}$ & skewness & kurtosis & $\begin{array}{c}\text { normality test } \\
\left(\mathrm{Chi}^{2}\right)\end{array}$ \\
\hline Australia & 0.038 & 1.046 & -2.79 & 83.12 & $6724.6^{* * *}$ \\
Austria & 0.033 & 0.797 & -0.30 & 18.83 & $1993.9^{* * *}$ \\
Belgium & 0.029 & 0.850 & -0.44 & 16.09 & $1956.6^{* * *}$ \\
Canada & 0.032 & 0.821 & -0.79 & 16.92 & $2459.8^{* * *}$ \\
Denmark & 0.042 & 0.944 & -0.94 & 36.50 & $3407.4^{* * *}$ \\
France & 0.038 & 1.135 & -0.37 & 7.86 & $1093.8^{* * *}$ \\
Germany & 0.028 & 0.993 & -0.66 & 11.08 & $1819.1^{* * *}$ \\
Hong Kong & 0.048 & 1.682 & -2.34 & 57.93 & $5861.6^{* * *}$ \\
Ireland & 0.047 & 1.067 & -0.40 & 18.97 & $2088.3^{* * *}$ \\
Italy & 0.039 & 1.312 & -0.26 & 7.92 & $1015.2^{* * *}$ \\
Japan & 0.023 & 1.031 & -0.36 & 15.09 & $1807.6^{* * *}$ \\
Netherlands & 0.033 & 1.018 & -0.32 & 9.77 & $1301.8^{* * *}$ \\
South Africa & 0.061 & 1.291 & -0.74 & 12.87 & $2091.7^{* * *}$ \\
Singapore & 0.026 & 1.279 & -1.00 & 35.72 & $3490.2^{* * *}$ \\
Switzerland & 0.032 & 0.890 & -0.98 & 18.53 & $2831.2^{* * *}$ \\
United Kingdom & 0.039 & 1.031 & -0.25 & 11.35 & $1417.4^{* * *}$ \\
United States & 0.033 & 0.982 & -1.20 & 30.82 & $3660.7^{* * *}$ \\
\hline \hline
\end{tabular}

Note: Stock market data is daily local currency denominated. The test for normality is based on D'Agostino et al. (1990). *** implies rejection at the $1 \%$ level.

volatility, but this turns out not to be the case. The lowest volatility is observed in the Austrian market $(0.797 \%)$, whereas the highest is in Hong Kong (1.682\%). Hence, the volatility in Hong Kong is more than twice as large as the Austrian.

All countries face significant negative skewness, indicating lower tails. Moreover, kurtosis is significantly larger than 3, which corresponds to the normal distribution. Excess kurtosis implies that the distributions have fat tails. Normality is strongly reject for all series, indicating that any assumption of normally distributed returns is not valid.

\subsubsection{Financial liberalization}

Several indicators are available to measure the degree of financial openness of an economy. The most detailed indicator in terms of disaggregation and coverage across time and countries is KAOPEN developed by Chinn and Itô (2008). For each country, the value of KAOPEN is constructed from four categories of financial openness in the IMF's Annual Report on Exchange Arrangements and Exchange Restrictions: 1) The presence of multiple exchange rates, 2) restrictions on current account transactions, 
3) restrictions on capital account transactions and 4) Requirement of surrender of export proceeds. ${ }^{14}$ The larger KAOPEN is, the more financially open a country is.

A bilateral measure needs to be constructed since KAOPEN (and other alternatives) are indicators for a single country. Define the bilateral indicator of financial liberalization as

$$
\text { financial liberalization }_{i j, t}=\min \left(K A O P E N_{i, t}, K A O P E N_{j, t}\right) \text {, }
$$

where financial liberalization $n_{i j, t}$ has the value of the least open country.

Another traditional measure to capture financial liberalization is the IMF dummy, where a value of 1 implies that a country has capital account restrictions in force and 0 implies no restrictions. KAOPEN's main advantage is its higher disaggregation compared to the IMF dummy. Alternatives with higher disaggregation than the IMF dummy include indicators by Quinn (1997) and Miniane (2004). However, both are available only for a limited number of countries and for a limited time span.

\subsubsection{Trade integration}

The first indicator of trade integration is based on the measure of trade competition by Glick and Rose (1999) and aims to assess the extent to which two countries compete in the same export markets. If two countries compete in the same export markets it seems reasonable that both countries' stock markets react similarly to shocks originating in these export markets.

The trade competition indicator of Glick and Rose (1999) is given by

$$
\text { trade competition }_{i j, t}=\sum_{1}^{k} \frac{x_{i k, t}+x_{j k, t}}{x_{i, t}+x_{j, t}} *\left(1-\frac{x_{i k, t} / x_{i, t}-x_{j k, t} / x_{j, t}}{x_{i k, t} / x_{i, t}+x_{j k, t} / x_{j, t}}\right),
$$

where $x_{i k, t}$ represents exports from country $i$ to country $k$ at time $t$ and $x_{i, t}$ and $x_{j, t}$ represent total exports of countries $i$ and $j$ respectively. The countries considered in $k$ are all countries in the sample and the rest of

\footnotetext{
${ }^{14}$ Consult Chinn and Itô (2008) and both author's websites for more details on the construction of KAOPEN.
} 
the world, except for $i$ and $j$. This measure increases as country $i$ and $j$ 's export shares are more similar.

The second indicator of trade integration aims at measuring the strength of direct trade between two countries. In order to determine the strength of a bilateral trade relationship, we use the indicator constructed by Frankel and Rose (1998):

$$
\text { bilateral trade } \operatorname{trj}_{i, t}=\frac{X_{i j, t}+M_{i j, t}}{G D P_{i, t}+G D P_{j, t}},
$$

where $X$ and $M$ are nominal USD exports and imports respectively and GDP is nominal GDP in USD. This measure increases as bilateral trade becomes more important relative to GDP. Trade data is extracted from the IMF's Direction of Trade Statistics and GDP data from the World Bank World Economic Indicators.

\subsubsection{Industrial structure}

Stock market indexes are more likely to comove if these have a similar industrial structure, since global industry specific shocks are transmitted to both countries. Industry structure data on Datastream stock market indexes are not directly available. As an alternative, industry value added data is used to determine the production structure of a country. The underlying assumption is that a country's production structure is reflected in its stock market industry composition. To determine the similarity of two countries' production structure the specialization indicator of Krugman (1991) is used. This industrial dissimilarity indicator is computed by summing the absolute differences of an industry's GDP share in two countries:

$$
\text { industrial dissimilarity }{ }_{i j, t}=\sum_{n=1}^{N}\left|s_{n, i, t}-s_{n, j, t}\right|,
$$

where $s_{n, i, t}$ is the GDP share of industry $n$ in country $i$ or $j$ at time $t$. There are $\mathrm{N}=9$ industries considered in the specialization index, using value added data from the EU KLEMS database and other datasets for non-EU countries. ${ }^{15}$

\footnotetext{
${ }^{15}$ Details about all databases are provided in the Appendix.
} 


\subsubsection{Exchange rate volatility}

Exchange rate volatility is calculated using the methodology of realized volatility by Andersen et al. (2003). Daily returns are used to calculate annual volatility by

$$
\text { exchange rate volatility }_{i j, t}=\sum_{d=1}^{D_{t}}\left[r_{t, d}^{i j}\right]^{2},
$$

with $r$ being the exchange rate return at day $d$ and $D$ represents the number of trading days in one year. Bilateral exchange volatility is calculated using exchange rate data from Datastream.

Several countries in the sample introduced the euro in 1999, thereby eliminating exchange rate volatility between them. To consider the effect of the introduction of the euro separately, a dummy variable called EMU is introduced. This variable is one as of 1999 for all pairs consisting of two countries using the euro as legal tender.

\subsection{Results}

\subsubsection{Baseline results}

The baseline results use the model in Equation (2.4) and the full set of explanatory variables from Section 2.4. We use data from 1974 until 2005 due to the availability of industry data only until 2005. For each quantile the autoregressive order in (2.4) is determined by adding enough lags of $p_{i j, t}$ to eliminate serial correlation. Cross-section and time dummies are not reported for the sake of brevity. A first observation from Table 2.2 is the strong serial dependence of coexceedance probabilities.

In order to remove all serial correlation two to three lags of the dependent variable need to be included. Note that the sum of the coefficients on Q25 and Q75 is around 0.5, indicating strong persistence. The results in Table 2.2 show that integration exerts asymmetric effects on comovement, i.e. the change in the comovement of stock market returns depends on the part of the return distribution. In particular, financial integration is found to increase comovement significantly in the left tail, but not in the far right tail.

Interestingly financial openness tends to increase comovement more in periods of bad returns for both stock markets. This finding relates to 
Table 2.2: Explaining codependence (baseline specification).

\begin{tabular}{|c|c|c|c|c|c|c|}
\hline & Q5 & Q10 & Q25 & Q75 & Q90 & Q95 \\
\hline Lagged probability $(-1)$ & $\begin{array}{c}0.133^{* * *} \\
(0.044)\end{array}$ & $\begin{array}{c}0.187^{* * *} \\
(0.045)\end{array}$ & $\begin{array}{c}0.234^{* * *} \\
(0.045)\end{array}$ & $\begin{array}{c}0.237^{* * *} \\
(0.045)\end{array}$ & $\begin{array}{c}0.162^{* * *} \\
(0.044)\end{array}$ & $\begin{array}{l}0.076^{*} \\
(0.043)\end{array}$ \\
\hline Lagged probability $(-2)$ & $\begin{array}{c}0.060 \\
(0.043)\end{array}$ & $\begin{array}{c}0.105^{* *} \\
(0.044)\end{array}$ & $\begin{array}{c}0.170^{* * *} \\
(0.044)\end{array}$ & $\begin{array}{c}0.171^{* * *} \\
(0.044)\end{array}$ & $\begin{array}{c}0.136^{* * *} \\
(0.042)\end{array}$ & $\begin{array}{c}0.067 \\
(0.042)\end{array}$ \\
\hline Lagged probability $(-3)$ & & $\begin{array}{c}0.095^{* *} \\
(0.043)\end{array}$ & $\begin{array}{c}0.116^{* * * *} \\
(0.043)\end{array}$ & $\begin{array}{c}0.096^{* *} \\
(0.043)\end{array}$ & $\begin{array}{c}0.102^{* *} \\
(0.042)\end{array}$ & \\
\hline Trade competition & $\begin{array}{c}0.177^{* *} \\
(0.090)\end{array}$ & $\begin{array}{c}0.119^{*} \\
(0.072)\end{array}$ & $\begin{array}{c}0.179 * * * \\
(0.051)\end{array}$ & $\begin{array}{c}0.145^{* * *} \\
(0.050)\end{array}$ & $\begin{array}{c}0.180^{* * *} \\
(0.062)\end{array}$ & $\begin{array}{c}0.189 * * * \\
(0.065)\end{array}$ \\
\hline Bilateral trade & $\begin{array}{c}-0.129 \\
(1.007)\end{array}$ & $\begin{array}{c}1.252 \\
(0.961)\end{array}$ & $\begin{array}{c}0.750 \\
(0.734)\end{array}$ & $\begin{array}{c}1.521^{* *} \\
(0.683)\end{array}$ & $\begin{array}{l}1.358^{*} \\
(0.762)\end{array}$ & $\begin{array}{c}0.730 \\
(0.852)\end{array}$ \\
\hline Financial liberalization & $\begin{array}{c}0.008^{* *} \\
(0.004)\end{array}$ & $\begin{array}{c}0.009 * * \\
(0.004)\end{array}$ & $\begin{array}{c}0.008 * * \\
(0.003)\end{array}$ & $\begin{array}{c}0.007^{* *} \\
(0.003)\end{array}$ & $\begin{array}{c}0.003 \\
(0.003)\end{array}$ & $\begin{array}{c}0.005 \\
(0.003)\end{array}$ \\
\hline Industrial dissimilarity & $\begin{array}{c}-0.075 \\
(0.058)\end{array}$ & $\begin{array}{c}-0.104^{* *} \\
(0.046)\end{array}$ & $\begin{array}{c}-0.108^{* * *} \\
(0.037)\end{array}$ & $\begin{array}{c}-0.066^{*} \\
(0.034)\end{array}$ & $\begin{array}{c}-0.099^{* *} \\
(0.039)\end{array}$ & $\begin{array}{c}-0.084^{*} \\
(0.043)\end{array}$ \\
\hline Exchange rate volatility & $\begin{array}{c}-0.289^{* *} \\
(0.131)\end{array}$ & $\begin{array}{c}-0.318^{* * *} \\
(0.115)\end{array}$ & $\begin{array}{c}-0.276^{* * *} \\
(0.094)\end{array}$ & $\begin{array}{l}-0.130 \\
(0.093)\end{array}$ & $\begin{array}{l}-0.163 \\
(0.104)\end{array}$ & $\begin{array}{c}-0.174^{*} \\
(0.096)\end{array}$ \\
\hline Joint EMU membership & $\begin{array}{c}0.068^{* * *} \\
(0.021)\end{array}$ & $\begin{array}{c}0.049^{* * *} \\
(0.018)\end{array}$ & $\begin{array}{l}0.026^{*} \\
(0.014)\end{array}$ & $\begin{array}{c}0.055^{* * *} \\
(0.016)\end{array}$ & $\begin{array}{c}0.076^{* * *} \\
(0.017)\end{array}$ & $\begin{array}{c}0.113^{* * *} \\
(0.016)\end{array}$ \\
\hline Number obs. & 3566 & 3488 & 3488 & 3488 & 3488 & 3566 \\
\hline $\mathrm{R}^{2}$ & 0.49 & 0.64 & 0.77 & 0.68 & 0.44 & 0.33 \\
\hline Hausman test (p-value) & 0.000 & 0.000 & 0.000 & 0.000 & 0.000 & 0.000 \\
\hline Wald test (p-value) & 0.000 & 0.000 & 0.000 & 0.000 & 0.000 & 0.000 \\
\hline Wooldridge test (p-value) & 0.737 & 0.359 & 0.329 & 0.122 & 0.377 & 0.284 \\
\hline Friedman test (p-value) & 1.000 & 1.000 & 1.000 & 1.000 & 1.000 & 1.000 \\
\hline Abs off-diagonal elements & 0.242 & 0.239 & 0.246 & 0.245 & 0.241 & 0.238 \\
\hline Frees (Q-statistic) & 0.000 & 0.000 & 0.000 & 0.000 & 0.000 & 0.000 \\
\hline
\end{tabular}

Note: Estimation of Equation (2.4) using FGLS cross section weights, fixed cross-section effects, common time shocks and Panel Corrected Standard Errors (SUR). *, ** and *** imply significance at the $10 \%, 5 \%$ and $1 \%$ level, respectively.

the contagion literature, where a financial crisis spreads quickly from one country to the other (see e.g. Forbes and Rigobon, 2002). Hence, the scope for portfolio diversification tends to decrease at times when it is much more needed. This is the dark side of financial integration.

The economic magnitude of the coefficient on financial liberalization is quite important. The difference between a very open and a very closed economy is five units. With a coefficient of 0.008 on the $5 \%$ quantile, this implies that the coexceedance probability increases by about four percentage points if a country liberalizes. A transition from closed to fully open is a change from -2.5 to 2.5 in the KAOPEN indicator.

Asymmetric effects are also present for trade integration, which is captured by bilateral trade intensity and trade competition. Trade competition affects comovement significantly across all quantiles, whereas bilateral trade has an effect only on the right tail.

The impact of industrial structure seems to exhibit symmetric effects. 
A negative sign implies that the more dissimilar countries are the lower is their comovement, confirming the findings of Roll (1992) that industrial composition is an important determinant to explain stock market comovement.

A decrease in exchange rate volatility strongly increases stock market comovement for the lower tail. This implies that stable exchange rates increase the occurrence of joint negative extreme events. A $10 \%$ increase in exchange rate volatility results in a $2.89 \%$ decrease in comovement for Q5, 3.18\% for Q10 and 2.76\% for Q25. This effect is not present in the right tail, where only Q95 is marginally significant. Moreover, the economic impact of EMU is large, ranging from a 2.6 percentage point increase in coexceedance for Q25 to 11.3 percentage points for Q95. This increase in comovement significantly lowers the diversification potential for investors within the European Monetary Union. Our results are in line with Fratzscher (2002) and Bartram et al. (2007), who find that the elimination of exchange rate volatility increases inter EMU stock market comovement strongly. Industrial dissimilarity and the exchange rate variables are found to act as important controls and ensure that model (2.4) does not suffer from important specification bias due to omitted variables.

We conduct several specification checks to investigate the appropriateness of the empirical approach. First, we apply the Hausman test to decide on the use of fixed or random cross section effects. The results in Table 2.2 clearly show that random effects are strongly rejected in favor of a fixed effects specification. Next, we test for the presence of heteroskedasticity in the residuals to justify the GLS approach. Table 2.2 shows that the Wald test strongly rejects homoskedasticity of the residuals, i.e. it justifies the GLS approach. The number of lags of the dependent variable needs to be sufficient to eliminate residual serial correlation. We apply the Wooldridge test for this purpose and conclude that serial correlation appears to be eliminated by the dynamics in the model. One lag is not sufficient to achieve this for Q5 and Q95. Finally, the Frees test shows the presence of cross sectional dependence, which justifies the need to use Panel Corrected Standard Errors to deal with this issue. ${ }^{16}$

\footnotetext{
${ }^{16}$ We also show the result of the Friedman test, which does not reject cross sectional independence. However, De Hoyos and Sarafidis (2006) point out that Friedman's (and Pesaran's) test are biased in cases where cross-sectional dependence is characterized by alternating correlations in the residuals. Indeed, the average absolute correlations are all around 0.24 , which is relatively high. Frees' test is not subject to this drawback and this
} 


\subsubsection{Comparing coexceedances with correlations}

Using correlations leads to underestimate the impact of trade and financial integration on stock market comovement. To illustrate this, the column "realized correlation" in Table 2.3 reports the estimates of model (2.4), using realized correlation as dependent variable instead of $p_{i j, t}$. The estimation of such a model fails to capture the positive impact of trade variables on the comovement of stock markets.

Table 2.3: Explaining codependence with realized correlation.

\begin{tabular}{lcc}
\hline \hline & Realized correlation & FZ-transform \\
\hline Lagged correlation (-1) & $0.356^{* * *}$ & $0.440^{* * *}$ \\
& $(0.051)$ & $(0.053)$ \\
Lagged correlation (-2) & $0.115^{* *}$ & $0.147^{* * *}$ \\
& $(0.052)$ & $(0.053)$ \\
Lagged correlation (-3) & $0.132^{* * *}$ & \\
& $(0.049)$ & \\
Trade competition & 0.157 & $0.420^{*}$ \\
& $(0.103)$ & $(0.244)$ \\
Bilateral trade & 1.361 & 3.579 \\
& $(1.111)$ & $(3.033)$ \\
Financial liberalization & $0.011^{* *}$ & $0.021^{*}$ \\
& $(0.005)$ & $(0.011)$ \\
Industrial dissimilarity & $-0.189^{* * *}$ & $-0.408^{* *}$ \\
& $(0.068)$ & $(0.159)$ \\
Exchange rate volatility & $-0.571^{* * *}$ & $-0.964^{* * *}$ \\
& $(0.168)$ & $(0.369)$ \\
Joint EMU membership & $0.038^{*}$ & $0.177^{* * *}$ \\
& $(0.020)$ & $(0.060)$ \\
\hline Number obs. & 3488 & 3566 \\
$\mathrm{R}^{2}$ & 0.85 & 0.78 \\
\hline \hline
\end{tabular}

Note: Estimation of Equation (2.4), where $p_{i j, t}$ should be replaced with realized correlations $\left(\rho_{i j, t}\right)$, using FGLS cross section weights, fixed cross-section effects, common time shocks and Panel Corrected Standard Errors (SUR). *, ** and $* * *$ imply significance at the $10 \%, 5 \%$ and $1 \%$ level, respectively.

Since correlations are bounded between minus one and one it seems reasonable to map this variable as well to the $(-\infty, \infty)$ domain. To this

test strongly rejects the assumption of cross-sectional independence. 
aim, we apply the Fisher-Z transformation to the correlations:

$$
\rho_{i j, t}^{F Z}=\ln \left(\frac{1+\rho_{i j, t}}{1-\rho_{i j, t}}\right),
$$

where $\rho_{i j t}$ is the correlation coefficient for countries $\mathrm{i}$ and $\mathrm{j}$ at time $\mathrm{t}$. The second column in Table 2.3 shows the results if we use the Fisher$\mathrm{Z}$ transform. Most key results seem to be robust, but there are a couple differences with the first column.

The asymmetric effect of the variables is illustrated by the impact of bilateral trade on comovement. Countries with strong bilateral trade face an increase only on Q75 and Q90. Of course, this cannot be accounted for with a traditional analysis involving correlations. Moreover, the results show that financial liberalization has a strong positive impact, but do not show that the effect is different across the return distribution. The estimated results in column 1 show a very weak impact of EMU, which seems an awkward finding since this variable is highly significant in Table 2.2. In contrast, exchange rate volatility has a strong significant impact on correlations, whereas Table 2.3 shows this effect is only present for the left tail quantiles. In sum, correlations are unable to capture the specific effects coexceedance probabilities show.

\subsubsection{Robustness}

In the previous section we compare the baseline model to estimates from using realized correlation. We also report the results for the Fisher$\mathrm{Z}$ transform of correlation and find that the statistical significance of some variables changes quite severely. Since the codependence probability is bounded between zero and one it seems reasonable to map this variable as well to the $(-\infty, \infty)$ domain. A logistic transformation seems straightforward, but cannot be executed. Some observations have a zero value and this would be mapped into $-\infty$.

An alternative approach is to use the Fisher-Z transformation as well for the codependence probabilities. The resulting estimates are presented in Table 2.4. However, as probabilities are limited between zero and one, these are not mapped into the domain $(-\infty, \infty)$, but into $[0, \infty)$, which is only unbounded on one side.

Naturally the coefficient values change, but notice the strong correspondence between Table 2.4 and Table 2.3. First, we confirm that trade 
Table 2.4: Explaining codependence local returns (Fisher-Z transformation).

\begin{tabular}{lcccccc}
\hline \hline & $\mathrm{Q} 5$ & $\mathrm{Q} 10$ & $\mathrm{Q} 25$ & $\mathrm{Q} 75$ & $\mathrm{Q} 90$ & $\mathrm{Q} 95$ \\
\hline lagged probability (-1) & $0.144^{* * *}$ & $0.199^{* * *}$ & $0.261^{* * *}$ & $0.254^{* * *}$ & $0.173^{* * *}$ & $0.083^{*}$ \\
& $(0.044)$ & $(0.046)$ & $(0.046)$ & $(0.046)$ & $(0.045)$ & $(0.043)$ \\
lagged probability (-2) & 0.063 & $0.111^{* *}$ & $0.181^{* * *}$ & $0.173^{* * *}$ & $0.141^{* * *}$ & $0.071^{*}$ \\
& $(0.044)$ & $(0.045)$ & $(0.046)$ & $(0.045)$ & $(0.043)$ & $(0.042)$ \\
lagged probability (-3) & & $0.100^{* *}$ & $0.119^{* * *}$ & $0.098^{* *}$ & $0.107^{* *}$ & \\
& & $(0.044)$ & $(0.045)$ & $(0.044)$ & $(0.043)$ & \\
trade competition & $0.363^{*}$ & 0.236 & $0.388^{* * *}$ & $0.344^{* * *}$ & $0.376^{* * *}$ & $0.385^{* * *}$ \\
& $(0.191)$ & $(0.159)$ & $(0.123)$ & $(0.118)$ & $(0.132)$ & $(0.135)$ \\
bilateral trade & -0.305 & 3.200 & 2.074 & $3.728^{* *}$ & $2.804^{*}$ & 1.439 \\
& $(2.188)$ & $(2.230)$ & $(1.877)$ & $(1.705)$ & $(1.638)$ & $(1.792)$ \\
financial liberalization & $0.016^{*}$ & $0.018^{* *}$ & $0.017^{* * *}$ & $0.014^{*}$ & 0.005 & 0.010 \\
& $(0.009)$ & $(0.008)$ & $(0.006)$ & $(0.007)$ & $(0.007)$ & $(0.007)$ \\
industrial dissimilarity & -0.147 & $-0.225^{* *}$ & $-0.259^{* * *}$ & $-0.141^{*}$ & $-0.201^{* *}$ & $-0.166^{*}$ \\
& $(0.127)$ & $(0.102)$ & $(0.089)$ & $(0.079)$ & $(0.083)$ & $(0.090)$ \\
exchange rate volatility & $-0.577^{* *}$ & $-0.655^{* * *}$ & $-0.638^{* * *}$ & -0.279 & -0.332 & $-0.345^{*}$ \\
& $(0.280)$ & $(0.253)$ & $(0.224)$ & $(0.218)$ & $(0.222)$ & $(0.198)$ \\
joint EMU membership & $0.161^{* * *}$ & $0.119^{* * *}$ & $0.067^{*}$ & $0.145^{* * *}$ & $0.172^{* * *}$ & $0.240^{* * *}$ \\
& $(0.048)$ & $(0.042)$ & $(0.036)$ & $(0.040)$ & $(0.037)$ & $(0.030)$ \\
\hline Number obs & 3566 & 3488 & 3488 & 3488 & 3488 & 3566 \\
R2 & 0.455 & 0.60 & 0.69 & 0.63 & 0.41 & 0.30 \\
\hline \hline
\end{tabular}

Note: Estimation of Equation (2.4) using FGLS cross section weights, fixed cross-section effects, common time shocks and Panel Corrected Standard Errors (SUR). * ${ }^{* *}$ and *** imply significance at the $10 \%, 5 \%$ and $1 \%$ level, respectively.

competition has a strong impacts across all quantiles, albeit smaller on the $5 \%$ and $10 \%$ quantiles. Second, financial liberalization has its strongest impact on the left tail quantiles, although the statistical significance is slightly lower in Table 2.4. Third, the patterns of exchange rate volatility and joint EMU membership are identical, the former impacts mostly the lower tail, whereas the latter has the largest impact on the upper tail.

The disadvantage of the Fisher- $\mathrm{Z}$ transformation is the difficulty to interpret the magnitude of the coefficients. An important advantage of using the probabilities in the domain $[0,1]$ is the possibility to judge on economic significance, instead of statistical significance only. Moreover, the objective of the Fisher- $\mathrm{Z}$ transformation is to obtain an unbounded normal distribution. Due to the characteristics of the coexceedance probabilities this is not achieved. Consequently, this transformation is not a very attractive alternative.

To check the robustness of the results to the use of KAOPEN as indicator of financial liberalization, we use the IMF capital controls dummy instead of KAOPEN. Table 2.5 reports the results obtained with this alternative measure. 
Table 2.5: Explaining codependence using the IMF capital controls dummy.

\begin{tabular}{lcccccc}
\hline \hline & Q5 & Q10 & Q25 & Q75 & Q90 & Q95 \\
\hline Lagged probability (-1) & $0.134^{* * *}$ & $0.187^{* * *}$ & $0.241^{* * *}$ & $0.266^{* * *}$ & $0.162^{* * *}$ & $0.074^{*}$ \\
& $(0.044)$ & $(0.045)$ & $(0.045)$ & $(0.045)$ & $(0.044)$ & $(0.043)$ \\
Lagged probability (-2) & 0.061 & $0.107^{* *}$ & $0.173^{* * *}$ & $0.146^{* * *}$ & $0.137^{* * *}$ & 0.065 \\
& $(0.043)$ & $(0.044)$ & $(0.045)$ & $(0.045)$ & $(0.043)$ & $(0.042)$ \\
Lagged probability (-3) & & $0.097^{* *}$ & $0.119^{* * *}$ & $0.085^{* *}$ & $0.101^{* *}$ & \\
& & $(0.043)$ & $(0.043)$ & $(0.043)$ & $(0.042)$ & \\
Trade competition & $0.178^{* *}$ & $0.125^{*}$ & $0.176^{* * *}$ & $0.133^{* *}$ & $0.181^{* * *}$ & $0.196^{* * *}$ \\
& $(0.090)$ & $(0.073)$ & $(0.051)$ & $(0.052)$ & $(0.062)$ & $(0.066)$ \\
Bilateral trade & -0.126 & 1.231 & 0.665 & $1.539^{* *}$ & $1.344^{*}$ & 0.716 \\
& $(1.004)$ & $(0.954)$ & $(0.729)$ & $(0.670)$ & $(0.757)$ & $(0.843)$ \\
Financial liberalization & $-0.018^{*}$ & $-0.017^{*}$ & -0.007 & -0.008 & -0.006 & $-0.016^{* *}$ \\
(IMF Dummy) & $(0.010)$ & $(0.009)$ & $(0.007)$ & $(0.007)$ & $(0.007)$ & $(0.008)$ \\
Industrial dissimilarity & -0.081 & $-0.107^{* *}$ & $-0.105^{* * *}$ & -0.041 & $-0.101^{* * *}$ & $-0.095^{* *}$ \\
& $(0.058)$ & $(0.046)$ & $(0.038)$ & $(0.034)$ & $(0.039)$ & $(0.042)$ \\
Exchange rate volatility & $-0.288^{* *}$ & $-0.309^{* * *}$ & $-0.268^{* * *}$ & -0.078 & -0.161 & $-0.174^{*}$ \\
& $(0.132)$ & $(0.115)$ & $(0.094)$ & $(0.093)$ & $(0.105)$ & $(0.096)$ \\
Joint EMU membership & $0.069^{* * *}$ & $0.051^{* * *}$ & $0.029^{* *}$ & $0.058^{* * *}$ & $0.076^{* * *}$ & $0.113^{* * *}$ \\
& $(0.022)$ & $(0.018)$ & $(0.014)$ & $(0.017)$ & $(0.017)$ & $(0.016)$ \\
\hline Number obs. & 3566 & 3488 & 3488 & 3488 & 3488 & 3566 \\
$\mathrm{R}^{2}$ & 0.49 & 0.64 & 0.77 & 0.71 & 0.44 & 0.33 \\
\hline \hline
\end{tabular}

Note: Estimation of Equation (2.4) using FGLS cross section weights, fixed cross-section effects, common time shocks and Panel Corrected Standard Errors (SUR). *, ** and *** imply significance at the $10 \%, 5 \%$ and $1 \%$ level, respectively.

The results are similar to those from the KAOPEN measure, both for the financial integration variable and the other determinants of comovement. Note that a negative sign on the IMF dummy implies a reduction in comovement when restrictions are imposed. First, the coefficients on the lagged dependent variable and the explanatory variables are virtually identical to Table 2.2. Second, the IMF dummy variable confirms that the strongest effect of financial liberalization is on the lower tail.

Note that financial liberalization is significant for the $95 \%$ quantile. Nevertheless, one has to keep in mind that the IMF dummy is a very simplistic $0 / 1$ variable to capture financial liberalization. The disaggregation KAOPEN offers is especially important for our sample consisting of mostly developed countries, which are in general financially open. Put differently, the dummy variable cannot capture smaller changes in financial openness. However, in general, both variables show the same pattern across the distribution for financial liberalization.

Using local currency returns suggests a role for inflation differences as an explanatory variable (see e.g. Cai et al., 2009). However, this turns out not to be the case. When we include inflation differences, these are never significant for any estimated quantile. Therefore, concerns that 
Table 2.6: Explaining codependence with no t-1 shift for Canada and the United States.

\begin{tabular}{lcccccc}
\hline \hline & Q5 & Q10 & Q25 & Q75 & Q90 & Q95 \\
\hline Lagged probability (-1) & $0.125^{* * *}$ & $0.179^{* * *}$ & $0.209^{* * *}$ & $0.227^{* * *}$ & $0.143^{* * *}$ & $0.093^{* *}$ \\
& $(0.043)$ & $(0.045)$ & $(0.045)$ & $(0.045)$ & $(0.045)$ & $(0.044)$ \\
Lagged probability (-2) & $0.109^{* *}$ & $0.140^{* * *}$ & $0.166^{* * *}$ & $0.168^{* * *}$ & $0.108^{* *}$ & $0.073^{*}$ \\
& $(0.043)$ & $(0.044)$ & $(0.045)$ & $(0.044)$ & $(0.044)$ & $(0.043)$ \\
Lagged probability (-3) & & 0.065 & $0.102^{* *}$ & $0.095^{* *}$ & $0.121^{* * *}$ & \\
& & $(0.044)$ & $(0.043)$ & $(0.043)$ & $(0.043)$ & 0.025 \\
Trade competition & 0.119 & 0.088 & $0.084^{*}$ & 0.080 & 0.057 \\
& $(0.083)$ & $(0.067)$ & $(0.047)$ & $(0.053)$ & $(0.067)$ & $(0.073)$ \\
Bilateral trade & 0.217 & 1.029 & 0.842 & $1.653^{* *}$ & $1.296^{*}$ & 0.937 \\
& $(1.037)$ & $(0.975)$ & $(0.726)$ & $(0.670)$ & $(0.794)$ & $(0.918)$ \\
Financial liberalization & $0.010^{* * *}$ & $0.010^{* * *}$ & $0.009^{* * *}$ & $0.011^{* * *}$ & $0.008^{* *}$ & $0.007^{* *}$ \\
& $(0.003)$ & $(0.003)$ & $(0.003)$ & $(0.003)$ & $(0.003)$ & $(0.003)$ \\
Industrial dissimilarity & $-0.127^{* *}$ & $-0.124^{* * *}$ & $-0.123^{* * *}$ & $-0.117^{* * *}$ & $-0.184^{* * *}$ & $-0.175^{* * *}$ \\
& $(0.059)$ & $(0.045)$ & $(0.039)$ & $(0.033)$ & $(0.039)$ & $(0.043)$ \\
Exchange rate volatility & $-0.281^{* *}$ & $-0.295^{* * *}$ & $-0.240^{* * *}$ & $-0.174^{* *}$ & $-0.214^{* *}$ & $-0.196^{* *}$ \\
& $(0.118)$ & $(0.100)$ & $(0.093)$ & $(0.086)$ & $(0.095)$ & $(0.094)$ \\
Joint EMU membership & $0.062^{* * *}$ & $0.045^{* * *}$ & $0.025^{* *}$ & $0.037^{* * *}$ & $0.054^{* * *}$ & $0.093^{* * *}$ \\
& $(0.021)$ & $(0.017)$ & $(0.013)$ & $(0.014)$ & $(0.017)$ & $(0.018)$ \\
\hline Number obs. & 3566 & 3488 & 3488 & 3488 & 3488 & 3566 \\
$\mathrm{R}^{2}$ & 0.51 & 0.64 & 0.79 & 0.68 & 0.47 & 0.37 \\
\hline \hline
\end{tabular}

Note: Estimation of Equation (2.4) using FGLS cross section weights, fixed cross-section effects, common time shocks and Panel Corrected Standard Errors (SUR). *, ** and *** imply significance at the $10 \%, 5 \%$ and $1 \%$ level, respectively.

coexceedances may be severely impacted by local currency price movements are not necessary. In addition, when including interest rate differentials also no significant coefficients are obtained. Results of these estimations are not reported but are available upon request.

Since we are using returns from different time zones, we face the issue of nonsynchronous trading. So far, we chose to match d-1 returns in Canada and the US with time d returns elsewhere for the following reasons. First, results show that the coexceedance probabilities of Canada and the US visà-vis other countries are significantly higher when we consider d-1 returns for both countries instead of date d returns. This is in line with the findings of Bae et al. (2003) who find this result for correlations between the US and Asia. Second, we follow the recent literature, which prefers to match day d-1 returns in North America with day d returns elsewhere (see e.g. Poon et al., 2004). Nevertheless, for robustness purposes, we report the results with no time shift in Table 2.6.

The results of Table 2.6 are broadly in line with those of Table 2.2. However, there are some slight differences. First, the impact of trade competition is weakened across the quantiles and it is only significant 
for Q25. In contrast, the effects of bilateral trade are identical to Table 2.2. Second, the right tail quantiles show a significant positive effect of financial liberalization on comovement in Table 2.6. However, notice that the general pattern is identical to Table 2.2, with a larger impact on Q5 and Q10, compared to Q90 and Q95. Notice that in Table 2.6 exchange rate volatility is also in the right tail significant, but the magnitude is much weaker than in the left tail. The remaining variables show identical results as in Table 2.2.

\subsection{Conclusion}

In conclusion, this chapter shows the asymmetric impact of global integration processes on stock market comovement at different parts of the return distribution. We measure comovement by estimating coexeendance probabilities using the methodology of Cappiello et al. (2005). These coexceedance probabilities are analyzed in a gravity model using bilateral trade, finance, industry and exchange rate indicators.

Our findings suggest that the global integration process has asymmetric effects on comovement at different parts of the return distribution. First, trade integration increases comovement across all quantiles. Second, financial liberalization has a strong positive impact on the left tail and only a minor effect on the right tail. Finally, a decrease in exchange rate volatility has a strong positive impact on lower tail comovement, but no effect on right tail comovement. Once exchange rate volatility is eliminated by e.g. the introduction of the euro, this has a strong effect on comovement as well, but especially on the upper tail.

The increase in comovements due to the global integration process illustrates the dark side of global integration. Investors will experience more difficulties in reaping the gains from asset diversification, where especially diversification in bad times will become more challenging.

\subsection{Appendix A: Data sources}

\section{Stock market indexes}

Thomson Datastream. Datastream national stock market indexes. Daily local currency denominated prices from 1974-2006. 


\section{Financial liberalization}

IMF Annual Report on Exchange Arrangements and Exchange Restrictions. Capital controls dummy.

Menzie Chinn (KAOPEN). Financial liberalization data on KAOPEN is available from 1974 until 2006. Data for the Netherlands is missing from 1975-1980 and Switzerland 1973-1995. For the Netherlands, assume a gradual linear liberalization from 1975 until 1980. On the basis of alternative measures (e.g. the Quinn indicator and the capital controls dummy) Switzerland is fully open as of 1974.

\section{Trade integration}

IMF Direction of Trade Statistics. Bilateral import and export data in US\$ from 1974-2006. There is incomplete data for Hong Kong and Singapore (1980-2006) and South Africa. However, most data can be completed by using the trade partner's export and import figures. For Belgium simplifying assumptions are necessary since only data for the Belgium-Luxembourg currency union is available before 1999 .

World Bank World Development Indicators. Nominal GDP in US\$ for all countries 1974-2006.

\section{Industrial structure}

All EU countries, Japan and the United States: EU KLEMS November 2007 (1974-2005). Australia: Australian Bureau of Statistics (1975-2006). Canada: CANSIM (1974-1978) and GGDC 60 Industry database (19792003). Hong Kong and Singapore: GGDC 10-Sector database (1974-2005). South Africa: Statistics South Africa (1986-2006). Switzerland: Statistics Switzerland (1990-2006).

\section{Exchange rate volatility}

Thomson Datastream. Daily exchange rates of all currencies vis-à-vis the UK Pound from 1974-2006. Since 1999 volatility for EMU pairs is zero.

\section{Short term interest rates}

Global Financial Data, monthly frequency. 


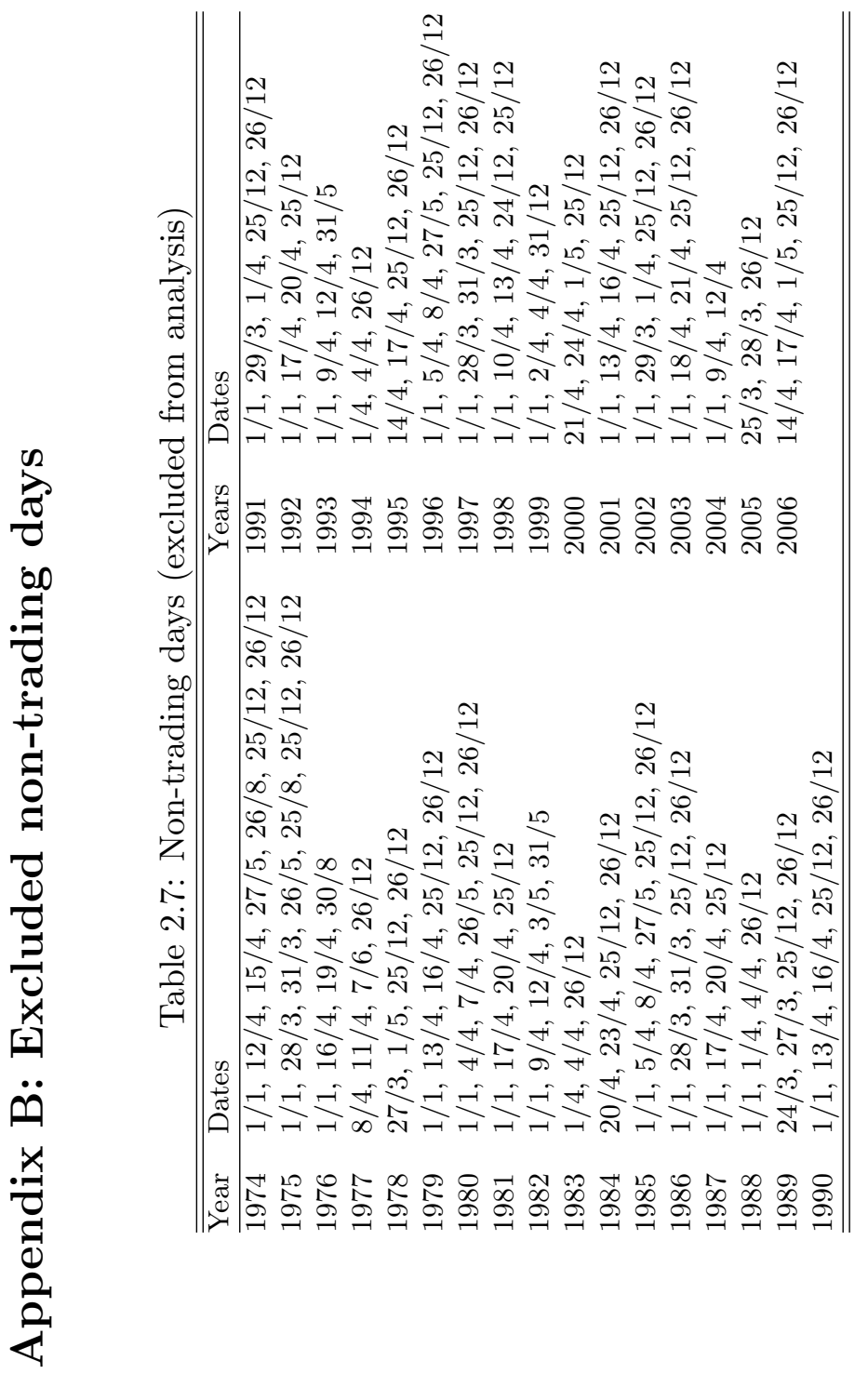

ஸे 


\section{DYNAMIC INTERNATIONAL Portfolio Adjustment: Rational INVESTORS AND THE HOME BIAS}

\subsection{Introduction}

Despite the well known benefits from international portfolio diversification international investors still exhibit a great deal of home bias in their equity allocations. ${ }^{1}$ Already in the late sixties and early seventies several authors show the large benefits of international equity diversification (See e.g. Grubel, 1968; Solnik, 1974). Since the early seventies financial markets have liberalized, thereby reducing the barriers of cross border asset holdings. However, the equity home bias anomaly remains present to date and economists have not been able to fully explain its causes. Not surprisingly, Obstfeld and Rogoff (2001) have singled out the equity home bias as one of the six major puzzles in macroeconomics.

Most research on the home bias focuses on explaining the frictions in international markets that hinder the investor to optimally diversify his portfolio. These frictions include, among others, transaction costs (Heathcote and Perri, 2004), capital controls (Chan et al., 2005), equity market development (Berkel, 2007) and informational asymmetries (Van Nieuwerburgh and Veldkamp, 2009). ${ }^{2}$ These papers seek to find the determinants of the lack of international equity diversification.

\footnotetext{
${ }^{1}$ This chapter is based on Vermeulen (2010).

${ }^{2}$ Several institutional factors, which are difficult to quantify, play a role as well in explaining the equity home bias. For example, large investors such as pension funds are often constrained in the amount of foreign assets they may hold (Iglesias and Palacios, 2000). Another example are many employees in Anglo-Saxon countries and especially the United States who invest a large part of their pension savings in their own firm (Benartzi, 2001).
} 
This chapter focuses on the factors explaining cross border asset holdings, thereby investigating only the properties of the foreign share of resident's equity portfolios. Early studies focus solely on the foreign equity position of the United States (e.g Ahearne et al., 2004). However, the IMF's construction of the Coordinated Portfolio Investment Survey has enabled researchers to use detailed bilateral data on aggregate bilateral asset holdings for a large number of countries. Recent studies find that geographical proximity, trade and currency unions appear to be the main determinants (See e.g. Portes and Rey (2005); Aviat and Coeurdacier (2007); Lane and Milesi-Ferretti (2008)). Hence, many factors used to explained trade patterns are useful in describing bilateral asset holdings. In addition, capital controls (Bekaert and Wang, 2009) and information asymmetries (Andrade and Chhaochharia, 2009) are important determinants as well.

The International Capital Asset Pricing Model (ICAPM) predicts that each investor holds a share of foreign equities equal to their respective share of world market capitalization. The existence of home bias in portfolio equity holdings implies that the investor overweights domestic equities, thereby creating hedging demands for equities that comove less with the domestic equity market. Put differently, given the existence of the home bias, investors need to overweight their investment in low comoving assets compared to the ICAPM market portfolio. ${ }^{3}$ Hence, the investor aims to compensate for his overinvestment in domestic equities by bringing his portfolio closer to the market portfolio.

Existing studies find mixed evidence of the investor's behavior in response to stock market comovement. Once informational frictions are controlled for Portes and Rey (2005) establish a weak negative reaction of foreign investment to covariance. However, their evidence is weak and changes across specifications. A related study by Lane and Milesi-Ferretti (2008) find a positive relationship between portfolio equity allocations and correlations. This result questions the rationality of investors, because investors do not reap the benefits of global diversification when they overinvest in high comoving equities.

However, Coeurdacier and Guibaud (2009) point at an endogeneity

\footnotetext{
${ }^{3}$ See Coeurdacier and Guibaud (2009) for a more formal treatment of this prediction. It is important to realize that due to different correlations, the optimal foreign investment portfolio is different from the ICAPM prediction. However, the expected sign on correlation is always negative.
} 
problem when correlation is used as an explanatory variable. There is a clear simultaneity bias, because equity holdings are determined by correlations, but correlations are also dependent on investors' equity demands. These authors find that once frictions and endogeneity concerns are controlled for, international investors behave rationally by overinvesting in low comoving assets and underinvesting in high comoving assets.

This chapter offers two main contributions to the literature on international equity portfolio allocations. First, the international investor's portfolio allocation problem is estimated using a dynamic model. Introducing dynamics offers several advantages, such as the ability to easily take time-invariant frictions into account. In contrast, previous studies model the investor's portfolio optimization in a static (equilibrium) context and do not consider potential dynamics. In addition, where the previous literature considers the level equity allocations, here the the year-to-year portfolio changes are studied. It is unlikely that current equity allocations are in equilibrium, therefore this chapter aims to investigate the short run dynamics in international equity allocations.

The second main contribution is related to the measurement of comovement. Correlation is the standard method to measure the comovement of two time series. However, this is quite restrictive because correlations only provide one number which summarizes how two time series comove in good and bad states of the world. Therefore, this chapter also measures upper and lower tail comovement, where only a specific part of the return distribution is taken into account. Doing so provides more detailed information on the comovement properties in different states of the market. Several studies such as Ang and Bekaert (2002) show the importance of distinguishing between comovement across different parts of the return distribution. Since international investors seeking diversification benefits dislike situations where all markets turn bad, i.e. a joint stock market crash, they treat joint booms differently from joint crashes. Hence, this chapter investigates possible asymmetric reactions to upper and lower tail dependence.

Tail dependence is measured using the coexceedance probability methodology of Cappiello et al. (2005), where comovement of two return series is calculated on a specific part of the return distribution. In this chapter the $5 \%, 10 \%$ and $25 \%$ lower tail and $75 \%, 90 \%$ and $95 \%$ upper tail coexceedance probabilities are calculated. Similar to correlations, coexceedance probabilities also face endogeneity issues as these are influenced by trade 
and financial integration as well (See e.g. Beine et al., 2010).

Bilateral aggregate international portfolio allocations for 40 source and 44 host countries from 2001-2007 are taken from the IMF's Coordinated Portfolio Investment Survey (CPIS) database. These bilateral allocations are studied empirically in a dynamic panel gravity framework using System GMM. It is necessary to include dynamics due to the large persistence of equity positions across time. Ignoring serial correlation results in biased estimates. The System GMM framework is especially attractive when including dynamics and facing endogeneity problems. Specifically, portfolio allocations and asset market comovements are jointly determined by international financial integration. The System GMM approach seems to be better able to deal with the Nickell bias, compared to a fixed effects estimation.

Using a dynamic portfolio adjustment approach, results show that investors diversify away from high comoving equities in favor of low comoving equities. These results are confirmed along two dimensions. First, as the full dataset faces homogeneity issues in the pooled estimation, two samples are constructed. One sample is based on statistical poolability and the other by selecting an economically homogeneous group. Second, both measures of comovement (correlation and coexceedance probabilities) have a negative impact on asset allocations in both samples. However, the left tail probabilities are not significantly negative indicating that investors do not strongly diversify away from extreme negative events. Perhaps surprising, investors do diversify away from equity markets that jointly experience a boom.

The most important control variables are the change in market capitalizations and changes in gdp per capita, which both have a positive impact on equity holdings. Capital account openness matters in some estimations as well. Trade, industrial differences and exchange rate volatility have a smaller impact in the short run adjustment process. Robustness checks show that additional control variables do not provide extra information.

When taking a dynamic equilibrium equity allocation approach and estimating the model in levels, there appears to be no relationship between comovement and equity positions. Accounting for dynamics is extremely important in the level equation, because the coefficient on the lagged variable is around 0.8. Not accounting for these dynamics implies that the residuals are serially correlated and the estimated coefficients biased. All control variables have a significant effect and their signs in line with the 
findings of the previous literature.

A final robustness check investigates the importance of home-biasedness on equity allocation changes. There appears to be a catch up process where strongly home biased countries' investors increase their foreign equity holdings faster than investors from countries with a low home bias. In addition, investors in strongly home biased countries react stronger to correlations than low home biased investors. This is consistent with the theoretical predictions of larger hedging in the former group. To compensate for their large degree of home-biasedness they need to react stronger to comovement.

The chapter is organized as follows. Section 3.2 introduces the methodology to measure stock market comovement and outlines the empirical framework. Section 3.3 discusses the database and Section 3.4 presents the results. Section 3.5 conducts several robustness checks and Section 3.6 concludes.

\subsection{Empirical methodology}

\subsubsection{Capturing stock market comovement}

This chapter applies two distinct measures to capture stock market comovement. First, annual realized correlations are calculated using the method of Andersen et al. (2001) and second, the methodology of Cappiello et al. (2005) is used to calculate annual coexceedance probabilities. Correlation is a measure of average comovement, i.e. correlations summarize the joint behavior of two return series using the entire return distribution. Basically, coexceedance probabilities disaggregate the stock markets' return distributions and measure the comovement of both series in a certain region of the return distribution. Each method is discussed in turn.

\section{Realized correlation}

Let $p_{i, t, d}$ be the value of the stock market index of country $i$ during year $t$ on day $d$, where $i=1, \ldots, N$, with $N$ being the number of countries considered, $t=1, \ldots, T$, where $\mathrm{T}$ are the number of years and $d=1, \ldots, D_{t}$, with $D_{t}$ being the number of trading days in year $t$. Daily returns on stock index $i$ are calculated by $r_{i, t, d}=\left[\ln \left(p_{i, t, d}\right)-\ln \left(p_{i, t, d-1}\right)\right] * 100$.

Using the method of quadratic variation (Andersen et al., 2001), annual 
index volatility is given by

$$
\sigma_{i, t}^{2}=\sum_{d=1}^{D_{t}}\left[r_{i, t, d}\right]^{2},
$$

with $\sigma_{i, t}^{2}$ being annual index volatility of stock market $i$. As shown by Andersen et al. (2001) it is possible to calculate the annual covariance between two assets using the same methodology to obtain realized covariance

$$
\sigma_{i j, t}=\sum_{d=1}^{D_{t}}\left[r_{i, t, d} * r_{j, t, d}\right] .
$$

The calculation of realized correlation is straightforward from (3.1) and (3.2) as

$$
\rho_{i j, t}=\frac{\sigma_{i j, t}}{\sigma_{i, t} * \sigma_{j, t}},
$$

where $\rho_{i j, t}$ is the realized correlation between index $i$ and index $j$ during year $t$.

\section{Coexceedance probabilities}

Bilateral stock market coexceedance probabilities are calculated using the methodology of Cappiello et al. (2005), which in turn is based on the CAViaR method developed in Engle and Manganelli (2004). Given a return series $r_{i, t, d}$ as defined above, the CAViaR method aims to model only one specific quantile $q_{\theta, i, t, d}$ of the conditional distribution of returns, that is the value for which $\operatorname{Pr}\left[\mathrm{r}_{i, t, d}<\mathrm{q}_{\theta, i, t, d} \mid \Omega_{t, d}\right]=\theta$ holds, where $\mathrm{r}_{i, t, d}$ is the actual return, $\Omega_{t, d}$ the information set up to time $(t, d)$ and $\theta$ is the probability level (e.g. 10\%) corresponding to the quantile whose process is to be modeled. In words, $\mathrm{q}_{\theta, i, t, d}$ is the value such that there is a $\theta \%$ probability that $\mathrm{r}_{i, t, d}$ is lower than it and a $(1-\theta \%)$ probability that $\mathrm{r}_{i, t, d}$ is higher. The subscripts $i$ and $t$ are omitted below for notational convenience when only one time series is discussed. In case of ambiguity all subscripts are included.

An explicit data generating process describing the behavior of the quantiles is necessary to calculate the regression quantiles $\mathrm{q}_{\theta d}$. Following 
Cappiello et al. (2005) the CAViaR specification is: ${ }^{4}$

$$
q\left(\beta_{\theta}\right)_{d}=\beta_{1}+\beta_{2} * r_{d-1}+\beta_{3} * q\left(\beta_{\theta}\right)_{d-1}+\beta_{4} * r_{d-2}+\beta_{5} *\left|r_{d-1}\right| .
$$

The parameter vector $\beta_{\theta}$ is estimated by minimizing the objective function:

$$
\min _{\beta_{\theta}} D_{T}^{-1} \sum_{d=1}^{D_{T}} \rho_{\theta}\left(r_{d}-q\left(\beta_{\theta}\right)_{d}\right),
$$

where $\rho_{\theta}(\lambda)=[\theta-I(\lambda \leq 0)] \lambda$ is the quantile loss function, $I(\cdot)$ the indicator function, and $\theta$ the probability level. This method, first introduced by Koenker and Bassett Jr. (1978), ensures that asymptotically there are $\theta \cdot T$ exceedances, that is realizations $\mathrm{r}_{d}$ such that $\mathrm{r}_{d}<\mathrm{q}_{\theta d}$. However, it may happen in finite samples that the number of exceedances does not equal the theoretical value $\theta \cdot D_{t}$.

In order to correct for this finite sample effect, a set of yearly dummies $\delta=\left\{d_{t}\right\}_{t=1, \ldots, T}$ is included in (3.3), giving the new specification for the quantile process:

$q\left(\beta_{\theta}, \delta\right)_{d}=\beta_{1}+\beta_{2} * r_{d-1}+\beta_{3} * q\left(\beta_{\theta}, \delta\right)_{d-1}+\beta_{4} * r_{d-2}+\beta_{5} *\left|r_{d-1}\right|+\delta_{1} d_{1}+\ldots+\delta_{T} d_{T}$.

Due to the long time series available, in practical implementations it is often numerically infeasible to minimize (3.4) relative to the set of parameters $\left\{\beta_{\theta}, \delta\right\}$.

Therefore a two step estimation procedure is applied. First, solve the minimization problem (3.4) with respect to $\beta_{\theta}$ using the specification (3.3) for the conditional quantile. Then plug the estimates $\hat{\beta}_{\theta}$ into (3.5) to obtain a vector $\tilde{q}_{\theta d}=\left\{q(\hat{\beta}, \delta)_{t}\right\}_{t=1, \ldots, T}$. In the second step substitute the $\tilde{q}_{\theta d}$ into (3.4) to obtain a new expected quantile loss function that is minimized to obtain the estimates of $\delta_{t}$. The set of estimates from the above procedure delivers a fitted process $\hat{q}_{\theta d}$ such that the yearly rate of exceedances matches the nominal value of $\theta$.

The following step is to build an indicator vector of exceedances, $\mathrm{I}_{d}^{i}\left(\hat{\beta}_{\theta}\right) \equiv I\left(r_{d}<q_{\theta d}\right)$, that takes the value one for each date in which an exceedance takes place, i.e. $\mathrm{r}_{d}<\mathrm{q}_{\theta d}$ and value zero otherwise values of $\theta<50 \%$. The reverse is applied when $\theta>50 \%$. This

\footnotetext{
${ }^{4}$ In Cappiello et al. (2005) $\beta_{4}$ is constrained as $-\beta_{2} * \beta_{3}$. Here $\beta_{4}$ is unconstrained since no stability problems arise when no restrictions are imposed.
} 
procedure is repeated for each time series that enters the dataset. More specifically, each time series is given by returns on stock indexes in different countries. Since the present analysis focuses on comovements between series a measure of "coexceedance" is needed. Put differently, a measure of the frequency at which the index returns in two different countries is constructed, where $\mathrm{r}_{i, t, d}$ and $\mathrm{r}_{j, t, d}$, lie at the same date below the value of the respective quantiles, $\mathrm{q}_{\theta d}^{i}$ and $\mathrm{q}_{\theta d}^{j}$. This is obtained by multiplying the two indicator vectors to obtain the new variable $I_{d}^{i j}\left(\hat{\beta}_{\theta}\right) \equiv I_{d}^{i}\left(\beta_{\theta}\right)$. $I_{d}^{j}\left(\beta_{\theta}\right)$. Finally, conditional "coexceedance" frequencies are transformed into "coexceedance" probabilities, that is the probability of $r_{i, t, d}<q_{\theta t}^{i}$ conditional on $r_{j, t, d}<q_{\theta t}^{j}$ at date $d\left(p\left(r_{d}^{i}<q_{\theta d}^{i}, r_{d}^{j}<q_{\theta d}^{j}\right) / \theta\right)$.

In order to do so, it suffices to run a regression of $\mathrm{I}_{d}^{i j} / \theta$ on yearly dummy variables. The coefficients of the dummy variables are estimates of the time varying conditional coexceedance probabilities $p_{i j, t}(\theta) .{ }^{5}$

\subsubsection{Estimation method}

This chapter tests the international investor's portfolio adjustments in response to asset market comovements. According to portfolio theory, hedging demands emerge if investors overinvest in one asset. In response, rational investors increase their holding of low comoving assets at the expense of strong comoving assets. Hence, the model in levels is

$\ln \left(\right.$ Equity $\left._{i j, t}\right)=\beta_{1} \ln \left(\right.$ Equity $\left._{i j, t-1}\right)+\beta_{2}$ Comove $_{i j, t}+\gamma \mathbf{X}_{\mathbf{i j}, \mathbf{t}}+\eta_{\mathbf{i j}}+\delta_{\mathbf{t}}+\epsilon_{\mathbf{i j}, \mathbf{t}}^{\mathbf{l}}$,

where Equity $y_{i j, t}$ is the amount of portfolio equity residents of country i own in country j measured in US $\$$, Comove is either captured by correlation or a specific coexceedance probability, $X_{i j, t}$ is a matrix of time-varying control variables, $\eta_{i j}$ are cross sectional fixed effects, $\delta_{t}$ are time dummies and $\epsilon_{i j, t}^{l}$ is the residual of the level equation.

In this set-up international investors determine this period's equity allocations based on previous period's allocations and observed comovement. Studying a full adjustment to equilibrium is unrealistic as only seven observation are available for each country pair. Hence, it makes more sense to investigate if investor reallocations are in the correct direction.

\footnotetext{
${ }^{5}$ For more details and proof of the consistency of the estimators, see Cappiello et al. (2005). The analysis is conducted in Matlab and based on the codes of Simone Manganelli.
} 
Therefore, in an alternative approach the dependent variable can be written in first differences. Since $\Delta \ln \left(\right.$ Equity $\left._{i j, t}\right)$ turns out to be serially correlated, dynamics in the first differences need to be included as well

$$
\Delta \ln \left(\text { Equity }_{i j, t}\right)=\xi_{1} \Delta \ln \left(\text { Equity }_{i j, t-1}\right)+\xi_{2} \text { Comove }_{i j, t}+\psi \mathbf{Z}_{\mathbf{i j}, \mathbf{t}}+\mu_{\mathbf{i j}}+\nu_{\mathbf{t}}+\epsilon_{\mathbf{i j}, \mathbf{t}}^{\mathbf{d}},
$$

where fixed effects $\mu_{i j}$ and time dummies $\nu_{t}$ are allowed to be present in the first differences. Here $\epsilon_{i j, t}^{d}$ is the residual of the first difference equation. This model considers the dynamic adjustment process of international investors who decide to increase or decrease their holdings of certain foreign assets based on observed comovement. Some variables in $Z_{i j, t}$ are the first differences of their counterparts in $X_{i j, t}$, whereas other variables can remain in levels in the estimation.

Equations (3.6) and (3.7) are estimated using two-step System GMM (Blundell and Bond, 1998), where Comove is treated as an endogenous variable. Hence the instrument space consists of lags 2 up to all possible further lags of $\ln \left(\right.$ Equity $\left._{i j, t}\right)$ or $\Delta \ln \left(\right.$ Equity $\left._{i j, t}\right)$ and Comove $_{i j, t}$, plus the contemporaneous value of the exogenous variables $X_{i j, t}\left(Z_{i j, t}\right)$. The time dummies are only included as instruments in the level equation. These time dummies capture common shocks in the sample and reduce concerns of biases induced by cross sectional dependence (Phillips and Sul, 2003). The Hansen test is used to judge on the validity of the instrument set and robust standard errors are reported. ${ }^{6}$ Furthermore, the Windmeijer (2005) correction is applied.

The main advantage of using System GMM compared to a fixed effects specification is the ability of the former to deal with the potential endogeneity of Comove. Dealing with endogeneity is also possible in fixed effects instrumental variable set-up. However, the main challenge is to find appropriate instruments for the endogenous variable. Finding variables that explain Comove, but without having a direct effect on Equity, will be especially difficult. ${ }^{7}$ For example, trade has important explanatory power for both equity positions (Portes and Rey, 2005) and coexceedance probabilities (Beine et al., 2010). A System GMM approach overcomes

\footnotetext{
${ }^{6}$ The Sargan test is not robust against heteroskedasticity and cannot be interpreted appropriately in two-step System GMM estimation procedure.

${ }^{7}$ Coeurdacier and Guibaud (2009) use correlations between equity markets during 1950-1975 as instruments for correlations during 2001-2005. However, the problem with this choice of instrument is the inability of the instrument to capture time varying effects during 2001-2005.
} 
these problems.

In addition, System GMM avoids the well know Nickell bias, known to be especially severe in large $\mathrm{N}$, small $\mathrm{T}$ samples such as the one used here. System GMM allows for time-constant fixed effects, which may capture important variables such as distance or a common language. It is not necessary to include these explicitly. Even worse, including these may even lead to inefficiencies. The importance of time constant variables favors even more a first difference approach by explaining the annual changes in equity allocations.

One caveat in the estimation is the use of Comove, which is an estimated variable and induces the generated regressor problem (Pagan, 1984). The issue is similar to a two stage least squares estimation, when one does not correct the standard errors for the first step instrumentation. Practically, accounting for the generated regressor problem increases the standard errors of the coefficient on the generated variable. It is important to note that the point estimate of the coefficients are unbiased in all estimations. However, the standard errors should be interpreted conservatively at the $5 \%$ significance level. Note that the standard errors have already been "blown up" using several corrections, such as the Windmeijer (2005) correction. $^{8}$

\subsection{Data}

Aggregate bilateral portfolio equity allocations are recorded in the International Monetary Funds's Coordinated Portfolio Investment Survey (CPIS). The CPIS dataset records the amount of portfolio equity (in US\$) that country i's residents own in country $\mathrm{j}$. Based on CPIS and national stock market index data availability, 40 source and 44 host countries are analyzed from 2001-2007. ${ }^{9}$ The four excluded source countries are China, India,

\footnotetext{
${ }^{8} \mathrm{~A}$ potential method to deal with the generated regressor problem would be to implement a bootstrap procedure. Unfortunately there are no bootstrap methods available for this specific situation. Several technical issues create difficulties in implementing a bootstrap procedure. First, the quantiles, from which the coexeedance probabilities are calculated, are modeled variables using an optimization algorith. Therefore, a quantile regression bootstrap in the spirit of Hahn (1995) is not possible. Second, Hall and Horowitz (1996) show that inference can be biased in GMM when the bootstrap estimates are based on an empirical distribution which implements a moment condition that does not necessarily hold in the population of bootstrap samples. Moreover, even after the adjustment of the moment conditions, biases in the augmented GMM bootstrap are reduced, but not eliminated.

${ }^{9}$ See Table 3.7 in the Appendix for a complete list of all source and host countries.
} 
Mexico and Peru. China and Peru are excluded because they do not provide any data on their resident's asset allocations during 2001-2007, whereas India and Mexico are excluded because they do not provide data during the first years of the sample.

The dataset captures over $80 \%$ of all bilateral portfolio equity holdings. Although the included source and host countries account for $97 \%$ and $92 \%$, respectively, of all international portfolio equity holdings in 2001 (92\% and $89 \%$ in 2007) there is attrition due to several reasons. Part of the data of the included source countries is missing, because it is either classified as being unallocated or confidential. However, a large fraction of the gap between $80 \%$ and the full $100 \%$ is held by or invested into so called tax havens, such as Bermuda, Guernsey, Jersey and the Isle of Man.

Even though the CPIS database is recognized as the best database available on aggregate cross-border asset holdings, a careful treatment of its data is necessary. Lane and Milesi-Feretti (2007) point at four important issues. First, the country coverage is incomplete (e.g. no source data for China, India, Mexico and Peru). Second, there is underreporting for some countries (e.g. the German data excludes households, which amounts to about $20 \%$ of the total). Third, some data are confidential and not reported (e.g. Australia does not report asset holding in a number of countries). Fourth, there is overreporting due to third party holdings, which is particularly present in the data of Ireland and Luxembourg. Basically, funds are invested from an outside country into Ireland and Luxembourg and these countries channel investments again to other countries. Hence, the portfolio equity allocations in Ireland and Luxembourg do not solely reflect investment in these countries' companies. ${ }^{10}$ Special attention is directed to these issues in the empirical analysis. However, it is important to realize that as long as these issues are relatively stable over time, they should not pose empirical problems, because the benchmark model is estimated in first differences.

Daily stock market indexes are retrieved from Thomson Datastream for all countries in US\$. These Datastream indexes are selected because they capture all listed companies in a country and not e.g. only the 25 most traded ones. Moreover, the methodology to calculate the index is the same across countries. When only local currency denominated returns are available, these are converted into US\$ using daily exchange rates. ${ }^{11}$

\footnotetext{
${ }^{10}$ This is similar to the situation of the so called tax havens mentioned above.

${ }^{11}$ Results are qualitatively the same when local currency denominated returns are used.
} 
Using daily data invokes the non-synchronous trading problem, because stock markets across the globe do not share the same trading hours. In order to overcome this problem this chapter follows Bae et al. (2003) by assuming that the trading day starts in the U.S. Therefore, returns on day $d$ in the Americas is matched with day $d+1$ returns in Asia, Australia, Europe and Africa. ${ }^{12}$ From these series the different comovement measures are calculated as outlined in Section 3.2.1 above.

Several control variables are included to avoid misspecification biases and capture effects not explained by stock market comovements. An important determinant of portfolio allocation is the market capitalization of an asset w.r.t. total world market capitalization. Since bilateral relationships are considered, both the market capitalization of country i and $\mathrm{j}$ matter for the amount of country $\mathrm{j}$ equities residents from country i hold. Hence, $\ln \left(M C a p_{i t} * M C a p_{j t}\right)$ is used in the estimations, where market capitalization is recorded in US $\$$ from Thomson Datastream.

There are many indicators to capture the "strength" of bilateral trade relationships (see e.g. Frankel and Rose, 1998). Here, trade $_{i j t}$ is captured by $\ln \left(\left[\right.\right.$ export $_{i j t} *$ import $\left.\left._{i j t}\right] /\left[g d p_{i t} * g d p_{j t}\right]\right)$. Both bilateral trade and gdp are recorded in US $\$$ and taken from the IMF's Direction of Trade Statistics and the World Bank's World Economic Outlook, respectively. The results are robust to using different measures of trade intensity, such as the one by Frankel and Rose (1998).

The economic development of a country pair is captured using the expression $\ln \left(G D P /\right.$ capita $_{i t} * G D P /$ capita $\left._{j t}\right)$. This product aims to capture first the effect of richer countries being able to hold more foreign equity and second, hold relatively more equity in richer foreign countries, ceteris paribus. The data are from the World Bank World Economic Outlook.

Annual bilateral exchange rate volatility is calculated using realized volatility calculated from daily exchange rate returns. Bilateral exchange rates are calculated using a individual country exchange rates against the US\$. For example, the bilateral exchange rate Argentinian Real vs. Japanese Yen is $(\mathrm{ARS} / \mathrm{US} \$) *(\mathrm{JPY} / \mathrm{US} \$)^{-1}=(\mathrm{ARS} / \mathrm{JPY})$. Higher exchange rate volatility creates uncertainty about future payoffs. It is sensible to expect that equity holdings will be lower when there is high exchange rate volatility.

\footnotetext{
Estimation results can be provided upon request.

${ }^{12}$ For a discussion on this treatment of the non-synchronous trading problem and the underlying assumptions, please consult Beine et al. (2010).
} 
Differences in industrial structures can be an importance incentive for foreign investment. The Krugman (1991) measure is used as an indicator to capture industrial structure differences. This indicator of industrial differences is computed by summing up the absolute value of the difference of an industry's market value between two countries:

$$
\operatorname{indus}_{i j, t}=\sum_{n=1}^{N}\left|s_{n, i, t}-s_{n, j, t}\right|,
$$

where $s_{n, i, t}$ is the market value of industry $n$ in country $i$ or $j$ at time t. There are $\mathrm{N}=40$ industries considered in the specialization index using Datastream sector indexes.

Capital account openness is measured using the KAOPEN indicator of Chinn and Itô (2008). This variable indicates the degree of financial openness for individual countries, hence $K A O P E N_{i, t}$ and $K A O P E N_{j, t}$ are both included. As countries are more open it is easier to freely invest in foreign equity markets. Hence, financial openness has a positive effect on foreign equity accumulation.

Stock market turnover rate and the percentage of offshore deposits in the host country are used to in the robustness section to capture the attractiveness of the host country specifically. These data are taken from the World Bank Financial Structure database, constructed by Beck et al. (2000).

All estimations exploit the panel dimension of the dataset by including unobserved fixed effects. Doing so eliminates the need to include time-invariant variables such as distance, the existence of a colonial link, a common border or a common language.

\subsection{Results}

\subsubsection{Baseline results}

Equation (3.7) is estimated to capture the dynamic portfolio adjustment process. The dependent variable is the annual change in $\ln \left(E_{\text {Equity }} \mathrm{y}_{\mathrm{j}, \mathrm{t}}\right)$ and the dynamics are governed by the first lag of $\Delta \ln \left(E_{\text {quity }}\right.$ ij,t $)$. Recall that $E_{\text {quity }}$ ij,t are country i's residents end of year portfolio equity holdings of country j's equities. These timing issues are important for the interpretation of the independent variables. All available data for all 
countries is used in this estimation, resulting in 1297 country pairs.

The independent variables are included as follows. First, the model assumes that comovement during year $\mathrm{t}$ directs the investor's portfolio change during year t. Comovement is measured in levels as investors observe actual correlations. Using first differences of correlations may lead to strange reallocations, e.g. a change from -0.5 to -0.2 is not the same a change from 0.6 to 0.9 . Therefore, it is not attractive to consider correlations in first differences.

Second, the change in $\ln \left(M C a p_{i, t} * M C a p_{j, t}\right)$ captures changes in market valuations during year t. This variable aims to capture the effect of increases and decreases in $\Delta \ln \left(E_{\text {quity }}\right.$ ij,t $)$ due to valuation gains (or losses). Third, trade relationships stimulate the holding of bilateral equity assets. Fourth, the change in $\ln (G D P /$ capita $)$ captures among others the change in economic development, making fast growing emerging markets an attractive destination for future equity gains. Industrial differences and capital account openness are taken in levels. Note that the one year lag $(t-1)$ is used for industrial dissimilarity and capital account openness.

Table 3.1 shows the results of the first difference estimation using System GMM. The dynamics have a strong and significantly negative impact across all measures of comovement, indicating mean reversion. Most importantly, the coefficient on correlation is economically large and statistically highly significant. For example, when correlations change from 0.5 to 0.6 , investors will reduce their foreign portfolio holdings by about four percent.

Since investors treat gains differently from losses (See e.g. Köbberling and Wakker, 2005) they will most likely worry more about comovement in bad states than in good states. Put differently, investors are more unhappy when their domestic and foreign investment jointly exhibit large losses, compared to the joy they have when both equities boom. This prediction is not confirmed by the results in Table 3.1. Both the left tail and right tail quantiles have a negative sign, indicating diversification away from comoving assets across the entire return distribution. However, the effect seems to be more pronounced in the right tail as Q5 and Q10 are not significantly negative. This implies that investors diversify away from equities that jointly boom, but do not diversify away from equities that jointly crash.

Market capitalization and gdp per capita have the expected positive sign and both coefficients are significant. However, the coefficient on trade 
Table 3.1: Dynamic Adjustment International Equity Investment: System GMM, full sample

\begin{tabular}{|c|c|c|c|c|c|c|c|}
\hline & corr & $\mathrm{q} 05$ & $\mathrm{q} 10$ & $\mathrm{q} 25$ & $\mathrm{q} 75$ & q90 & q95 \\
\hline$\Delta$ lequity $_{t-1}$ & $\begin{array}{c}-0.105^{* * *} \\
(0.026)\end{array}$ & $\begin{array}{c}-0.113^{* * *} \\
(0.028)\end{array}$ & $\begin{array}{c}-0.092^{* * *} \\
(0.027)\end{array}$ & $\begin{array}{c}-0.091^{* * *} \\
(0.026)\end{array}$ & $\begin{array}{c}-0.098^{* * *} \\
(0.027)\end{array}$ & $\begin{array}{c}-0.117^{* * *} \\
(0.027)\end{array}$ & $\begin{array}{c}-0.105^{* * *} \\
(0.026)\end{array}$ \\
\hline correlation $_{t}$ & $\begin{array}{c}-0.389^{* * * *} \\
(0.127)\end{array}$ & & & & & & \\
\hline $\mathrm{q} 05_{t}$ & & $\begin{array}{l}-0.416 \\
(0.292)\end{array}$ & & & & & \\
\hline $\mathrm{q} 10_{t}$ & & & $\begin{array}{l}-0.428 \\
(0.301)\end{array}$ & & & & \\
\hline $\mathrm{q} 25_{t}$ & & & & $\begin{array}{c}-0.533^{* *} \\
(0.245)\end{array}$ & & & \\
\hline $\mathrm{q} 75_{t}$ & & & & & $\begin{array}{c}-0.673^{* * *} \\
(0.214)\end{array}$ & & \\
\hline $\mathrm{q} 90_{t}$ & & & & & & $\begin{array}{c}-0.546^{* * *} \\
(0.179)\end{array}$ & \\
\hline q95t & & & & & & & $\begin{array}{c}-0.525^{* * *} \\
(0.188)\end{array}$ \\
\hline$\Delta \operatorname{lmcap}_{t}$ & $\begin{array}{c}0.431^{* * *} \\
(0.071)\end{array}$ & $\begin{array}{c}0.407^{* * * *} \\
(0.075)\end{array}$ & $\begin{array}{c}0.407^{* * * *} \\
(0.074)\end{array}$ & $\begin{array}{c}0.440^{* * *} \\
(0.071)\end{array}$ & $\begin{array}{c}0.419 * * * \\
(0.074)\end{array}$ & $\begin{array}{c}0.429 * * * \\
(0.074)\end{array}$ & $\begin{array}{c}0.406^{* * * *} \\
(0.071)\end{array}$ \\
\hline $\operatorname{trade}_{t}$ & $\begin{array}{c}0.006 \\
(0.004)\end{array}$ & $\begin{array}{c}0.005 \\
(0.006)\end{array}$ & $\begin{array}{c}0.006 \\
(0.005)\end{array}$ & $\begin{array}{c}0.004 \\
(0.004)\end{array}$ & $\begin{array}{c}0.006 \\
(0.004)\end{array}$ & $\begin{array}{c}0.006 \\
(0.004)\end{array}$ & $\begin{array}{c}0.005 \\
(0.004)\end{array}$ \\
\hline$\Delta \operatorname{lgdp} \_c a p_{t}$ & $\begin{array}{c}0.566^{* * *} \\
(0.183)\end{array}$ & $\begin{array}{l}0.434^{* *} \\
(0.187)\end{array}$ & $\begin{array}{c}0.426^{* *} \\
(0.190)\end{array}$ & $\begin{array}{c}0.607^{* * * *} \\
(0.177)\end{array}$ & $\begin{array}{c}0.609^{* * * *} \\
(0.180)\end{array}$ & $\begin{array}{c}0.647^{* * * *} \\
(0.183)\end{array}$ & $\begin{array}{c}0.609^{* * *} \\
(0.183)\end{array}$ \\
\hline $\operatorname{indus}_{t-1}$ & $\begin{array}{c}0.028 \\
(0.049)\end{array}$ & $\begin{array}{c}0.067 \\
(0.053)\end{array}$ & $\begin{array}{c}0.066 \\
(0.051)\end{array}$ & $\begin{array}{c}0.057 \\
(0.048)\end{array}$ & $\begin{array}{c}0.022 \\
(0.048)\end{array}$ & $\begin{array}{c}0.024 \\
(0.048)\end{array}$ & $\begin{array}{c}0.017 \\
(0.049)\end{array}$ \\
\hline $\mathrm{xvol}_{t}$ & $\begin{array}{l}-0.004^{*} \\
(0.002)\end{array}$ & $\begin{array}{l}-0.003 \\
(0.002)\end{array}$ & $\begin{array}{l}-0.003 \\
(0.002)\end{array}$ & $\begin{array}{l}-0.002 \\
(0.002)\end{array}$ & $\begin{array}{l}-0.004^{*} \\
(0.002)\end{array}$ & $\begin{array}{l}-0.004^{*} \\
(0.002)\end{array}$ & $\begin{array}{l}-0.004^{*} \\
(0.002)\end{array}$ \\
\hline kaopen_ot-1 & $\begin{array}{c}0.009 \\
(0.016)\end{array}$ & $\begin{array}{c}0.009 \\
(0.017)\end{array}$ & $\begin{array}{c}0.010 \\
(0.016)\end{array}$ & $\begin{array}{c}0.011 \\
(0.016)\end{array}$ & $\begin{array}{c}0.010 \\
(0.016)\end{array}$ & $\begin{array}{c}0.012 \\
(0.016)\end{array}$ & $\begin{array}{c}0.012 \\
(0.016)\end{array}$ \\
\hline kaopen_d $d_{t-1}$ & $\begin{array}{l}-0.008 \\
(0.011)\end{array}$ & $\begin{array}{l}-0.014 \\
(0.012)\end{array}$ & $\begin{array}{l}-0.015 \\
(0.013)\end{array}$ & $\begin{array}{l}-0.005 \\
(0.012)\end{array}$ & $\begin{array}{l}-0.011 \\
(0.011)\end{array}$ & $\begin{array}{l}-0.003 \\
(0.011)\end{array}$ & $\begin{array}{l}-0.011 \\
(0.011)\end{array}$ \\
\hline Observations & 5678 & 5678 & 5678 & 5678 & 5678 & 5678 & 5678 \\
\hline Number of id & 1297 & 1297 & 1297 & 1297 & 1297 & 1297 & 1297 \\
\hline $\operatorname{AR}(2)$ & 0.710 & 0.804 & 0.561 & 0.544 & 0.552 & 0.772 & 0.632 \\
\hline Hansen & 0.027 & 0.000 & 0.002 & 0.043 & 0.006 & 0.001 & 0.068 \\
\hline
\end{tabular}

Note: Estimation of Equation (3.7) using Two Stage System GMM, where either correlation or a coexceedance probability (Q5, Q10, Q25, Q75, Q90, Q95) is used as a measure of comovement. $*, * *, * *$ imply significance at the $10 \%, 5 \%$ and $1 \%$, respectively.

is positive, but not significant. This result is striking because previous studies always find a strong impact of trade on bilateral asset holdings (See e.g. Aviat and Coeurdacier (2007)). One explanation for the current result is the relative stability of trade relationships across time. Consequently, by analyzing first-differences trade relationships are less important for changes. The results do not change when the year-to-year change in trade is included as control variable.

The coefficients on industrial differences and capital account openness are insignificant. One reason for this is the slow process of changes in 
industrial structure and capital account policies. Due to the relatively short time frame and the use of first differences these variables become less important. Exchange rate volatility is significantly negative at the $10 \%$ level for correlation, Q90 and Q95. Exchange rate volatility increases uncertainty about foreign returns when converting these in local currencies. Hence, the negative sign indicates that the higher volatility is, the less investors will invest in those assets. Fidora et al. (2007) show the importance of (real) exchange rate volatility in the portfolio asset allocation decision. This factor appears to be of minor importance when considering first differences.

Quantitatively, the change in the product of market capitalizations is a major determinant of asset allocation changes. Basically, a $10 \%$ increase in the market capitalization products results in a $4 \%$ increase in country $i$ 's assets in country $j$. Combined with the negative coefficient on $\ln \left(E_{\text {quity }} \mathrm{ij}_{\mathrm{t}-1}\right)$ the process is not explosive. Therefore, the process can safely be modeled in first differences without concerns over long term stability.

Note however that the Hansen test rejects the choice of the instrument set for all estimations at the $10 \%$ level and for most even at the $1 \%$ level. One possible reason for this is heterogeneity in the panel. Since all source and destination countries are pooled in one sample, without considering the appropriateness of this assumption, there may be biases due to outliers.

In order to overcome possible heterogeneity problems, two approaches are implemented to find a poolable (valid) sample for the estimations. First, a statistical approach and second, an economic approach are employed to find a homogeneous group of countries. ${ }^{13}$ Due to the bilateral nature of the panel there are several restrictions possible: restrict source countries, restrict host countries, restrict bilateral pairs. This chapter focuses on the asset allocation of source countries and a poolable sample is searched by restricting the number of source countries. Put differently, when e.g. Argentina is excluded as a source country all bilateral pairs with Argentina as source country are eliminated. The statistical and economic approach will be discussed in turn.

\footnotetext{
${ }^{13} \mathrm{~A}$ related approach is to restrict the number of lags used as instruments from $\ln \left(\right.$ Equity $\left._{i, t}\right)$ and Comove $_{i j, t}$. Such a strategy has two disadvantages. First, the relatively small instrument set is reduced further, which decreases precision. Second, it is not possible to find one instrument set reduction that validates the Hansen test for all measures of comovement. Using different instrument sets for each quantile creates an undesirable arbitrariness.
} 


\subsubsection{Statistical poolability}

The objective of statistical poolability is to start with the largest sample possible and allow the data to decide which countries need to be excluded. Kapetanios (2006) proposes an information criteria based approach to find a poolable sample. The general idea of his method is to split the data in several samples and choose that split of the data which maximizes the information criteria. Unfortunately, this set-up is in a maximum likelihood context and it is not clear how to generalize this to System GMM estimators. Another important assumption is $\mathrm{T}>\mathrm{N}$, which is not the case in the current panel where $T=7$ and $N>1000$. Similar problems arise when using the approach of Paap et al. (2005).

Hence, an alternative method is needed. The main criterion to judge if a two-step System GMM estimation is valid is the Hansen test. Therefore, it is possible to exploit this test statistic to construct an algorithm maximizing the Hansen p-value. Consider a very simple algorithm. First, estimate the full model and exclude one source country. Then proceed to the next step, where the country is excluded whose exclusion increases the Hansen p-value most. Continue excluding countries in this manner until the Hansen p-value is above $10 \%$. The results of this approach are presented in Table 3.2.

For each column the algorithm is conducted individually. This results in the following source countries being excluded: Malaysia and New Zealand for correlation; Chile, Hungary, Korea, New Zealand and South Africa for Q5; Chile, New Zealand and South Africa for Q10; Korea for Q25; Korea, New Zealand and South Africa for Q75; Austria, Belgium, Brazil, Indonesia, New Zealand, Norway and Singapore for Q90 and only New Zealand for Q95. Perhaps surprising is the exclusion of New Zealand in all estimations. Apparently the foreign asset allocation of New Zealand is quite different from the other countries. A closer inspection of New Zealand's data shows that quite a large number of destination countries are labeled as confidential, i.e. no data available. Therefore a large number of these have been excluded, providing a very poor representation of the actual foreign equity allocations.

In general, very few countries need to be excluded to obtain a poolable sample passing the Hansen test. The results of Table 3.2 are in line with those of Table 3.1. Perhaps the contrast between the upper and lower tail is even sharpened in these results. In the lower tail, only Q25 is significantly negative at the $10 \%$ level. However, the upper tail quantiles 
Table 3.2: Dynamic Adjustment International Equity Investment: Restricted Sample, statistical reduction

\begin{tabular}{|c|c|c|c|c|c|c|c|}
\hline & corr & q05 & q10 & $\mathrm{q} 25$ & $\mathrm{q} 75$ & q90 & $\mathrm{q} 95$ \\
\hline$\overline{\Delta \text { lequity }_{t-1}}$ & $\begin{array}{c}-0.102^{* * *} \\
(0.026)\end{array}$ & $\begin{array}{c}-0.115^{* * *} \\
(0.028)\end{array}$ & $\begin{array}{c}-0.100^{* * *} \\
(0.028)\end{array}$ & $\begin{array}{c}-0.093^{* * *} \\
(0.026)\end{array}$ & $\begin{array}{c}-0.103^{* * *} \\
(0.026)\end{array}$ & $\begin{array}{c}-0.104^{* * *} \\
(0.028)\end{array}$ & $\begin{array}{c}-0.101^{* * *} \\
(0.026)\end{array}$ \\
\hline correlation $_{t}$ & $\begin{array}{c}-0.415^{* * *} \\
(0.126)\end{array}$ & & & & & & \\
\hline $\mathrm{q} 05_{t}$ & & $\begin{array}{l}-0.303 \\
(0.285)\end{array}$ & & & & & \\
\hline $\mathrm{q} 10_{t}$ & & & $\begin{array}{l}-0.135 \\
(0.315)\end{array}$ & & & & \\
\hline $\mathrm{q} 25_{t}$ & & & & $\begin{array}{c}-0.427^{*} \\
(0.237)\end{array}$ & & & \\
\hline $\mathrm{q} 75_{t}$ & & & & & $\begin{array}{c}-0.510^{* *} \\
(0.201)\end{array}$ & & \\
\hline $\mathrm{q} 90_{t}$ & & & & & & $\begin{array}{c}-0.465^{* *} \\
(0.189)\end{array}$ & \\
\hline q95 & & & & & & & $\begin{array}{c}-0.535^{* * *} \\
(0.185)\end{array}$ \\
\hline$\Delta \operatorname{lmcap}_{t}$ & $\begin{array}{c}0.424^{* * *} \\
(0.072)\end{array}$ & $\begin{array}{c}0.411^{* * *} \\
(0.069)\end{array}$ & $\begin{array}{c}0.392^{* * *} \\
(0.073)\end{array}$ & $\begin{array}{c}0.431^{* * *} \\
(0.070)\end{array}$ & $\begin{array}{c}0.371^{* * *} \\
(0.074)\end{array}$ & $\begin{array}{c}0.501^{* * *} \\
(0.081)\end{array}$ & $\begin{array}{c}0.406^{* * *} \\
(0.072)\end{array}$ \\
\hline $\operatorname{trade}_{t}$ & $\begin{array}{c}0.008^{* *} \\
(0.004)\end{array}$ & $\begin{array}{c}0.006 \\
(0.005)\end{array}$ & $\begin{array}{c}0.004 \\
(0.005)\end{array}$ & $\begin{array}{c}0.003 \\
(0.004)\end{array}$ & $\begin{array}{c}0.004 \\
(0.004)\end{array}$ & $\begin{array}{c}0.004 \\
(0.004)\end{array}$ & $\begin{array}{l}0.006^{*} \\
(0.004)\end{array}$ \\
\hline$\Delta \operatorname{lgdp} \_\operatorname{cap}_{t}$ & $\begin{array}{c}0.550^{* * *} * \\
(0.183)\end{array}$ & $\begin{array}{l}0.312^{*} \\
(0.183)\end{array}$ & $\begin{array}{c}0.423^{* *} \\
(0.190)\end{array}$ & $\begin{array}{c}0.513^{* * *} \\
(0.173)\end{array}$ & $\begin{array}{c}0.606^{* * * *} \\
(0.172)\end{array}$ & $\begin{array}{c}0.696^{* * *} \\
(0.198)\end{array}$ & $\begin{array}{c}0.586^{* * *} \\
(0.183)\end{array}$ \\
\hline $\operatorname{indus}_{t-1}$ & $\begin{array}{c}0.046 \\
(0.047)\end{array}$ & $\begin{array}{c}0.077 \\
(0.050)\end{array}$ & $\begin{array}{l}0.093^{*} \\
(0.050)\end{array}$ & $\begin{array}{c}0.066 \\
(0.047)\end{array}$ & $\begin{array}{c}0.032 \\
(0.046)\end{array}$ & $\begin{array}{c}0.005 \\
(0.053)\end{array}$ & $\begin{array}{c}0.018 \\
(0.048)\end{array}$ \\
\hline $\mathrm{xvol}_{t}$ & $\begin{array}{l}-0.004^{*} \\
(0.002)\end{array}$ & $\begin{array}{c}0.000 \\
(0.002)\end{array}$ & $\begin{array}{c}0.000 \\
(0.002)\end{array}$ & $\begin{array}{l}-0.002 \\
(0.002)\end{array}$ & $\begin{array}{l}-0.009 \\
(0.002)\end{array}$ & $\begin{array}{c}-0.005^{* *} \\
(0.002)\end{array}$ & $\begin{array}{l}-0.004^{*} \\
(0.002)\end{array}$ \\
\hline kaopen_o $t-1$ & $\begin{array}{c}0.016 \\
(0.018)\end{array}$ & $\begin{array}{c}0.011 \\
(0.021)\end{array}$ & $\begin{array}{l}-0.037^{*} \\
(0.020)\end{array}$ & $\begin{array}{c}0.043^{* * *} \\
(0.014)\end{array}$ & $\begin{array}{c}0.022 \\
(0.019)\end{array}$ & $\begin{array}{c}0.006 \\
(0.016)\end{array}$ & $\begin{array}{c}0.012 \\
(0.016)\end{array}$ \\
\hline kaopen_d $d_{t-1}$ & $\begin{array}{l}-0.012 \\
(0.011)\end{array}$ & $\begin{array}{l}-0.014 \\
(0.011)\end{array}$ & $\begin{array}{l}-0.023^{*} \\
(0.013)\end{array}$ & $\begin{array}{l}-0.006 \\
(0.011)\end{array}$ & $\begin{array}{l}-0.016 \\
(0.011)\end{array}$ & $\begin{array}{c}0.003 \\
(0.012)\end{array}$ & $\begin{array}{l}-0.011 \\
(0.011)\end{array}$ \\
\hline Observations & 5491 & 4872 & 5356 & 5545 & 5367 & 4685 & 5633 \\
\hline Number of id & 1249 & 1106 & 1215 & 1264 & 1218 & 1074 & 1282 \\
\hline $\operatorname{AR}(2)$ & 0.816 & 0.300 & 0.964 & 0.514 & 0.637 & 0.664 & 0.589 \\
\hline Hansen & 0.139 & 0.129 & 0.121 & 0.172 & 0.148 & 0.123 & 0.172 \\
\hline
\end{tabular}

Note: Estimation of Equation (3.7) using Two Stage System GMM, where either correlation or a coexceedance probability (Q5, Q10, Q25, Q75, Q90, Q95) is used as a measure of comovement. $*, * *, * * *$ imply significance at the $10 \%, 5 \%$ and $1 \%$, respectively.

are all significant at at least 5\%. The coefficient on correlation is again highly significantly negative. Note also that trade now has a significant positive impact on asset reallocations for correlation and the $95 \%$ quantile.

\subsubsection{Economic poolability}

An alternative method to construct a statistically poolable sample is to make the decision on economic grounds. One important issue of the CPIS dataset is its accuracy. When comparing the CPIS dataset with micro data from mutual funds Hau and Rey (2009) find that the quality of the CPIS 
data is especially high for the asset allocations of developed countries.

Lane and Milesi-Ferretti (2008) show that there are important differences when investigating cross-border asset allocations for a full sample and a restricted sample with only OECD countries as source countries. For example, with all countries pooled the coefficient on stock market comovement is significantly positive, but when considering only OECD countries the coefficient on this variable is insignificant in their estimations. However, note that they do not account for endogeneity and dynamics.

Most developed countries liberalized their financial markets during the 1970s and 1980s, whereas developing countries only started doing so in the late 1980s and 1990s (Bekaert et al., 2005). This implies that residents in OECD countries had much earlier access to foreign equity markets than residents in developing countries. Hence, they have had more time to come closer to their "optimal" internationally diversified equity portfolios.

As only developed countries are member of the OECD this is likely to be a relatively homogeneous group with similar access to international equity markets. When estimating the model taking only OECD countries as source countries the results are again very much in line with previous results obtained in Tables 3.1 and 3.2, both quantitatively and qualitatively. However, there are some minor differences for the lower tail quantiles, where Q5 is large and significantly negative and Q25 is not significant anymore. Unfortunately, the Hansen test rejects the instrument set for Q5, Q75 and Q90. These results are not reported but available on request.

In order to obtain a poolable sample for Q5 New Zealand, Norway and Turkey are excluded, for Q75 New Zealand and Turkey and for Q90 only New Zealand. Table 3.3 shows the results when these source countries are excluded from the OECD only for those quantiles involved. Note that the the results are close to the ones of Tables 3.1 and 3.2. Moreover, New Zealand appears to be an odd country in the sample w.r.t. international equity allocations. Most likely due to the reasons mentioned above.

When excluding the three countries involved in Q5 from all estimated columns identical results are obtained. When comparing with previous results, the coefficient on Q25 becomes insignificant, whereas Q5 becomes marginally significant. However, the strong asymmetry between lower and upper tail returns pertains. Moreover, the size of the coefficients is very close to those in the statistical sample.

Again the magnitude of $\Delta \operatorname{lmcap}_{t}$ is very large. A $10 \%$ growth in the bilateral product of market capitalizations results in an increase of about 
Table 3.3: Dynamic Adjustment International Equity Investment: OECD Sample

\begin{tabular}{|c|c|c|c|c|c|c|c|}
\hline & corr & $\mathrm{q} 05$ & q10 & q25 & $\mathrm{q} 75$ & q90 & $\mathrm{q} 95$ \\
\hline$\overline{\Delta \text { lequity }_{t-1}}$ & $-0.125^{* * *}$ & $-0.113^{* * *}$ & $-0.091^{* * *}$ & $-0.115^{* * *}$ & $-0.110^{* * *}$ & $-0.113^{* * *}$ & $-0.114^{* * *}$ \\
\hline & $(0.031)$ & $(0.035)$ & $(0.032)$ & $(0.032)$ & $(0.035)$ & $(0.032)$ & $(0.033)$ \\
\hline correlation $_{t}$ & $\begin{array}{c}-0.378^{* * *} \\
(0.141)\end{array}$ & & & & & & \\
\hline $\mathrm{q} 05_{t}$ & & $\begin{array}{c}-0.424^{*} \\
(0.247)\end{array}$ & & & & & \\
\hline $\mathrm{q} 10_{t}$ & & & $\begin{array}{l}-0.018 \\
(0.316)\end{array}$ & & & & \\
\hline $\mathrm{q} 25_{t}$ & & & & $\begin{array}{l}-0.239 \\
(0.235)\end{array}$ & & & \\
\hline $\mathrm{q} 75_{t}$ & & & & & $\begin{array}{c}-0.696^{* * *} \\
(0.186)\end{array}$ & & \\
\hline $\mathrm{q} 90_{t}$ & & & & & & $\begin{array}{c}-0.465^{* * *} \\
(0.163)\end{array}$ & \\
\hline q95 & & & & & & & $\begin{array}{c}-0.431^{* *} \\
(0.170)\end{array}$ \\
\hline$\Delta \operatorname{lmcap}_{t}$ & $\begin{array}{c}0.464^{* * *} \\
(0.074)\end{array}$ & $\begin{array}{c}0.498^{* * *} \\
(0.074)\end{array}$ & $\begin{array}{c}0.451^{* * *} \\
(0.075)\end{array}$ & $\begin{array}{c}0.484^{* * *} \\
(0.073)\end{array}$ & $\begin{array}{c}0.568^{* * *} \\
(0.078)\end{array}$ & $\begin{array}{c}0.467^{* * *} \\
(0.078)\end{array}$ & $\begin{array}{c}0.440^{* * *} \\
(0.074)\end{array}$ \\
\hline $\operatorname{trade}_{t}$ & $\begin{array}{c}0.006 \\
(0.005)\end{array}$ & $\begin{array}{l}0.011^{*} \\
(0.006)\end{array}$ & $\begin{array}{l}-0.003 \\
(0.007)\end{array}$ & $\begin{array}{l}-0.000 \\
(0.005)\end{array}$ & $\begin{array}{c}0.009^{* *} \\
(0.004)\end{array}$ & $\begin{array}{c}0.006 \\
(0.004)\end{array}$ & $\begin{array}{c}0.003 \\
(0.004)\end{array}$ \\
\hline$\Delta \operatorname{lgdp} \_\operatorname{cap}_{t}$ & $\begin{array}{c}0.662^{* * *} \\
(0.197)\end{array}$ & $\begin{array}{c}0.516^{* *} \\
(0.204)\end{array}$ & $\begin{array}{c}0.472^{* *} \\
(0.202)\end{array}$ & $\begin{array}{c}0.604^{* * *} \\
(0.178)\end{array}$ & $\begin{array}{c}0.610^{* * *} \\
(0.189)\end{array}$ & $\begin{array}{c}0.633^{* * *} \\
(0.195)\end{array}$ & $\begin{array}{c}0.730 * * * \\
(0.202)\end{array}$ \\
\hline $\operatorname{indus}_{t-1}$ & $\begin{array}{c}0.037 \\
(0.049)\end{array}$ & $\begin{array}{c}0.125^{* *} \\
(0.049)\end{array}$ & $\begin{array}{c}0.111^{* *} \\
(0.051)\end{array}$ & $\begin{array}{l}0.080^{*} \\
(0.045)\end{array}$ & $\begin{array}{c}0.050 \\
(0.044)\end{array}$ & $\begin{array}{c}0.064 \\
(0.047)\end{array}$ & $\begin{array}{c}0.052 \\
(0.050)\end{array}$ \\
\hline $\mathrm{xvol}_{t}$ & $\begin{array}{c}-0.003^{*} \\
(0.002)\end{array}$ & $\begin{array}{l}-0.002 \\
(0.002)\end{array}$ & $\begin{array}{l}-0.002 \\
(0.002)\end{array}$ & $\begin{array}{l}-0.003 \\
(0.002)\end{array}$ & $\begin{array}{c}-0.003^{*} \\
(0.002)\end{array}$ & $\begin{array}{c}-0.004^{* *} \\
(0.002)\end{array}$ & $\begin{array}{l}-0.003^{*} \\
(0.002)\end{array}$ \\
\hline kaopen_o $t-1$ & $\begin{array}{c}-0.110^{* * *} \\
(0.034)\end{array}$ & $\begin{array}{c}-0.251^{* * *} \\
(0.028)\end{array}$ & $\begin{array}{c}-0.104^{* * *} \\
(0.032)\end{array}$ & $\begin{array}{c}-0.095^{* * *} \\
(0.032)\end{array}$ & $\begin{array}{c}-0.242^{* * *} \\
(0.027)\end{array}$ & $\begin{array}{c}-0.111^{* * *} \\
(0.035)\end{array}$ & $\begin{array}{c}-0.102^{* * *} \\
(0.033)\end{array}$ \\
\hline kaopen_d $\mathrm{d}_{t-1}$ & $\begin{array}{l}-0.014 \\
(0.012)\end{array}$ & $\begin{array}{l}-0.018 \\
(0.011)\end{array}$ & $\begin{array}{c}-0.033^{* *} \\
(0.013)\end{array}$ & $\begin{array}{l}-0.019 \\
(0.012)\end{array}$ & $\begin{array}{l}-0.013 \\
(0.010)\end{array}$ & $\begin{array}{l}-0.019^{*} \\
(0.011)\end{array}$ & $\begin{array}{c}-0.022^{* *} \\
(0.011)\end{array}$ \\
\hline Observations & 4505 & 4203 & 4505 & 4505 & 4398 & 4460 & 4505 \\
\hline Number of id & 995 & 924 & 995 & 995 & 964 & 980 & 995 \\
\hline $\operatorname{AR}(2)$ & 0.537 & 0.791 & 0.877 & 0.662 & 0.859 & 0.688 & 0.700 \\
\hline Hansen & 0.414 & 0.123 & 0.153 & 0.384 & 0.101 & 0.186 & 0.557 \\
\hline
\end{tabular}

Note: Estimation of Equation (3.7) using Two Stage System GMM, where either correlation or a coexceedance probability (Q5, Q10, Q25, Q75, Q90, Q95) is used as a measure of comovement. $*, * *, * * *$ imply significance at the $10 \%, 5 \%$ and $1 \%$, respectively.

$5 \%$ in foreign equity holdings. This control variable is therefore the main determinant of changes in foreign asset holdings.

There is a negative coefficient on the capital account openness level of the origin county. This implies that the growth rate in foreign equity positions lower is for more financially open countries. One possible explanation may be that these countries are already closer to equilibrium than closed countries, which have accumulated fewer foreign assets in the past.

In addition, several other alternative grouping of developed countries 
can be estimated as well. For example, Hong Kong and Singapore are not member of the OECD, but both countries have highly developed financial markets and a high standard of living. Including those countries leads again to similar results. These tables are omitted for brevity but can be provided on request.

\subsection{Robustness}

\subsubsection{Additional control variables}

Several robustness checks are conducted to verify the validity of the results obtained above. Both estimations of Table 3.2 and 3.3 are used when investigating the impact of additional control variables. In this section only correlation is considered as the measure of comovement.

Table 3.4 present the results with additional control variables added to the benchmark specification. Columns (1)-(3) consider the "statistically poolable sample" and columns (4)-(6) consider the "economically poolable sample".

First start with columns (1)-(3). In column (1) the bilateral exchange rate appreciation between the currency of country $i$ and $j$ during year $\mathrm{t}$ is added. Since all equity positions are measured in US\$ it is likely that equity positions are influenced by currency appreciations or depreciations. For example, when Canadian residents invest in United Kingdom equities, these equities lose value (measured in US\$) when the UK Pound depreciates against the US\$, thereby altering Canadian portfolio equity investments in the UK. However, what crucially matters is the Canadian dollar vs. UK pound exchange rate development.

Columns (1) and (5) shows that these concerns are unwarranted. They appear to be fully taken into account by the $\ln \left(M C a p_{i t} * M C a p_{j t}\right)$ variable. Therefore, measuring all variables in US $\$$ does not lead to biased results, i.e. the coefficient on correlation is virtually unchanged.

The level of institutional quality of the destination country is another factor investors are concerned about, because an unreliable government increases the riskiness of the investment. For example, Alfaro et al. (2008) show that institutional quality is an important factor to attract foreign capital. Institutional quality is measured as the sum of three separate indicators in the World Bank Governance indicators: Government effectiveness, Rule of law and Control of corruption. Both the institutional 


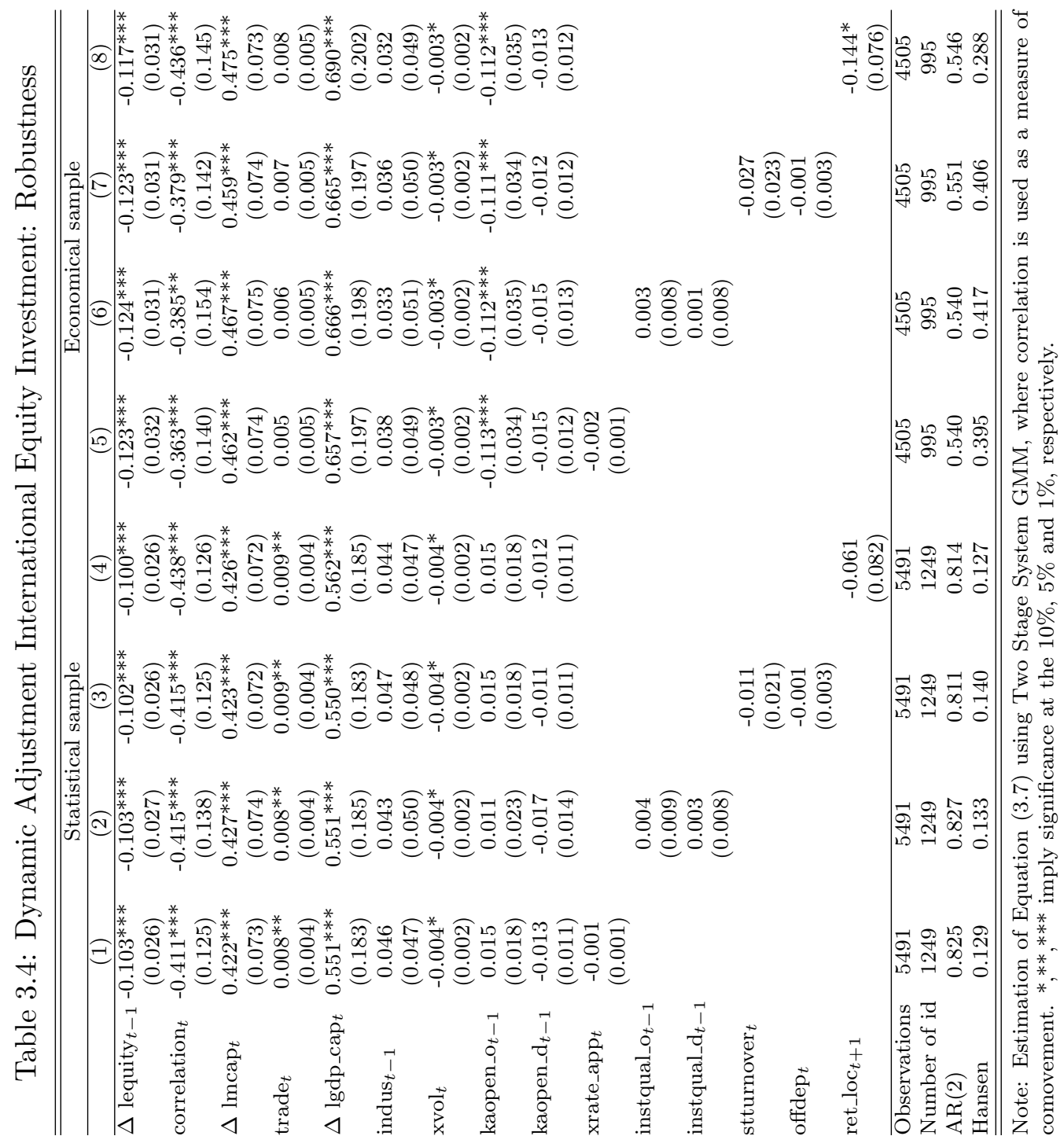


quality of country $i$ and $j$ are included.

Dahlquist et al. (2003) report a strong relationship between corporate governance in countries and the equity positions of international investors. Basically, investors hold fewer shares in countries with bad corporate governance. As the timeframe considered in this chapter (2001-2007) is quite short, no large changes are expected. Since first differences are considered, corporate governance is likely to be of minor importance here.

The results in column (2) show that this factor is not very important. Even though, a higher institutional quality of the source country increase asset holdings. One reason for the insignificance of institutional quality is a strong collinearity with capital account policy. Several authors show that these variables are closely related (See e.g. Edison et al., 2004). Including institutional quality as an additional control variable does not add additional information.

Investments in liquid equity markets are more attractive compared to investments in equities with a low turnover rate. A more liquid stock market makes it easier to buy and sell assets when the investor decides to alter his investment positions. Longstaff (2009) argues that liquidity is an important factor guiding investor diversification. Put differently, investors prefer to concentrate their investments in a single asset when the alternative asset is very illiquid. The stock market turnover rate captures the liquidity of the market, where a higher turnover rate indicates higher liquidity. Column (3) shows that increased liquidity in isolation is of minor importance. However, relatively liquid markets show strong persistence in liquidity, so this effect may be relatively constant across time. Hence, it is not very important in the first-difference equation.

The percentage of offshore deposits is a marginally significant factor guiding portfolio holdings. This percentage aims to capture the degree with which the country channels funds abroad. These results are in line with Lane and Milesi-Ferretti (2008), who argue that some countries are not the final destination of invested equity, but these countries only channel funds to other countries. As column (3) shows, including both of these control variables does not change the coefficient on correlation.

The final robustness check is the inclusion of expected returns in the model. In column (4) the actual return of equity market $j$ during year $t+1$ is included, measured in local currency returns. ${ }^{14}$ So, this variable

\footnotetext{
${ }^{14}$ Including the actual return during year $t+1$ in US\$ leads to same the results.
} 
aims to capture a possible increase in equity holdings during year $t$, when investors expect high future returns. Including expected returns is difficult, because an observed measure of expectations is not available. Therefore, I assume investors have perfect foresight by including realized future returns. Interestingly, there is no effect of expected future returns on equity allocations.

When considering the addition of the extra control variables to the OECD sample, most results are identical. However, the expected future return has a negative effect on portfolio allocations. This seems odd, OECD countries appear to diversify away from markets that outperform in the future. Most important is the robustness of the coefficient on correlation, which is always around 0.4 across all six columns.

\subsubsection{Asset allocations in levels}

In order to compare the results in this chapter with studies investigating asset allocations in levels (e.g. Coeurdacier and Guibaud, 2009; Bekaert and Wang, 2009) Equation (3.6) is estimated for the full dataset. Again one lag of the dependent variable is included to deal with the persistence of equity allocations. Due to the high persistence of $\ln \left(E_{\text {quity }}\right.$ ij,t $)$ some instruments are invalid. When the dependent variable is close to a random walk, past levels do not provide much information on future changes, rending these instruments invalid (Blundell and Bond, 1998). Hence, lags of $\ln \left(E_{q u i t y} y_{i j, t}\right)$ and correlation/coexceedance are only used in the level equation.

Table 3.5 shows the results of the level equation. The persistence of the level is emphasized by a large $\operatorname{AR}(1)$ coefficient of around 0.8 . Surprisingly, with the exception of Q5 no single indicator of comovement is significantly negative. In contrast, Coeurdacier and Guibaud (2009) find a significant negative relationship and Bekaert and Wang (2009) find a significant positive relationship. Basically, the results in Table 3.5 are inbetween these results. However, it is important to keep in mind that previous studies do not take dynamics into account, whereas these are highly significant even in first-differences.

All control variables appear to be important in the level equation and have the expected sign. First, the product of market capitalizations has a strong positive effect as do trade and gdp per capita. Trade is much more important in this case, which is in line with previous research (Aviat and Coeurdacier, 2007). Industrial dissimilarity has a positive effect on asset 


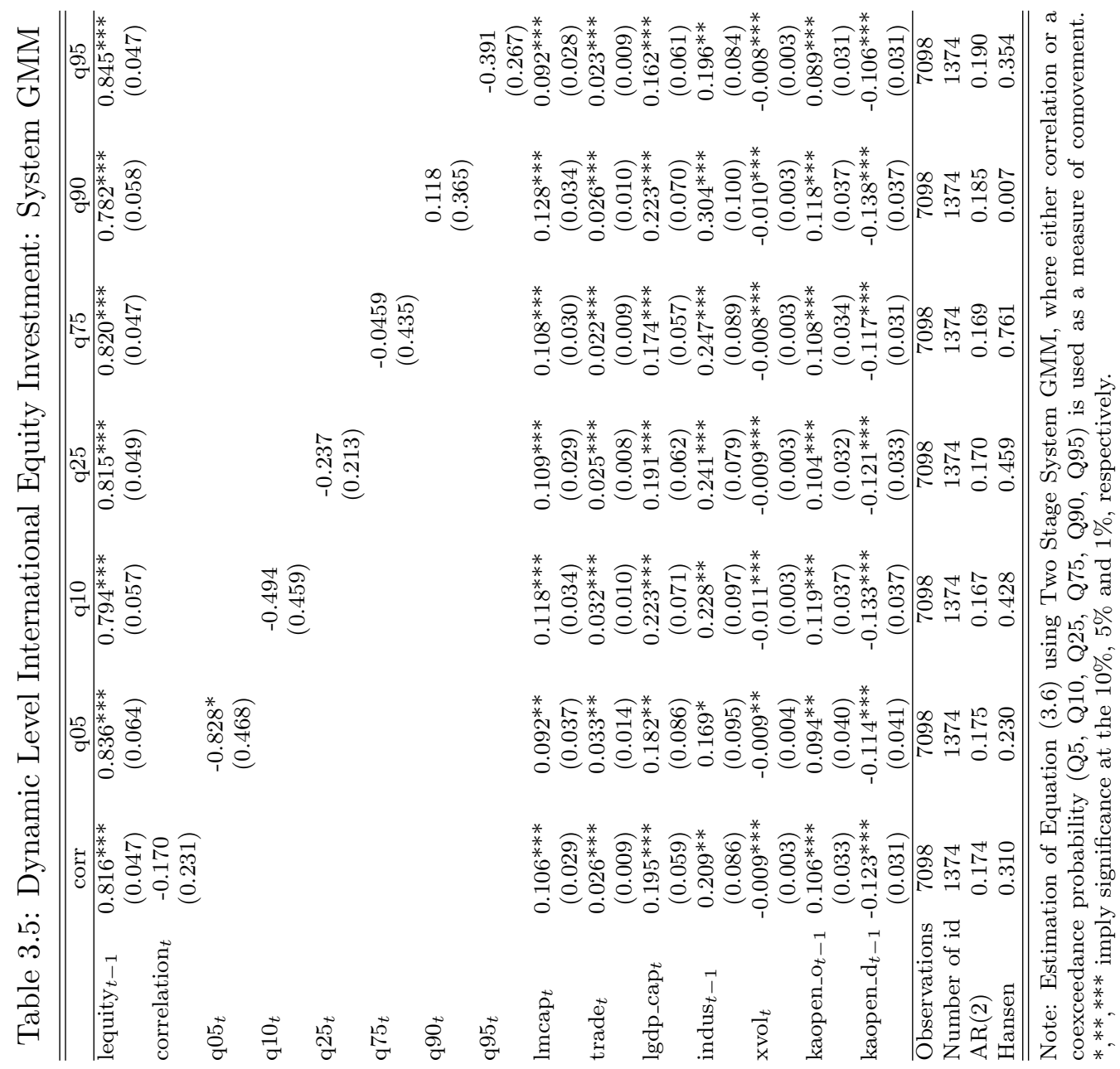


holdings and confirms that industry differences are an important motivation for asset diversification (See e.g. Campa and Fernandes, 2006). Exchange rate volatility has a negative effect on asset holdings, confirming the finding of Fidora et al. (2007). Capital account openness of the source country has a positive effect on foreign equity holdings. Put differently, countries which are financially more open hold larger shares of foreign assets. Perhaps unintuitive is the negative effect of capital account openness of the host country, where one would expect that more open countries attract more foreign equity investors.

When comparing the results of Table 3.5 with the results obtained before we can conclude that investors adapt their international equity portfolios in response to observed comovements in the "correct" direction. However, their current equity portfolios appears to be unrelated to comovements. Hence, this justifies viewing the equity allocation problem as a short run dynamic adjustment process and judge investors on their year-to-year portfolio changes.

\subsubsection{Does the degree of home biasedness matter?}

When the investor overinvests in his domestic market the ICAPM predicts that hedging demands create excess demand for low comoving equities. This prediction implies that hedging demands are likely to be larger the more biased the investor is towards domestic equities. Therefore, in this section the effect of home biasedness on portfolio adjustment is investigated akin to Coeurdacier and Guibaud (2009).

Define home bias using the standard measure of Warnock (2002):

$$
H B_{i t}=1-\frac{\frac{F A_{i t}}{M C A P_{i t}+F A_{i t}-F L_{i t}}}{1-\frac{M C A P_{i t}}{M C A P_{w t}}},
$$

where $F A_{i t}$ and $F L_{i t}$ are country i's total foreign assets and liabilities, respectively, $M C A P_{i t}$ is country i's stock market capitalization and $M C A P_{w t}$ is total world stock market capitalization. The sum of $M C A P_{i t}$ and $F A_{i t}$ minus $F L_{i t}$ is country i's aggregate equity wealth.

The one year lagged value of home bias is included in the regressions to avoid the simultaneity bias. This variable is treated as a predetermined variable in the instrument set. Table 3.6 presents the results of the estimations with home bias included. The left panel includes all countries, 
whereas the right panel consists only of OECD source countries (with New Zealand, Norway and Turkey excluded).

Table 3.6: Dynamic Adjustment International Equity Investment: System GMM and Home Bias

\begin{tabular}{|c|c|c|c|c|c|c|}
\hline & \multicolumn{3}{|c|}{ Statistical sample } & \multicolumn{3}{|c|}{ Economical sample } \\
\hline & $(1)$ & $(2)$ & (3) & $(4)$ & $(5)$ & (6) \\
\hline \multicolumn{2}{|c|}{$\Delta$ lequity $_{t-1}-0.102^{* * *}$} & $-0.105^{* * *}$ & $-0.094^{* * *}$ & $-0.117^{* * *}$ & $-0.124^{* * *}$ & $-0.111^{* * *}$ \\
\hline & $(0.028)$ & $(0.026)$ & $(0.028)$ & $(0.033)$ & $(0.032)$ & $(0.032)$ \\
\hline \multirow[t]{2}{*}{ correlation $_{t}$} & $-0.292^{* *}$ & $-0.285^{* *}$ & & -0.208 & $-0.290 * *$ & \\
\hline & $(0.120)$ & $(0.124)$ & & $(0.141)$ & $(0.139)$ & \\
\hline \multirow[t]{2}{*}{$\mathrm{hb}_{t-1}$} & $-0.013^{* * *}$ & $0.890^{* * *}$ & & $-0.016^{* * *}$ & $0.823^{* * *}$ & \\
\hline & $(0.005)$ & $(0.247)$ & & $(0.005)$ & $(0.207)$ & \\
\hline \multirow[t]{2}{*}{$\operatorname{hbcorr}_{t}$} & & & $-0.572^{* *}$ & & & $-0.645^{* *}$ \\
\hline & & & $(0.229)$ & & & $(0.266)$ \\
\hline \multirow[t]{2}{*}{$\Delta$ lmcap } & $0.394^{* * *}$ & $0.405^{* * *}$ & $0.417^{* * *}$ & $0.436^{* * *}$ & $0.452^{* * *}$ & $0.466^{* * *}$ \\
\hline & $(0.073)$ & $(0.078)$ & $(0.080)$ & $(0.076)$ & $(0.080)$ & $(0.084)$ \\
\hline \multirow[t]{2}{*}{$\operatorname{trade}_{t}$} & 0.004 & $0.009^{* *}$ & 0.005 & -0.002 & 0.009 & 0.004 \\
\hline & $(0.004)$ & $(0.004)$ & $(0.004)$ & $(0.005)$ & $(0.006)$ & $(0.005)$ \\
\hline \multirow[t]{2}{*}{$\Delta$ lgdp_cap $t_{t}$} & $0.479^{* * *}$ & $0.858^{* * *}$ & $0.806^{* * *}$ & $0.501^{* *}$ & $1.037^{* * *}$ & $0.969 * * *$ \\
\hline & $(0.185)$ & $(0.197)$ & $(0.218)$ & $(0.219)$ & $(0.229)$ & $(0.242)$ \\
\hline \multirow[t]{2}{*}{ indus $_{t-1}$} & $0.103^{* *}$ & $0.134^{* *}$ & 0.057 & $0.115^{* *}$ & $0.128^{* *}$ & 0.052 \\
\hline & $(0.051)$ & $(0.054)$ & $(0.056)$ & $(0.054)$ & $(0.056)$ & $(0.059)$ \\
\hline \multirow[t]{2}{*}{$\mathrm{xvol}_{t}$} & $-0.004^{*}$ & -0.003 & -0.004 & $-0.003^{*}$ & -0.002 & -0.003 \\
\hline & $(0.002)$ & $(0.002)$ & $(0.002)$ & $(0.002)$ & $(0.002)$ & $(0.002)$ \\
\hline \multirow[t]{2}{*}{ kaopen_o $t-1$} & 0.025 & $0.090^{* * *}$ & -0.005 & $-0.130 * * *$ & -0.005 & $-0.140^{* * *}$ \\
\hline & $(0.017)$ & $(0.024)$ & $(0.020)$ & $(0.039)$ & $(0.048)$ & $(0.037)$ \\
\hline \multirow[t]{2}{*}{ kaopen_d $d_{t-1}$} & -0.013 & -0.020 & -0.014 & -0.017 & -0.021 & -0.013 \\
\hline & $(0.011)$ & $(0.013)$ & $(0.013)$ & $(0.012)$ & $(0.013)$ & $(0.014)$ \\
\hline Observations & 5491 & 5045 & 5045 & 4505 & 4098 & 4098 \\
\hline Number of id & 1249 & 1152 & 1152 & 995 & 911 & 911 \\
\hline $\operatorname{AR}(2)$ & 0.808 & 0.870 & 0.788 & 0.603 & 0.509 & 0.584 \\
\hline Hansen & 0.001 & 0.121 & 0.0871 & 0.000 & 0.265 & 0.433 \\
\hline
\end{tabular}

Note: Estimation of Equation (3.7) using Two Stage System GMM, where correlation is used as a measure of comovement. $*, * *, * * *$ imply significance at the $10 \%, 5 \%$ and $1 \%$, respectively.

Columns (1) and (4) show a negative effect of home biasedness on equity positions, with a negative coefficient on correlation, albeit not significant in column (4). However, the Hansen test indicates that the instrument set is not valid for this estimation. A closer inspection of the home bias variable shows that Ireland has a value below zero, whereas Luxembourg and Russia have values above one. This causes interpretation problems of the home bias variable and these countries are excluded in columns (2)-(3) and (5)-(6).

The estimations in columns (2) and (5) are not rejected by the Hansen test and show a quite different picture. First, correlation has a large significantly negative effect on equity holdings, which is consistent with 
previous results. In addition, the home bias variable has a significantly positive effect on equity holdings. This implies that countries with a large home bias are in a "catch up" process, with their foreign equity holding increasing faster than for low home biased countries.

Finally, columns (3) and (6) use the interaction variable homebias * correlation in the estimation following Coeurdacier and Guibaud (2009). The coefficient on hbcorr is larger than that on correlation, implying that more home biased countries' investors diversify away stronger from correlated equities than low home biased countries do. This confirms the results of Coeurdacier and Guibaud (2009). Apparently, effective diversification of a small foreign equity share is more important or easier, compared to diversifying a large foreign equity share when a country is already internationally diversified.

\subsection{Conclusion}

In conclusion, this chapter shows that international equity investors adjust their portfolio in response to observed comovements, but not always in the direction we would expect. Since international investors overinvest in their domestic stock market, hedging demands are created to invest in equities which comove little with the domestic stock market.

CPIS data for 40 source and 44 host countries is used to capture annual aggregate international portfolio adjustments during 2001-2007. Stock market comovement is measured using realized correlation and coexceedance probabilities. These coexceedance probabilities disaggregate comovement across different parts of the return distributing and are constructed using the methodology of Cappiello et al. (2005).

The equity allocation process is modeled as a dynamic adjustment process, where the effect of comovement on year-to-year changes in equity holdings is explained. This model is estimated using a two-step System GMM procedure, with comovement being treated as an endogenous variable. Taking care of dynamics is necessary due to the large persistence of equity allocations. In addition, the System GMM procedure is a straightforward method to deal with endogeneity problems when it is not possible to find appropriate external instruments.

The empirical analysis shows that investors indeed reduce their holdings of strongly comoving equities. Two different samples are investigated to 
address potential poolability concerns, one sample is based on statistical arguments and the other one is based on economic arguments. Results show that portfolio adjustments are significantly negative related to correlations. However, when disaggregating the return distributions and distinguishing between left and right tail dependence, it appears that international investors do not strongly diversify away from equities showing large left tail dependence. Put differently, investors diversify away from equity market that jointly boom, but do not diversify away from equity markets that jointly crash. This hurts the effective use of international equity markets for risk diversification. Several robustness checks confirm the above mentioned results.

\subsection{Appendix A: Data sources}

Bilateral and total portfolio equity holdings in US\$ are from the IMF's Coordinated Portfolio Investment Survey, 2001-2007.

Stock market return and capitalization data are retrieved from Thomson Datastream, both in US\$ and local currency. Market capitalization is also disaggregated into 40 industries. This is used to calculated the industrial difference indicator.

GDP and GDP per capita in US\$ are from the World Bank World Development Indicators.

Bilateral trade data in US\$ are from the IMF's Direction of Trade Statistics.

Exchange rates vis-à-vis the US\$ are from Global Financial Data. Bilateral exchange rates are calculated using the local currency vs. US\$ exchange rates.

The Chinn and Itô capital account measure KAOPEN is used to measure the degree of financial openness. The data and a detailed description on its construction are available at http://www.ssc.wisc.edu/ mchinn/ research.html

Institional quality is derived from the World Bank's Aggregate Governance Indicators. For more details, please consult Daniel Kaufmann, Aart Kraay and Massimo Mastruzzi (2009). "Governance Matters VIII: 
Governance Indicators for 1996-2008”. World Bank Policy Research June 2009.

Data on the host country's financial system is derived from the World Bank's Financial Structure Dataset. More information is available in Thorsten Beck, Asli Demirg-Kunt and Ross Levine, (2000), "A New Database on Financial Development and Structure", World Bank Economic Review 14, 597-605.

\subsection{Appendix B: Country sample}

Table 3.7: Source and host country sample

\begin{tabular}{|c|c|c|c|}
\hline \multicolumn{4}{|c|}{ Source countries } \\
\hline Argentina & Finland & Japan & Russia \\
\hline Australia & France & Korea & Singapore \\
\hline Austria & Germany & Luxembourg & South Africa \\
\hline Belgium & Greece & Malaysia & Spain \\
\hline Brazil & Hong Kong & Netherlands & Sweden \\
\hline Canada & Hungary & New Zealand & Switzerland \\
\hline Chile & Indonesia & Norway & Thailand \\
\hline Colombia & Ireland & Philippines & Turkey \\
\hline Czech Republic & Israel & Poland & United Kingdom \\
\hline Denmark & Italy & Portugal & United States \\
\hline \multicolumn{4}{|c|}{ Host countries } \\
\hline Argentina & Finland & Japan & Portugal \\
\hline Australia & France & Korea & Russia \\
\hline Austria & Germany & Luxembourg & Singapore \\
\hline Belgium & Greece & Malaysia & South Africa \\
\hline Brazil & Hong Kong & Mexico & Spain \\
\hline Canada & Hungary & Netherlands & Sweden \\
\hline Chile & India & New Zealand & Switzerland \\
\hline China & Indonesia & Norway & Thailand \\
\hline Colombia & Ireland & Peru & Turkey \\
\hline Czech Republic & Israel & Philippines & United Kingdom \\
\hline Denmark & Italy & Poland & United States \\
\hline
\end{tabular}




\section{4}

\section{The International Wealth EFFECT: A GLOBAL ERror-CORRECTING ANALYSIS}

\subsection{Introduction}

Households in the 1990s have witnessed substantial movements in their financial wealth, mainly owing to price changes in domestic and international stock markets. ${ }^{1}$ Over this decade, US and Scandinavian stock prices more than doubled in real terms, while many European countries experienced only moderate increases, and Asian countries, inflicted by the financial crisis in 1997, even saw considerable stock price decreases. At the end of the 1990s, stock markets culminated in the technology bubble, followed by its burst and plummeting stock prices in the early 2000s. Later, a remarkable and prolonged rebound set in which lasted until the recent outbreak of the subprime mortgage crisis in the US. As stock market wealth comprises the majority of most household's financial assets, housing wealth generally comprises the majority of non-financial assets. Although most countries shared a marked and almost exponential increase in housing prices over the past ten years, housing wealth was also exposed to country-individual cycles. $^{2}$

Much research emanates from this background and pursues the question of how these pronounced swings in financial and non-financial household wealth affect consumption decisions. This question refers to the so-called consumption-wealth effect or domestic wealth effect, which is theoretically

\footnotetext{
${ }^{1}$ This chapter is based on the paper Holinski and Vermeulen (2009).

${ }^{2}$ A notable exception is Switzerland, which experienced a stagnating housing market prior to the subprime mortgage crisis.
} 
motivated by Friedman's (1957) work on the consumption function and Modigliani's and Brumberg's (1954) life cycle consumption hypothesis. Empirical work on quantifying the impact of wealth on consumption dates back to the early contribution of Ando and Modigliani (1963) and has generated much interest among academics and policymakers thereafter. ${ }^{3}$

The objective of the present chapter is to take up the domestic wealth effect and empirically link it to the trade balance. Considering the process of international integration of financial and real markets, we have all reasons to believe that changes in stock and housing prices affect not only consumption decisions through the domestic wealth effect, but further transmit into countries' decisions on importing and exporting goods and services. We refer to this link where asset price movements are transmitted to the trade balance via consumption decisions as the international wealth effect and investigate it for a group of five of the world's most industrialized economies (G5) - the US, UK, Japan, Germany and France. We are particularly interested in the relative strength of the international wealth effect and test whether or not it can emerge as a potent alternative to the traditional exchange rate channel in correcting global current account imbalances.

Both theories, Friedman (1957) and Modigliani and Brumberg (1954), have in common that households consume out of their discounted value of total lifetime resources. That is, they smooth consumption over their life span by borrowing against future income when they are young, accumulating wealth during working age through saving and running down their wealth in retirement. Hence, any unexpected change in household wealth that is perceived as permanent will trigger households to adjust their consumption plans by a fraction of this change in wealth. The marginal propensity to consume out of different forms of household wealth is ultimately an empirical issue and it has been found to be larger if the asset meets one or more of the following criteria: (1) the asset is liquid, (2) its value is easy to determine, (3) it is deemed appropriate to finance consumption and (4) the price change is considered to be permanent and certain.

Considering these criteria, it is not clear a priori if consumption is more responsive to changes in stock market or housing wealth. The first three

\footnotetext{
${ }^{3}$ For a comprehensive review of preceding studies on the domestic wealth effect, see Poterba (2000).
} 
criteria seem more applicable to stock market wealth (although mortgage deregulations make it increasingly possible to extract wealth from houses), while the last criterion is more applicable to housing wealth. A number of recent empirical studies on the domestic wealth effect find mixed evidence. They can be sorted along two dimensions: first, whether they address a single country, the US, (e.g. Ludvigson and Steindel, 1999; Mehra, 2001; Lettau and Ludvigson, 2004), or a panel of countries (e.g. Ludwig and Sløk, 2004; Case et al., 2005), and second, whether they distinguish between different forms of household wealth (e.g. Ludwig and Sløk, 2004; Case et al., 2005) or consider aggregated wealth only (e.g. Ludvigson and Steindel, 1999; Lettau and Ludvigson, 2001, 2004). We will review each dimension in turn.

Ludvigson and Steindel (1999) and Mehra (2001) employ cointegration techniques to study the domestic wealth effect in the US with quarterly data over the time period 1953 to 1997 and 1959 to 2000, respectively. They both arrive at the result that a dollar increase in wealth leads to a 3 to 5 percent increase in aggregate consumption. Moreover, Ludvigson and Steindel (1999) emphasize that the impact of movements in wealth appear to affect consumption contemporaneously and not with a lag. Lettau and Ludvigson $(2001,2004)$ argue in their studies that the linkage between wealth and consumption cannot be understood without distinguishing between permanent and transitory movements. Using a cointegration framework that allows discriminating permanent from transitory behavior, they find for the US that only permanent movements in wealth affect aggregate consumption in the range of the aforementioned 3 to 5 percent. Case et al. (2005) extend the analysis to a panel of 14 countries and distinguish between stock market and housing wealth. They find at best a weak effect of stock market wealth on consumption, but strong evidence of a housing wealth effect. The estimated marginal propensity to consume out of housing wealth ranges between 11 to 14 percent. On the other hand, Ludwig and Sløk (2004) find no clear evidence that the responsiveness of consumption differs between changes in stock market and housing wealth for a panel of 16 OECD countries. However, they report that the structure of the financial system and the time period considered are decisive determinants for the estimated marginal propensity to consume out of wealth. Economies with market-based financial systems report on average higher marginal propensities than economies with bank-based financial systems. Moreover, the marginal propensity is found to be higher 
in the period between 1985 to 2000 as compared to the earlier years between 1960 to 1984.

We argue in the present chapter that real and financial integration provoke an international perspective. Real integration, for instance the removal of barriers in trade of goods and services, brings about changes in aggregate consumption that impact not only the given country's trade balance, but those of its trading partner as well. In addition, financial integration implies that countries hold a considerable share of their aggregate wealth in foreign assets, for instance one-third of worldwide equity market capitalization was owned by foreign investors in 2006. In the same vein, mortgage securitization allows investors to easily participate in foreign housing markets without actually owning property. All this bears the consequence, that, if stock or housing prices move in one country, it will affect the configuration of wealth positions across borders. In order to account properly for this new macroeconomic order, we base our empirical study of the international wealth effect on the global vector autoregression (GVAR) model introduced by Pesaran et al. (2004) - hereafter PSW and advanced in Dees et al. (2007). Following PSW, we first capture the impact of movements in stock market and housing wealth on consumption and the trade balance by estimating country-individual vector errorcorrecting models (VECM). In addition to relevant domestic variables, we include the corresponding weakly-exogenous, trade-weighted foreign variables in these models. They fulfill two purposes: first, they proxy global unobserved common factors that serve as important international transmission channels, and second, they allow simultaneously solving the country-specific VECMs into an error-correcting GVAR representation. We proceed accordingly and first estimate a total of 29 country-specific VECMs with data at quarterly frequency over the time period 1981Q1 to 2006Q4. The models cover all countries and regions that figure prominently in the current debate on global imbalances - the US, China, Europe, Asia and oilexporting countries. A complete list of the included countries is presented in Table 4.1.

Next, we combine the country-individual models into a single error-correcting GVAR which allows studying the international wealth effect with an explicit account of the complex international transmission channels of an integrated world. To date, empirical evidence on the international wealth effect is scarce. Despite the potential importance of asset prices for international trade balance positions, we are aware of only one previous 
Table 4.1: Countries and regions in the model

\begin{tabular}{llll}
\hline \hline Country & Country code & Country & Country code \\
\hline United States & USA & Other OECD & \\
China & CHN & Australia & AUS \\
India & IND & Canada & CAN \\
Japan & JPN & Mexico & MEX \\
& & New Zealand & NZL \\
Europe & & & \\
Austria & AUT & South-East Asia & \\
Belgium & BEL & Indonesia & IDN \\
Denmark & DNK & Korea & KOR \\
Finland & FIN & Malaysia & MYS \\
France & FRA & Philippines & PHL \\
Germany & DEU & Singapore & SGP \\
Italy & ITA & Thailand & THA \\
Luxembourg & LUX & & \\
Netherlands & NLD & Oil & \\
Norway & NOR & Saudi Arabia & SAU \\
Spain & ESP & & \\
Sweden & SWE & & \\
Switzerland & CHE & & \\
United Kingdom & GBR & & \\
\hline \hline
\end{tabular}

study that addresses the issue. Fratzscher et al. (2007) investigate the relative importance of stock market and housing prices for the US current account. ${ }^{4}$ Using a Bayesian structural vector autoregressive model, they find that asset prices account for up to 32 percent of movements of the US trade balance, while real exchange rates explain only around 7 percent and at shorter horizons. Their results suggest that the international wealth effect exerts considerable influence on the external adjustment process of the US. To account for the international dimension, they define US variables in differences to proxy for the rest of the world. Our empirical methodology is therefore much more comprehensive than the one by Fratzscher et al. (2007). Instead of leaving the rest of the world unmodeled, our GVAR methodology explicitly accounts for the rest of the world by means of the 29 country models. Considering, for instance, a shock to US asset markets, we allow for the possibility that the shock translates into the asset markets, and subsequently consumption decisions, of the other 28 countries from where it potentially feeds back into the US trade balance.

An alternative channel through which asset prices transmit to the trade

\footnotetext{
${ }^{4}$ See Fratzscher and Straub (2009) for a more recent application.
} 
balance of a country is worth considering here. This alternative channel of transmission is business and private expenditures on investments. The theoretical roots of this alternative are based on Tobin's $q$-theory of business investment. It says that firms find it worthwhile to invest in their capital stock in bullish asset markets as the ratio between the market value and the replacement value of its capital stock increases (Tobin, 1969). Moreover the financing of business investment is facilitated during these times. Also, the $q$-theory can be generalized to private housing investment and explain how shocks to real housing prices transmit to the trade balance without affecting consumption decisions.

Although we do not explicitly model this alternative transmission channel, we are aware of it when testing for the domestic and international wealth effect for the G5 countries. For each country, we expose stock market and housing prices to a negative shock and integrate out how consumption and the trade balance respond. To put these responses into perspective, we also consider a depreciating shock to the real effective exchange rate. This allows further insight into whether asset price movements emerge as a credible alternative to the exchange rate channel for the external adjustment process of a country. In addition, we conduct a variance-decomposition to assess the relevance of exchange rate, stock price and housing price movements on variations in the trade balance and consumption. An interesting question will be if our empirical methodology confirms the results of Fratzscher et al. (2007) for the US and whether or not they can be generalized to the G5 countries.

To preview the results of the present chapter, our main findings are: first, movements in the real effective exchange rate affect consumption decisions only in the US. This points at the prominent role that the foreign sector plays for US consumption. Second, the domestic and international wealth effect, following a shock to domestic real stock prices, can not be generalized. They are at work in the US, UK and, to a lesser extent, in France but cannot be confirmed for Germany and Japan. Third, we observe an improving trade balance in the US, UK and France, following a negative shock to domestic real housing prices. It seems, however, that movements in housing prices do not transmit to the trade balance via the international wealth effect, but are possibly induced by business and private expenditures on investments. Fourth, in relative terms, domestic stock and housing prices exert at least as much influence on the trade balance as the real effective exchange rate does. 
The rest of the chapter is organized as follows. Section 4.2 sets out the empirical setup and the data series that we have used. Section 4.3 analyzes the dynamic properties of our model by means of impulse response functions, while Section 4.4 shows the corresponding forecast error variance decomposition. In Section 4.5 we expose our models to stability tests as a robustness check. Section 4.6 concludes.

\subsection{Constructing the GVAR model}

In this section, we first motivate the variables that are included in the country-individual models and discuss data considerations. Next we briefly outline the GVAR methodology and then address a number of issues that surround the proper fitting of the models to the data generation process. ${ }^{5}$

\subsubsection{Variable selection and data considerations}

The inclusion of variables in the country-individual models is guided by simple aggregate demand functions of open economy models. ${ }^{6}$ Moreover, we subject the models to a number of specification tests to ensure reliable inference on all included variables. We consider the following $k_{i} \times 1$ vector of endogenous variables,

$$
\mathbf{y}_{i t}=\left[\begin{array}{lllllllll}
t b_{i t} & r c_{i t} & r y_{i t} & r e e r_{i t} & r s_{i t} & r h_{i t} & r_{i t}^{s} & r_{i t}^{l} & p_{i t}^{o i l}
\end{array}\right]^{\prime} .^{7}
$$

for the country-individual VECM, $i$. The trade balance $\left(t b_{i t}\right)$ is defined as the $\log$ of exports over imports; real consumption $\left(r c_{i t}\right)$ is the $\log$ of household consumption deflated by the consumer price index; real gross domestic product $\left(r y_{i t}\right)$ is the log of nominal gross domestic product deflated by the consumer price index; the real effective exchange rate $\left(\right.$ reer $\left._{i t}\right)$ is expressed in logs; real stock market prices $\left(r s_{i t}\right)$ are the log of a broad stock market index deflated by the consumer price index; real housing prices $\left(r h_{i t}\right)$ are the log of a housing price index deflated by the consumer price index; the short term real interest rate $\left(r_{i t}^{s}\right)$ is the log of a three-month

\footnotetext{
${ }^{5}$ For a full exposition of the GVAR methodology, we refer the interested reader to Pesaran et al. (2004) and Dees et al. (2007).

${ }^{6}$ See for instance, Obstfeld and Rogoff (1996) or Sørensen and Whitta-Jacobsen (2005) for a textbook treatment.

${ }^{7}$ Depending on the availability of data, we may include fewer variables in some country models. See appendix for data availability and sources.
} 
money market rate deflated by the consumer price index and adjusted for quarterly frequency and the real long term interest rate $\left(r_{i t}^{l}\right)$ is the log of the rate on ten-year government bonds deflated by the consumer price index and adjusted for quarterly frequency. A notable exception constitutes the treatment of the oil price $\left(p_{i t}^{o i l}\right)$, which controls for global political events as an observable common factor to all countries in our sample. Despite the growing importance of other regions in the world, we follow Dees et al. (2007) and include $p_{i t}^{\text {oil }}$ as an endogenous variable only in the US model, while retaining it as weakly-exogenous in all other country models.

Note that we include $r y_{i t}$ and $r c_{i t}$ in the country models. We see at least two reasons for the inclusion of both. First, it allows for careful study of the various transmission channels of shocks to asset prices and the exchange rate, e.g. we are able to observe how savings - the difference between $r y_{i t}$ and $r c_{i t}$ - react to these shocks. Second, we seek to get a grip on the often leveled criticism that the observed wealth effect is spurious. Poterba and Samwick (1995) argue for instance that observed correlations between asset prices and consumption stem from the fact that asset prices convey information about future income growth. Movements in financial and nonfinancial household wealth are captured by $r s_{i t}$ and $r h_{i t}$, respectively. The use of price indices as proxies for household wealth can be viewed as a limitation of our analysis, but studies by Ludwig and Sløk (2004) and Fratzscher et al. (2007) confirm that differences to volume based proxies for wealth are immaterial in estimations. Moreover, price indices allow exploiting the quarterly frequency at which these data are available. In the academic debate about causes and solutions to recent global current account imbalances, recurrent arguments include necessary exchange rate adjustments (e.g Blanchard et al. (2005), Holinski et al. (2009)) and relative output growth rates due to productivity differentials (e.g. Corsetti et al. (2008), Bems et al. (2007)). We control for these arguments with the variables reer $i t$ and $r y_{i t}$. Moreover, we decided to include $r_{i t}^{s}$ and $r_{i t}^{l}$ in the country models since specification tests show their importance for a sound modeling of stock market and housing prices. Additionally, by including both we allow for possible effects of bond markets.

In order to link the individual country-models and create international transmission channels, we match the domestic variables with tradeweighted foreign variables. The foreign variables remain unmodeled in the country models and thus need to satisfy weak exogeneity requirements for inference and impulse response analysis. We test and elaborate on the 
weak-exogeneity condition below. The $k_{i}^{*} \times 1$ vector of foreign variables is denoted by

$$
\mathbf{y}_{i t}^{*}=\left[\begin{array}{lllllll}
r c_{i t}^{*} & r y_{i t}^{*} & r s_{i t}^{*} & r h_{i t}^{*} & r_{i t}^{s^{*}} & r_{i t}^{l^{*}} & \left.p_{i t}^{o i l}\right]^{\prime}
\end{array}\right.
$$

and constructed as trade-weighted averages

$$
\begin{array}{rlrl}
r c_{i t}^{*}=\sum_{j=1}^{N} w_{i j}^{r c} r c_{j t} & r y_{i t}^{*}=\sum_{j=1}^{N} w_{i j}^{r y} r y_{j t} & r s_{i t}^{*}=\sum_{j=1}^{N} w_{i j}^{r s} r s_{j t} \\
r h_{i t}^{*}=\sum_{j=1}^{N} w_{i j}^{r h} r h_{j t} & r_{i t}^{s^{*}}=\sum_{j=1}^{N} w_{i j}^{r^{s}} r_{j t}^{s} & r_{i t}^{l^{*}}=\sum_{j=1}^{N} w_{i j}^{r l} r_{j t}^{l}
\end{array}
$$

where the country-specific trade-weights, $w_{i j}^{r c}, w_{i j}^{r y}, w_{i j}^{r s}, w_{i j}^{r h}, w_{i j}^{r^{s}}$ and $w_{i j}^{r^{l}}$ for $i, j=1,2, \ldots N$, are the sum of bilateral exports and imports between country $i$ and $j$ relative to total exports and imports of country $i{ }^{8} \mathrm{We}$ employ time-invariant trade-weights in the construction of foreign variables, which we obtain as averages over the years 2000 - 2004. ${ }^{9}$ Obviously, the correct choice of the weights is key in creating the international transmission channels. The use of information on bilateral trade in goods and services seems to be the natural choice for our study of the international wealth effect. An alternative choice is information on bilateral capital flows. However, data are not consistently available for all countries in our sample and we do not expect significant differences. The literature on the geography of portfolio investment shows that underlying trade in goods and services are key correlates for the observed patterns of capital flows (Portes and Rey, 2005; Lane and Milesi-Ferretti, 2008). The 29x29 trade share matrix that has been used in constructing the country-specific foreign variables are provided in Table 4.2 below.

\subsubsection{The GVAR methodology}

The GVAR methodology proceeds in two stages. The first stage is the estimation stage of the following reduced form augmented vector

\footnotetext{
${ }^{8}$ We adjust the trade-weights if data are not available for some countries and some variables.

${ }^{9}$ Section 4.5 discusses the implications of using time-varying trade-weights on the construction of the starred variables and the number of cointegrating relationships.
} 


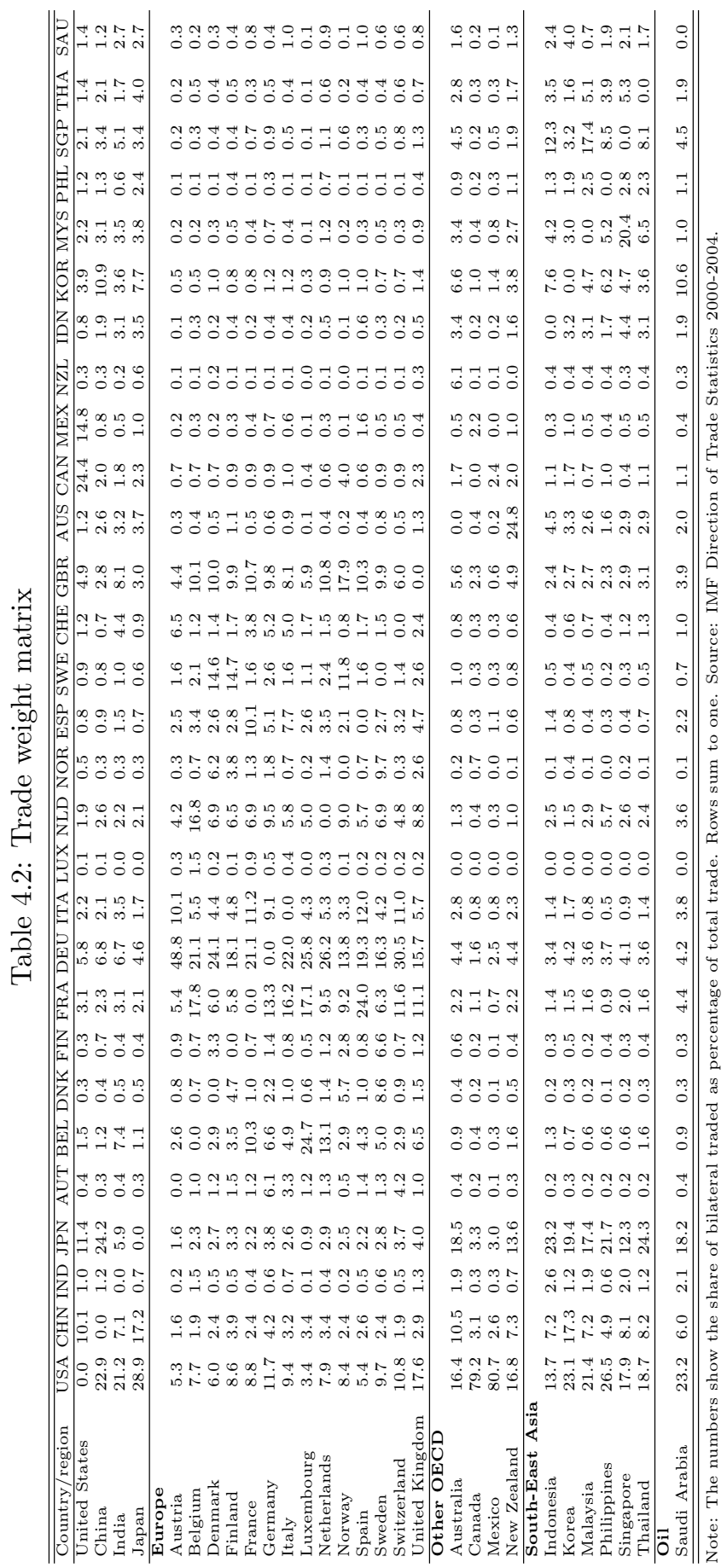


autoregression, $\operatorname{VARX}(p, q)$, model for each country $i$ in our sample

$$
\begin{aligned}
\mathbf{y}_{i t}=\boldsymbol{\delta}_{i 0}+\boldsymbol{\delta}_{i 1} t+\sum_{l=1}^{p} \boldsymbol{\Phi}_{i l} \mathbf{y}_{i, t-l}+\sum_{m=0}^{q} \boldsymbol{\Psi}_{i m} \mathbf{y}_{i, t-m}^{*}+\boldsymbol{\epsilon}_{i t}, & i=1,2, \ldots, N, \\
t & =1,2, \ldots, T
\end{aligned}
$$

where $\boldsymbol{\delta}_{i 0}$ and $\boldsymbol{\delta}_{i 1}$ are $k_{i} \times 1$ coefficient vectors of the deterministic intercept and time trend. ${ }^{10} \mathbf{y}_{i t}$ is a $k_{i} \times 1$ vector of country-specific variables with corresponding $k_{i} \times k_{i}$ matrices of lagged coefficients, denoted by $\boldsymbol{\Phi}_{i l} . \mathbf{y}_{i t}^{*}$ is a $k_{i}^{*} \times 1$ vector of trade-weighted foreign variables with corresponding $k_{i} \times k_{i}^{*}$ matrices of contemporaneous and lagged coefficients, denoted by $\boldsymbol{\Psi}_{i m} . \boldsymbol{\epsilon}_{i t}$ is a $k_{i} \times 1$ vector of zero mean, idiosyncratic country-specific shocks, assumed to be serially uncorrelated with time invariant covariance matrix $\Sigma_{i i}$. We determine the order of the dynamic specification according to the Akaike information criterion (AIC). To reduce the number of estimated parameters, we allow at maximum for a $\operatorname{VARX}(2,1)$ specification. The lag orders of the individual countries are reported in Table 4.3.

The modeling approach is well-suited to deal with variables that are approximately integrated of order one, in which case the $\operatorname{VARX}(2,1)$ can be written and estimated in a compact error-correction representation as

$$
\Delta \mathbf{y}_{i t}=\boldsymbol{\delta}_{i 0}+\boldsymbol{\delta}_{i 1} t-\left(\mathbf{A}_{i}-\mathbf{B}_{i}-\mathbf{C}_{i}\right) \mathbf{z}_{i, t-1}+\boldsymbol{\Psi}_{i 0} \Delta \mathbf{y}_{i, t}^{*}-\boldsymbol{\Phi}_{i 2} \Delta \mathbf{y}_{i, t-1}+\boldsymbol{\epsilon}_{i t}
$$

where

$$
\begin{aligned}
\mathbf{z}_{i t} & =\left(\begin{array}{c}
\mathbf{y}_{i t} \\
\mathbf{y}_{i t}^{*}
\end{array}\right), \\
\mathbf{A}_{i}=\left(\mathbf{I}_{k_{i}},-\boldsymbol{\Psi}_{i 0}\right), \quad \mathbf{B}_{i} & =\left(\boldsymbol{\Phi}_{i 1}, \boldsymbol{\Psi}_{i 1}\right), \quad \mathbf{C}_{i}=\left(\boldsymbol{\Phi}_{i 2}, \mathbf{0}_{k_{i}^{*}}\right) .
\end{aligned}
$$

$\mathbf{A}_{i}, \mathbf{B}_{i}$ and $\mathbf{C}_{i}$ are matrices of dimension $k_{i} \times\left(k_{i}+k_{i}^{*}\right)$. The error-correcting properties of each country model are thus summarized in the $k_{i} \times\left(k_{i}+k_{i}^{*}\right)$ matrix

$$
\boldsymbol{\Pi}_{i}=\left(\mathbf{A}_{i}-\mathbf{B}_{i}-\mathbf{C}_{i}\right)
$$

where the rank, $r_{i}$, of $\boldsymbol{\Pi}_{i}$ determines the number of long-run relationships between domestic and country-specific foreign variables, $\mathbf{y}_{i}$ and $\mathbf{y}_{i}^{*}$. To identify the rank of the cointegrating space for each country model, we use the trace test statistic which is known to be more robust to departures from

\footnotetext{
${ }^{10}$ The estimations are based on the GAUSS code of L. Vanessa Smith (2006).
} 
Table 4.3: VARX order and number of cointegrating relationships

\begin{tabular}{|c|c|c|c|}
\hline \multirow[b]{2}{*}{ Country/region } & \multicolumn{2}{|c|}{ 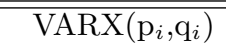 } & \multirow{2}{*}{$\begin{array}{c}\text { \# Cointegrating } \\
\text { relationships }\end{array}$} \\
\hline & $\mathrm{p}_{i}$ & $\mathrm{q}_{i}$ & \\
\hline United States & 2 & 1 & 3 \\
\hline China & 2 & 1 & 2 \\
\hline India & 2 & 1 & 1 \\
\hline Japan & 2 & 1 & 4 \\
\hline \multicolumn{4}{|l|}{ Europe } \\
\hline Austria & 2 & 1 & 4 \\
\hline Belgium & 2 & 1 & 5 \\
\hline Denmark & 2 & 1 & 5 \\
\hline Finland & 2 & 1 & 3 \\
\hline France & 2 & 1 & 3 \\
\hline Germany & 1 & 1 & 3 \\
\hline Italy & 2 & 1 & 3 \\
\hline Luxembourg & 2 & 1 & 3 \\
\hline Netherlands & 2 & 1 & 3 \\
\hline Norway & 2 & 1 & 4 \\
\hline Spain & 2 & 1 & 5 \\
\hline Sweden & 2 & 1 & 6 \\
\hline Switzerland & 2 & 1 & 4 \\
\hline United Kingdom & 2 & 1 & 3 \\
\hline \multicolumn{4}{|l|}{ Other OECD } \\
\hline Australia & 2 & 1 & 3 \\
\hline Canada & 2 & 1 & 4 \\
\hline Mexico & 2 & 1 & 3 \\
\hline New Zealand & 2 & 1 & 3 \\
\hline \multicolumn{4}{|c|}{ South-East Asia } \\
\hline Indonesia & 1 & 1 & 2 \\
\hline Korea & 2 & 1 & 4 \\
\hline Malaysia & 2 & 1 & 2 \\
\hline Philippines & 2 & 1 & 3 \\
\hline Singapore & 1 & 1 & 3 \\
\hline Thailand & 2 & 1 & 3 \\
\hline \multicolumn{4}{|l|}{ Oil } \\
\hline Saudi Arabia & 2 & 1 & 2 \\
\hline
\end{tabular}

Note: VARX order determined by the AIC, with $\mathrm{p} \leq 2$ and $\mathrm{q}=1$.

normal errors than the maximum eigenvalue test (Cheung and Lai, 1993). ${ }^{11}$ The number of long-run relationships according to the trace test statistic is listed for each country in Table 4.3. Below we elaborate on the integration

\footnotetext{
${ }^{11}$ Departure from normal errors is particularly relevant in our study which includes equity and housing prices, interest rates and the real effective exchange rate.
} 
properties of our variables and the long-run relationships between them. Note that the contemporaneous dependence of the domestic variables, $\mathbf{y}_{i t}$, on the foreign variables, $\mathbf{y}_{i t}^{*}$, in (4.4) and (4.5) makes it necessary to solve the country-specific models simultaneously for all of the domestic variables, $\mathbf{y}_{i t}$. This is the second stage of the GVAR methodology, where we cast the country-specific models into its global representation. First rewrite (4.5) as

$$
\mathbf{A}_{i} \Delta \mathbf{z}_{i t}=\boldsymbol{\delta}_{i 0}+\boldsymbol{\delta}_{i 1} t-\left(\mathbf{A}_{i}-\mathbf{B}_{i}-\mathbf{C}_{i}\right) \mathbf{z}_{i, t-1}-\boldsymbol{\Phi}_{i 2} \Delta \mathbf{y}_{i, t-1}+\boldsymbol{\epsilon}_{i t}
$$

and stack the endogenous variables of all individual country models in a $k \times 1$ global variable vector $\mathbf{y}_{t}=\left(\mathbf{y}_{1 t}, \mathbf{y}_{2 t} \ldots \mathbf{y}_{N t}\right)^{\prime}$ with $k=\sum_{i=1}^{N} k_{i}$. Next stack the country individual models of (4.6) and solve for the global VECM representation

$$
\mathbf{F} \Delta \mathbf{y}_{t}=\boldsymbol{\delta}_{0}+\boldsymbol{\delta}_{1} t-(\mathbf{F}-\mathbf{G}-\mathbf{H}) \mathbf{y}_{t-1}+\boldsymbol{\Phi}_{2} \Delta \mathbf{y}_{t-1}+\boldsymbol{\epsilon}_{t}
$$

where

$$
\boldsymbol{\delta}_{0}=\left(\begin{array}{c}
\boldsymbol{\delta}_{10} \\
\boldsymbol{\delta}_{20} \\
\vdots \\
\boldsymbol{\delta}_{N 0}
\end{array}\right), \quad \boldsymbol{\delta}_{1}=\left(\begin{array}{c}
\boldsymbol{\delta}_{11} \\
\boldsymbol{\delta}_{21} \\
\vdots \\
\boldsymbol{\delta}_{N 1}
\end{array}\right), \quad \phi_{2}=\left(\begin{array}{c}
\boldsymbol{\Phi}_{12} \\
\boldsymbol{\Phi}_{22} \\
\vdots \\
\boldsymbol{\Phi}_{N 2}
\end{array}\right), \quad \boldsymbol{\epsilon}_{t}=\left(\begin{array}{c}
\boldsymbol{\epsilon}_{1 t} \\
\boldsymbol{\epsilon}_{2 t} \\
\vdots \\
\boldsymbol{\epsilon}_{N t}
\end{array}\right) \text {, }
$$

and

$$
\mathbf{F}=\left(\begin{array}{c}
\mathbf{A}_{1} \mathbf{W}_{1} \\
\mathbf{A}_{2} \mathbf{W}_{2} \\
\vdots \\
\mathbf{A}_{N} \mathbf{W}_{N}
\end{array}\right), \quad \mathbf{G}=\left(\begin{array}{c}
\mathbf{B}_{1} \mathbf{W}_{1} \\
\mathbf{B}_{2} \mathbf{B}_{2} \\
\vdots \\
\mathbf{B}_{N} \mathbf{W}_{N}
\end{array}\right), \quad \mathbf{H}=\left(\begin{array}{c}
\mathbf{C}_{1} \mathbf{W}_{1} \\
\mathbf{C}_{2} \mathbf{W}_{2} \\
\vdots \\
\mathbf{C}_{N} \mathbf{W}_{N}
\end{array}\right)
$$

The $\mathbf{W}_{i}$ s are country-specific $\left(k_{i}+k_{i}^{*}\right) \times k$ matrices of fixed constants defined by the trade-weights that were used above in the construction of the foreign variables. $\mathbf{W}_{i}$ is best thought of as the link matrix that allows the country individual models to be written in terms of the global variable vector, $\mathbf{y}_{t}$. The global VECM of (4.7) allows for interaction among the included economies through three different but interrelated channels: (1) the contemporaneous dependence of domestic variables, $\mathbf{y}_{i t}$, on foreign variables, $\mathbf{y}_{i t}^{*}$, and on its lagged values, (2) the dependence of all endogenous variables on common global exogenous variables (e.g. oil price), and (3) the 
nonzero contemporaneous dependence of shocks in country $i$ on shocks in country $j$. Cross-country shocks are allowed to be weakly correlated in $\Sigma_{i j}$.

Note that in the global VECM representation, domestic variables are no longer contemporaneously dependent on foreign variables. This implies that we can solve the global model forward recursively, obtain future values of all endogenous variables and conduct impulse response analysis. We do so in Section 4.3. Before, we have a closer look at the statistical properties of the data series that we include in our model.

\subsubsection{Properties and specification of the data series}

As a first step in specifying the country individual model, we have to determine the integration properties of the included variables. The errorcorrection representation of the GVAR methodology assumes that the included variables are approximately integrated of order one. We follow PSW and base our unit root tests on weighted symmetric estimations of ADF type regressions that possess superior power performance compared to standard ADF tests (Park and Fuller, 1995).

Tables 4.4 and 4.5 present unit root $t$-statistics for the levels, first and second differences of the country-specific endogenous variables. The lag length of the tests is selected according to the AIC. The test results largely confirm well known results from previous literature. Real consumption, real output, real effective exchange rates and real stock and oil prices are unambiguously $I(1)$ processes for the vast majority of countries, or else $\mathrm{I}(0) / \mathrm{I}(1)$ borderline cases. A different picture emerges for the unit root tests of the trade balances. Here, we find for a number of countries stationary data series, however, the trade balances of our focus countries are unambiguously $I(1)$. The real housing price series are $I(1)$ processes with four notable exceptions: the US, Belgium, the Netherlands and Sweden. For these countries, we observe an exponential increase in housing prices over the past years of the sample period that renders the processes $I(2)$. Reducing the sample period by the last eight quarters produces I(1) real housing price processes for all countries in our sample. From the impulse response analysis below and the eigenvalues of the GVAR model we can conclude that the found integration order of housing prices does not impair the model's stability. Finally, the hypothesis that interest rates are $I(1)$ is rejected for many countries and may result in an efficiency loss in estimation. Overall, however, it seems appropriate for our modeling 


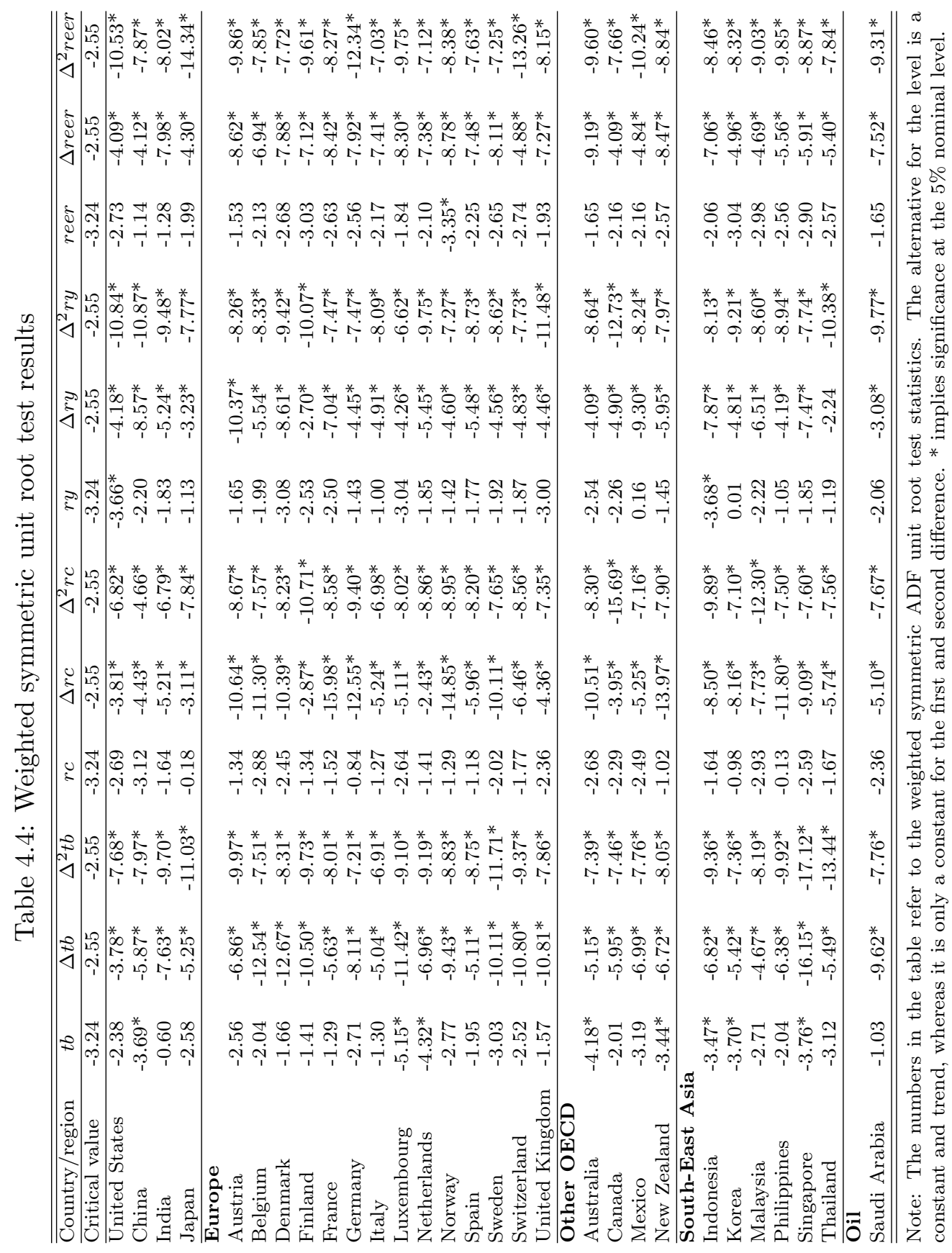







strategy to treat all variables as approximately $I(1)$. The estimation of the country individual models and the impulse response analysis below lend credibility to this conclusion.

Having established the integration properties, we proceed with specifying the number of long run cointegrating relationships that exist between domestic and foreign variables in each country model. Empirical evidence in the literature provides suggestions. Lettau and Ludvigson (2001) find a cointegrating vector between consumption, wealth and personal income for the US. Case and Shiller (2003) and Black et al. (2006) document cointegrating relationships between housing prices, income and interest rates for the US. Specifically, Case and Shiller (2003) find stable price/income ratios for over forty US states. There is some evidence that international stock markets are cointegrated (Kasa, 1992), but these results are challenged by Richards (1995). Meese and Rogoff (1988) investigate the cointegrating properties of real exchange rates and real interest rate differentials, but reject a stable relationship between both variables. On the other hand, Bergvall (2004) finds a single cointegrating relationship between the trade balance, exchange rates, relative GDP and the real oil price for Scandinavian countries. Based on the trace statistic, Table 4.3 shows the number of cointegrating relationships in our country models. The number ranges from 1 for India to 6 for Sweden, but for the great majority of countries, including our G5 countries, we find 3 to 4 cointegrating relationships.

Finally, a key assumption underlying our estimation strategy is the weak exogeneity of the country-specific foreign variables, $\mathbf{y}_{i t}^{*}$. It is best understood as the statistical formalization of the standard assumption in the small open-economy literature where it is generally assumed that most economies are too small relative to the size of the world economy to have an impact on the latter. The weak exogeneity assumption rules out any long run feedback from the endogenous variables, $\mathbf{y}_{i t}$, to the foreign variables, $\mathbf{y}_{i t}^{*}$ and can be formally tested following Johansen (1992) and Harbo et al. (1999). They provide an $F$-test for the joint significance of the estimated error-correcting terms of (4.5) in the marginal model of the country-specific foreign variables, $\mathbf{y}_{i t}^{*}$. To test, for instance, the weak exogeneity of foreign real output in the US country model, we need to consider the joint hypothesis that $\gamma_{U S, j}=0, j=1,2,3$ in the auxiliary 
regression

$$
\begin{array}{r}
\Delta r y_{U S, t}^{*}=\delta_{U S}+\sum_{j=1}^{3} \gamma_{U S, j} E C M_{U S, t-1}^{j}+\sum_{k=1}^{l} \xi_{U S, k} \Delta \mathbf{r y}_{U S, t-k} \\
+\sum_{m=1}^{n} \vartheta_{U S, m} \Delta \mathbf{r y}_{U S, t-m}^{*}+\epsilon_{U S, t}
\end{array}
$$

where $E C M_{U S, t-1}^{j}$ are the three long-run relationships found in the US country model and $\Delta \mathbf{r y}_{U S}$ and $\Delta \mathbf{r y}_{U S}^{*}$ are defined above. Table 4.6 reports the $F$-statistics for all country-specific foreign variables based on the lag order of the underlying VAR model. We find 8 out of 172 cases to be statistically significant at the $5 \%$ nominal level. All other foreign variables pass the weak exogeneity test. For our study, it is reassuring that for our set of focus countries, weak exogeneity can only be rejected for foreign real output in the Japanese country model, while all other foreign variables are weakly exogenous. ${ }^{12}$ Given the size and importance of the US equity market, we exclude foreign real stock prices from the US country model because these cannot be considered as weakly exogenous.

\subsection{Generalized Impulse Response Analysis}

The complex cross-border interdependencies that are an integral part of our global model are best summarized by investigating the dynamic response of the system to shocks in the error of a given variable. The analysis is carried out by making use of generalized impulse response functions (GIRF) which have been introduced by Koop et al. (1996) for non-linear systems and advanced by Pesaran and Shin (1998) for vector error-correcting systems. The GIRF is an alternative to the orthogonalized impulse response (OIR) function that is proposed in the traditional VAR literature (Sims, 1980). While OIR functions rely on a set of orthogonalized shocks, the GIRF considers the shock to an individual error and integrates out the effects of the other shocks based on the historically observed distribution of all errors. Unlike OIR functions, the GIRF neither requires imposing identification restrictions, nor is it variant to the ordering of the endogenous variables

\footnotetext{
${ }^{12}$ As a robustness check, we excluded those foreign variables that do not pass the weak exogeneity test from the country models. The differences in estimation are immaterial.
} 
Table 4.6: Weak exogeneity test

\begin{tabular}{|c|c|c|c|c|c|c|c|c|}
\hline Country/region & F-test & $r y^{*}$ & $r c^{*}$ & $r s^{*}$ & $r h^{*}$ & $r^{l *}$ & $r^{s *}$ & $\overline{\text { oil }^{*}}$ \\
\hline United States & $\mathrm{F}(3,74)$ & 0.40 & 1.19 & - & 0.92 & 0.26 & 1.34 & - \\
\hline China & $\mathrm{F}(2,83)$ & 2.34 & 0.41 & - & - & - & 0.50 & 0.47 \\
\hline India & $\mathrm{F}(1,81)$ & 0.48 & $4.88^{*}$ & 3.32 & - & - & 0.67 & $5.48^{* *}$ \\
\hline Japan & $\mathrm{F}(4,75)$ & $2.60^{*}$ & 0.21 & 1.64 & - & 1.54 & 1.16 & 1.36 \\
\hline \multicolumn{9}{|l|}{ Europe } \\
\hline Austria & $\mathrm{F}(4,75)$ & 0.57 & 0.27 & 1.61 & - & 0.94 & 1.02 & 0.52 \\
\hline Belgium & $\mathrm{F}(5,72)$ & 0.76 & 0.28 & 0.55 & 1.16 & 0.85 & 1.18 & 1.04 \\
\hline Denmark & $\mathrm{F}(5,72)$ & 0.99 & 0.56 & 0.68 & 1.10 & 1.03 & 1.03 & 0.49 \\
\hline Finland & $\mathrm{F}(3,77)$ & 1.85 & 0.96 & 0.33 & 0.53 & - & 1.50 & 0.52 \\
\hline France & $\mathrm{F}(3,74)$ & 0.87 & 0.87 & 0.26 & 2.28 & 1.39 & 2.15 & 0.15 \\
\hline Germany & $\mathrm{F}(3,83)$ & 1.67 & 0.37 & 1.18 & - & 3.36 & 2.37 & 1.02 \\
\hline Italy & $\mathrm{F}(3,76)$ & 1.84 & 1.12 & 0.47 & - & 0.29 & 0.53 & 1.32 \\
\hline Luxembourg & $\mathrm{F}(3,79)$ & 0.82 & 0.93 & 1.50 & - & $3.40^{*}$ & - & 0.58 \\
\hline Netherlands & $\mathrm{F}(3,74)$ & 0.10 & 0.06 & 0.73 & 0.25 & 0.42 & 0.41 & 0.10 \\
\hline Norway & $\mathrm{F}(4,73)$ & 1.24 & 0.12 & 0.33 & 1.78 & 0.68 & 0.90 & 0.54 \\
\hline Spain & $\mathrm{F}(5,72)$ & 1.12 & 0.08 & 0.91 & $2.39^{*}$ & 0.69 & 1.00 & 1.22 \\
\hline Sweden & $\mathrm{F}(6,71)$ & 0.82 & 1.50 & 0.64 & 0.54 & 0.71 & 1.63 & 0.56 \\
\hline Switzerland & $\mathrm{F}(4,73)$ & 0.22 & 0.30 & 1.93 & 2.34 & 1.49 & 1.08 & 0.35 \\
\hline United Kingdom & $\mathrm{F}(3,74)$ & 0.77 & 0.66 & 0.91 & 0.27 & 0.45 & 0.89 & 0.34 \\
\hline \multicolumn{9}{|l|}{ Other OECD } \\
\hline Australia & $\mathrm{F}(3,74)$ & 0.23 & 0.30 & 1.39 & 0.65 & 1.50 & 0.42 & 1.12 \\
\hline Canada & $\mathrm{F}(4,73)$ & 0.60 & 0.71 & 0.43 & 0.70 & 0.25 & 0.16 & 0.85 \\
\hline Mexico & $\mathrm{F}(3,79)$ & 0.20 & 4.33 & 0.02 & - & - & 3.88 & 0.31 \\
\hline New Zealand & $\mathrm{F}(3,74)$ & 1.04 & 0.63 & 2.29 & $4.07^{* *}$ & 0.44 & 0.74 & 0.10 \\
\hline \multicolumn{9}{|l|}{ South-East Asia } \\
\hline Indonesia & $\mathrm{F}(2,88)$ & $3.29 *$ & 1.00 & - & - & - & 0.89 & 0.36 \\
\hline Korea & $\mathrm{F}(4,75)$ & $4.32^{* *}$ & 1.08 & 1.72 & - & 1.62 & 0.73 & 0.62 \\
\hline Malaysia & $\mathrm{F}(2,80)$ & 0.88 & 0.07 & 0.15 & - & - & 0.01 & 0.98 \\
\hline Philippines & $\mathrm{F}(3,79)$ & 0.18 & 0.03 & 1.88 & - & - & 0.69 & 0.06 \\
\hline Singapore & $\mathrm{F}(3,85)$ & 0.22 & 2.18 & 0.52 & - & - & 0.29 & 0.53 \\
\hline Thailand & $\mathrm{F}(3,76)$ & 0.41 & 0.70 & 0.94 & - & 1.39 & 0.69 & 0.91 \\
\hline \multicolumn{9}{|l|}{ Oil } \\
\hline Saudi Arabia & $\mathrm{F}(2,86)$ & 2.44 & 0.56 & - & - & - & - & 1.81 \\
\hline
\end{tabular}

Note: $*$ implies significance at the $5 \%$ nominal level and $* *$ at the $1 \%$ nominal level.

in the global vector, $\mathbf{y}_{t}$. Both are clearly important considerations in our model that considers a total of 204 endogenous variables in 29 country models.

In what follows, we will investigate the time profiles and dynamic responses of domestic variables to a one standard error negative shock to (1) the real effective exchange rate, (2) domestic real stock prices and, if available, (3) domestic real housing prices. We will focus mainly on the 
response of domestic consumption and the trade balance to investigate the international wealth effect transmission channel. The figures show the bootstrapped median impulse responses for the first 20 quarters following the shock together with the associated $90 \%$ confidence bounds. ${ }^{13}$ To stay focused we will concentrate on the G5 countries in the exposition of our results.

\subsubsection{Domestic and international wealth effects in the US}

The first column of Figure 4.1 shows the GIRFs for a one standard error negative shock to the US real effective exchange rate. This shock is equivalent to a currency depreciation of about $2 \%$ per quarter. The shock is highly persistent and thus the real effective exchange rate converges only slowly back to its mean as implied by long run PPP theory. The exchange rate depreciation leads to a statistically significant fall in real consumption of about $0.1 \%$ on impact and up to $0.4 \%$ after 20 quarters. Interestingly, the fall in consumption translates immediately into a statistically significant improvement of the US trade balance by about $0.3 \%$. We do not observe the initial J-curve effect, which confirms previous studies (e.g Rose and Yellen, 1989). Taken together, the responses of real consumption and the trade balance lend support to the view that US trade balance deficits are, by and large, driven by US demand for imported goods and services. This view contrasts with Goldberg and Tille (2006) and Gust and Sheets (2006). Both studies argue that exchange rate movements are largely passed through to the trade balance via exports, leaving US expenditure on imports relatively unchanged.

Next, we expose US real stock prices to a one standard error negative shock. The associated GIRFs are shown in the second column of Figure 4.1. The shock amounts to a drop in real stock prices of $5-6 \%$ per quarter over the entire time horizon. The high persistence in the stock price behaviour following an initial shock can be attributed to the data series being integrated of order unity. Most importantly, on impact and over time we observe the domestic and international wealth effect at work. US real consumption falls by $0.1 \%$ on impact, by $0.5 \%$ after 4 quarters and by $0.7 \%$ after 20 quarters. The response of US real consumption is statistically significant throughout. As hypothesized, the domestic wealth

\footnotetext{
${ }^{13}$ The confidence bounds are obtained using the sieve bootstrap procedure analagous to Dees et al. (2007) with 2000 replications.
} 
Figure 4.1: United States: Domestic response to a real effective exchange rate (first column), real stock price (second column) and real housing price shock (third column)
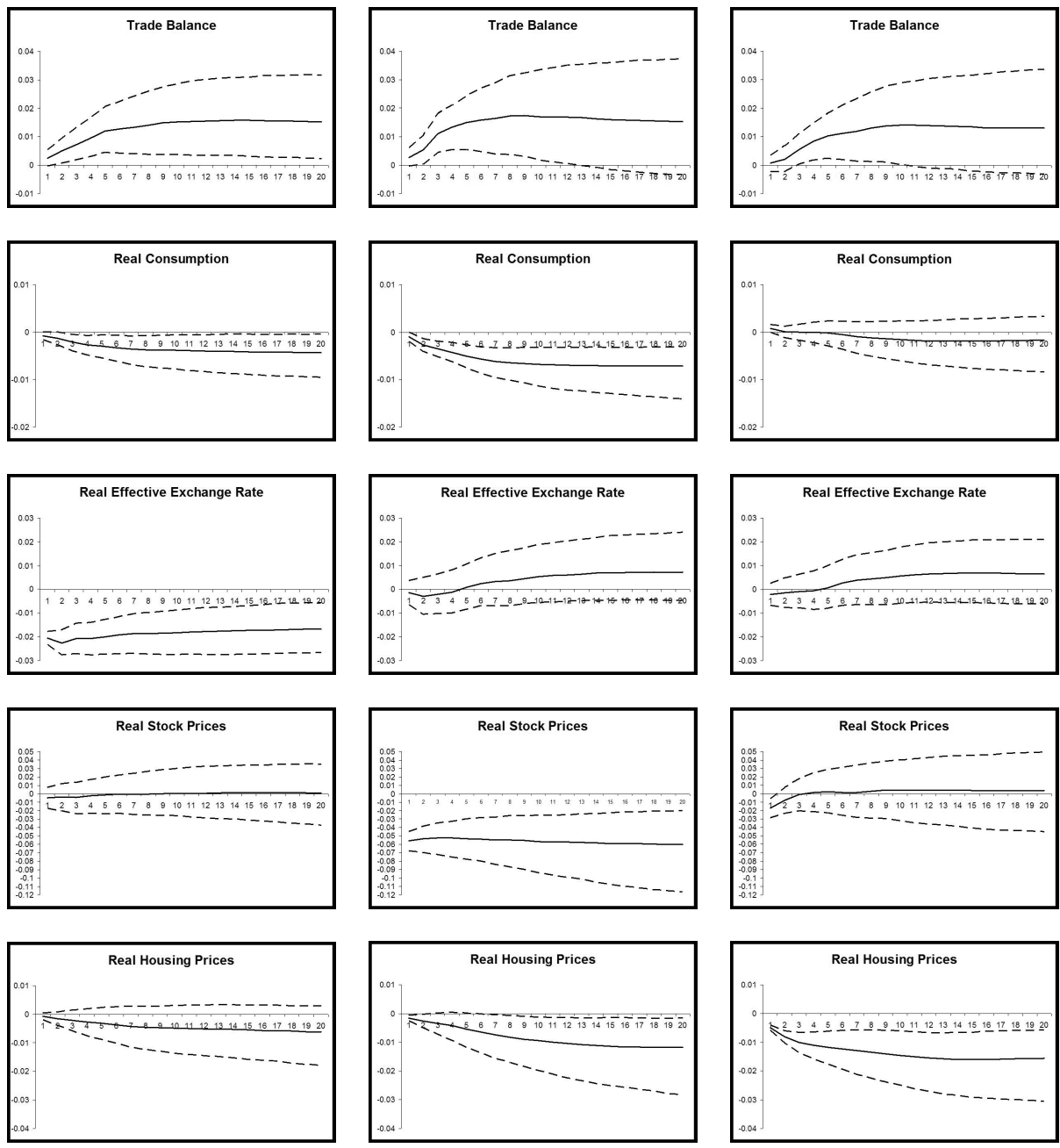
effect becomes international - the fall in real consumption transmits into the US trade balance. Initially, the US trade balance improves by $0.3 \%$, but it improves further by up to $1.7 \%$ after 8 quarters. The trade balance improvement is statistically significant over the first 12 quarters.

Note that real housing prices deteriorate significantly following a negative stock market shock. This decrease becomes significant after about eight quarters and remains significant after twenty quarters. The combined decrease in stock and housing prices may explain the strong effect of the stock market shock on consumption and consequently on the trade balance.

Finally, in the third column of Figure 4.1 a similar, yet less pronounced and statistically significant picture emerges for a one standard error negative shock to US real housing prices. The shock to US housing prices implies initially a $0.5 \%$ price decrease that stabilizes as a price decrease of about $1.5 \%$ over time. We observe that US real consumption turns negative after four quarters by up to $0.2 \%$. However, the decrease in consumption ceases to be statistically significant. On the contrary, the trade balance improves following the negative shock to US real housing prices by $1.3 \%$ after 20 quarters and is statistically significant between quarters 1 and 10 . Given the insignificant response of US real consumption, the transmission channel of housing price movements to the US trade balance, and thus evidence for the domestic and international wealth effect, is less clear cut. We conjecture that private and business investments are likely transmission channels.

When comparing the relevance of the real effective exchange rate and real stock and housing prices for the US trade balance, we find that all three variables bear equal importance. A one standard error negative shock to any variable improves the US trade balance on impact, and, even more over time (between $1.3 \%$ to $1.5 \%$ ).

\subsubsection{Domestic and international wealth effects in the UK}

In the first column of Figure 4.2, we show the GIRFs of a one standard error negative shock to the UK real effective exchange rate. The shock results in a $2 \%$ depreciation of the UK real effective exchange rate per quarter. The depreciation is persistent over time. Unlike in the US, we do not observe a statistically significant effect of the relative price change on UK real consumption. This suggests that the foreign sector plays a less pivotal role for UK consumption decisisons than it does for the US. Also, the UK 
trade balance is less responsive to real effective exchange rate changes than the trade balance in the US. We find the classical J-curve behavior of the UK trade balance in response to a real effective exchange rate depreciation - an initial worsening over the first 3 quarters followed by an improvement over the subsequent 11 quarters. Note, however, that the trade balance response is not statistically significant at any point in time.

The shock to the real effective exchange rate serves as a benchmark against which we now evaluate shocks to UK real stock and housing prices. The second column of Figure 4.2 shows the GIRFs of a one standard error negative shock to UK stock prices. The shock implies a fall in stock prices of about $3.3 \%$ on impact, $2.7 \%$ after 4 quarters and $1.8 \%$ after 20 quarters. Similar to the US, we observe the domestic and international wealth effects at work for the UK. The fall in stock prices translates on impact into a statistically significant contraction of UK real consumption of about $0.1 \%$, from where it further accelerates to $0.6 \%$ after 4 quarters and $0.7 \%$ after 20 quarters. The contraction is statistically significant over the entire time horizon. By way of comparison, we find the domestic wealth effect in the UK to be of the same order of magnitude as in the US.

Also, for a one standard deviation negative shock to UK real housing prices, we observe responses of UK real consumption and the UK trade balance that are, by and large, comparable to the respective responses in the US. The associated GIRFs are shown in the third column of Figure 4.2. The shock amounts to a fall in UK real housing prices of about $1.2 \%$ on impact and up to $2.2 \%$ after 5 quarters. On impact, the shock to real housing prices leads to the same statistically significant contraction of UK consumption as the shock to real stock prices - in both cases about $0.1 \%$. Over time, however, UK real consumption continues to contract by about $0.1-0.2 \%$, but its statistical significance ceases after the second quarter. This is reminiscent of the US real consumption response to the shock in real US housing prices. Similarly, we find that the UK trade balance improves considerably following the negative shock to UK real housing prices - in quarters 7 and 8 by up to $0.7 \%$. The trade balance improvement is statistically significant between quarters 2 and 11. Again, a likely transmission channel are private and business expenditures on investments.

As with the US, we find that responses of UK real consumption and its trade balance to shocks to real stock and housing prices provide support for the existence of the domestic and international wealth effects. Unlike with 
Figure 4.2: United Kingdom: Domestic response to a real effective exchange rate (first column), real stock price (second column) and real housing price shock (third column)
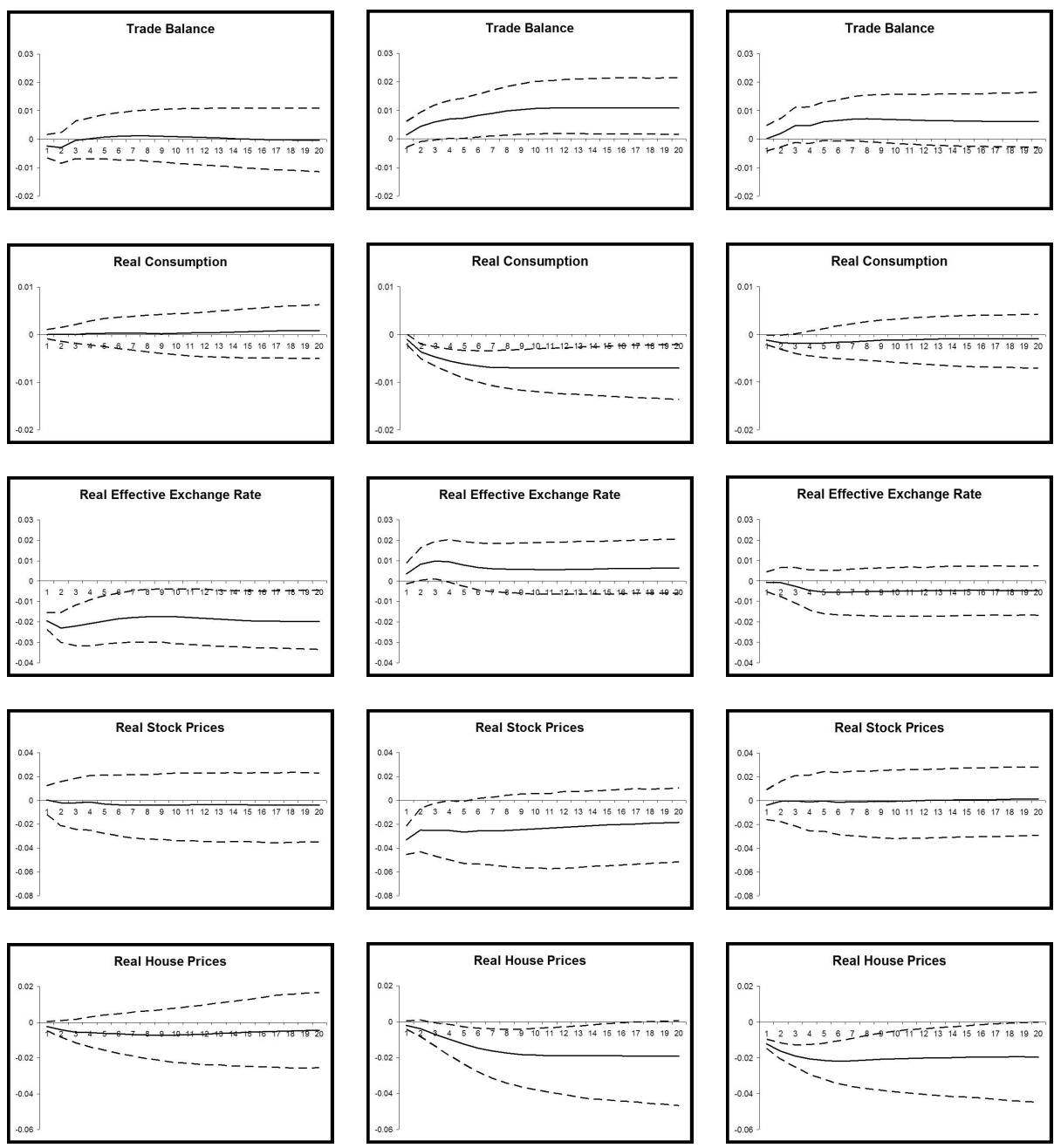
the US, however, we observe that movements in the real effective exchange rate have neither a significant impact on UK consumption decisions, nor on the UK trade balance.

\subsubsection{Domestic and international wealth effects in France}

Similar to the two preceding countries, we also investigate for France the responses to a one standard negative shock to the French real effective exchange rate and compare it to the respective responses that are induced by shocks to French real stock and housing prices. The first column of Figure 4.3 shows the GIRFs of the negative shock to the French real effective exchange rate. The one standard error corresponds to an exchange rate depreciation of $1.2 \%$ on impact. Over time, the depreciation settles around $1.6 \%$. Like before, we can attribute the persistence of the shock to the integration property of the underlying data series. As with the UK, we do not observe a statistically significant effect of the real effective exchange rate change on French real consumption. We take from it that the dependence of US consumption on the relative prices of foreign goods and services is special. Furthermore, as for the UK, we observe that the French trade balance displays the aforementioned J-curve behavior without being statistically significant. These results are in line with Lee and Chinn (2006), who do not find a significant response of the French current account balance to a real exchange rate shock.

Columns 2 and 3 of Figure 4.3 show the GIRFs of one standard error negative shocks to French real stock and housing prices, respectively. The first shock implies a fall in French real stock prices of around $4.4 \%$ on impact and $3.7 \%$ over time. Again, we find the domestic and international wealth effects at work. Following the shock to domestic stock prices, French consumption contracts initially by $0.2 \%$, and further by up to $0.4 \%$ in quarter 20 . The statistical significance of the contraction ceases after 3 quarters. It is interesting to note that the response of French real consumption is about half of the respective response of real consumption in the US and UK and less statistically significant. This is suggestive of the finding that the domestic wealth effect is less pronounced for countries with bank-based, in contrast to market-based, financial systems (Ludwig and Sløk, 2004).

The one standard deviation negative shock to French real housing prices leads to a fall in real housing prices of $1.2 \%$ on impact that accelerates to 
Figure 4.3: France: Domestic response to a real effective exchange rate (first column), real stock price (second column) and real housing price shock (third column)
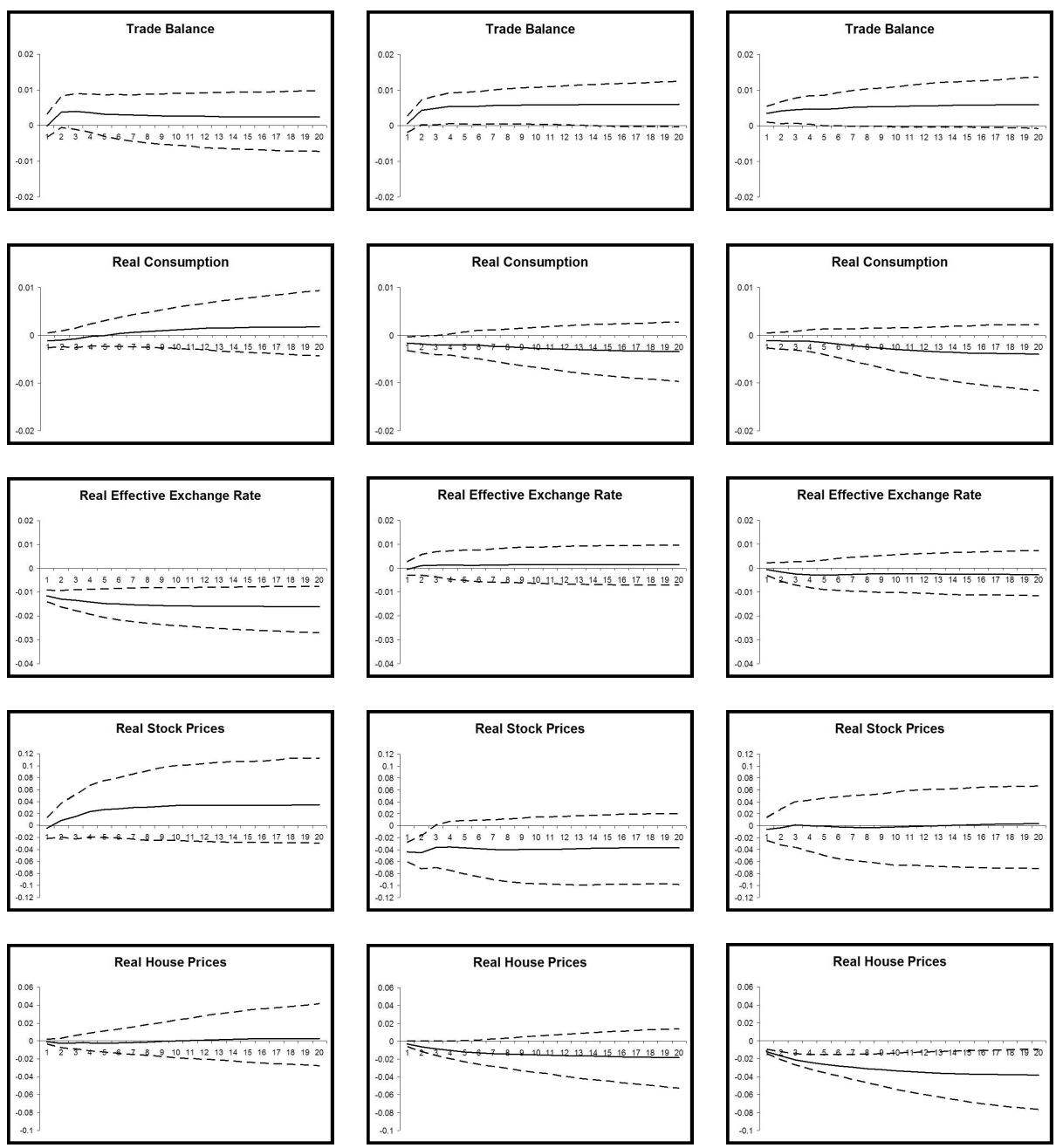
$2.6 \%$ after 4 quarters and $4.1 \%$ after 20 quarters. The responses to the shock resemble, by and large, our findings for the US and UK. French real consumption contracts by 0.1 to $0.4 \%$, but the contraction turns out to be statistically insignificant. At the same time, we observe an improved French trade balance of $0.3 \%$ on impact, $0.5 \%$ after 4 quarters and eventually $0.6 \%$ after 20 quarters. The response is statistically significant over the first 4 quarters and becomes marginally insignificant thereafter.

Overall, the results for France are in line with what we have found for the US and UK. Movements in real effective exchange rates matter most for US real consumption and the US trade balance, less for the UK and France. Shocks to real stock prices unfold their domestic and international wealth effects for all three countries, but to a lesser extent for France. And finally, shocks to real housing prices transmit into the trade balances of all three countries, but real consumption does not seem to be the relevant channel.

\subsubsection{Domestic and international wealth effects in Japan and Germany}

We jointly present the results for Japan and Germany as for these countries real housing price data series are not available. The dynamic analysis is thus narrowed down to negative shocks of one standard deviation to the real effective exchange rates and real stock prices in both countries. The first column of Figure 4.4 shows the GIRFs for a negative shock to the real effective exchange rate of Japan. The shock corresponds to a depreciation of about $3 \%$ on impact and remains at this level after 20 quarters. While we observe that the depreciation of the exchange rate translates into reduced real consumption, $0.07 \%$ after 4 quarters and $0.27 \%$ after 20 quarters, the response is statistically insignificant.

Similarly, the Japanese trade balance displays the classic J-curve behavior, which is only statistically significant on impact. Gupta-Kapoor and Ramakrishnan (1999) provide empirical evidence in favor of the existance of the J-curve for Japan. Next we expose Japanese real stock prices to a one standard deviation negative real stock price shock. It implies a fall in stock prices of $6.2 \%$ on impact and about $5.3 \%$ after a few quarters. The corresponding GIRFs are shown in the second column of Figure 4.4 and provide evidence for the existence of the domestic wealth effect, but fail to recognize the international wealth effect. Following the shock to 
Figure 4.4: Japan: Domestic response to a real effective exchange rate (first column) and real stock price shock (second column)
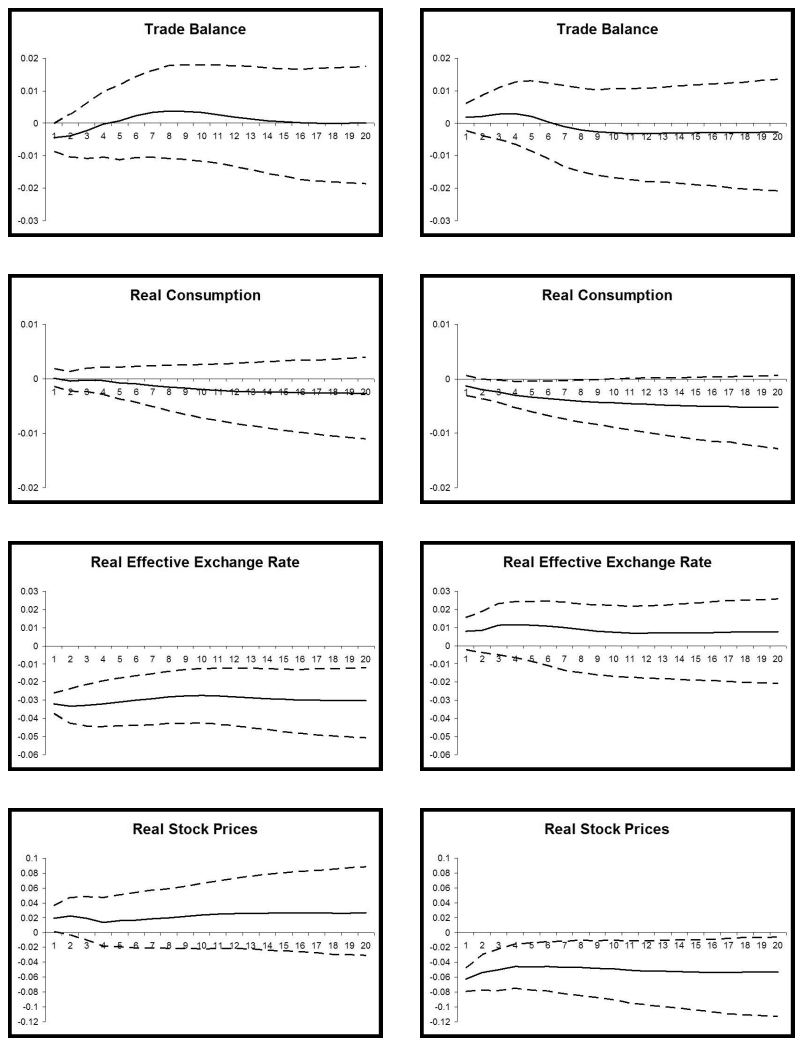
Japanese real stock prices, we find that real consumption in Japan drops by $0.1 \%$ on impact, and further by up to $0.5 \%$ after 20 quarters. The drop is statistically significant over the first 10 quarters. However, the response of consumption does not translate into the Japanese trade balance. There, we do not observe any statistically significant change.

Figure 4.5 shows the GIRFs for one standard deviation negative shocks to the real effective exchange rate and real stock prices of Germany. For this country, we do not find the domestic or international wealth effects at work - real consumption and the trade balance do not change significantly following the shock to German real stock prices. Similarly, we find that the real effective exchange rate does not exert a significant influence on real consumption and the trade balance in Germany. The reunification of the country produced breaks in the first quarter of 1991 in most German data series. While the GVAR methodology copes with co-breaking data series, we also transformed the data series and included a dummy in the short-term dynamics of the model. The above described results are found to be robust across specifications.

\subsection{Forecast error variance decomposition}

Complementary to the GIRF analysis in the previous section, we conduct a generalized forecast error variance decomposition (GFEVD) to answer the question of how much of the error variance in forecasting the trade balance and real consumption can be attributed to shocks in the real effective exchange rate, real stock market and real housing prices. The results are shown in Table 4.7 and strongly confirm our previous findings from the generalized impulse response analysis. They can be summarized as: first, shocks to the real effective exchange rate are by far most influential for real consumption and the trade balance in the US. Over all time horizons, these shocks explain up to $18.3 \%$ of the variation in real consumption and $21.6 \%$ of the variation in the trade balance. By contrast, in all other G5 countries, shocks to the real effective exchange rate contribute at most $2.5 \%$ to the variation in real consumption and $9.4 \%$ to the variation in the trade balance. Particularly, the pronounced impact that shocks to the real effective exchange rate have on US consumption decisions provides a strong case for the prominent role that the foreign sector plays in the US.

These results confirm the findings of Lane and Milesi-Ferretti (2002), 
Figure 4.5: Germany: Domestic response to a real effective exchange rate (first column) and real stock price shock (second column)
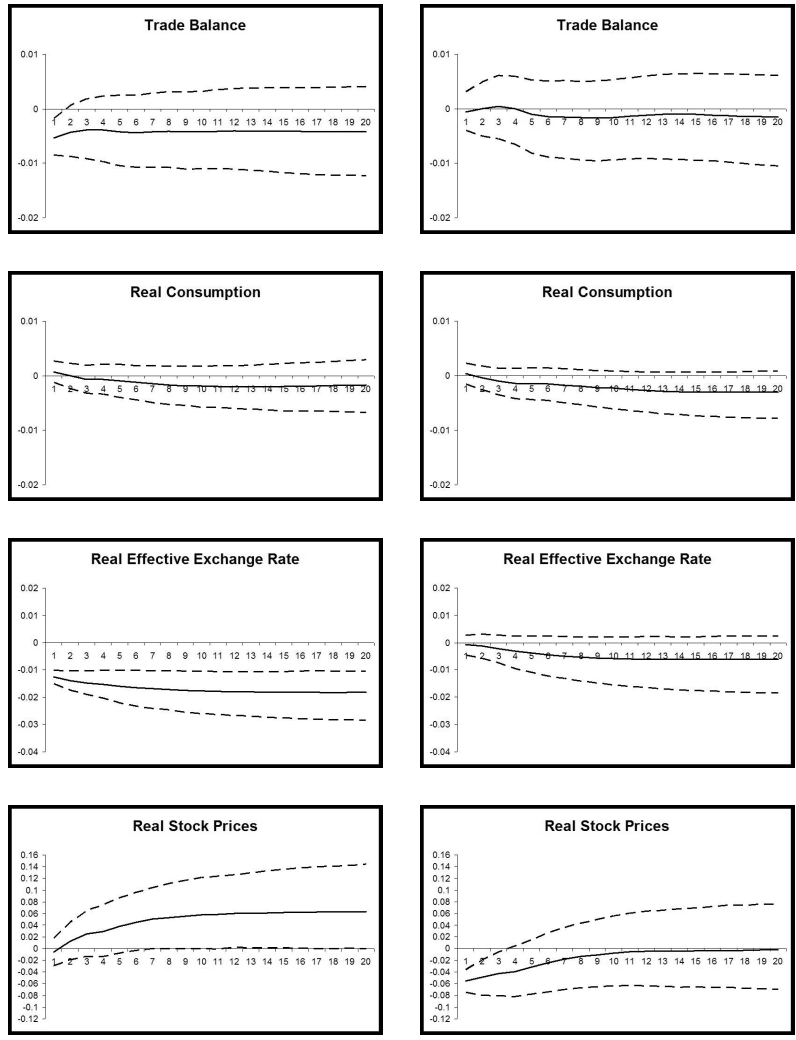
Table 4.7: Proportion of the N-step ahead Forecast Error Variance Explained by Conditioning on Contemporaneous and Future Innovations of the Country Equations

\begin{tabular}{|c|c|c|c|c|c|c|c|}
\hline \multirow{3}{*}{$\begin{array}{l}\text { GFEVD } \\
\text { Country } \\
\text { USA }\end{array}$} & \multicolumn{3}{|c|}{ Trade Balance } & \multicolumn{4}{|c|}{ Real Consumption } \\
\hline & reer & $r s$ & $r h$ & $r c$ & reer & $r s$ & $r h$ \\
\hline & \multicolumn{7}{|c|}{ USA } \\
\hline 4 quarters 27.9 & 19.2 & 29.1 & 13.4 & 38.4 & 15.9 & 33.8 & 0.3 \\
\hline 8 quarters 12.5 & 21.6 & 30.8 & 18.6 & 33.0 & 17.6 & 41.1 & 1.4 \\
\hline 12 quarters 7.6 & 21.4 & 28.4 & 19.8 & 31.4 & 18.0 & 43.0 & 2.7 \\
\hline 16 quarters 5.7 & 21.3 & 26.2 & 19.8 & 30.6 & 18.2 & 43.2 & 3.3 \\
\hline 20 quarters 4.7 & 21.1 & 24.8 & 19.5 & 30.1 & 18.3 & 43.2 & 3.7 \\
\hline \multicolumn{8}{|l|}{ UK } \\
\hline 4 quarters 39.0 & 4.2 & 13.0 & 8.2 & 10.2 & 0.1 & 20.4 & 3.2 \\
\hline 8 quarters 21.6 & 2.0 & 18.8 & 8.8 & 4.8 & 0.2 & 22.9 & 1.5 \\
\hline 12 quarters 15.7 & 1.2 & 21.1 & 7.8 & 3.2 & 0.2 & 24.0 & 0.9 \\
\hline 16 quarters 13.1 & 0.9 & 21.6 & 6.8 & 2.4 & 0.1 & 24.5 & 0.6 \\
\hline 20 quarters 11.6 & 0.7 & 21.5 & 6.2 & 1.9 & 0.1 & 24.6 & 0.5 \\
\hline \multicolumn{8}{|l|}{ FRA } \\
\hline 4 quarters 62.7 & 2.3 & 6.5 & 1.7 & 24.0 & 2.3 & 4.6 & 0.8 \\
\hline 8 quarters 57.1 & 2.1 & 7.3 & 1.9 & 7.3 & 1.5 & 2.5 & 1.5 \\
\hline 12 quarters 52.0 & 1.3 & 7.2 & 2.0 & 4.6 & 1.9 & 1.8 & 1.6 \\
\hline 16 quarters 47.4 & 0.9 & 6.9 & 2.0 & 3.7 & 2.3 & 1.5 & 1.5 \\
\hline 20 quarters 43.7 & 0.7 & 6.7 & 2.1 & 3.4 & 2.5 & 1.4 & 1.4 \\
\hline \multicolumn{8}{|l|}{ GER } \\
\hline 4 quarters 85.3 & 6.5 & 0.6 & - & 65.6 & 0.3 & 5.8 & - \\
\hline 8 quarters 83.9 & 8.0 & 1. & - & 33.6 & 0.2 & 10.2 & - \\
\hline 12 quarters 83.6 & 8.7 & 1.9 & - & 18.0 & 0.1 & 10.5 & - \\
\hline 16 quarters 83.6 & 9.1 & 2.2 & - & 11.3 & 0.1 & 9.5 & - \\
\hline 20 quarters 83.7 & 9.4 & 2.4 & - & 7.9 & 0.1 & 8.2 & - \\
\hline \multicolumn{8}{|l|}{ JPN } \\
\hline 4 quarters 49.3 & 0.5 & 2.3 & - & 73.1 & 0.3 & 17.7 & - \\
\hline 8 quarters 37.7 & 0.8 & 1.7 & - & 54.2 & 1.2 & 26.9 & - \\
\hline 12 quarters 32.8 & 0.6 & 1.2 & - & 41.1 & 1.7 & 28.3 & - \\
\hline 16 quarters30.6 & 0.5 & 0.9 & - & 32.9 & 1.8 & 27.8 & - \\
\hline 20 quarters 29.5 & 0.4 & 0.8 & - & 27.7 & 1.6 & 27.2 & - \\
\hline
\end{tabular}

Note: The numbers show the percentage of the forecast error variance explained of the trade balance and consumption, by the domestic real effective exchange rate, stock prices and housing prices.

who find a strong relationship between the real exchange rate and the trade balance for the US, a weaker relationship for Germany and no connection for France and the UK. However, Lane and Milesi-Ferretti (2002) find a strong dependence of the Japanese trade balance on the real exchange rate, 
whereas we find that the real effective exchange rate does not play a role.

Second, except for Germany, we find in all other G5 countries that shocks to real stock prices explain a substantially greater share of the variation in real consumption and the trade balance than real effective exchange rates do. We take from it that domestic stock price movements constitute a potent alternative to the traditional exchange rate channel in shaping a country's external adjustment process. The international wealth effect is a likely channel.

Third, in all G5 countries, shocks to real housing prices contribute a greater share to the forecast error variance of the trade balance than of real consumption. This points at the potential relevance of business and private investment decisions for passing through housing price shocks to the trade balance. The international wealth effect plays a subordinated role. And finally, the forecast error variance decomposition confirms the idiosyncratic behavior of the German trade balance and real consumption - about $84 \%$ of the variation in the trade balance and up to $66 \%$ of the variation in real consumption are explained by their own shocks.

\subsection{Stability and specification of the global VAR}

One of the underlying assumptions of the GVAR is structural stability of long-run coefficients, short-run coefficients and the error variances. In this setting the model faces problems in case of structural breaks. However, this is not a problem specific to the GVAR, but to macroeconometric models in general. Unfortunately, there is no consensus on how to best model breaks and there are no satisfactory methods available in the literature. So, our main aim is to construct a model as robust as possible to possible breaks. Dees et al. (2007) point out that the structural problem is reduced within the GVAR by the inclusion of foreign variables in the country-individual models. The GVAR is able to accommodate the so-called 'co-breaking', which should make it more robust to the possibility of structural breaks than reduced-form single-equation models. ${ }^{14}$

In order to address the concerns on structural stability, we conduct a battery of structural break tests to judge the (in-)stability of the short run coefficients. ${ }^{15}$ Following Dees et al. (2007), we consider structural stability

\footnotetext{
${ }^{14}$ For more details we refer to Hendry (1996) and Hendry and Mizon (1998).

${ }^{15}$ Detecting instability of the long run coefficients using structural breaks tests may be
} 
tests that are based on the residuals of the individual equations of the country individual models. Here we use ten different stability tests: the Ploberger and Krämer (1992) maximal OLS CUSUM statistic $\left(\mathrm{PK}_{\text {sup }}\right)$, its mean square variant $\left(\mathrm{PK}_{m s q}\right)$, the Nyblom (1989) test (Nyblom), which considers a non-stationary alternative, the Wald form of the Quandt (1960) likelihood ratio statistic (QLR), the mean Wald statistic (MW) of Hansen (1992) and Andrews and Ploberger (1994) and the Andrews and Ploberger (1994) Wald statistic based on the exponential average (APW). For the latter four tests we also apply the heteroskedastic-robust versions.

Table 4.8 shows the test results, where for each variable the percentage of rejections at the $5 \%$ nominal level is reported. The last column shows the total number of rejections by each test. When we consider the $\mathrm{PK}_{\text {sup }}$ and $\mathrm{PK}_{m s q}$ test the total rejection rate of parameter stability is $4.4 \%$ and $2.9 \%$, respectively. This implies that we reject coefficient stability only for a small number of variables. The Nyblom test shows similar results, both versions show rejection rates lower than $10 \%$ and based on these results there seems to be little concern about parameter stability.

Table 4.8: Tests of parameter constancy

\begin{tabular}{lcccccccccc}
\hline \hline Test & \multicolumn{10}{c}{ Domestic variables } \\
\hline & $t b$ & $r y$ & reer & $r c$ & $r s$ & $r h$ & $r^{l}$ & $r^{s}$ & oil & \\
\hline$P K_{\text {sup }}$ & 3.4 & 0.0 & 6.9 & 10.3 & 0.0 & 14.3 & 5.0 & 0.0 & 0.0 & 4.4 \\
PK & 3.4 & 0.0 & 0.0 & 6.9 & 0.0 & 21.4 & 0.0 & 0.0 & 0.0 & 2.9 \\
Nyblom & 10.3 & 0.0 & 10.3 & 3.4 & 15.4 & 14.3 & 10.0 & 14.8 & 0.0 & 9.3 \\
robust-N & 6.9 & 6.9 & 0.0 & 3.4 & 11.5 & 7.1 & 0.0 & 7.4 & 0.0 & 5.4 \\
QLR & 37.9 & 10.3 & 24.1 & 17.2 & 34.6 & 42.9 & 35.0 & 44.4 & 0.0 & 29.4 \\
robust-QLR & 7.7 & 7.7 & 3.8 & 3.8 & 12.5 & 25.0 & 0.0 & 18.5 & 0.0 & 9.1 \\
MW & 24.1 & 13.8 & 17.2 & 13.8 & 30.8 & 14.3 & 20.0 & 22.2 & 0.0 & 19.6 \\
robust-MW & 15.4 & 15.4 & 3.8 & 3.8 & 16.7 & 16.7 & 5.3 & 18.5 & 0.0 & 11.8 \\
APW & 37.9 & 10.3 & 24.1 & 17.2 & 34.6 & 35.7 & 35.0 & 44.4 & 0.0 & 28.9 \\
robust-APW 7.7 & 15.4 & 3.8 & 3.8 & 16.7 & 25.0 & 0.0 & 18.5 & 0.0 & 10.7 \\
\hline \hline
\end{tabular}

Note: The table reports the percentages of rejections of the null of parameter constancy per variable across the country-specific models at the $5 \%$ nominal level.

Interestingly, the tests do not always reject stability for the same variables. The PK tests never reject stability for stock market prices, whereas the Nyblom tests show relatively high rejection rates. A similar story applies to short-term interest rates.

infeasible due to the large number of variables in each VECX* model, in combination with a relatively small time series dimension. 
The QLR, MW and APW tests show very high rejection rates across all variables. Both the QLR and APW tests shows rejection rates of over 30\% for stock prices, housing prices, short-term and long-term interest rates. The QLR rejects stability for 60 out of 204 variables and the results for MW and APW show similar rejection rates. However, the rejection rates are much lower when we take heteroskedasticity into account in these tests. Accounting for heteroskedasticity is especially important for variables such as stock and housing prices. In this situation all tests show rejection rates close to $10 \%$. Notice that the drop is especially strong for those variables which had high rejection rates before accounting for heteroskedasticity.

These findings imply that the main reason of rejection by the tests appears to be breaks in error variances and not changes in the parameter coefficients. So, most of the structural parameters in our model seem to be relatively stable and concerns for structural breaks are mitigated. In line with Dees et al. (2007), we account for heteroskedasticity by using robust bootstrapped standard errors for the confidence bounds of the GIRFs and interpret the GIRFs conservatively by taking $90 \%$ confidence bounds.

Finally, we address the implications of using time-varying trade-weights on the starred variables and the number of cointegrating relationships. Table 4.9 displays the correlation coefficients of country-specific foreign variables using constant and time-varying trade weights. Since the countryspecific foreign variables are calculated as the product of trade weights and the respective economic variables, these will follow the development of the relevant variable in the other countries strongly if the general trend is increasing.

The results confirm this expectation and show a very strong relationship, emphasized by a correlation coefficient close to one, between the starred variables using fixed or varying trade weights. However, part of this strong relationship may be reflected by common time trend. Therefore, Table 4.9 considers also the correlation between the first differenced starred variables. Correlations are again very high, especially for the financial data (stock market prices, housing prices and interest rates) where virtually are correlations are above 0.9 .

Most developed countries show very high correlations for GDP and consumption as well, whereas correlations are slightly lower for most developing countries. This can be explained by a relatively larger change in trade patterns for developing countries. Put differently, during the past thirty years developing countries trade more and more to different 
Table 4.9: Correlation coefficients of country-specific foreign variables using constant and time-varying trade weights

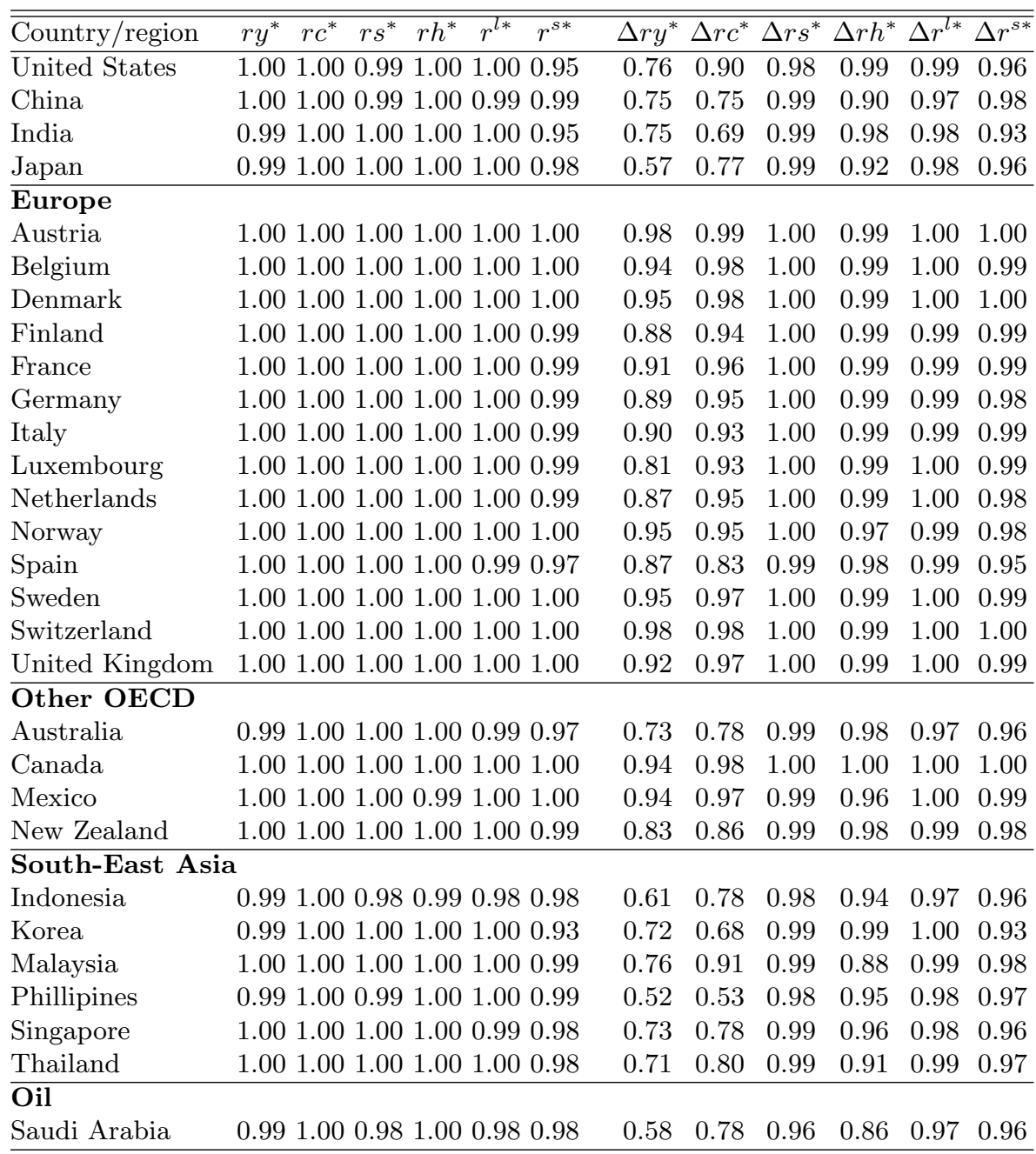

Note: The table reports the correlation coefficients of country-specific foreign variables using constant and time-varying trade weights.

trading partners and these changing patterns explain their lower correlation coefficients. However, correlations are still around 0.7, which is a very large number. Therefore, the fixed trade weights are representative of the full timeframe considered.

The number of cointegrating vectors changes slightly for a number of countries when employing time-varying weights. There are several countries 
for which the trace test selects one cointegrating vector less: Finland, Philippines, Saudi-Arabia, Sweden, Thailand and the United Kingdom. Others will get one more: Australia, Denmark, France, Singapore and the United States. Overall, this sensitivity is similar to Dees et al. (2007) for their GVAR model when they employ time-varying instead of fixed tradeweights. A full exposition of the results using time-varying trade-weights can be provided upon request.

\subsection{Conclusion}

In this chapter we empirically test the link between real stock and housing prices, consumption and the trade balance. Against the background of an established theoretical and empirical literature that links asset prices to consumption through the domestic wealth effect, we argue that the current surge of real and financial integration provokes an international perspective. Hence, we hypothesize that movements in real stock and housing prices not only transmit into a country's consumption decision, but further into the trade balance. We refer to this second link as the international wealth effect and test it using the recent GVAR methodology of PSW. The GVAR methodology is particularly suited for our study since it explicitly accounts for the complex interdependencies that exist across countries. It proceeds in two steps. First, we estimate individual VECMs for 29 countries over the period 1981Q1-2006Q4. Second, we combine these country individual models into a global VAR representation using information on bilateral trade patterns. The global VAR model allows conducting generalized impulse response studies and forecast error variance decompositions that provide evidence in favor of the existence of the domestic and international wealth effect in the US, UK and France. In these countries, exposing real stock prices to a one standard deviation negative shock results in a statistically significant contraction of real consumption and improvement of the trade balance. Moreover we observe that the trade balances of the same countries improve following a negative shock to real housing prices. Since the shock is not transmitted through consumption, hence the international wealth effect, we conjecture that business and private expenditures on investments are the likely transmission channels. We also test the domestic and international wealth effect for Germany and Japan, but do not find any statistically significant results. To determine the relative importance 
of real stock and housing prices for consumption and the trade balance, we also consider the real effective exchange rate in our studies and find compelling evidence that asset prices are at least as important drivers of international trade balances as real effective exchange rates. This finding is a crucial impetus in the recent debate on global current account imbalances. In this context, we also find that movements in the real effective exchange rate exert a considerable influence on US real consumption and the trade balance. This influence is not paralleled by any other country and points at the prominent role that the foreign sector plays for the US.

\subsection{Appendix: Data sources}

- Trade data for all countries are from the IMF Direction of Trade Statistics at the quarterly frequency and in US\$. The trade balance is constructed as the log of exports over imports and seasonally adjusted in EViews using the X12 method of the US Census Bureau.

- Nominal consumption, nominal output and inflation data are from the IMF International Financial Statistics at the quarterly frequency an in domestic currency. For China, India, Indonesia, Malaysia, New Zealand, Saudi Arabia and Thailand annual data are interpolated to a quarterly frequency in some cases. We interpolate the data by first taking logs and assuming a constant growth rate between two annual observations. Real consumption and real output are seasonally adjusted in EViews using the X12 method of the US Census Bureau.

- Real effective exchange rate data are taken from the IMF International Financial Statistics at the quarterly frequency.

- Stock price data are from Global Financial Data using a large domestic stock market index. Stock market index prices are denominated in local currencies and at the quarterly frequency.

- United States (S\&P 500 Composite Price Index), Japan (Nikkei 225 Stock Average) and India (Bombay SE Sensitive Index)

- European countries: Austria (Wiener Boersekammer Share Index), Belgium (Brussels All-Share Price Index), Denmark (OMX Copenhagen All-Share Price Index), Finland (OMX Helsinki 
All-Share Price Index), France (SBF-250 Index), Germany (CDAX Composite Index), Italy (Banca Commerciale Italiana Index), Luxembourg (LuXX Index), Netherlands (All-Share Price Index), Norway (Oslo SE All-Share Index), Spain (Madrid SE General Index), Sweden (Affarsvarlden General Index) and United Kingdom (FTSE All-Share Index)

- Other OECD: Australia (ASX All-Ordinaries), Canada (S\&P/TSX 300 Composite), Mexico (SE Indice de Precios y Cotizaciones) and New Zealand (SE Share Capital All Index)

- South-East Asia: Korea (SE Stock Price Index KOSPI), Malaysia (KLSE Composite), Philippines (Manila SE Composite Index), Singapore (FTSE All-Share Index) and Thailand (SET General Index)

- Housing price data are from the Bank of International Settlements at quarterly frequency.

- Both short term and long term interest rates are from the IMF International Financial Statistics at the quarterly frequency.

- The oil price is the price in US\$ of one barrel Brent crude and retrieved through Datastream. 


\section{5}

\section{Remittances ANd FinANCIAL OPENNESS}

\subsection{Introduction}

Official global remittances sent to developing countries have reached 300 billion US dollar in 2008 and have become a significant source of income for many of these developing countries. In fact, for quite a few countries remittance receipts exceed $20 \%$ of GDP (e.g. Guyana, Honduras, Jordan and several more). These remittances appear to be a stable source of income over time, compared to e.g. foreign direct investment, and their value quite often exceeds official development aid. The importance of remittances has been recognized by policy makers, global institutions, such as the World Bank, and academics alike. ${ }^{1}$

A growing academic literature has been devoted to analyze the microeconomic and macroeconomic effects of remittances in developing countries (see Schiff and Ozden, 2006, 2007, for a synthesis). The effects of remittances on receiving countries seem indeed numerous. At a microeconomic level, remittances have been found to boost investment in human capital and educational attainments, thereby reducing poverty in many developing countries. Furthermore, there is significant evidence that remittances increase not only consumption but tend to also raise health levels and investment in public infrastructure. At a macroeconomic level, the existence of a positive relationship between remittances and growth is more controversial. While remittances tend to favor the accumulation of important production factors such as physical capital and education,

\footnotetext{
${ }^{1}$ In particular, given the importance of the remittances for a large set of countries, the World Bank devoted substantial efforts to monitor, understand and forecast remittance flows. See website link www.go.worldnak.org/ssw3DDNL.
} 
they exert detrimental effects in terms of labor market incentives. They also create 'Dutch disease' effects through the appreciation of domestic currencies, leading to further deindustrialization in the receiving country. Nevertheless, the recent literature shows that appropriately used migrant remittances, combined with sound government policies, have a positive net effect on economic growth.

The growing importance of remittances and their positive impact on the economic conditions in receiving countries create for their governments strong incentives to facilitate the attraction of those flows. In some countries such as Mexico and the Philippines, explicit programs have been set up to increase the flows of the received remittances. Among the possible schemes aimed at boosting these receipts, the opening of financial borders is a possible policy instrument of governments. By decreasing the cost of the remittances sent through the official way or by relaxing the restriction of financial flows coming from abroad, governments can significantly boost the total amount of the received funds. Financial openness creates, however, new costs and risks for the receiving countries. One of the most important costs is the increased exposure to financial crises and to macroeconomic instability. Therefore, the final decision to open the financial borders is likely to result from a trade-off between the various benefits drawn from the attracted remittances and the increased macroeconomic risk. In turn, those benefits will depend on the initial size of the incoming remittances, which depend on a set of factors unrelated to financial openness. Those factors include among others the size of the existing diaspora and their location.

In this paper, we proceed to a political economy investigation of the choice of the degree of financial openness by government with respect to their situation in terms of incoming remittances. We first develop a small model that expresses the trade off faced by government in their decision to open the financial borders. We show that the optimal degree of openness depends on the initial size of the incoming remittances which in turn depends on factors that are exogenous for the government, such as the size the total diaspora, its location or the economic conditions of the destination countries. Then, we investigate empirically that link for a sample of 66 mostly developing countries from 1980-2005. Financial openness is classified according to three regimes (closed, neutral or open) based on the KAOPEN financial openness indicator of Chinn and Itô (2008). In addition to remittances we account for institutional quality, 
trade openness and domestic financial development.

Empirically we use a dynamic generalized ordered logit model to establish the link between remittances and financial openness. This framework is attractive because it is well suited to deal with the ordinal nature of the financial openness indicator. Moreover, it is possible to take unobserved heterogeneity into account. In addition, we apply a two-step method akin to two stage least squares to deal with the endogeneity of remittance receipts and potential measurement errors.

To preview our results, we find a strong positive effect of remittances on financial openness. The more remittances a country receives, the more likely it will be financially open. The positive effect of remittances on financial openness is robust to instrumentation of remittances, both in a balanced and unbalanced sample.

A counterfactual analysis shows that remittances have an important effect on country's financial openness policy. Results indicate that large remittance receiving countries have a much larger probability of being financially closed when they do not receive remittances anymore.

The paper is organized as follows. We first review the existing related literature and provide some stylized facts(Section 5.2). In Section 5.3 we introduce a theoretical model that captures the trade-off between the benefits and the costs of opening the financial borders and hence the determinants of the government's decision. The empirical model and results are discussed in Section 5.4. In Section 5.5 we study two counterfactual scenarios to assess the economic importance of remittance receipts for individual countries. Section 5.6 concludes.

\subsection{Motivation, existing related literature and stylized facts}

In this section, we cover the related literature. Our paper provides a political economy analysis of the choice of financial openness based on the incentive to attract remittances from abroad. It is thus related to the literature on the effects of remittances and the one dealing with financial integration. We also provide specific examples of governmental schemes. Finally, we provide preliminary evidence in favour of a link between the cost to remit and the degree of financial openness of the receiving country. 


\subsubsection{Related literature on the effects of remittances}

The exiting literature on the impact of remittances suggests that remittances exert important effects on the economic situation of the receiving countries.

The academic debate has focused on both micro- and macroeconomic effects of remittances. First, a number of micro studies investigate the poverty reduction effect of remittances. Country studies show that remittances play an important role in reducing poverty in e.g. Lesotho (Gustafsson and Makonnen, 1993), Guatemala (Adams, 2006) and Mexico (Acosta et al., 2006). A second strand investigates how remittance recipients spend their receipts. In general, households either consume or invest their receipts, where investment (especially in human capital) can potentially accelerate future economic growth. Recent studies (e.g. Dustmann and Kirchkamp, 2002; Cox-Edwards and Ureta, 2003; Adams, 2006) show that a sizable fraction of remittances are invested in education, health care and physical assets. Indeed, beyond the direct effect that remittances exert on spending, the fact that households receive money from abroad can be seen as a strong increase in collateral that in turn might increase investment. Remittances alleviate liquidity constraints that can act as important constrains on investment in education in a set of developing countries. In countries with a minimal level of banking development, the permanent inflow of remittances can act as a collateral for borrowing by the households. In turn, this might favour investment in human capital, small businesses or infrastructure. Finally, since remittances give rise to some increase in aggregate consumption, this leads to increase in public revenues in countries that tax consumption.

In response, macroeconomic studies started to focus on the effects of remittances on economic growth. While there is ample evidence that remittances reduce poverty (Adams and Page, 2005) and boost aggregate demand, the effects on growth are not clear cut. One reason is that remittances might alter the behaviour of receiving households (the so-called moral hazard effects) or induce price developments that are detrimental for the development of the country. One of these effect is the so-called Dutch Disease effect through which the flow of remittances induces a real exchange rate appreciation that affects negatively the activity of the tradable manufacturing sector (Acosta et al., 2009).

However, recent studies find that remittances have a positive impact 
on economic growth. Giuliano and Ruiz-Arranz (2009) show that in the economies where the financial system is underdeveloped, remittances alleviate credit constraints and work as a substitute for financial development, improving the allocation of capital and therefore accelerating economic growth. On the other hand, Mundaca (2009) shows that financial development potentially leads to better use of remittances, thus fostering growth. Recent research conducted by Aggarwal et al. (2006) also shows that remittances may directly promote financial development. In particular, they find that remittances have a significant and positive impact on bank deposits to GDP. Overall, the literature finds that net effect on growth seems to be positive, without even considering the positive impact remittances can have on the income distribution.

\subsubsection{Government policies}

The favourable effects of remittances on the economic situation of receiving countries have induced some governments to implement specific programs to promote remittance receipts.

The Philippines provides a clear-cut example, where the government explicitly promotes emigration to receive remittances. In 1982, the Philippine Overseas Employment Administration (POEA) has been created by Executive Order No. 797. Article I of this order clearly mentions the main objectives:

- "3. Recruitment and place workers to service the requirements of overseas employers for trained and competent Filipino workers;"

- "4. Promote the development of skills and careful selection of Filipino workers for overseas employment;"

- “\%. Generate Foreign exchange from the earnings of Filipinos employed under its programs;"

These objectives clearly show that the Philippine government's aim is to maximize remittance receipts. Moreover, articles VII and IX state the objectives even clearer:

- "k. Formulate and implement programs for the effective monitoring of foreign exchange remittances of overseas contract workers." (Art. VII, Sec. 31) 
- "4. Maximize foreign exchange generation from Filipino workers and seamen;" (Art. IX, Sec. 37)

The Mexican program Citizen Initiative 3x1 (Iniciativa Ciudadana 3x1 in Spanish) is another example of a government initiated scheme to promote remittance receipts from migrants. In the United States Mexican migrants run over 2000 so called Hometown Associations (HTAs), which support their local communities in Mexico. Under Citizen Initiative 3x1 remittances from Mexican HTAs are matched with local, state and federal governments' funds to finance mostly basic infrastructure in rural areas. By investing in basic infrastructure, such as building roads, bridges and irrigation systems, necessary conditions are created for economic growth. In effect, remittances are generous and in some municipalities the funds received by Citizen Initiative $3 x 1$ are larger than the municipality's total budget (Orozco and Lapointe, 2004).

By matching migrant's remittances the Mexican government is able to channel remittance receipts to productive use, which benefits the country's long term growth. In addition, the development of rural areas reduces the problems induced by urbanization, e.g. lack of proper housing for Mexico City's expanding population. The success of the program is enormous and the only problem the government faces is that

"[t]he amounts committed to the program by HTAs has increased so rapidly in recent years that, at times, the government does not have the budget to match the funds" (Maimbo and Ratha, 2005, p. 123).

While some specific microeconomic programs such as those presented above might be desirable, there are complementary macroeconomic reforms that can be implemented on a larger scale. ${ }^{2}$ One example is the choice of the exchange rate regime. Freund and Spatafora (2008) find that the existence of multiple exchange rates significantly reduces the amount of recorded remittances. Singer (2009) shows that the size of incoming remittances increase the likelihood that policymakers of developing countries will adopt fixed exchange rates. Our paper considers an alternative policy option , i.e. the openness of the financial borders. Financial liberalization turns out to be a more global option encompassing the choice of the exchange rate regime. ${ }^{3}$

\footnotetext{
${ }^{2}$ For several other examples of government programs to promote remittance receipts see e.g. Maimbo and Ratha (2005).

${ }^{3}$ Our indicator of financial openness includes the existence of multiple exchange rates for instance.
} 
Financial liberalization exerts two specific effects on the flows of remittances. First, financial liberalization facilitates foreign financial transactions. In case of financial autarky, it is almost impossible for some migrants to send remittances through the formal way. While informal ways can always be relied on and are not always more expensive at first glance, these involve much more risk. Furthermore, the informal channel is often used for illegal purposes, with the danger of being considered as a criminal. ${ }^{4}$ For some pairs of countries that are quite distant, physical transportation of money might be not only dangerous but also may involve higher costs. Second, more financial openness will also lower (formal) remittances' transaction costs and will provide incentives to send remittances trough the formal market. Financial borders are often associated to controls and constraints on international financial flows such as foreign direct investments, portfolio investments and remittances sent through the banking system. This leads to an increase in the cost and to lower transfers compared to a liberalized regime.

\subsubsection{Stylized facts}

To illustrate the impact of financial openness on the cost of sending remittances, Table 5.1 provides the results of a gravity regression relating the (bilateral) cost of sending remittances from country $i$ to country $j$ and the degree of financial openness in country $j$. The cost of sending remittances denoted by $c_{i j}$ is drawn from the new dataset built by the World Bank on the remittance costs across 134 country corridors, involving 14 sending countries and 72 potential receiving countries. The data come from a survey conducted by the World Bank and are available only for 2008 and $2009 .^{5}$

The World bank data include two components of the cost of remitting, i.e. the exchange rate margin associated to currency conversion and the fixed fee associated to the international transfer. The data reveals that the total cost of remitting can be substantial. Total costs of more than 15 percent are not unusual. Furthermore, those costs are observed for the most popular transfer corridors. They might be expected to be even more

\footnotetext{
${ }^{4}$ See for instance http://www.interpol.int/Public/FinancialCrime/MoneyLaundering /Hawala/default.asp about the Hawala system, one of the most popular informal channels for remittances, and money laundering.

${ }^{5}$ The full data and the related explanations are available at www.remittanceprices.org.
} 
important for remitting between less popular country pairs. We report here the regression results obtained with the cost of sending 500 USD but we get quite the same qualitative conclusions with the other measure based on the cost of sending 200 USD.

In line with Beck and Peria (2009), we account for factors that are bilateral to $i$ and $j$, origin specific and destination specific. Since our purpose is to focus on the impact on destination specific factors such as financial openness and since our dataset is only cross-sectional, we capture the origin specific factors by fixed effects, denoted by $\alpha_{i}$. Included bilateral factors are the log of distance between the two countries, the log of the stock of migrants from country $j$ living in country $i$, the existence of colonial links and a common official language. For convenience in exposition, these factors are collected in the matrix $x_{i j, k}$ in Equation (5.1). The destination specific factors include some index of bank concentration (Herfindahl index) to capture the impact of bank competition (denoted by $b a n k_{j}$ ) and our index of financial integration (denoted by kaopen $_{j}$ ). The index of financial integration we use in this paper is the KAOPEN index developed by Chinn and Itô (2008). We provide more information on this indicator in Section 5.4.1. The higher the index, the more financially open a country is.

The estimated equation is:

$$
c_{i j}=\alpha_{i}+\beta_{1} \text { kaopen }_{j}+\beta_{2} \text { bank }_{j}+\sum_{k} \gamma_{k} x_{i j, k}+\epsilon_{i j}
$$

The results in Table 5.1 shed light on the relationship between financial openness and the cost of sending remittances through the official channel. In both specifications reported in Table 5.1, $\beta_{1}$ is found to be negative and significant at the 5 percent level. The results show that the higher the openness of the receiving countries, the lower the cost to send remittances to that country, everything equal elsewhere. The results suggest that one reason to open the financial borders for governments of remittances receiving countries is to lower the transaction costs. In turn, this should increase the total amount sent by the migrants, especially since the cost is supported by them.

The World Bank dataset also reveals an important feature concerning the operating country corridors. The dataset covers 14 sending countries and 72 receiving countries. Nevertheless, prices were obtained by the surveyors of the WB only for 134 country corridors. This means that the 
Table 5.1: Cost of remitting $\$ 500$

\begin{tabular}{lcc}
\hline \hline variable & $(1)$ & $(2)$ \\
\hline kaopen & $-0.256^{* *}$ & $-0.270^{* *}$ \\
& $(0.126)$ & $(0.125)$ \\
bank concentration host & $4.347^{* * *}$ & $3.991^{* * *}$ \\
& $(0.919)$ & $(0.842)$ \\
log(number of migrants) & -0.246 & $-0.277^{* *}$ \\
& $(0.158)$ & $(0.124)$ \\
common language & -0.385 & \\
& $(0.481)$ & \\
distance & 0.000 & \\
& $(0.000)$ & \\
colony & 0.153 & \\
& $(0.564)$ & \\
\hline Observations & 89 \\
$R^{2}$ & 0.956 & 0.955 \\
\hline \hline Note: Estimation of Equation $\quad(5.1)$ using \\
OLS, with robust standard errors. $*, * * * * *$ \\
imply significance at the $10 \%, 5 \%$ and $1 \%$, \\
respectively.
\end{tabular}

dataset contains 87 percent of missing observations. Of course, the reasons of those missing observations might be numerous. Part of the missing data might be due to the fact that it is possible to send remittances but that the cost was unknown by the service providers at the time of the survey. In turn, the prices might be unknown because there is little demand for that particular corridor. Importantly, some missing data might also reflect that some or all service providers do not offer that service for this particular country corridor. Whatever the various reasons, the important proportion of missing data for the costs of sending remittances suggests that in many case, sending remittances through the formal channel might be cumbersome for the migrants. Part of the impossibility of sending remittances to a particular country might be due to the fact that the country is not fully opened to international financial flows.

\subsubsection{Financial openness as an option}

A related literature in international finance investigates the relationship between capital account/financial openness, financial development and 
economic growth. ${ }^{6}$ A large number of studies find a positive effect of financial openness on economic growth (e.g. Quinn, 1997; Bekaert et al., 2005; Quinn and Toyoda, 2008). However, this positive view is challenged by others (e.g. Edison et al., 2002). Klein and Olivei (2008) argue that the lack of a positive growth effect of financial openness in developing countries is due to a missing effect of financial openness on financial development for these countries. However, Chinn and Itô (2006) do find a positive effect of financial openness on domestic financial development if the institutional quality in the country is of a sufficiently high level.

The importance of threshold levels of institutional quality and macroeconomic policies has been advocated further by Kose et al. (2009). Due to the positive effects of remittances on macroeconomic stability and financial development, it is attractive for remittance receiving countries to liberalize their capital account and increase their financial openness to accelerate economic growth. Hence, remittances can have an important direct effect on a developing countries' financial openness and therefore an indirect impact on growth. However, financial openness does not only have positive effects, but also creates costs for governments. First, from the Mundell-Fleming model we know that the government needs to give up either exchange rate stability or monetary policy when allowing the free movement of capital. If the government aims to control all three factors, countries risk being hit by speculative attacks, where the only option left is to devaluate the currency. The Argentine experience during the early 2000 s is an illustrative example. In order to curtail inflation in the early 1990s Argentina pegged its currency to the US\$. Due to large public deficits (financed in part by the Central Bank) and a revaluation of the US\$ vs. the Brazilian real and the euro made Argentina's export sector uncompetitive. Hence, both imports and foreign debt increased. This resulted in a severe economic crisis and in 2002 the peg with the US\$ was abandoned.

Second, financial openness induces potential contagion effects, where healthy countries can become affected due to ill neighbors. Kaminsky and Reinhart (2000) show the important role of the financial sector and how the actions of financial market participants can lead to instability, facilitated by financial openness. This contagion risk was especially prevailing during

\footnotetext{
${ }^{6}$ Remittances are recorded in both the current and capital account of the balance of payments. Hence, when we refer to capital account/financial openness this ought to be interpreted not strictly as capital account transactions. Therefore, we use the more general term financial openness to assess the ease of sending and receiving remittances.
} 
the 1997 Asian financial crisis, where countries such as Korea had sound macroeconomic policies, but entered in economic hardship due to capital flight induced by herd behavior. In addition, financial openness increases the comovement of stock markets, especially in times of crisis (Beine et al., 2010). Hence, countries will become more integrated in the world economy and be less able to steer their own economy. The potential positive and negative effects of financial openness need to be weighted by governments in their choice regarding the degree of financial openness. More specifically for developing countries, they need to weight the positive effects of remittances to the potential risks of increased macroeconomic volatility.

\subsection{The Model}

This section formalizes the trade off a remittance receiving country's government faces: the positive economic effects of remittance receipts vs. potentially increasing macroeconomic instability. To keep the model tractable and intuitive, we consider a simple static model with 3 decision agents: one migrant remitter $(\mathrm{m})$, one recipient household (f), which can consist of one or more individuals, and the government of the receiving household's country whose objective it is to maximize revenues. ${ }^{7}$

\subsubsection{The household}

The representative household's utility is a function of family consumption, $z^{f}$. Family consumption depends on the family income generated in the source country, $I^{f}$, that without loss of generality can be set equal to 0 , and remittances, $R$, sent by the representative migrant remitter. Therefore the income of the family depends on remittances sent from abroad.

Even if the literature shows that remittances can be either consumed or invested in the form of land, housing acquisition, health, education, and microenterprises (for example Dustmann and Kirchkamp, 2002; Woodruff and Zenteno, 2001), for simplicity, we assume that the household consumes all the income.

\footnotetext{
${ }^{7}$ In this section we want to introduce a very simple and intuitive model to provide insights in the underlying mechanisms of the government's financial openness policy. We decide to use a static model for illustrative purposes since a dynamic model will be much more complex, being beyond the scope of this section. The empirical model we are going to test includes dynamics.
} 
More formally, considering a standard functional form for the utility function $U^{f}$, the representative household maximizes:

$$
U^{f}=\ln \left(z^{f}\right)
$$

subject to their budget constraint:

$$
z^{f}\left(1+t^{c}\right)=I^{f}+R
$$

The price of consumption is normalized to 1 . Remittances are not directly taxed by the government, but indirectly taxed through an ad valorem consumption tax. The assumption that remittances are not directly taxed is in line with the general practice of avoiding taxing these flows by governments in the recipient countries (see for example World Bank, 2006).

\subsubsection{The migrant}

The representative migrant's utility $U^{m}$ depends on his own consumption, $z^{m}$, and on the utility of the recipient household, whose importance in the migrants' utility function is represented by the altruistic parameter $\gamma \in(0,1){ }^{8}$

$$
U^{m}=\ln \left(z^{m}\right)+\gamma \ln \left(z^{f}\right) .
$$

In order to determine the optimal level of remittances, the migrant maximizes his utility function subject to his budget constraint, given by:

$$
z^{m}=I^{m}-R(1+\rho),
$$

where $z^{m}$ denotes consumption of the migrant, $I^{m}$ and $R$ denote

\footnotetext{
${ }^{8}$ For ease of exposition we consider only altruism as the migrant's motivation to remit, and we follow a similar way of modeling as in Rapoport and Docquier (2006) (See e.g. Rapoport and Docquier (2006) and Carling (2008) for alternative motives). Here, it is only important that the migrant is willing to remit part of his income, irrespective of the exact motives.
} 
respectively the income of the migrant and the amount of remittances. The price of consumption, as before, is normalized to 1, therefore, prices are assumed to be the same across the host and origin country. However, this assumption does not change any of the substantive implications of the model. The cost of sending remittances depends on the parameter $\rho$, a kind of iceberg cost, which reflects the degree of financial openness of the migrant origin country. The more open the country is, the less costly is to send remittances home and vice versa. Costs can be interpreted in a broader sense, i.e. in terms of easiness of the transactions. ${ }^{9}$

Ruling out the possibility of negative transfers from the migrant to the household, the maximization problem of the migrant can be written as:

$$
\begin{aligned}
\max _{R} U^{m} & =\ln \left(I^{m}-R(1+\rho)\right)+\gamma \ln \left(\left(I^{f}+R\right) /(1+t)\right) \\
& =\ln \left(I^{m}-R(1+\rho)\right)+\gamma \ln \left(I^{f}+R\right)-\gamma \ln (1+t) .
\end{aligned}
$$

The first order condition is given by:

$$
\partial U^{m} / \partial R=-\frac{1+\rho}{I^{m}-R(1+\rho)}+\frac{\gamma}{I^{f}+R}=0,
$$

and the optimal amount of remittances is

$$
R^{*}=\frac{\gamma I^{m}}{(1+\rho)(1+\gamma)}-\frac{I^{f}}{1+\gamma}
$$

Doing some comparative-statics, it is easy to see that the model predicts that transfers to the origin household increase with the income of the migrant, $\frac{\partial R}{\partial I^{m}}>0$, and with the altruistic parameter, $\frac{\partial R}{\partial \gamma}>0$, and decrease with the wealth of the origin family, $\frac{\partial R}{\partial I^{f}}<0$. Moreover, transfers are decreasing in $\rho, \frac{\partial R}{\partial \rho}<0$, predicting that the more the home country is financially closed, the less migrants are going to remit.

\footnotetext{
${ }^{9}$ The cost can be interpreted also as the "risks in sending remittances". It is plausible to think that a more open financial system provides incentives to use the formal system in sending remittances, therefore lowering the risks faced when sending money through the informal channel. A lower risk will induce more remittances. Here, we do not distinguish between formal and informal remittances, as only the formal ones are observed.
} 


\subsubsection{The government}

The government chooses the degree of financial openness in order to maximize its revenues, which it derives from taxing consumption. Since remittances are fully spend on consumption, the government tries to maximize remittances receipts. Hence, the government has a strong incentive to open its financial borders to attract remittances. On the other hand, controls are beneficial, because they insulate domestic markets from external shocks. Ceteris paribus, the more open a country is, the higher is capital flow volatility, the probability of external shocks and economic crises. ${ }^{10}$ Naturally, the risk of incurring a financial crisis depends on several country characteristics, e.g. institutional quality.

We introduce a simple cost function to capture the risk-cost of the government. The government incurs a country-specific cost $\xi$, which it will pay with probability $\pi \in[0,1]$. We assume that the probability is decreasing in $\rho$, and it is equal to 0 when $\rho \rightarrow+\infty$ (fully closed) and equal to 1 when $\rho=0$ (fully open).

More formally, the government maximization problem is given by

$$
\begin{aligned}
\max _{\rho} V_{g} & =z^{f} t-\pi \xi \\
& =\frac{t}{(1+t)}\left(I^{f}+R\right)-\pi \xi,
\end{aligned}
$$

The first order condition is

$$
\partial V / \partial \rho=\frac{t}{(1+t)} \frac{\partial R}{\partial \rho}-\xi \frac{\partial \pi}{\partial \rho}=0 .
$$

From Equation (5.8) it is easy to see that $\frac{\partial R}{\partial \rho}<0$, predicting that the more financially closed the home country is, the less migrants are going to remit. At the same time $\frac{\partial \pi}{\partial \rho}$ is negative, meaning that the more the home country is financially closed, the lower the probability to pay a cost $\xi$. In order to determine the optimum level of $\rho$, the government faces the tradeoff between the expected earnings that it will derive from the (indirect)

\footnotetext{
${ }^{10}$ Alesina et al. (1994) list four main motives for capital controls: (i) limit volatile capital flows; (ii) maintain the domestic tax base; (iii) retain domestic savings; and (iv) sustain structural reform. Even if Alesina et al. (1994) identify the governments' attempt to collect revenue from financial repression as the main motive for controls, there are a lot of examples where financial crises were mainly due to capital flights (for example the Asian crisis in 1997).
} 
taxation of remittances and the expected cost of opening, cost depending on country characteristics.

For given $t$, then the optimum $\rho$ will depend negatively on $R$ and positively on $\xi, \rho^{*}=\rho(R, \xi)$. In case of interior solution, the government may choose a $\rho^{*}$ which reflects intermediate or limited openness.

More explicitly, for analytical tractability, let's take the particular case for the crisis probability $\pi=\frac{1}{(1+\rho)^{2}}$. After some calculations, the optimum level of $\rho$ is given by:

$$
\rho^{*}=\operatorname{Max}\left(2 \xi \frac{1+\gamma}{\gamma} \frac{1}{I^{m}} \frac{1+t}{t}-1,0\right)
$$

Doing some comparative statics, it is easy to see that the optimum level of $\rho$ depends negatively on $I^{m}, \gamma, t$, and positively on $\xi$. This shows that the higher the cost of opening $\xi$, the higher $\rho$ (lower financial openness), and the higher the income of the migrant and its degree of altruism, the lower $\rho$ (higher financial openness). This last observation implies that the optimal level of financial openness depends positively on remittances, because remittances in their turn are positively related to $I^{m}$, and $\gamma$, and therefore related to factors which include migrants' destination country characteristics. Given $\rho^{*}$, it is possible to calculate the optimal level of remittances, $R^{*}=\frac{1}{2 \xi}\left(\frac{1+\gamma}{\gamma}\right)^{2}\left(I^{m}\right)^{2} \frac{t}{1+t}-\frac{I^{f}}{1+\gamma}$, showing that the optimal level of remittances depends negatively, among other things, on the cost of opening $\left(\frac{\partial R^{*}}{\partial \xi}<0\right)$. Therefore, the higher the cost of opening, the lower the degree of financial openness and the lower the optimal amount of remittances.

All these results provide us with a testable prediction: for given characteristics of the country, the higher the level of remittances, the more financially open the country will be. In testing for this relationship, a case for intermediate or limited openness should be accounted for. Moreover, it is important to control for reverse causality, as the migrant's decision to remit will depend on the degree of financial openness, as suggested by equation 5.8 . 


\subsection{Empirical Analysis}

\subsubsection{Data}

\section{Measuring Financial Openness Policy}

We use the KAOPEN measure, constructed by Chinn and Itô (2008), to capture the degree of barriers to remitting money for migrants. The major advantage of this indicator is that it includes a large set of factors affecting the possibility and the cost of remitting. KAOPEN is based on the IMF's Annual Report on Exchange Arrangements and Exchange Restrictions (AREAER). The AREAER reports tables, which summarize for each country the restrictions on foreign transactions that are in place. For each type of restrictions, there is either a one if restrictions are present or zero if no restrictions are in place. However, to calculate KAOPEN these zeros and ones are reversed to construct a measure of openness, where one implies open and zero closed.

The following four categories are considered in KAOPEN: i) The presence of multiple exchange rates $\left(K_{i t}^{1}\right)$, ii) Restrictions on current account transactions $\left(K_{i t}^{2}\right)$, iii) Restrictions on capital account transactions $\left(K_{i t}^{3}\right)$ and iv) Requirement of surrender of export proceeds $\left(K_{i t}^{4}\right)$. To calculate the third category a five year window is used: share $K_{i t}^{3}=$ $\left(K_{i t}^{3}+K_{i, t-1}^{3}+K_{i, t-2}^{3}+K_{i, t-3}^{3}+K_{i, t-4}^{3}\right) / 5$ and KAOPEN is calculated as the first principal component of $K_{t}^{1}, K_{t}^{2}$, share $K_{t}^{3}$ and $K_{t}^{4}$.

KAOPEN's broadness is an important advantage compared to considering only a single indicator. In general, the correlation between the various components and the KAOPEN is quite high: 0.384 for $K^{1}, 0.788$ for $K^{2}, 0.83$ for $K^{3}$ and 0.88 for $K^{4}$ (Chinn and Itô, 2008). For remittances, the restrictions on current and capital account transactions are the most important categories. We will discuss in more detail how each category in KAOPEN matters for the remitting migrant.

Migrant remittances are defined as the sum of workers' remittances, compensation of employees, and migrants' transfers. The first two categories are recorded in the current account and the third in the capital account. The distinction on current and capital account depends to a large degree on the number of years the migrant lives in the sending country. However, the World Bank states: "Although the residence guideline in the manual is clear, this rule is often not followed for various reasons" (World Bank Data Factsheet). Countries do not all consistently record 
a certain type of transfer in the specific balance of payments account. For example, in Brazil about $20 \%$ of total remittances are recorded in the capital account. Other countries simply pool all three categories in a single account, usually the current account. Therefore there is a lot of arbitrariness. Hence, it is important to consider both restrictions on current and capital transfers to accurately capture the barriers to remit. The high correlation between KAOPEN and both these subcomponents is very important, because restrictions on these transaction channels affect remitters strongest.

Some clear examples of restrictions are the requirement to repatriate all foreign currency proceeds for residents in Morocco and Tunisia. This will discourage migrants to remit when the exchange rate is not very attractive. Furthermore, return migration is discouraged. The 2000 edition of the IMF's AREAER states for Tunisia: "Nonresident Tunisian nationals returning to definitively to the country must declare and repatriate their assets or proceeds and revenue from their holdings abroad." Some countries, e.g. the Philippines allow for foreign currency deposits. However, the 1985 AREAER states: "Philippine nationals working abroad are required to repatriate minimum shares of their foreign earnings, ranging from 50 percent to 80 percent". These conditions have been relaxed during the past decades, but are important during the time frame we study.

Other examples include Vietnam, which mandates migrants to invest 30 percent of their remittances in a government fund. Some countries, such as Colombia and Ecuador tax remittances, whereas others, e.g. Brazil, mandate that all foreign exchange go through the central bank (Agunias, 2006). However, during the eighties and nineties more countries imposed restrictions, but many of these were abandoned once the governments realized the positive effects of remittances. The AREAER indicates that quite a few countries require the surrender of export proceeds. This requirement is also closely related to the mandatory conversion of foreign currencies into domestic currency. While not affecting directly migrants, the requirement of surrender of export proceeds might be considered as reflecting some uncertainty regarding the extortion of remittances. Hence, including this factor in KAOPEN helps to obtain a more complete picture of the total financial openness policy of a country.

The existence of multiple exchange rates creates extra costs for migrants remitting. In fact, Freund and Spatafora (2008) show that the existence of multiple exchange rates significantly reduces the amount of recorded 
remittances. In addition, the World Bank data on the cost of remitting shows that there are sizeable exchange rate margins (extra costs above interbank rate) for several countries when remitting internationally. For example, when transferring from the U.S. to Brazil the average exchange rate margin is around 3\%, from the U.K. to Kenya 5\%, from France to Morocco 2\%, Canada to India 5\%, etcetera. There is quite some competition in these remittance corridors, so costs will be even higher for less popular country pairs. Those exchange rate margins are of course added to the fixed fee associated to the transfer.

Dual exchange rates are still in place for a large number of countries (Reinhart and Rogoff, 2004). As remitters are most likely low priority, they will not receive the most favorable exchange rate, which makes remitting less attractive. However, countries receiving large amounts of remittances are more likely to opt for a fixed exchange rate regime (Singer, 2009). Naturally, fixed exchange rates reduce the costs of remitting. Hence, we expect large remittance receiving countries to have a very low probability of a double exchange rate regime.

Quite often a dual exchange rate regime is in place after a balance of payments crisis. For example, India opted for a dual exchange rate regime in 1992 right after the balance of payments crisis of 1991. Basically, there was an official rate for selected government and private transactions and a market determined rate for all other transactions. Naturally, this market rate was worse than the official rate.

To sum up, the KAOPEN index is a broad indicator of financial openness, which captures a set of various relevant factors affecting the cost of remitting. It is therefore more representative of the overall policy of a country regarding its degree of financial openness. As we are interested in government policy measures, de facto indicators of financial openness policy based on parity conditions or cross border asset holdings are of limited use to address this paper's research question.

Due to its straightforward and transparent construction KAOPEN is available for virtually all countries in the world. The indicator is easily constructed and therefore annually updated. ${ }^{11}$ This large coverage is necessary to analyze the large number of countries in this study. In this paper a subset of 66 countries is considered. This restricted set of 66

\footnotetext{
${ }^{11}$ The data and a detailed description on its construction are available at http://www.ssc.wisc.edu/ mchinn/research.html. Recently, an updated version of the database up to 2007 has been released.
} 
countries is due to the exclusion of OECD countries and the requirement of full data availability for KAOPEN and remittances data from 1980 until 2005. Alternative financial openness policy indicators by Quinn (1997) and Miniane (2004) do not cover a large enough country span and do not fully cover the timeframe we consider. ${ }^{12}$ For the common country/timeframe KAOPEN shows a strong correlation with the other two indicators.

Figure 5.1 shows a quantile graph of the KAOPEN database pooling all 66 countries across all years. The values of KAOPEN range between about -1.9 and 2.6. Note that these values are not of a cardinal nature, i.e. -1 is not twice as closed as -0.5. The higher KAOPEN the more financially open a country is.

Figure 5.1: Quantile graph of KAOPEN 1980-2005

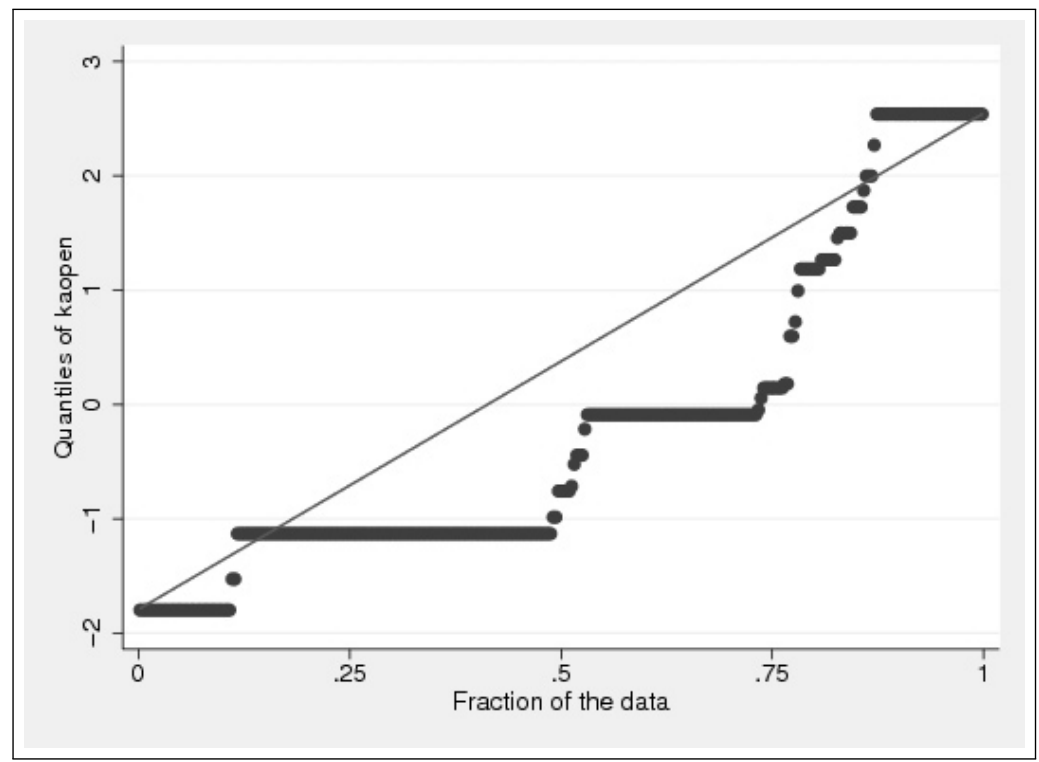

As many countries have become financially open during 1980-2005, the overall mean of KAOPEN increases over time. The largest increases took place during the 1990s when many developing countries chose to open their capital account. Another characteristic of this variable is its strong persistence over time.

A closer inspection of Figure 5.1 reveals that many observations have exactly the same value. There appear to be several "levels" of financial

\footnotetext{
${ }^{12}$ For a detailed comparison of different indicators we refer to Edison et al. (2004) and Miniane (2004).
} 
openness, with only few observations in between these levels. These levels can be associated with the number of restrictions in the subcategories of KAOPEN. The lowest level (-1.91) implies that all four subcomponents of KAOPEN are closed, the second lowest $(-1.13)$ represent that three out of four channels are closed, etcetera. The top level (2.54) represents those countries with all four categories open.

The categorical nature of KAOPEN casts doubt on the appropriateness of treating it as a continuous variable in regression models. Therefore, this characteristic will be important for our choice of estimation method. We will elaborate on this issue in Section 5.4.2 below.

\section{Control Variables}

Remittances. Data on remittances are taken from the World Bank and they are based on the IMF's Balance of Payments Statistics Yearbook (2008). With some exceptions, these data are constructed as the sum of three items in the Balance of Payment Statistics Yearbook: workers' remittances (part of the current transfers in the current account), compensation of employees (part of the income component of the current account), and migrant transfers (part of the capital account). More specifically, workers' remittances include current transfers made by migrants who are employed and resident in another economy, typically include transfers of workers who move to another country and stay for one year or longer; compensation of employees consists of wages, salaries and other benefits earned by nonresident workers for work performed for resident of other countries, typically include earnings from border and seasonal workers. Finally, migrant transfers comprises financial items that arise from the migration or change of residence of individuals from one economy to another.

Data from the IMF/World Bank are recognized as the best available data on remittances. Unfortunately, this data does not take into account remittances sent through informal channels (for example, money transfer that do not involve any formal contracts). Freund and Spatafora (2008) provide a table summarizing the results of earlier studies on the estimated fraction of unofficial remittances compared to official inflows in several countries. This table shows that are quite a few differences between countries and that the share of unofficial remittances may be quite high in some cases. For example, the share of informal remittances is quite 
low in Guatemala and the Dominican Republic, $5 \%$ and $15 \%$ respectively. However, in other countries the majority of remittances received may be unofficial, e.g. Bangladesh $54 \%$ and Uganda $80 \% .{ }^{13}$

Other data. In order to explain the determinants of financial openness, data drawn from a several number of sources are considered.

Financial development measures. Measures of financial development are extracted from the data set of Beck et al. (2000). In particular we consider the ratio of bank credit over bank deposit and a measure of liquid liabilities over GDP.

Institutional quality measures. In order to consider the importance of institutional quality on the degree of financial openness, we use the composite Polity2 index from the Polity IV data set, which is the difference between the Polity's democracy and autocracy indices. It ranges from -10 (strongly autocratic countries) to +10 (strongly democratic countries). Polity IV contains annual information on regime and authority characteristics for all independent countries. Legal origin dummies, taken from La Porta et al. (1999) are also considered.

Trade Openness. It is often claimed that trade openness is a precondition for financial openness (e.g. Chinn and Itô, 2002; Tornell et al., 2004). To test this hypothesis a variable capturing trade openness is included. In particular, we include the updated version of Sachs and Warner's trade policy openness indicator of Wacziarg and Welch (2008).

Macro-economic control variables. To control for the level of development of the economy, per capita GDP from the World Development Indicators and income dummies according to the World Bank classification are considered.

\subsubsection{Gologit model}

The categorical nature of the financial openness indicator KAOPEN warrants an empirical estimation technique able to deal with this type of data. ${ }^{14}$ We choose to employ the Generalized Ordered Logit Model (gologit) for this purpose. ${ }^{15}$ The choice for the number of categories is

\footnotetext{
${ }^{13}$ Possible effects of unrecorded remittances on the estimation results are discussed in Section 5.4.4.

${ }^{14}$ Appendix B reports results based on estimations where KAOPEN is treated as a continuous variables. These results are discussed in Section 5.4.4.

${ }^{15}$ For a detailed exposition on the gologit model we refer to Williams (2006). We use Richard Williams' gologit2 Stata module to estimate the model.
} 
guided by the distribution of the data in Figure 5.1 and the properties of the gologit model. The number of categories should be in proportion to the number of data points, i.e. choosing too many categories will result in estimation problems.

We opt for three financial openness categories: "closed", "neutral" and "open". A country is considered closed when it imposes restrictions on at least three of the four subcategories in KAOPEN. If there is at most one restriction on the four subcategories in KAOPEN, the country is considered to be open. When there are two restrictions out of four, the country is considered to have a neutral openness policy. Since the subcategory capital account openness is calculated over a five year period, there are points in between the levels (See Figure 5.1). Hence, we define the following categories: "closed" $=0$ for KAOPEN below -1.1, "neutral" $=1$ for KAOPEN between -1.1 and 1 and "open" = 2 for KAOPEN above 1. Using this choice for the categories, we can write the gologit model as

$$
\begin{aligned}
& P\left(Y_{i t}>0\right)=g\left(X_{i t} \beta_{0}\right)=\frac{\exp \left(\alpha_{0}+X_{i t} \beta_{0}\right)}{1+\left[\exp \left(\alpha_{0}+X_{i t} \beta_{0}\right)\right]}, \\
& P\left(Y_{i t}>1\right)=g\left(X_{i t} \beta_{1}\right)=\frac{\exp \left(\alpha_{1}+X_{i t} \beta_{1}\right)}{1+\left[\exp \left(\alpha_{1}+X_{i t} \beta_{1}\right)\right]},
\end{aligned}
$$

where $Y_{i t}$ is the categorical dependent variable taking values 0,1 and 2 . $X_{i t}$ is a vector of independent variables corresponding to observation $i$ at time $t, \beta_{0}$ and $\beta_{1}$ are vectors of coefficients and $\alpha_{0}$ and $\alpha_{1}$ are constants.

From Equation (5.12) we can determine the probabilities that $\mathrm{Y}$ will take on each of the values 0,1 or 2 conditional on the explanatory variables

$$
\begin{aligned}
& P\left(Y_{i t}=0\right)=1-g\left(X_{i t} \beta_{0}\right) \\
& P\left(Y_{i t}=1\right)=g\left(X_{i t} \beta_{0}\right)-g\left(X_{i t} \beta_{1}\right) \\
& P\left(Y_{i t}=2\right)=g\left(X_{i t} \beta_{1}\right) .
\end{aligned}
$$

The gologit model is a general specification, which nests more restrictive models such as the ordered logit model (ologit). This ologit model is sometimes referred to as proportional odds model. It is more restrictive because it assumes $\beta_{0}=\beta_{1}$, i.e. it imposes the parallel lines assumption. Note that the gologit model is able to nest this assumption for all or only subset of variables. When only two categories are considered, the gologit 
model boils down to the familiar logit model for binary data.

We incorporate dynamics in the gologit model to capture the persistence of KAOPEN. This is done in a similar fashion as in Contoyannis et al. (2004), who introduce dynamics in an ordered probit model. Moreover, we explicitly incorporate starting values as suggested by Wooldridge (2005) to deal with the initial conditions problem in nonlinear dynamic panel data models with unobserved heterogeneity. So, rewriting Equation (5.12) as

$$
\begin{aligned}
P\left(Y_{i t}>0\right) & =\frac{\exp \left(\alpha_{0}+\bar{X}_{i, t-1 \mid t-5} \beta_{0}+Y_{i, t-5} \gamma_{0}+Y_{i, 0} \xi_{0}+\delta_{t}\right)}{1+\exp \left(\alpha_{0}+X_{i, t-1 \mid t-5} \beta_{0}+Y_{i, t-5} \gamma_{0}+Y_{i, 0} \delta_{0}+\delta_{t}\right)}, \\
P\left(Y_{i t}>1\right) & \left.=\frac{\exp \left(\alpha_{1}+\bar{X}_{i, t-1 \mid t-5} \beta_{1}+Y_{i, t-5} \gamma_{1}+Y_{i, 0} \xi_{1}+\delta_{t}\right)}{1+\exp \left(\alpha_{1}+X_{i, t-1 \mid t-5} \beta_{1}+Y_{i, t-5} \gamma_{1}+Y_{i, 0} \delta_{1}+\delta_{t}\right.}\right)
\end{aligned}
$$

where $Y_{i, t-5}$ is the one period lag (five years) of $Y_{i t}$ and $Y_{i, 0}$ is the initial value of $Y_{i t}$ at time $t=1980$. The matrix $X$ contains the variable of interest, the remittance/gdp ratio, and other control variables (the polity2 indicator to capture institutional quality, the Wacziarg and Welch trade openness indicator and the bank credit/ bank deposit ratio). All explanatory variables are calculated as five year averages from t-5 until t-1, where an average is included if the variable is available for at least three years in the $\mathrm{t}-1-\mathrm{t}-5$ time span. Time dummies are added to the model to capture common time shocks.

By using $\mathrm{t}-1-\mathrm{t}-5$ averages we avoid a potential simultaneity bias since all variables are now predetermined. However, they are not strictly exogenous.

Contoyannis et al. (2004) estimate a random effects ordered probit model,where they take explicit care of unobserved heterogeneity using random effects. As their sample is a typical micro panel, i.e. survey data, a random effects specification is more appropriate. However, in our case we are dealing with a macro panel, where one may consider introducing fixed effects to capture unobserved heterogeneity. However, when countries do not change their financial openness during 1980-2005 this is already captured by initial conditions. Consequently, by incorporating a large set of explanatory variables, initial conditions and time dummies we aim to minimize the potential bias arising from unobserved heterogeneity. 


\subsubsection{Benchmark results}

Table 5.2 shows the results of the estimation of Equation (5.13) using five specifications, denoted $(1), \ldots,(5)$, on an unbalanced panel. ${ }^{16}$ For every specification there are two columns with parameter estimates, indicated by $0-2$ or $1-2$. Since KAOPEN is split into three categories, we estimate two slopes inbetween these categories, i.e. from 0 to 1 and 1 to 2 . When the coefficients in columns 0-1 and 1-2 are equal, we have been able to impose slope homogeneity across the categories.

The Brant test is used to determine for which variable slope homogeneity is imposed. First, the unrestricted model, i.e. without slope homogeneity, is estimated. For each variable, the Brant test calculates a p-value to determine if slope homogeneity is rejected or not. Second, we reestimate the model by imposing slope homogeneity on the variable with the highest p-value. Third, the Brant test is calculated again for all variables and we impose slope homogeneity for the variable with the highest p-value as well, i.e. the model is reestimated with slope homogeneity on two variables. This iterative procedure is continued until slope homogeneity is rejected significantly at $5 \%$ for all remaining variables in the model. The tables in this paper report only the results from this final model. In Table 5.2 we assume slope homogeneity for all variables, except for the small states variable.

Column(1) reports our baseline specification, where we account for dynamics, initial conditions, the variable of interest remittances and several control variables. First, accounting for dynamics is important when explaining the determinants of financial openness. Note that "closed" is our baseline category. For both neutral and open capital account policies the lagged openness level is an important positive determinant of current openness. This effect is especially strong for a financially open policy. Moreover, if a country is open in 1980, it is very likely to remain open as shown by the large and positive coefficient on the initial condition.

The coefficient on remittances is positive and significant at the $1 \%$ level. This implies that once a country receives more remittances, it will be more likely to liberalize its capital account, ceteris paribus. Note that the coefficients on remittances are very stable across all specifications.

Other control variables show that improved institutions increase the

\footnotetext{
${ }^{16}$ Table 5.6 in the Appendix shows the estimation results for a balanced panel. The balanced sample consists of 43 countries. Both samples yield similar results.
} 


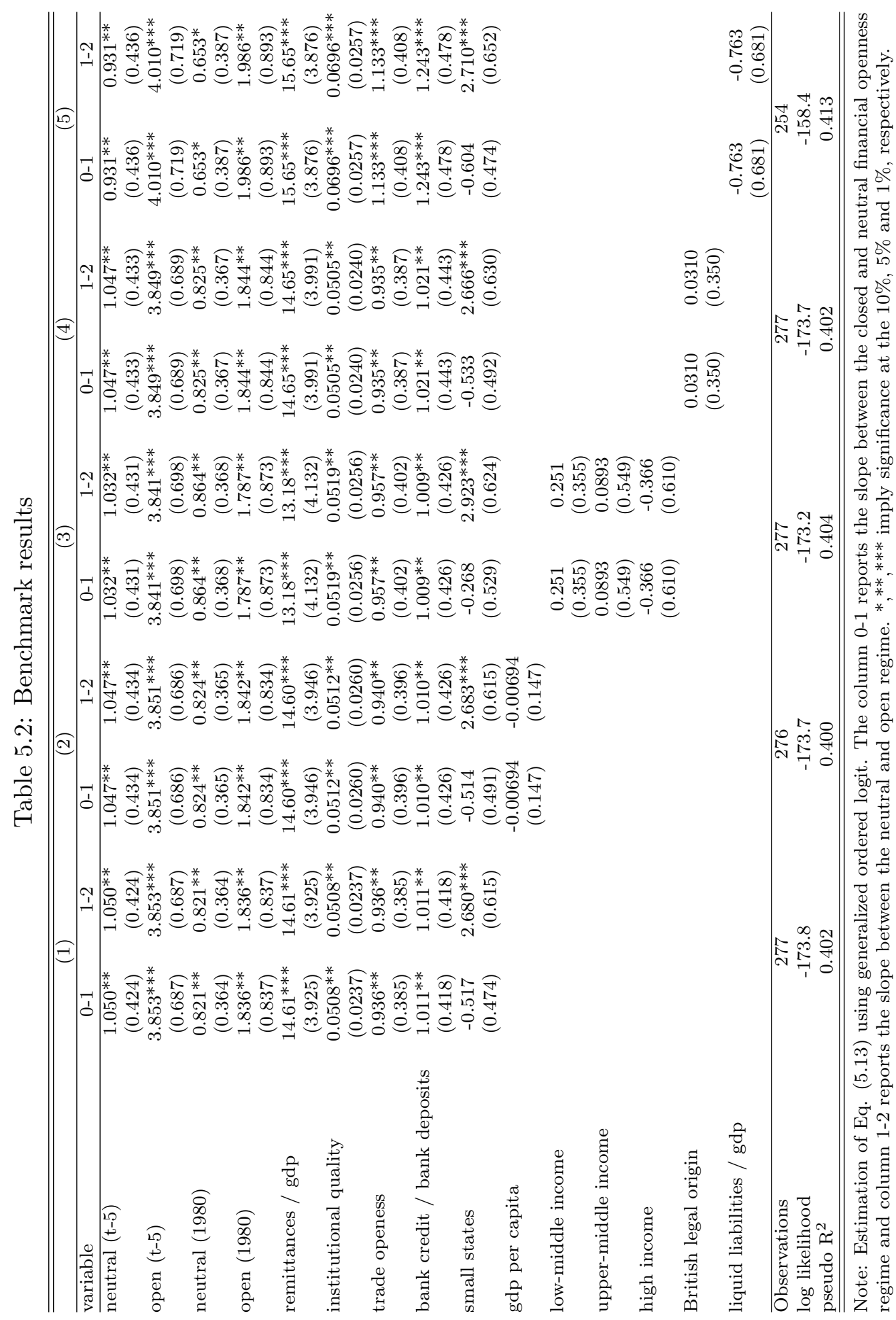


probability of financial openness. Moreover, a liberalized trade policy has a positive effect on financial openness as well, which is in line with the literature showing the importance of trade liberalization preceding financial liberalization. More bank credits relative to bank deposits have a positive impact on financial openness. This indicates that a more efficient domestic financial system induces the country to become more financially open. Apparently, small states have an increased probability to be open. However, the slope heterogeneity assumption does not hold here, since the coefficient for the 0-1 transition is insignificant.

In columns (2)-(5), other potential explanatory variables are added to the baseline specification. In column (2) GDP per capita is added to investigate if a country's standard of living affects its liberalization policy. This variable turns out to be insignificant. Moreover, when including income dummies in column (3), we also do not find any relationship between the income level and financial openness. One reason for these findings is that we capture GDP per capita adequately with the initial conditions, as most countries which start out relatively rich remain rich. Another factor that might play a role is the occurrence of an endogeneity bias, since financially liberalized countries tend to grow faster (Bekaert et al., 2005).

Some authors argue that the legal origin of a country is related to financial openness (e.g. Brune and Guisinger, 2003). Although this is likely to be captured by the initial conditions and/or institutional quality (La Porta et al., 1999), it is explicitly included in column (4). However, the coefficient on British legal origin turns out to be insignificant. Unreported results show that a French legal origin dummy is also insignificant.

As the bank credit over bank deposits ratio captures the general development level of the financial system, other variables may be included to capture additional characteristics of a country's financial development. In column (5) we incorporate the private credit over GDP ratio, which shows how large the financial sector is relative to the economy. Some authors argue (see e.g. Braun and Raddatz, 2007) that a large domestic financial system may substitute for international sources of capital financing. Hence, a large domestic financial sector may result in a more closed financial openness policy. The private credit over GDP ratio has a negative coefficient, which is in line with Braun and Raddatz (2007), but this variable is insignificant. ${ }^{17}$

\footnotetext{
${ }^{17}$ The impossible trinity states that a country's government can pursue at most two
} 
Model (1) is our baseline specification and captures the most relevant variables explaining financial openness. However, there may be some distrust in the results of the estimations in Table 5.2 due to a potential endogeneity bias. Even though all variables are predetermined, they are not strictly exogenous. Especially, we are concerned about the potential endogeneity of remittances. The first concern is reverse causality, since the cheaper it is to remit, the higher will be remittances, ceteris paribus. Put differently, if transaction costs are very high, a migrant will not remit or remit a lower fraction of his income compared to situation without transaction costs.

A second point of concern is a potential bias due to measurement error. As the IMF/World Bank data only registers official flows, we miss those remittances sent through unofficial channels. The size of unofficial remittances is likely to be correlated with financial openness, since unofficial channels are not attractive when transaction costs of official channels are small. In order to address these concerns, we adopt an instrumental approach in the next section.

\subsubsection{Instrumentation}

Instrumental variable (IV) methods are a common approach to deal with endogeneity problems. In linear models, the literature guiding the use of instrumentation is well developed and widespread. In particular, it is possible to use the very popular two-stage least squares technique (2SLS), and for dynamic panel data models, as in our case, the Arellano-Bover system GMM. Unfortunately, in a nonlinear framework, it is not easy to find a suitable method to account for endogeneity and there appears to be some confusion around the application of instrumental variable methods in this setting.

Very recently, Terza et al. (2008), address this issue. In the literature. there are two instrumental variables-based approaches to correct for endogeneity in non-linear models. The first one is the two-stage residual inclusion (2SRI) and the second one is the two-stage predictor substitution (2SPS). 2SPS is very similar to the linear 2SLS estimator. In the first-

out of the following three policies: 1. A fixed exchange rate, 2. Free capital flows and 3. An independent monetary policy. This suggests to include the country's exchange rate regime as a control variable. Unreported results, which are available upon request, show that the exchange rate regime has no impact on financial openness. 
stage of $2 \mathrm{SPS}$, reduced form regressions are estimated with any consistent estimation technique, then the results are used to generate predicted values for the endogenous variables. In the second-stage, the endogenous variables are replaced by their predicted values obtained from the first-stage. The 2SRI estimator has the same first stage as 2SPS, but in the second stage the endogenous variables are not replaced by their predicted values. Instead, the first-stage residuals are included in the second stage, reflecting the component of the error term that is correlated with the endogenous explanatory variables, and thereby correcting for endogeneity. ${ }^{18}$ Terza et al. (2008) support the use of 2SRI, showing that 2SRI is generally statistically consistent in the broader class of non-linear model, whereas 2SPS is not. Following their suggestion we use the 2SRI technique. ${ }^{19}$

A consistent estimation technique is required for first-stage estimation. In our context we apply a robust fixed effect estimation, thereby accounting for all time-constant variables explaining remittances, e.g. geographical characteristics, colonial history, linguistic and cultural features of a migrants' origin country.

Attempting to confront the endogeneity issue requires finding suitable instruments. To properly instrument remittances we need to find variables that must satisfy the following conditions: first, they need to be sufficiently correlated with the endogeneous variable (i.e. they must not be weak); and, second, they can neither have a (direct) influence on the dependent variable, capital account openness, nor be correlated with the error term in (5.13). Also, there must be at least as many instruments as there are endogenous regressors. In our case, we need one instrument for exact identification and at least 2 instruments for overidentification.

Instrumental estimation of model (5.13) allows also to take into account measurement errors in the key variable, i.e. the remittances variable. As explained before, remittances are subject to measurement errors due to the fact that informal remittances are not included in the official data. The size of this measurement error is likely to vary across countries.

We consider as instruments for remittances, the (lagged) total emigration rate to the six major OECD receiving countries, considering the Defoort (2008) data set, and the growth rate of very young people (0-14)

\footnotetext{
${ }^{18}$ We recall that the essence of the endogeneity problem is the correlation between the explanatory variable and the error term

${ }^{19}$ In not reported regressions, we used also the 2SPS technique. Results were in general similar to the ones obtained with 2SRI, even if less robust in the balanced sample.
} 
as a percentage of the total population (data are taken from the World Bank's World Development Indicators).

The emigration rate is positively correlated with remittances as a percentage of GDP, as one expect that workers from abroad send money to their family at home. At the aggregate level, therefore, the more workers migrate abroad, the larger the amounts of remittances received by their home country. Freund and Spatafora (2008) even argue that the stock of migrants in OECD countries is the primary determinant of remittances. ${ }^{20}$ Growth rate of very young population is supposed to be positively correlated with remittances, as family size increases, and in particular with more children in the family, migrants spend less on themselves, and spend more on young family members, e.g. on education, in their home country.

From our first stage estimation in Table 5.3, we can see that the estimated coefficients of our instruments are positive and statistically significant. They have very high joint explanatory power, which can be inferred from the high F-statistics for both the unbalanced and balances samples. This indicates that our instruments are strong. ${ }^{21}$

The second requirement for valid instruments is that they can neither have a (direct) influence on the dependent variable, financial openness, nor be correlated with the error term. In our case, we think that this is the case for both the lagged emigration rate and the growth rate of very young population.

If we do not see any direct correlation between our instruments and our dependent variable, some indirect correlation can be claimed, but from our data, this correlation appears quite weak. For example, as GDP per capita and income dummies are not significant in our benchmark estimation, we can exclude that the growth rate of very young population is correlated with our dependent variable through GDP per capita (population growth and GDP per capita are negatively correlated, as rich countries usually have a lower population growth rate). For the emigration rate, one can claim that the emigration rate is potentially correlated with capital

\footnotetext{
${ }^{20}$ The use of total emigration rate to the six major OECD countries as instrument for remittances as a percentage of GDP is also in line with Singer (2009) who, in his study on remittances and exchange regime policies, uses as instrument for remittances the fiveyear rolling average annual emigration to 15 advanced industrial countries, scaled by the sending country's population.

${ }^{21}$ In general, practitioners consider instruments as strong when the F-statistic is larger than ten.
} 
Table 5.3: First stage

\begin{tabular}{lcc}
\hline \hline variable & unbalanced & balanced \\
\hline neutral (t-5) & $0.00768^{* *}$ & $0.00976^{* *}$ \\
& $(0.00332)$ & $(0.00385)$ \\
open (t-5) & 0.00459 & 0.00433 \\
& $(0.00542)$ & $(0.00655)$ \\
emigration rate (t-5) & $0.684^{* * *}$ & $0.673^{* * *}$ \\
& $(0.136)$ & $(0.145)$ \\
growth rate young population & $0.123^{* *}$ & $0.129^{* *}$ \\
& $(0.0581)$ & $(0.0615)$ \\
institutional quality & $-0.000594^{*}$ & -0.000441 \\
& $(0.000349)$ & $(0.000378)$ \\
trade openess & -0.00124 & -0.000333 \\
& $(0.00552)$ & $(0.00666)$ \\
bank credit / bank deposits & $-0.00833^{*}$ & $-0.0106^{* *}$ \\
& $(0.00431)$ & $(0.00516)$ \\
\hline Observations & 277 & 215 \\
R-squared & 0.385 & 0.391 \\
Number of countries & 66 & 43 \\
F-stat & 29.76 & 25.24 \\
p-value (F-stat) & 0.000 & 0.000 \\
partial R & 0.2526 & 0.2489 \\
\hline \hline
\end{tabular}

Note: Estimation of first stage regression with remittances/gdp as dependent variable using fixed effects and robust standard errors. ${ }^{*}, * *, * * *$ imply significance at the $10 \%, 5 \%$ and $1 \%$, respectively.

account openness through institutional quality, considering capital account openness as a reflection of institutions. There are some papers assessing the relationship between migration and political institutions (e.g. Spilimbergo, 2009). Even if in our estimation, institutional quality is positive and highly significant, financial openness and institutional quality, measured as a corrected indicator of democracy, are unconditionally uncorrelated (for instance, there are very open countries with low level of democracy), therefore excluding a possible correlation between emigration rate and financial openness through institutional quality. ${ }^{22}$

In order to statistically test for correlation of our instruments with the error term, an over-identifying restrictions test has been performed. This test is a likelihood ratio test which compares the likelihood function of the two-stage estimates with the likelihood function of a specification which

\footnotetext{
${ }^{22}$ We consider the unconditional correlation between Kaopen and the Polity2 measure from the Polity IV data set. The correlation is 0.0713 with a p-value of 0.1395 .
} 
additionally includes our instruments. This test confirms the validity of our instruments both for the unbalanced and the balanced sample.

Table 5.4 shows the second-stage gologit results. The estimated coefficients of the residuals are positive and statistically significant in columns 0-1, negative and less significant in columns 1-2; they either test for endogeneity and capture the component of the error term correlated with the endogenous explanatory variables. Even correcting for endogeneity, the coefficient on remittances is positive and highly significant at the $1 \%$ level, with only a minor lower estimated coefficient compared to our benchmark estimation, both in the unbalanced and balanced sample. The residual variable in this second stage estimation is significantly different from zero in 3 out of the 4 equations reported in the Table. The significance of this variable can be seen as some indirect evidence of the need to instrument the remittance variable. In turn, in the spirit of the well-known Hausman test in the case of continuous models, this might provide indirect evidence in favour of reverse causality between financial openness and remittances. This interpretation should be nevertheless taken with caution. ${ }^{23}$

Now initial conditions are less important than previous estimation for the balanced sample. All the other results for our benchmark specification are confirmed.

In order to assess the robustness of our results we treat the dependent variable, financial openness, as a continuous variable using two different estimation techniques. First, we re-estimate our model using a linear 2SLS technique, considering the same set of instruments as before. Second, with the Arellano-Bover system GMM, considering the lagged dependent variable as predetermined, and remittances as endogenous and instrumented by their second and further lags. The regression results are reported in Appendix B. Also in these cases our main results are confirmed: the estimated coefficient of remittances is positive and significant at usual statistically level in both cases.

One concern with the results of Tables 5.2 and 5.4 is the quality of the remittances variable. As mentioned before, there is only data available for official remittance flows, i.e. unofficial remittances are not captured in the data. Suppose all countries have a certain fraction of remittances

\footnotetext{
${ }^{23}$ In the same perspective, it is impossible to assess the degree of reverse causality in our data from the mere comparison between estimates of Table 5.2 and of Table 5.4. The reason is that with respect to the basic estimates of the gologit model, the IV estimates correct for two different biases, i.e. the simultaneity bias and the measurement error one.
} 
Table 5.4: Instrumentation Second Stage Gologit

\begin{tabular}{lcccc}
\hline \hline & \multicolumn{2}{c}{ unbalanced } & \multicolumn{2}{c}{ balanced } \\
\hline variable & $0-1$ & $1-2$ & $0-1$ & $1-2$ \\
\hline neutral (t-5) & $1.167^{* * *}$ & $1.167^{* * *}$ & $1.322^{* *}$ & $1.322^{* *}$ \\
& $(0.430)$ & $(0.430)$ & $(0.523)$ & $(0.523)$ \\
open (t-5) & $3.937^{* * *}$ & $3.937^{* * *}$ & $3.666^{* * *}$ & $3.666^{* * *}$ \\
& $(0.687)$ & $(0.687)$ & $(0.770)$ & $(0.770)$ \\
neutral (1980) & $0.859^{* *}$ & $0.859^{* *}$ & 0.287 & 0.287 \\
& $(0.372)$ & $(0.372)$ & $(0.460)$ & $(0.460)$ \\
open (1980) & $1.717^{* *}$ & $1.717^{* *}$ & 1.290 & 1.290 \\
& $(0.851)$ & $(0.851)$ & $(0.854)$ & $(0.854)$ \\
remittances / gdp & $13.19^{* * *}$ & $13.19^{* * *}$ & $14.01^{* * *}$ & $14.01^{* * *}$ \\
& $(4.299)$ & $(4.299)$ & $(4.058)$ & $(4.058)$ \\
institutional quality & $0.0517^{* *}$ & $0.0517^{* *}$ & $0.0789^{* *}$ & $0.0789^{* *}$ \\
& $(0.0244)$ & $(0.0244)$ & $(0.0332)$ & $(0.0332)$ \\
trade openess & $0.988^{* *}$ & $0.988^{* *}$ & $1.198^{* *}$ & $1.198^{* *}$ \\
& $(0.390)$ & $(0.390)$ & $(0.491)$ & $(0.491)$ \\
bank credit / bank deposits & $0.969^{* *}$ & $0.969^{* *}$ & $2.866^{* * *}$ & -0.484 \\
& $(0.430)$ & $(0.430)$ & $(0.656)$ & $(0.872)$ \\
small states & -0.608 & $2.551^{* * *}$ & $-1.259^{* *}$ & $2.304^{* * *}$ \\
& $(0.445)$ & $(0.627)$ & $(0.573)$ & $(0.833)$ \\
residual & $33.08^{* *}$ & -15.60 & $57.93^{* * *}$ & $-26.51^{*}$ \\
& $(13.95)$ & $(15.89)$ & $(15.74)$ & $(15.24)$ \\
\hline Observations & \multicolumn{3}{c}{277} \\
log likelihood & -169.4 & \multicolumn{2}{c}{215} \\
pseudo R & \multicolumn{2}{c}{0.417} & 0.460 \\
Overid (LR test, p-val) & \multicolumn{2}{c}{0.141} & 0.257 \\
\hline \hline
\end{tabular}

Note: Estimation of Equation (5.13) using generalized ordered logit. The column 0-1 reports the slope between the closed and neutral financial openness regime and column 1-2 reports the slope between the neutral and open regime. $*, * *, * * *$ imply significance at the $10 \%, 5 \%$ and $1 \%$, respectively.

received through informal channels in 1980 . The potential effect on financial openness is captured by the initial conditions. Over time the fraction official vs. unofficial remittances is likely to increase. Due to financial innovations, official transactions have become cheaper since the 1980s. Consequently, we would expect that the increase in official remittances is larger than the increase in total remittances. In this case, the coefficient on remittances in Tables 5.2 and 5.4 is underestimated and the effect of remittances on capital account openness is even stronger than the estimated one. 


\subsubsection{Marginal effects}

From the estimated coefficients in Table 5.4 it is possible to calculate marginal effects. These marginal effects are calculated at the mean of each independent variable for all categories. Table 5.5 shows these marginal effects for both the unbalanced (left panel) and balanced sample (right panel). The interpretation of the coefficients is straightforward. Consider remittances in the unbalanced panel, the coefficient of about -3 implies that if the remittance over GDP ratio increases by one percentage point (e.g. from 2 to 3 percent), then this decreases the probability of ending up in a closed regime by 3 percentage points. Likewise, a one percentage point increase in remittances/GDP results increases the probability of ending up in the category neutral (open) by 2 (1) percentage point(s). These results show that countries which receive large amounts of remittances from abroad are unlikely to be financially closed, e.g. a ten percentage point increase in remittances reduces the probability of being in a closed regime by thirty two percentage points.

The coefficients on the lagged categories can be interpreted as transition probabilities. If a country has a neutral financial openness policy at t-5, it is unlikely to end up in a closed regime at time t. Put differently, the probability of ending up in a closed regime is reduced by 27 percentage points if a country has a neutral regime at $t-5$. This effect is even stronger when a country has an open financial policy at t-5 (-55 percentage points). Countries that have an open financial regime are likely to remain open. The probability of a country to be open at time $t$, when it is open at time t- 5 , increases by 66.7 percentage points.

Initial conditions do not seem to matter for the balanced sample, implying that countries are not "stuck" in a regime. Instead they are able to switch regimes when e.g. remittances increase strongly during the 1980-2005 period. For the unbalanced sample initial conditions do seem to matter, e.g. if you have a neutral regime in 1980 this increases the probability of being in a neutral regime in the future by 13 percentage points. Moreover, the probability to end up in a closed regime is reduced by 20 percentage points.

The quality of institutions has a positive effect on the probability of being in a neutral or open regime, i.e. countries with good institutions are less likely to have a closed financial regime.

Financial openness appears to go hand in hand with trade openness. 


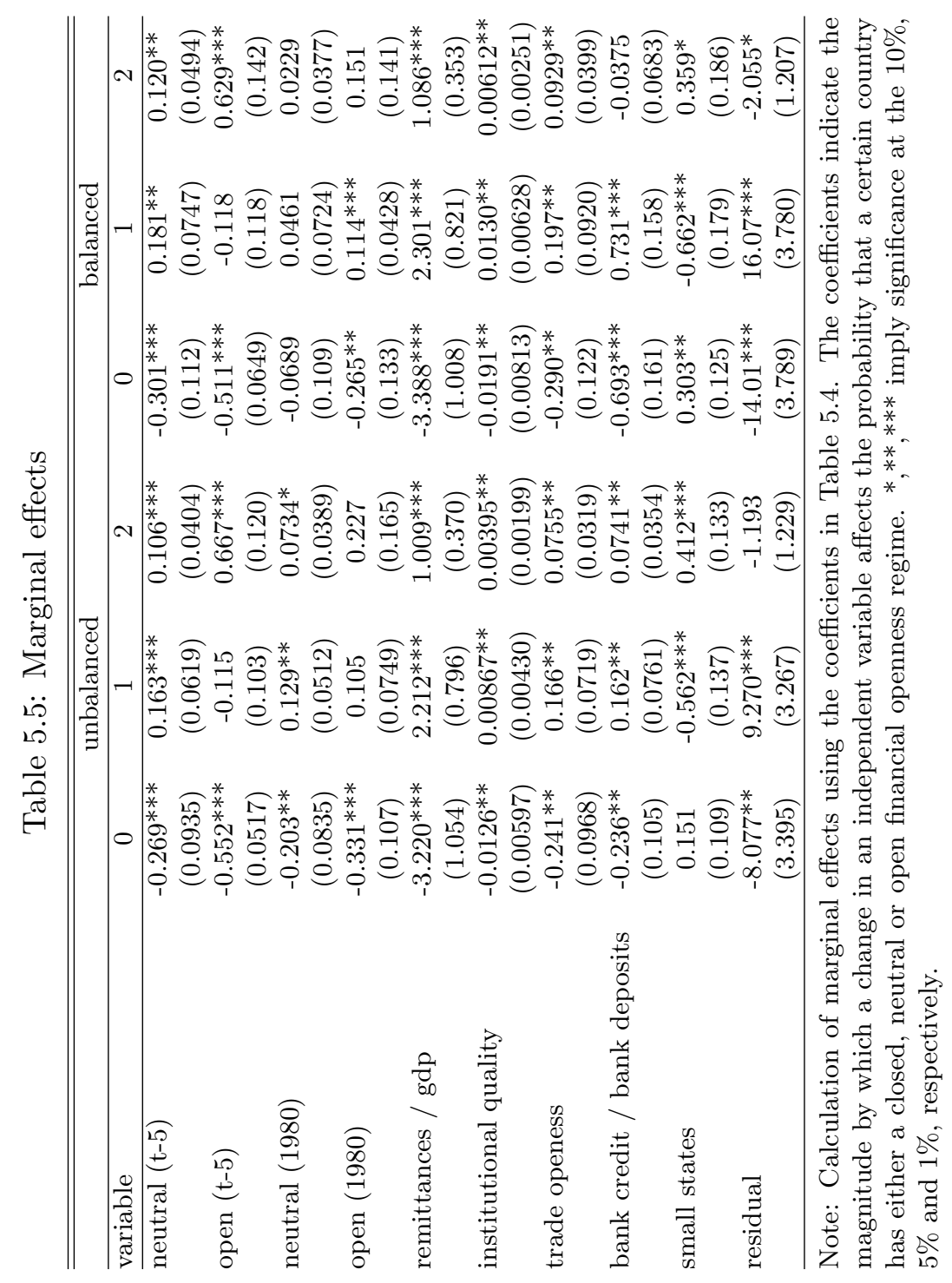


Countries with a closed trade policy are unlikely to have an open capital account policy. This finding is related to McKinnon (1991) who argues that trade openness is prerequisite for financial openness. Empirical evidence in favor of this reasoning has been provided by, among others, Chinn and Itô (2006). The findings in Table 5.5 are in line with this reasoning.

Economically, the size of this effect is large. When a country liberalizes its trade account, this reduces the probability of ending up in a closed regime by about $24 \%$ (or $29 \%$ in the balanced sample). Therefore, an increase in the remittance/gdp ratio of seven percentage points is similar in magnitude as a change from a closed to open trade regime. Note that the relative importance of trade openness and remittances is similar across financial openness regimes. With quite a few countries receiving remittances in excess of $10 \%$ of GDP, the importance of remittances is very obvious.

A higher bank credit/bank deposits ratio lowers the probability of a country to be financially closed. This implies that countries with more developed financial systems are more likely to have a neutral or open financial policy.

Small countries have a higher probability of being either closed or open. Apparently, governments of small states choose one of these extreme policies and have less preference for a neutral financial openness policy.

In sum, Table 5.5 confirms the predictions of the positive effect of remittances on a country's financial openness policy. Moreover, the impact of remittances on financial openness is not only statistically significant, but also economically large.

\subsection{Counterfactual analysis}

In order to further assess the economic effect of remittances, we investigate what the financial openness policy of a country would be under different scenarios. By keeping other country characteristics fixed at their observed values and varying only the amount of remittances received, the objective is to gain insight on the economic importance of remittances. We consider two specific scenarios. In the first scenario we show how the distribution of financial openness changes when a country receives zero remittances. The second scenario investigates the case when the amount of remittances received is doubled. We hypothesize, based on the results obtained in 
Sections 5.3 and 5.4, that large remittance receiving countries will have a lower financial openness in the first scenario and a higher financial openness under the second. Naturally, for countries receiving relatively few remittances we do not expect large effects on financial openness.

In Section 5.4 we calculated the marginal effects of each variable for the average country in the sample. This provides insights on the effects of a change in e.g. remittances for the "average country". Instead of using the average country's data, here country specific data will be used to calculate the country specific marginal effects. From these country specific characteristics, the estimated model parameters and the distributional properties of the logit model, we are able to calculate for each country individually the probabilities of ending up in a specific financial openness regime. $^{24}$

The intuition of the technique is straightforward when illustrating it for an individual country, say the Dominican Republic. The characteristics of this country, when predicting its 2005 financial openness regime, are as follows: 1) Financial openness in 1980 was "closed" and in 2000 it was "neutral", 2) The remittances/gdp ratio during 2000-2004 is 0.11, 3) It scored an 8 for institutional quality during these years, 4) The country is open to trade, 5) Its bank credit/bank deposit ratio during 2000-2004 is 1.43 and 6$)$ it is considered to be a small state. Under these conditions the model predicts the following regime probabilities for the Dominican Republic in 2005: 7\% "closed", 51\% "neutral" and 42\% "open".

Since the Dominican Republic's remittances/gdp ratio is $11 \%$, this will be set to $0 \%$ in scenario 1 and doubled to $22 \%$ in scenario 2 . Keeping all other variables constant we now obtain the following probabilities in scenario 1: 25\% "closed", $61 \%$ "neutral" and 14\% "open". Under scenario 2 this is: $2 \%$ "closed", $22 \%$ "neutral" and $76 \%$ "open". These numbers show the important impact remittances have on the Dominican Republic's financial openness policy regime. Therefore, remittances strongly impact the prospects of ending up in either the neutral or open regime. Based on the country's other characteristics there is a relatively small, but not negligible, $25 \%$ probability of ending up in the closed regime when no remittances are received. ${ }^{25}$

Figure 5.2 presents the changes in probabilities to end up in one of the

\footnotetext{
${ }^{24}$ The $\mathrm{mfx}$ postestimation command in Stata is used to calculate these probabilities.

${ }^{25}$ Table 5.8 shows in detail the probabilities for all the countries in the baseline case and the two scenarios
} 
Figure 5.2: Scenario 1 (zero remittances)
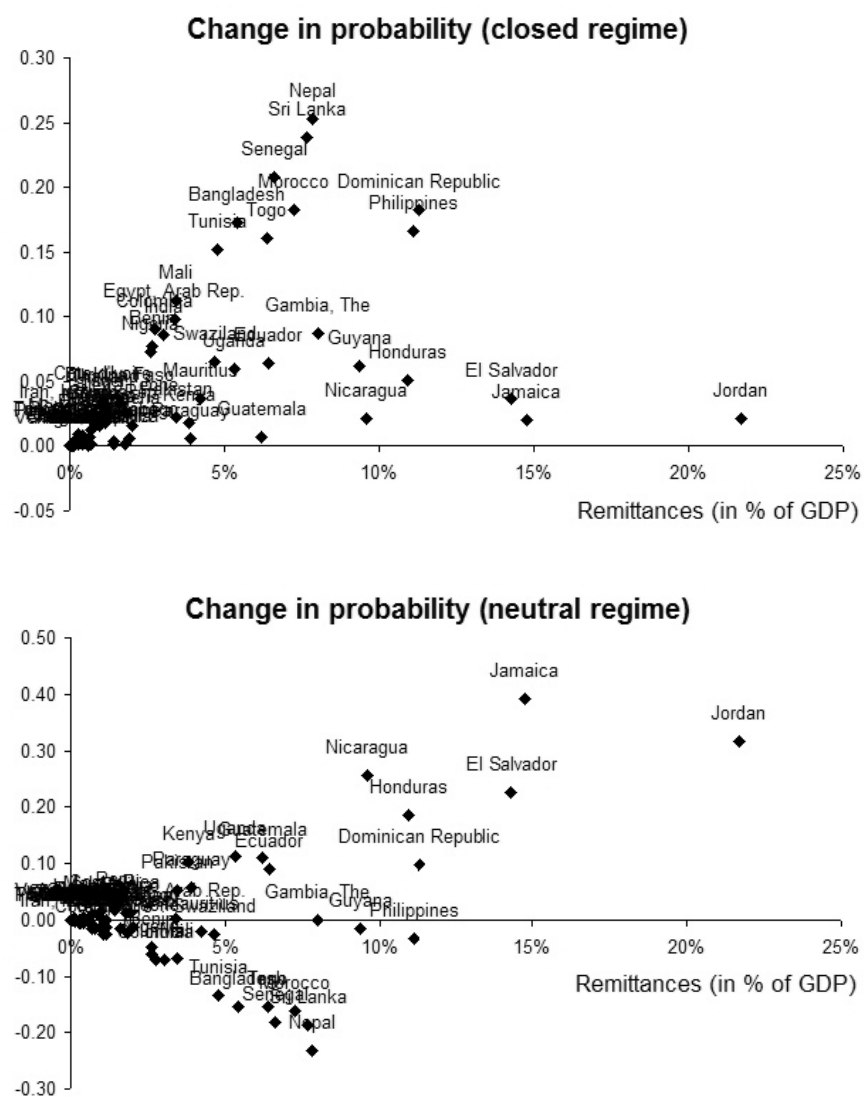

Change in probability (open regime)

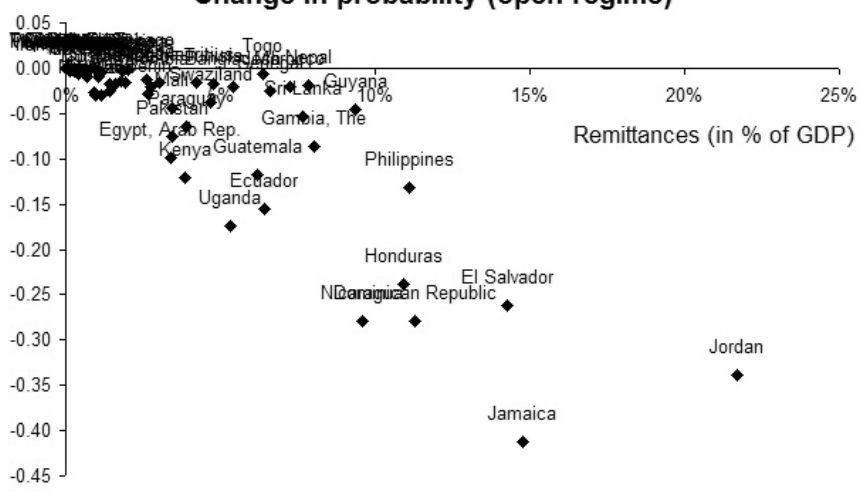


3 categories as a function of the average remittances/GDP ratio during 2000-2004 when a country receives zero remittances. It is easy to see that the higher the remittances/gdp ratio the higher the probability to become more closed. All countries face an increase in the probability to move to a lower financial openness category.

Let us focus on some particular countries, as an example. Jamaica is in an open regime in 2000 and receives a large amount of remittances relative to GDP. In the case of zero remittances, the probability to end up in an open regime widely decreases, while the probability to end up in a neutral regime increases. The probability to end up in a closed regime will be slightly affected.

Consider now the Philippines, a country which is intermediate open in 2000 and receiving a large amount of remittances. We can see that both the probability to be in an open or neutral regime will decrease, while the probability to end up in a closed regime increases. The same happens for countries with an intermediate amount of remittances and which are in a closed regime in 2000, such as Morocco.

On the opposite, the probabilities to end up in a certain regime will generally not change when the remittances/GDP ratio is very low. For example, Mexico is in an open regime in 2000 and does not receive that many remittances (in terms of GDP only $2 \%$, in absolute terms the figure is large), therefore its probability to have an open regime is unaffected in case it receives no remittances anymore.

Figure 5.3 presents the changes in probabilities to end up in one of the 3 categories as a function of remittances/GDP ratio in 2000 when the amount of remittances received is doubled. In general, the results of scenario 2 show the reverse pattern of scenario 1 .

Countries such as Jamaica, which are open and receive already a large amount of remittances, would face an increase in the probability to stay in the open regime. It is interesting to note, that countries like Morocco and Philippines instead, will strongly increase the probability to end up in a more open category, i.e. neutral for Morocco and open for Philippines, and strongly decrease the probability to remain in the current regime. 
Figure 5.3: Scenario 2 (double remittances)
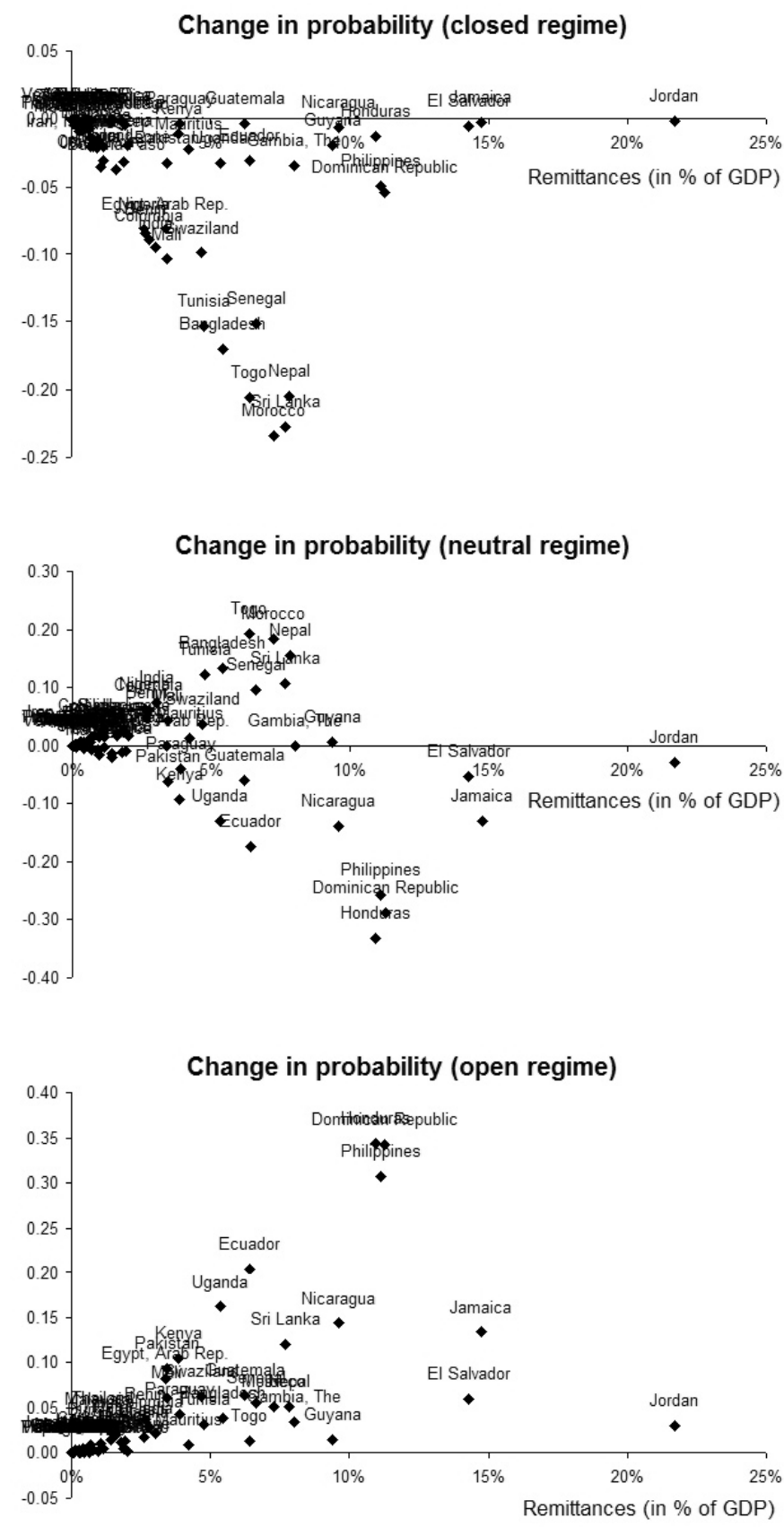


\subsection{Conclusion}

Workers' remittances have greatly increased during recent years, becoming a significant source of income for many developing countries. In addition to their increasing size, the stability and counter-cyclicality of these flows make them an important and reliable source of funds for developing countries. The importance of remittances on human capital investments, poverty reduction, and macro-economic stability has been widely recognized by researchers and policymakers. Therefore, it is attractive for remittance receiving countries to liberalize their capital account and increase their financial openness in order to attract more remittances through formal channels. Hence, remittances can have an important direct effect on a developing countries' financial openness.

In this paper we investigate the link between remittance receipts and financial openness for a sample of 66 mostly developing countries from 19802005. Empirically we use a dynamic generalized ordered logit model to establish the link between remittances and financial openness. In addition, we apply a two-step method akin to two stage least squares to deal with the potential endogeneity of remittances.

We find a highly positive effect of remittances on financial openness, i.e. the more remittances a country receives, the more likely it will be financially open. This positive effect is statistically significant and economically large. Through counterfactual experiments, we show that the probability to be financially opened is higher ceteris paribus for countries which receive a considerable amount of remittances.

\subsection{Appendix A: Robustness balanced panel pooled OLS estimation}




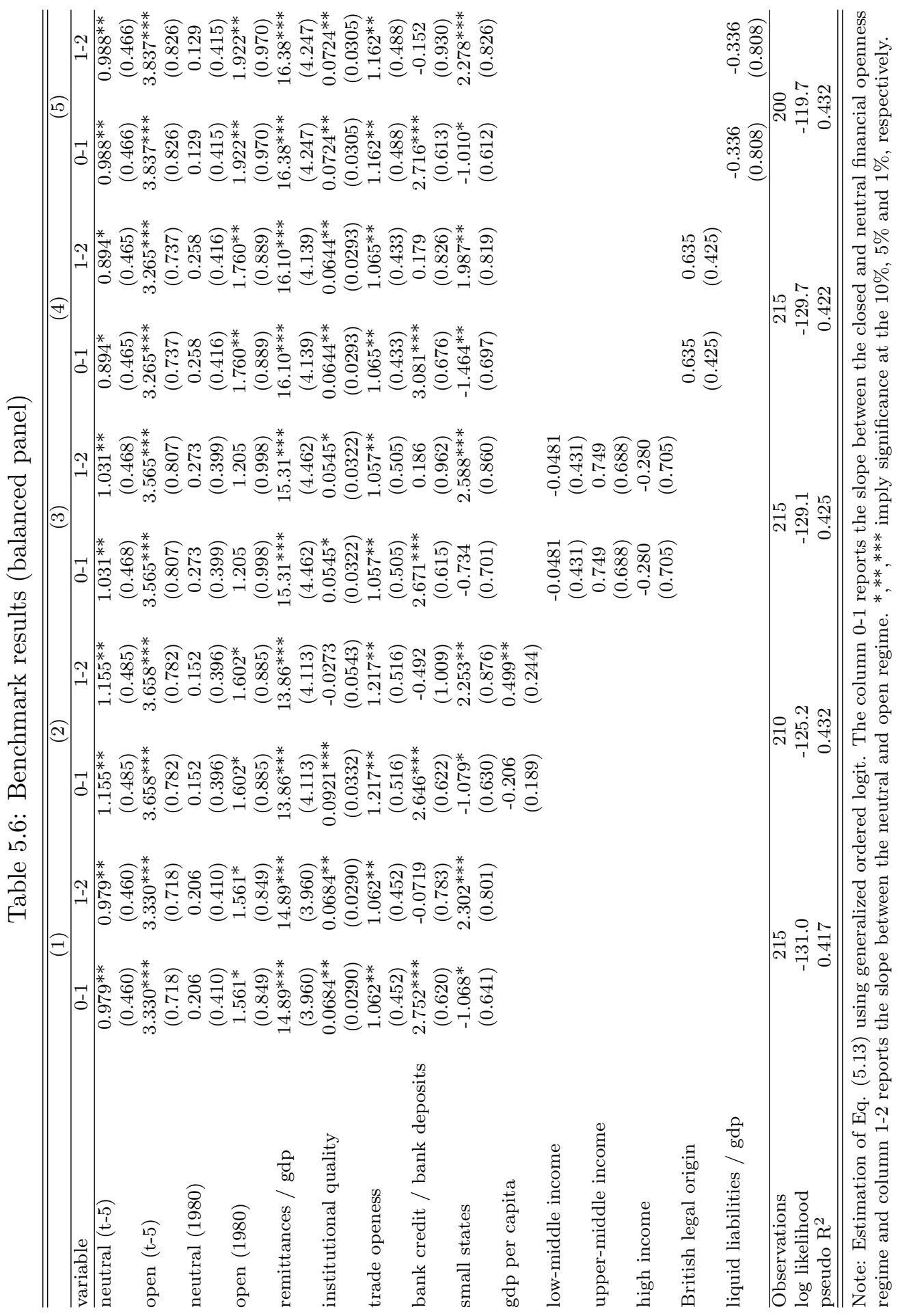




\subsection{Appendix B: Robustness using System GMM and 2SLS}

Table 5.7: Robustness using System GMM and 2SLS

\begin{tabular}{lcccc}
\hline \hline & \multicolumn{2}{c}{ unbalanced } & \multicolumn{2}{c}{ balanced } \\
\hline variable & SGMM & 2SLS & SGMM & 2SLS \\
\hline kaopen (t-5) & $0.503^{* * *}$ & $0.208^{* *}$ & $0.567^{* * *}$ & $0.244^{* *}$ \\
& $(0.131)$ & $(0.0942)$ & $(0.154)$ & $(0.110)$ \\
remittances / gdp & $14.92^{* *}$ & $24.27^{* * *}$ & $8.486^{* *}$ & $26.13^{* * *}$ \\
& $(5.813)$ & $(7.055)$ & $(4.056)$ & $(7.309)$ \\
institutional quality & $0.0272^{* *}$ & -0.0230 & 0.0233 & -0.0338 \\
& $(0.0136)$ & $(0.0218)$ & $(0.0147)$ & $(0.0227)$ \\
trade openess & $0.366^{*}$ & $0.852^{* * *}$ & $0.409^{*}$ & $0.910^{* * *}$ \\
& $(0.201)$ & $(0.256)$ & $(0.205)$ & $(0.275)$ \\
bank credit / bank deposits & $0.416^{* *}$ & $0.777^{* * *}$ & $0.445^{* *}$ & $1.011^{* * *}$ \\
& $(0.208)$ & $(0.222)$ & $(0.219)$ & $(0.221)$ \\
small states & 0.272 & & 0.293 & \\
& $(0.449)$ & & $(0.474)$ & \\
Observations & 277 & 276 & 215 & 215 \\
Number of countries & 66 & 65 & 43 & 43 \\
Number of instruments & 32 & & 32 & \\
AR(2) & 0.280 & & 0.218 & \\
Hansen J (p-value) & 0.172 & 0.163 & 0.194 & 0.295 \\
R-squared & & 0.355 & & 0.401 \\
F-statistic & & 30.25 & & 25.88 \\
Underidentification (p-value) & & 0.000255 & & 0.000368 \\
\hline \hline
\end{tabular}

Estimation of Equation (5.13) using System GMM and 2SLS. *,**,*** imply significance at the $10 \%, 5 \%$ and $1 \%$, respectively. 


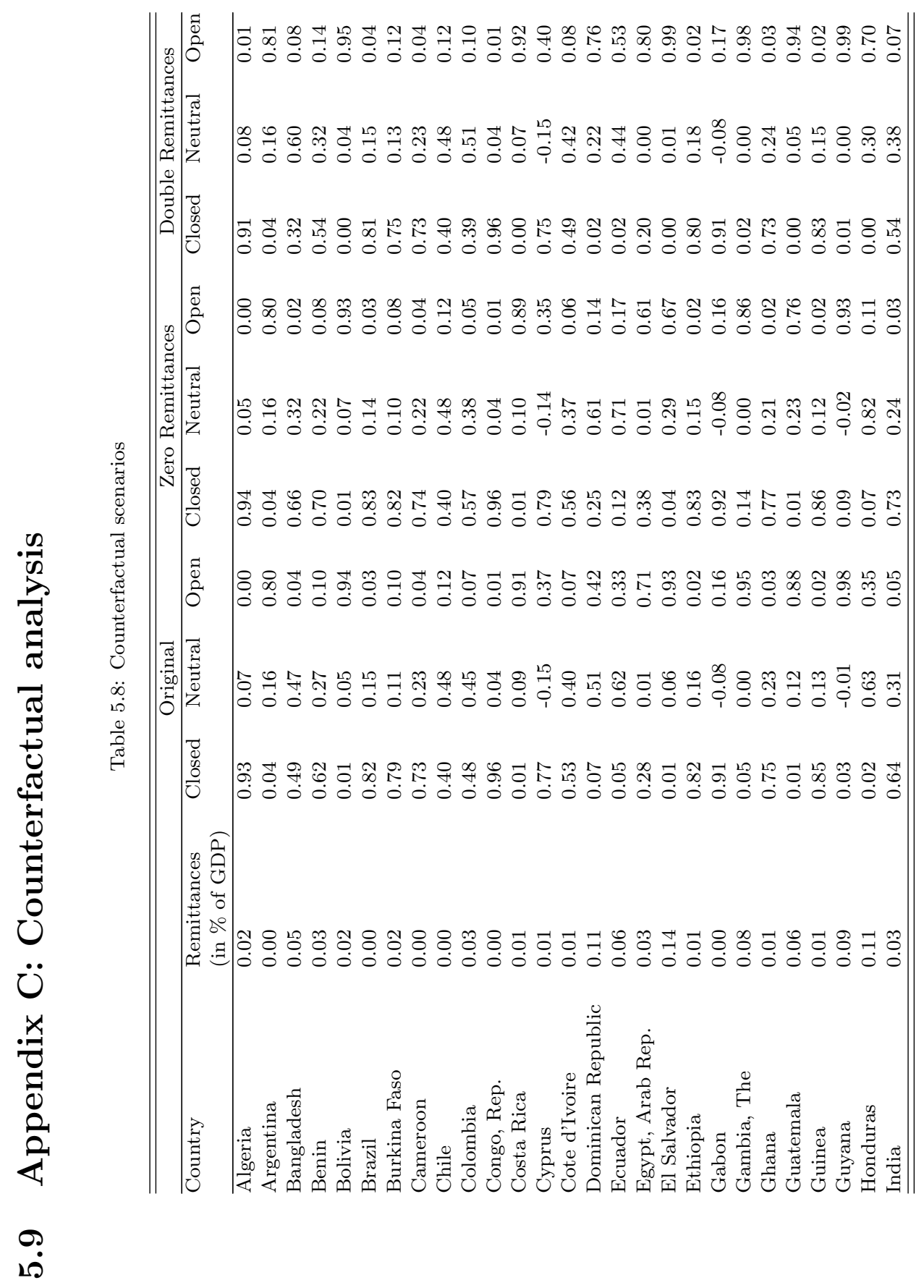




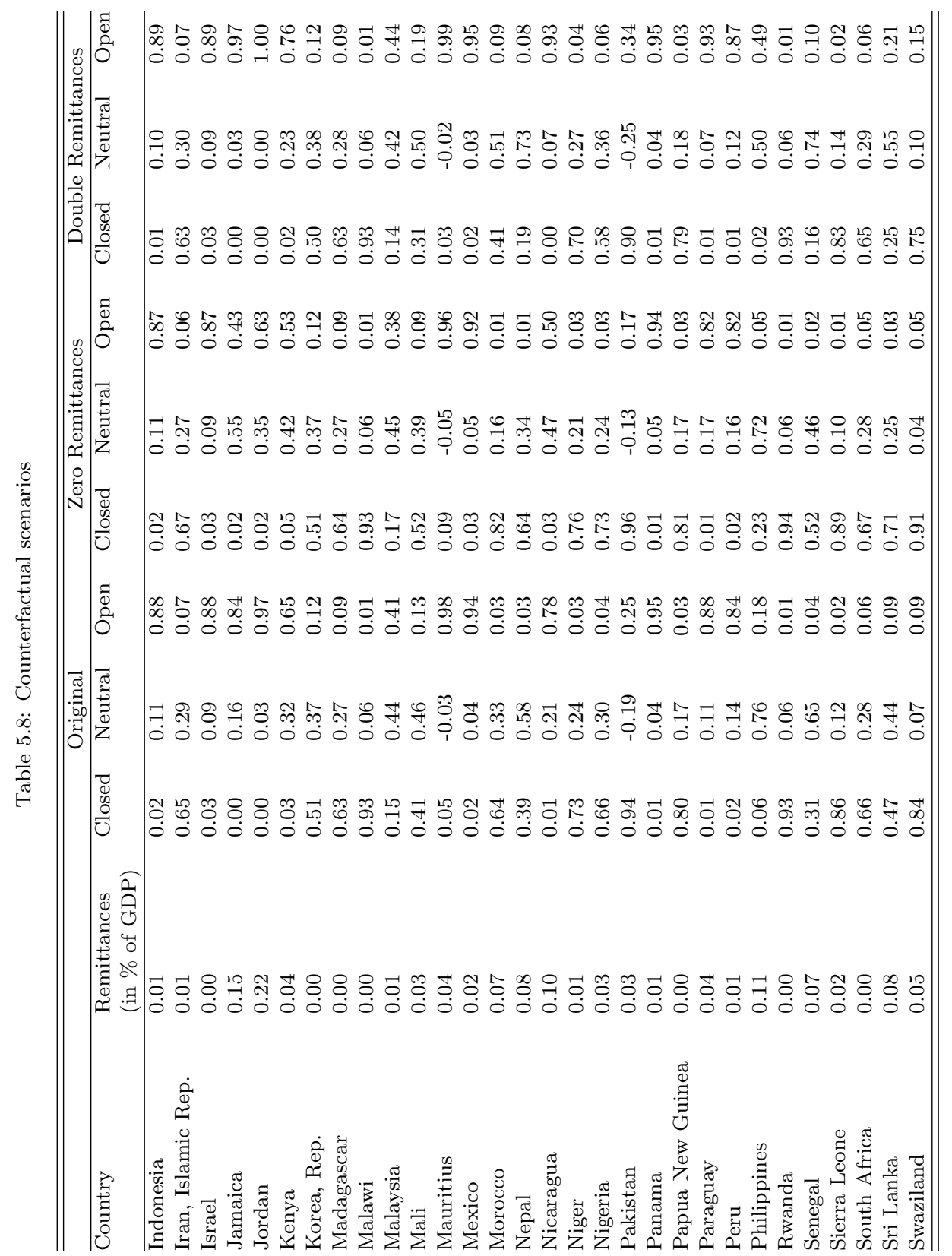




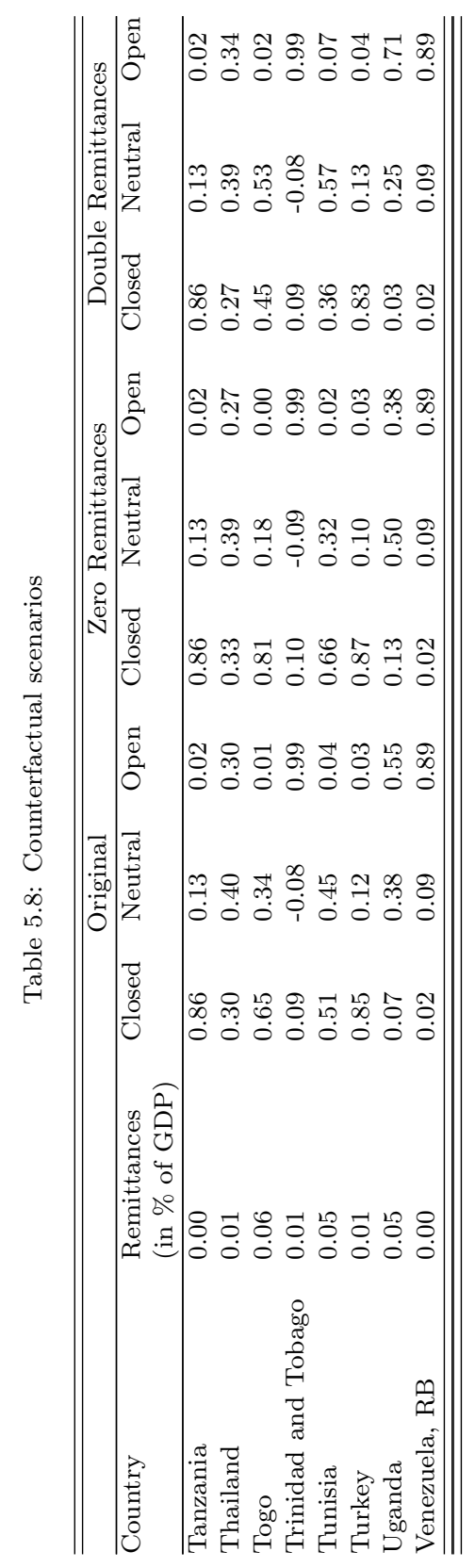





\section{Bibliography}

Acosta, P., P. Fajnzylber, and J. Lopez (2006). What is the Impact of International Remittances on Poverty and Inequality in Latin America?", in Ozden, C. and Schiff, M. (eds), International Migration, Economic Development and Policy, Chapter 2. Palgrave-Macmillan.

Acosta, P. A., E. K. Lartey, and F. S. Mandelman (2009). Remittances and the dutch disease. Journal of International Economics 79(1), 102-116.

Adams, R. (2006). Remittances Poverty and Investment in Guatemala, in: Ozden, C. and Schiff, M. (eds), International migration, remittances and the brain drain, Chapter 2. Palgrave-Macmillan.

Adams, R. and J. Page (2005). Do international migration and remittances reduce poverty in developing countries? World Development 33(10), $1645-1669$.

Aggarwal, R., A. Demirguc-Kunt, and M. Martinez Peria (2006). Do workers' remittances promote financial development? World Bank Policy Research Working Paper 3957.

Agunias, D. R. (2006). Remittances and development: Trends, impacts, and policy options; a review of the literature. Report Migration Policy Institute.

Ahearne, A., W. Griever, and F. Warnock (2004). Information costs and home bias: An analysis of US holdings of foreign equities. Journal of International Economics 62(2), 313-336. 
Alesina, A., V. Grilli, and G. Milesi-Ferretti (1994). The Political Economy of Capital Controls, in Leonardo Leiderman and Assaf Razin, eds., Capital mobility: The impact on consumption, investment, and growth. Cambridge: Cambridge University Press.

Alfaro, L., S. Kalemli-Ozcan, and V. Volosovych (2008). Why doesn't capital flow from rich to poor countries? An empirical investigation. The Review of Economics and Statistics 90(2), 347-368.

Andersen, T., T. Bollerslev, F. Diebold, and H. Ebens (2001). The distribution of realized stock return volatility. Journal of Financial Economics 61, 43-76.

Andersen, T. G., T. Bollerslev, F. X. Diebold, and P. Labys (2003). Modeling and forecasting realized volatility. Econometrica 71(2), 579625 .

Ando, A. and F. Modigliani (1963). The Life-Cycle Hypothesis of Savings: Aggregate Implications and Tests. The American Economic Review 103, $55-84$.

Andrade, S. and V. Chhaochharia (2009). Information immobility and foreign portfolio investment. Forthcoming in The Review of Financial Studies.

Andrews, D. and W. Ploberger (1994). Optimal Tests When a Nuisance Parameter is Present Only Under the Alternative. Econometrica 62, $1383-1414$.

Ang, A. and G. Bekaert (2002). International asset allocation with regime shifts. The Review of Financial Studies 15(4), 1137-1187.

Aviat, A. and N. Coeurdacier (2007). The geography of trade in goods and asset holdings. Journal of International Economics 71(1), 22-51.

Bae, K.-H., G. A. Karolyi, and R. M. Stulz (2003). A new approach to measuring financial contagion. The Review of Financial Studies 16(3), $717-763$.

Bartram, S. M., S. J. Taylor, and Y.-H. Wang (2007). The Euro and European financial market dependence. Journal of Banking 8 Finance 31(5), 1461-1481. 
Beck, T., A. Demirguc-Kunt, and R. Levine (2000). A new database on the structure and development of the financial sector. World Bank Economic Review 14(3), 597-605.

Beck, T. and M. S. M. Peria (2009). What explains the cost of remittances? an examination across 119 country corridors. Policy Research Working Paper Series 5072, The World Bank.

Beine, M. and B. Candelon (2009). Liberalization and stock market comovement between emerging economies. Forthcoming in Quantitative Finance.

Beine, M., A. Cosma, and R. Vermeulen (2010). The dark side of global integration: Increasing tail dependence. Journal of Banking \& Finance 34(1), 184-192.

Bekaert, G. and C. R. Harvey (2000). Foreign speculators and emerging equity markets. The Journal of Finance 55(2), 565-614.

Bekaert, G., C. R. Harvey, and C. Lundblad (2005). Does financial liberalization spur growth. Journal of Financial Economics 77, 3-55.

Bekaert, G. and X. Wang (2009). Home bias revisited. Mimeo Columbia University.

Bems, R., L. Dedola, and F. Smets (2007). US Imbalances: The Role of Technology and Policy. Journal of International Money and Finance 26(4), 523-545.

Benartzi, S. (2001). Excessive extrapolation and the allocation of 401(k) accounts to company stock. The Journal of Finance 56(5), 1747-1764.

Bergvall, A. (2004). What Determines Real Exchange Rates? The Nordic Countries. Scandinavian Journal of Economics 106(2), 315-337.

Berkel, B. (2007). Institutional determinants of international equity portfolios - a country-level analysis. The B.E. Journal of Macroeconomics 7(1), Article 34, 1-33.

Black, A., P. Hoesli, and M. Fraser (2006). House Prices, Fundamentals and Bubbles. Journal of Business Finance \& Accounting $33(9 \& 10)$, $1535-1555$. 
Blanchard, O., F. Giavazzi, and F. Sa (2005). The U.S. Current Account and the Dollar. Brookings papers on Economic Activity 1, 1-65.

Blundell, R. and S. Bond (1998). Initial conditions and moment restrictions in dynamic panel data models. Journal of Econometrics 68, 115-143.

Braun, M. and C. Raddatz (2007). Trade liberalization, capital account liberalization and the real effects of financial development. Journal of International Money and Finance 26(5), 730-761.

Brune, N. and A. Guisinger (2003). The diffusion of capital account liberalization in developing countries. Prepared for delivery at the 2003 Annual Meeting of the American Political Science Association.

Cai, Y., R. Y. Chou, and D. Li (2009). Explaining international stock correlations with CPI fluctuations and market volatility. Journal of Banking \& Finance 33(11), 2026-2035.

Campa, J. and N. Fernandes (2006). Sources of gains from international portfolio diversification. Journal of Empirical Finance 13, 417-443.

Cappiello, L., B. Gerard, and S. Manganelli (2005). Measuring comovements by regression quantiles. ECB Working Paper No. 501 (July 2005), European Central Bank.

Carling, J. (2008). The determinants of migrant remittances. Oxford Review of Economic Policy 24, 581-598.

Case, K. E., J. M. Quigley, and R. J. Shiller (2005). Comparing Wealth Effects: The Stock Market versus the Housing Market. B. E. Advances in Macroeconomics 5(1), Article 1.

Case, K. E. and R. J. Shiller (2003). Is There a Bubble in the Housing Market? Brookings Papers on Economic Activity 2003:2.

Chan, K., V. Covrig, and L. Ng (2005). What determines the domestic bias and foreign bias? Evidence from mutual fund equity allocations worldwide. The Journal of Finance 60(3), 1495-1534.

Cheung, Y. W. and K. S. Lai (1993). Finite-Sample Sizes of Johansen's Likelihood Ratio Test for Cointegration. Oxford Bulletin of Economics and Statistics 55, 313-328. 
Chinn, M. D. and K. J. Forbes (2004). A decomposition of global linkages in financial markets over time. The Review of Economics and Statistics 86(3), 705-722.

Chinn, M. D. and H. Itô (2002). Capital account liberalization, institutions and financial development: Cross country evidence. NBER Working Paper: Working Paper 8967.

Chinn, M. D. and H. Itô (2006). What matters for financial development? Capital controls, institutions and interactions. Journal of Development Economics 81, 163-192.

Chinn, M. D. and H. Itô (2008). A new measure of financial openness. Journal of Comparative Policy Analysis: Research and Practice 10(3), 309-322.

Christiansen, C. and A. Ranaldo (2009). Extreme coexeedances in new EU member states' stock markets. Journal of Banking 83 Finance 33(6), 1048-1057.

Coeurdacier, N. and S. Guibaud (2009). International portfolio diversification is better than you think. Forthcoming in Journal of International Money and Finance.

Contoyannis, P., A. Jones, and N. Rice (2004). The dynamics of health in the british household panel survey. Journal of Applied Econometrics 19, 473-503.

Corsetti, G., L. Dedola, and S. Leduc (2008). Productivity, External Balance and Exchange Rates: Evidence on the Transmission Mechanism Among G7 Countries. The Review of Economic Studies 75, 443-473.

Cox-Edwards, A. and M. Ureta (2003). International migration, remittances, and schooling: Evidence from El Salvador. Journal of Development Economics 72(2), 429-461.

D'Agostino, R. B., A. Balanger, and R. B. D'Agostino Jr. (1990). A suggestion for using powerful and informative tests of normality. American Statistician 44, 316-321.

Dahlquist, M., L. Pinkowitz, R. M. Stulz, and R. Williamson (2003). Corporate governance and the home bias. Journal of Financial and Quantitative Analysis 38(1), 87-110. 
Danielsson, J. and C. G. De Vries (2000). Value at risk and extreme returns. Annales d' Économie et Statistiques 60, 239-270.

De Hoyos, R. E. and V. Sarafidis (2006). Testing for cross-sectional dependence in panel-data models. The Stata Journal 6(4), 482-496.

Dees, S., F. Di Mauro, M. H. Pesaran, and L. V. Smith (2007). Exploring the International Linkages of the Euro Area: A Global VAR Analysis. Journal of Applied Econometrics 22, 1-38.

Defoort, C. (2008). Tendances de long terme en migrations internationales. analyse à partir des 6 principaux pays receveurs. Population-F 63(2), $317-352$.

Dungey, M., R. van Fry, B. González-Hermosillo, and V. L. Martin (2005). Empirical modeling of contagion: A review of methodologies. Quantitative Finance 5(1), 9-24.

Dustmann, C. and O. Kirchkamp (2002). The optimal migration duration and activity choice after remigration. Journal of Development Economics 67(2), 351-372.

Edison, H., M. Klein, L.-A. Ricci, and T. Slok (2004). Capital account liberalization and economic performance: Survey and synthesis. IMF Staff Papers 51(2), 220-256.

Edison, H., R. Levine, L.-A. Ricci, and T. Slok (2002). International financial integration and economic growth. Journal of International Money and Finance 21(6), 749-776.

Engle, R. F. and S. Manganelli (2004). CAViaR: Conditional autoregressive value at risk by regression quantiles. Journal of Business and Economic Statistics 22(4), 367-381.

Fidora, M., M. Fratzscher, and C. Thimann (2007). Home bias in global bond and equity markets: The role of real exchange rate volatility. Journal of International Money and Finance 26(4), 631-655.

Flavin, T. J., M. J. Hurley, and F. Rousseau (2002). Explaining stock market correlation: A gravity model approach. The Manchester School Supplement 70(1), 87-106. 
Forbes, K. J. and R. Rigobon (2002). No contagion, only interdependence: Measuring stock market comovements. The Journal of Finance 57(5), $2223-2261$.

Frankel, J. A. and A. K. Rose (1998). The endogeneity of the optimum currency area criteria. The Economic Journal 108(July 1998), 10091025.

Fratzscher, M. (2002). Financial market integration in europe: On the effects of EMU on stock markets. International Journal of Finance and Economics 7, 163-193.

Fratzscher, M., L. Juvenal, and L. Sarno (2007). Asset Prices, Exchange Rates and the Current Account. ECB Working Paper Series No. 790.

Fratzscher, M. and R. Straub (2009). Asset Prices and Current Account Fluctuations in G7 Economies. IMF Staff Papers 56(3), 633-654.

Freund, C. and N. Spatafora (2008). Remittances, transaction costs, and informality. Journal of Development Economics 86, 356-366.

Friedman, M. (1957). A Theory of the Consumption Function. Princeton: NJ: Princeton University Press.

Giuliano, P. and M. Ruiz-Arranz (2009). Remittances, financial development, and growth. Journal of Development Economics 90(1), 144-152.

Glick, R. and A. K. Rose (1999). Contagion and trade: Why are currency crises regional? Journal of International Money and Finance 18(4), 603-617.

Goetzmann, W., L. Li, and G. Rouwenhorst (2005). Long-term global market correlations. Journal of Business 78(1), 1-38.

Goldberg, L. and C. Tille (2006). The Internationalization of the Dollar and Trade Balance Adjustment. Federal Reserve Bank of New York Staff Report 255.

Grubel, H. (1968). Internationally diversified portfolios: Welfare gains and capital flows. American Economic Review 58(5), 1299-1314. 
Gupta-Kapoor, A. and U. Ramakrishnan (1999). Is There a J-Curve: A New Estimation for Japan. International Economic Journal 13(4), 7179 .

Gust, C. and N. Sheets (2006). The Adjustment of Global External Imbalances: Does Partial Exchange Rate Pass-Through to Trade Prices Matter? Federal Reserve Bank International Finance Discussion Papers No. 855.

Gustafsson, B. and N. Makonnen (1993). Poverty and remittances in Lesotho. Journal of African Economies 2(1), 49-73.

Hahn, J. (1995). Bootstrapping quantile regression estimators. Econometric Theory 11, 105-121.

Hall, P. and J. L. Horowitz (1996). Bootstrap critical values for tests based on generalized-method-of-moments estimators. Econometrica 64(4), 891-916.

Hansen, B. E. (1992). Tests for Parameter Instability in Regressions With I(1) Processes. Journal of Business \& Economic Statistics 10, 321-336.

Harbo, I., S. Johansen, B. Nielsen, and A. Rahbek (1999). Asymptotic Inference on Cointegrating Rank in Partial Systems. Journal of Business E Economic Statistics 16, 388-399.

Hartmann, P., S. Straetmans, and C. G. de Vries (2004). Asset market linkages in crisis periods. The Review of Economics and Statistics 86(1), $313-326$.

Hau, H. and H. Rey (2009). Global portfolio rebalancing under the microscope. Mimeo London Business School.

Heathcote, J. and F. Perri (2004). Financial globalization and real regionalization. Journal of Economic Theory 119, 207-243.

Hendry, D. F. (1996). A Theory of Co-Breaking. mimeo, University of Oxford.

Hendry, D. F. and G. E. Mizon (1998). Exogeneity, Causality and CoBreaking in Economic Policy Analysis of a Small Econometric Model of Money in the UK. Empirical Economics 23, 267-294. 
Holinski, N., C. Kool, and J. Muysken (2009). International Portfolio Balance - Modeling the External Adjustment Process. Meteor Research Memorandum RM/09/33.

Holinski, N. and R. Vermeulen (2009). The international wealth effect: A global error-correcting analysis. Meteor Research Memorandum $R M / 09 / 19$.

Iglesias, A. and R. J. Palacios (2000). Managing public pension reserves part i: Evidence from the international experience. Social Protection Discussion Paper Series No. 0003, The World Bank.

Johansen, S. (1992). Cointegration in Partial Systems and the Efficiency of Single-Equation Analysis. Journal of Econometrics 52, 389-402.

Kaminsky, G. and C. Reinhart (2000). On crises, contagion, and confusion. Journal of International Economics 51(1), 145-168.

Kapetanios, G. (2006). Cluster analysis of panel data sets using nonstandard optimisation of information criteria. Journal of Economic Dynamics \& Control 30, 1389-1408.

Karolyi, G. A. and R. M. Stulz (2003). Are financial assets priced locally or globally. in G.M. Constanides, M. Harris and R. Stulz (eds.), Handbook of the Economics of Finance Edition 1, Vol. 1, Chapter 16, North Holland Elsevier, New York, NY, 975-1020.

Kasa, K. (1992). Common Stochastic Trends in International Stock Markets. Journal of Monetary Economics 29, 95-124.

Klein, M. and G. Olivei (2008). Capital account liberalization, financial depth, and economic growth. Journal of International Money and Finance 27(6), 861-875.

Köbberling, V. and P. Wakker (2005). An index of loss aversion. Journal of Economic Theory 122, 119-131.

Koenker, R. and G. Bassett Jr. (1978). Regression quantiles. Econometrica 46, 33-50.

Koop, G., M. H. Pesaran, and S. M. Potter (1996). Impulse Response Analysis in Nonlinear Multivariate Models. Journal of Econometrics 74, 119-147. 
Kose, A., E. Prasad, K. Rogoff, and S.-J. Wei (2009). Financial globalization: A reappraisal. IMF Staff Papers 56(1), 8-62.

Krugman, P. (1991). Geography and Trade. Cambridge, MA: MIT Press.

La Porta, R., F. Lopes-de Silanes, A. Schleifer, and R. Vishny (1999). The quality of government. The Journal of Law, Economics \& Organization 15(1), 222-279.

Lane, P. and G.-M. Milesi-Feretti (2007). The external wealth of nations mark ii: Revised and extended estimates of foreign assets and liabilities, 1970 - 2004. Journal of International Economics 73(2), 223-250.

Lane, P. and G. M. Milesi-Ferretti (2002). External Wealth, the Trade Balance, and the Real Exchange Rate. European Economic Review 46, 1049-1071.

Lane, P. and G. M. Milesi-Ferretti (2008). International Investment Patterns. The Review of Economics \&3 Statistics 90(3), 538-549.

Lee, J. and M. D. Chinn (2006). Current Account Dynamics and Real Exchange Rate Dynamics in G7 Countries. Journal of International Money and Finance 25(2), 257-274.

Lettau, M. and S. Ludvigson (2001). Consumption, Aggregate Wealth, and Stock Returns. The Journal of Finance 56(3), 815-849.

Lettau, M. and S. Ludvigson (2004). Understanding Trend and Cycle in Asset Values: Reevaluating the Wealth Effect on Consumption. The American Economic Review 94(1), 276-299.

Longin, F. and B. Solnik (1995). Is the correlation in international equity returns constant: 1960-1990? Journal of International Money and Finance 14(1), 3-26.

Longstaff, F. (2009). Portfolio claustrophobia: Asset pricing in markets with illiquid assets. American Economic Review 99(4), 1119-1144.

Ludvigson, S. and C. Steindel (1999). How Important is the Stock Market Effect on Consumption. Federal Reserve Bank of New York Economic Policy Review 29-51. 
Ludwig, A. and T. Sløk (2004). The Relationship Between Stock Prices, House Prices and Consumption in OECD Countries. Topics in Macroeconomics 4 (1, Article 4), 1-26.

Maimbo, S. and D. Ratha (2005). Remittances, development impact and future prospects. The International Bank for Reconstruction and Development / The World Bank, Washington, DC.

McKinnon, R. (1991). The Order of Economic Liberalization: Financial Control in the Transition to a Market Economy. Baltimore: Johns Hopkins University Press.

Meese, R. and K. Rogoff (1988). Was it Real? The Exchange Rate-Interest Differential Over the Modern Floating-Rate Period. The Journal of Finance 43(4), 933-948.

Mehra, Y. P. (2001). The Wealth Effect in Empirical Life-Cycle Aggregate Consumption Equations. Federal Reserve Bank of Richmond Economic Quarterly 87(2), 45-68.

Miniane, J. (2004). A new set of measures on capital account restrictions. IMF Staff Papers 51(2), 276-308.

Modigliani, F. and R. Brumberg (1954). Utility Analysis and the Consumption Function: An Interpretation of Cross-Section Data. Rutgers University Press, New Brunswick.

Mundaca, G. (2009). Remittances, financial markets development and economic growth: The case of latin america and caribbean. Review of Development Economics 13(2), 288-303.

Nickell, S. (1981). Biases in dynamic models with fixed effects. Econometrica 49, 1417-1426.

Nyblom, J. (1989). Testing For the Constancy of Parameters Over Time. Journal of the American Statistical Association 84, 223-230.

Obstfeld, M. and K. Rogoff (1996). Foundations of International Macroeconomics. Cambridge, Massachusetts, US: The MIT Press.

Obstfeld, M. and K. Rogoff (2001). The Six Major Puzzles in International Macroeconomics: Is There a Common Cause? in In: NBER 
Macroeconomics Annual 2000, Volume 15, p. 339-412. National Bureau of Economic Research.

Orozco, M. and M. Lapointe (2004). Mexican hometown associations and development opportunities. Journal of International Affairs 57(2), 1-21.

Paap, R., P. Franses, and D. Van Dijk (2005). Does Africa grow slower than Asia, Latin america and the Middle East? evidence from a new data-based classification method. Journal of Development Economics 7\%, 553-570.

Pagan, A. (1984). Econometric issues in the analysis of regressions with generated regressors. International Economic Review 25(1), 221-247.

Park, H. and W. Fuller (1995). Alternative Estimators and Unit Root Tests for the Autoregression Process. Journal of Time Series Analysis 16, 415429 .

Pesaran, M. H. (2006). Estimation and inference in large heterogeneous panels with a multifactor error structure. Econometrica 74(4), 967-1012.

Pesaran, M. H., T. Schuermann, and S. M. Weiner (2004). Modeling Regional Interdependencies Using a Global Error-Correcting Macroeconometric Model. Journal of Business 85 Economic Statistics 22(2), $129-162$.

Pesaran, M. H. and Y. Shin (1998). Generalized Impulse Response Analysis in Linear Multivariate Models. Economics Letters 58, 17-29.

Phillips, P. C. B. and D. Sul (2003). Dynamic panel estimation and homogeneity testing under cross section dependence. Econometrics Journal 6, 217-259.

Ploberger, W. and W. Krämer (1992). The CUSUM Test With OLS Residuals. Econometrica 60, 271-286.

Poon, S.-H., M. Rockinger, and J. Tawn (2004). Extreme value dependence in financial markets: diagnostics, models, and financial implications. The Review of Financial Studies 17(2), 581-610.

Portes, R. and H. Rey (2005). The Determinants of Cross-Border Equity Flows. Journal of International Economics 65, 269-296. 
Poterba, J. M. (2000). Stock Market Wealth and Consumption. Journal of Economic Perspectives 13, 91-118.

Poterba, J. M. and A. A. Samwick (1995). Stock Ownership Patterns, Stock Market Fluctuations, and Consumption. Brookings Papers on Economic Activity 2, 295-357.

Quandt, R. (1960). Tests of the Hypothesis that a Linear Regression System Obeys Two Separate Regimes. Journal of the American Statistical Association 55, 324-330.

Quinn, D. P. (1997). The correlates of change in international financial regulation. American Political Science Review 91(3), 531-551.

Quinn, D. P. and A. M. Toyoda (2008). Does capital account liberalization lead to growth? The Review of Financial Studies 21(3), 1403-1449.

Rapoport, H. and F. Docquier (2006). The Economics of migrants' remittances, in S. Kolm and Jean Mercier Ythier, eds., Handbook on the economics of giving, altruism and reciprocity, Volume 1. Elsevier.

Reinhart, C. M. and K. S. Rogoff (2004). The modern history of exchange rate arrangements: A reinterpretation. Quarterly Journal of Economics 119(1), 1-48.

Richards, A. (1995). Comovements in National Stock Market Returns: Evidence of Predictability, but Not Cointegration. Journal of Monetary Economics 36, 631-654.

Roll, R. (1992). Industrial structure and the comparative behavior of international stock market indices. The Journal of Finance 47(1), 341.

Rose, A. K. and J. L. Yellen (1989). Is There a J-Curve? Journal of Monetary Economics 24, 53-68.

Schiff, M. and C. Ozden (2006). International migration, remittances and the brain drain. Palgrave-Macmillan.

Schiff, M. and C. Ozden (2007). International Migration, Economic Development and Policy. Palgrave-Macmillan.

Sims, C. (1980). Macroeconomics and Reality. Econometrica 48, 1-48. 
Singer, D. A. (2009). Migrant remittances and exchange rate regimes in the developing world. Mimeo Massachusetts Institute of Technology.

Solnik, B. (1974). An equilibrium model of the international capital market. Journal of Economic Theory 8(4), 500-524.

Sørensen, P. B. and H. J. Whitta-Jacobsen (2005). Introducing Advanced Macroeconomics: Growth $\&$ Business Cycles. Maidenhead, UK: Mc Graw Hill.

Spilimbergo, A. (2009). Democracy and foreign education. American Economic Review 99(1), 528-543.

Tahari, A., P. Brenner, E. De Vrijer, M. Moretti, A. Senhadji, G. Sensenbrenner, and J. Sol (2007). Financial sector reforms and prospects for financial integration in maghreb countries. IMF Working Paper WP/07/125.

Terza, J., A. Basu, and P. Rathouz (2008). A two-stage residual inclusion estimation: Addressing endogeneity in health econometric modeling. Journal of Health Economics 27, 531-543.

Tobin, J. (1969). A General Equilibrium Approach to Monetary Theory. Journal of Money, Credit and Banking 1, 15-29.

Tornell, A., F. Westermann, and L. Martinez (2004). The positive link between financial liberalization, growth and crises. National Bureau of Economic Research Working Paper Series 10293.

Van Nieuwerburgh, S. and L. Veldkamp (2009). Information immobility and the home bias puzzle. The Journal of Finance 64(3), 1187-1215.

Vermeulen, R. (2010). Dynamic international portfolio adjustment: Rational investors and the home bias. Mimeo University of Luxembourg.

Wacziarg, R. and K.-H. Welch (2008). Trade liberalization and growth: New evidence. The World Bank Economic Review 22(2), 187-231.

Wälti, S. (2008). Stock market synchronization and monetary integration. Mimeo Swiss Central Bank.

Warnock, F. (2002). Home bias and high turnover reconsidered. Journal of International Money and Finance 21(6), 795-805. 
Williams, R. (2006). Generalized ordered logit/ partial proportional odds models for ordinal dependent variables. The Stata Journal 6(1), 58-82.

Windmeijer, F. (2005). A finite sample correction for the variance of linear efficient two-step gmm estimators. Journal of Econometrics 126, 25-51.

Woodruff, C. and R. Zenteno (2001). Remittances and microenterprises in mexico. Working Paper, University of California, San Diego, Graduate School of International Relations and Pacific Studies.

Wooldridge, J. (2005). Simple solutions to the initial conditions problem in dynamic, nonlinear panel data models with unobserved heterogeneity. Journal of Applied Econometrics 20, 39-54.

World Bank, . (2006). Global Economic Prospects: Economic Implications of Remittances and Migration. Washington: The World Bank. 



\section{Nederlandse Samenvatting (Summary in Dutch)}

Dit proefschrift bundelt vier essays in het domein internationale financiële integratie, waarbij interacties tussen financiële markten en de reële economie steeds centraal staan. Internationale financiële integratie is moeilijk samen te vatten binnen een enkele definitie. Daarom moet dit onderwerp zo breed mogelijk geïnterpreteerd worden. Een belangrijke voorwaarde voor twee perfect financieel geïntegreerde markten is dat twee identieke aandelen dezelfde prijs hebben in beide markten. Prijsverschillen worden veroorzaakt door barrières waarbij bijvoorbeeld een investeerder uit land $\mathrm{A}$ niet aandelen in land $\mathrm{B}$ mag bezitten. Wanneer land $\mathrm{A}$ en $\mathrm{B}$ verschillend zijn zal dit resulteren in prijsverschillen, zelfs als beide aandelen identiek zijn. Een ander belangrijk aspect is de notie dat financiële openheid niet een zwart-wit verhaal is. Er zijn vele soorten barrières mogelijk, waardoor een land niet simpelweg als gesloten of open gekarakteriseerd kan worden. Daarnaast is financiële integratie een proces dat verandert gedurende de tijd, waarbij integratie uiteindelijk leidt tot dezelfde regels en toegang voor alle marktpartijen.

Internationale financiële transacties vinden al eeuwenlang plaats. Voor aandelenbezit specifiek geldt dit al vier eeuwen lang, waarbij Europese koloniale mogendheden vooral veel bezittingen hadden in hun voormalige koloniën. Daarnaast spreiden de rijken van deze tijd hun vermogen over verschillende beleggingen, zoals obligaties en leningen voor bijvoorbeeld plantages in Zuid Amerika of Azië. Aan het begin van de twintigste eeuw beleefde de internationale financiële integratie een hoogtepunt. Internationale transacties daalden sterk tussen de beide Wereldoorlogen en door 
de Wall Street crash van 1929. Sinds de Tweede Wereldoorlog neemt de financiële integratie toe, maar pas in de jaren zeventig versnelt dit proces om in 1990 weer het pre-Eerste Wereldoorlog niveau te bereiken. Sinds de jaren negentig en gedurende het eerste decennium van 2000 zijn de internationale transacties en bezittingen naar ongekende hoogte gestegen, waarbij de financiële stromen nu vele malen groter zijn dan de reële economie. Door deze grootte vindt er een hefboomeffect plaats waardoor veranderingen in de financiële markten een groot effect hebben op de reële economie. Dit is pijnlijk duidelijk geworden sinds de uitbraak van de subprime hypothekencrisis. Goed inzicht in de relaties tussen de financiële en reële economie is noodzakelijk om een economische crisis te lijf te gaan en te voorkomen. Dit proefschrift geeft inzicht in verschillende relaties die hierbij een belangrijke rol spelen.

Hoofdstuk 2 onderzoekt hoe nationale beursindexen bewegen gedurende goede en slechte beursdagen. In deze studie worden zeventien beurzen geanalyseerd gedurende 1974-2006. De gezamenlijke beweging van elk landenpaar wordt berekend met de co-overschrijdingsmethode van Cappiello et al (2005). Een slechte dag is als het verlies lager is dan het vooraf gestelde waarde-op- risico niveau in deze methode. Dit waardeop-risico niveau kan bijvoorbeeld tien procent zijn, waarbij dus $n$ op de tien dagen gekwalificeerd wordt als slechte dag. Hieruit volgt een kanspercentage dat elk paar van de zeventien beurzen een gezamenlijke slechte dag heeft. Deze jaarlijkse percentages worden in een dynamisch bilateraal model geschat door middel van de Feasible GLS methode. De resultaten laten zien dat deze kanspercentages sterk gestegen zijn sinds de jaren zeventig. Een belangrijke factor verantwoordelijk voor deze stijging is financiële liberalisatie, waardoor investeerders internationaal hun beleggingen kunnen spreiden. Opvallend is dat financiële liberalisatie de kans op een gezamenlijke crisis vergroot terwijl dit effect voor gezamenlijke hoge winsten afwezig is. Daarnaast leiden de toegenomen internationale handelscompetitie en de invoering van de euro tot een stijging in de kans op gezamenlijke crashes. Dientengevolge zijn de mogelijkheden om risico's effectief te spreiden over verschillende beurzen kleiner geworden.

Het belangrijkste doel van Hoofdstuk 3 is inzicht verkrijgen in de internationale portfolio veranderingen tengevolge van gezamenlijk aandelenbeursbewegingen. Standaard beleggingsmodellen gaan uit van een wereldwijde spreiding over verschillende aandelenbeurzen gelijk aan de ratio van de marktkapitalisatie van de lokale markt over de totale marktkapital- 
isatie van alle markten wereldwijd. De werkelijke spreiding laat een ander beeld zien waarbij duidelijk wordt dat internationale aandelenbeleggers een te grote positie hebben in lokale aandelen. Dit is de zogenaamde aandelen home bias. Indien beleggers dit home bias gedrag vertonen zullen zij hun buitenlandse beleggingen veranderen door minder te investeren in landen met vergelijkbare koersbewegingen en meer in beurzen die andere bewegingen vertonen. Deze theoretische voorspelling wordt empirisch getest in dit Hoofdstuk. De data komen uit de CPIS database van het IMF en bestaan uit jaarlijkse bilaterale data van 40 bronlanden met hun aandelenbeleggingen in 44 bestemmingslanden gedurende 2001-2007. Deze groep landen behelst ongeveer 85 procent van het totale internationale aandelenbezit. In het bijzonder worden de jaarlijkse veranderingen in deze beleggingen bestudeerd. De gezamenlijke bewegingen van een landenpaar worden op twee verschillende manieren gemeten. Ten eerste worden correlaties gebruikt en ten tweede worden staartkansen berekend zoals in Hoofdstuk 2. Deze staartkansen beschrijven de gezamenlijke bewegingen van twee beurzen gedurende goede en slechte dagen. Het dynamische model wordt geschat door middel van de Arellano-Bover GMM methode. Deze methode is robuust tegen de mogelijke endogeniteit van correlatie/staartkansen in de schatting. De resultaten laten zien dat investeerders inderdaad hun beleggingen verlagen in markten met een hoge correlatie ten opzichte van de thuismarkt. De staartkansen laten zien dat investeerders wel significant hun posities verkleinen in markten die tegelijkertijd sterk stijgen als de thuismarkt, maar niet significant verkleinen wanneer deze tegelijkertijd sterk dalen. Dit is geen positief nieuws, omdat het doel van internationale spreiding juist het voorkomen van gezamenlijke crashes is. Controle variabelen laten zien dat posities ook voor een belangrijk deel door waardeveranderingen gedreven worden en de groei in het bruto binnenlands product per hoofd van de bevolking. Traditionele controlevariabelen zoals bilaterale handel zijn niet significant als de jaar-tot-jaar veranderingen bestudeerd worden.

Hoofdstuk 4 beschrijft de empirische relatie tussen particulier bezit, consumptie en handelsbalans voor vijf van de grootste economiën: de Verenigde Staten, het Verenigd Koninkrijk, Frankrijk, Duitsland en Japan. De theorie van het wealth effect voorspelt dat de consumptie toeneemt indien bezittingen meer waard worden. Dit effect wordt versterkt als deze waardestijgingen als permanent beschouwd worden. In dit hoofdstuk wordt bekeken hoe de consumptieveranderingen de handelsbalans beïnvloeden. 
Om dit te onderzoeken wordt gebruik gemaakt van een groot macroeconometrisch model, het Global VAR model, van Pesaran et al (2004). Dit model wordt geschat voor 29 landen met kwartaaldata van 1980 tot en met 2006. Via een handelsmatrix worden de landen aan elkaar gekoppeld om lokale schokken internationaal te verspreiden. Deze handelsmatrix bestaat uit de relatieve gewichten van alle bilaterale handelsrelatie, bijvoorbeeld $40 \%$ voor Nederland als de handel Nederland-Duitsland $40 \%$ van de totale Nederlandse handel is. De gemodeleerde variabelen behelzen het bbp, consumptie en investeringen aan de reële kant van de economie. Daarnaast worden de reële wisselkoers, korte en lange rente toegevoegd. Onder particuliere bezittingen worden aandelen en huizenbezit verstaan. Om de waarde-ontwikkeling te meten zijn de lokale beursindex en de huizenprijsindex voor die landen waarvoor deze volledig beschikbaar is tussen 1980 en 2006 gebruikt. Door middel van Generalized Impulse Response Functions worden de effecten van een positieve schok op de reële wisselkoers en negatieve schokken in aandelenkoersen en huizenprijzen onderzocht voor de vijf eerder genoemde landen. De resultaten laten zien dat de Britse en Amerikaanse handelsbalans sterk beïnvloed wordt door veranderingen in de waarde van bezittingen. Dit effect is kleiner in Frankrijk en lijkt afwezig te zijn in Duitsland en Japan. Een variantie decompositie maakt duidelijk dat de schokken in bezittingen een groter effect hebben op de handelsbalans dan veranderingen in de reële wisselkoers voor Frankrijk, het Verenigd Koninkrijk en de Verenigde Staten.

In Hoofdstuk 5 worden de effecten van de grote sommen geld die migranten sturen naar hun familieleden op het extern financieel beleid van hun land van herkomst. Deze overschrijvingen zijn voor veel ontwikkelingslanden een belangrijke buitenlandse bron van inkomsten. Een inkomstenbron die groter en stabieler is dan bijvoorbeeld ontwikkelingshulp of investeringen van buitenlanders. Dit is een belangrijke reden om financiële transacties van emigranten aantrekkelijk te maken door een opener extern financieel beleid. Een opener beleid zal leiden tot lagere kosten voor migranten, waardoor het sturen van geld naar familieleden aantrekkelijker wordt. Helaas zijn er ook kosten verbonden aan een opener financieel beleid. Een belangrijk risico is de kans op grotere macro-economische fluctuaties wanneer buitenlandse investeerders gebruik maken van dit opener beleid. Zij kunnen snel met hun investeringen schuiven, waardoor landen bijvoorbeeld hun munt moeten devalueren. Een goed voorbeeld vormt de Azië-crisis waar veel snel groeiende Aziatische 
landen gebruik maakten van korte-termijn schulden om investeringen en consumptie te financieren. Indien deze kredietfaciliteit verdwijnt moet er sterk gesneden worden in bijvoorbeeld import van goederen. Het risico op zulke crisis is kleiner wanneer de transacties van migranten groot zijn. Deze buitenlandse valuta kunnen gebruikt worden voor de import. Een simpel model maakt deze afweging duidelijk en geeft inzicht in het positieve effect van migranten transacties op financiële openheid. In de empirische analyse wordt gedurende 1980-2005 de financiële openheid van 66 voornamelijk ontwikkelingslanden bestudeerd. Hiervoor wordt een dynamic generalized ordered logit model gebruikt. Dit gologit model is uitermate geschikt om categorische variabelen te schatten, zoals financieel openheid beleid in dit geval. Er wordt rekening gehouden met persistentie, initieel financieel beleid, handelsopenheid, institutionele kwaliteit en de geavanceerdheid van het lokale bancaire stelsel. Een tweestap schatter vergelijkbaar met instrumentele variable analyze wordt gebruikt om rekening te houden met de endogeniteit van migranten transacties. De resultaten laten zien dat de transacties van migranten een significant positief effect hebben op het financiële openheid beleid van hun land van herkomst. Dit positieve effect is niet alleen statistisch significant, maar ook economisch van groot belang. Een hypothetische studie laat zien dat veel grote ontvangers van transacties (gemeten in procent van het bbp) veel meer financieel gesloten zouden zijn indien hun migranten geen geld meer naar familie zouden overmaken. 



\section{Short Curriculum Vitae}

Robert John Gerard Vermeulen was born on 25 September 1983 in Heerlen, the Netherlands. He attended high school at Sophianum Gulpen, obtained his HAVO (Higher General Secondary Education) degree in 2000 and VWO (Pre-University Eduction) degree in 2002. In September 2002, Robert started studying International Economic Studies at Maastricht University and obtained his Bachelor degree in 2005 and MPhil in Economic and Financial Research in 2007, both degrees with distinction. During Fall 2004 he was on exchange at the University of California, Berkeley.

After graduation, Robert started his $\mathrm{PhD}$ research at the University of Luxembourg and Maastricht University under the joint supervision of Prof. Michel Beine and Prof. Bertrand Candelon. The results of his PhD research are summarized in this dissertation and have been presented at various international conferences. Parts of this thesis are published or forthcoming in international peer reviewed academic journals. Robert was the co-chair of the 2010 Spring Meeting of Young Economists in Luxembourg. 